Savoir

C. Basset-Mens, A. Avadí, C. Bessou, I. Acosta-Alba, Y. Biard, S. Payen, eds

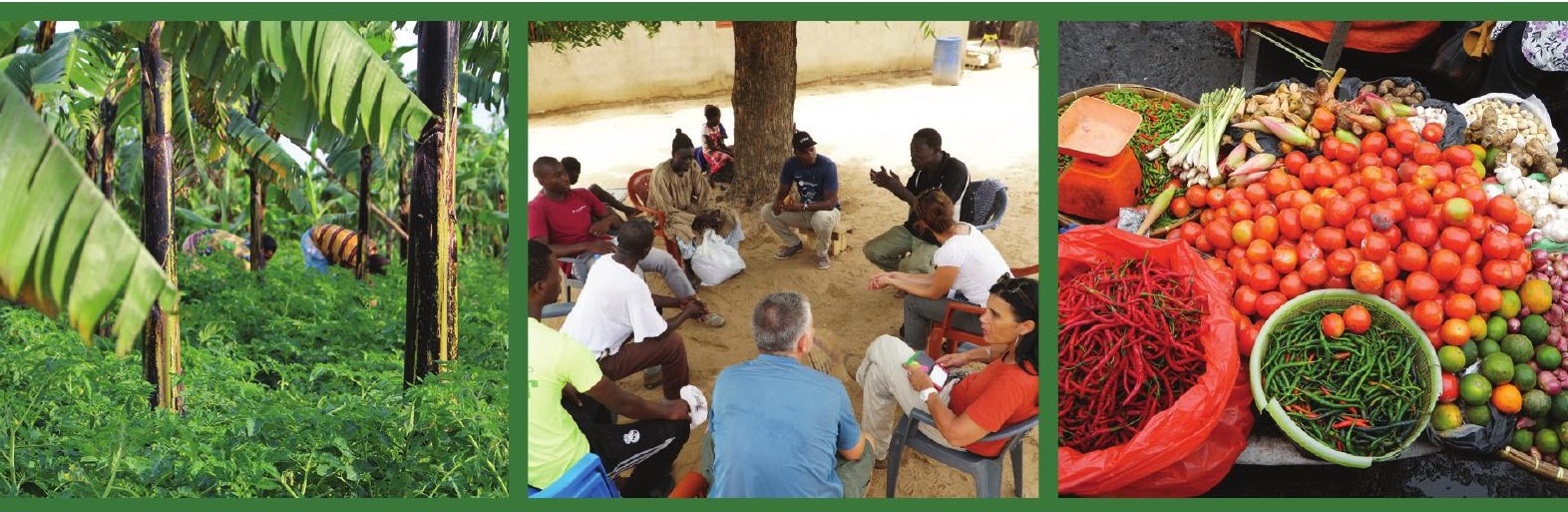

\title{
Life Cycle Assessment of agri-food systems
}

An operational guide dedicated to developing and emerging economies 



\section{Life Cycle Assessment of agri-food systems}

\section{An operational guide dedicated to emerging and developing economies}

Claudine Basset-Mens, Angel Avadí, Cécile Bessou, Ivonne Acosta-Alba, Yannick Biard, Sandra Payen, eds 
Books published in english by éditions Quæ

Agroecology: research for the transition of agri-food systems and territories

Thierry Caquet, Chantal Gascuel, Michèle Tixier-Boichard, coord.

2020, 96 p.

Artificialized land and land take

Drivers, impacts and potential responses

Maylis Desrousseaux, Béatrice Béchet, Yves Le Bissonnais, Anne Ruas, Bertrand Schmitt, coord. 2020, eBook

Can organic agriculture cope without copper for disease control?

Synthesis of the Collective Scientific Assessment Report

Didier Andrivon, Isabelle Savini, coord.

2019, eBook

Innovation and development in agricultural and food systems

Guy Faure, Yuna Chiffoleau, Frédéric Goulet, Ludovic Temple, Jean-Marc Touzard, coord. 2018, eBook

To cite the book:

Basset-Mens C, Avadí A, Bessou C, Acosta-Alba I, Biard Y, Payen S (Eds), 2021. Life Cycle Assessment of agri-food systems. An operational guide dedicated to emerging and developing economies, éditions Quæ, Versailles, 210 p. DOI:10.35690/978-2-7592-3467-7

Éditions Quæ

RD 10

78026 Versailles Cedex

(C) Éditions Quæ, 2021

ISBN PDF: 978-2-7592-3467-7

ISBN ePub: 978-2-7592-3468-4

ISSN: $1952-1251$

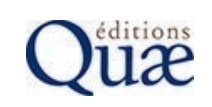

www.quae.com www.quae-open.com

This publication is distributed under license CC-by-NC-ND 4.0.
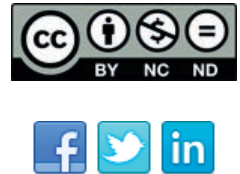

For any question, comment or suggestion: quae-numerique@quae.fr 


\section{Table of contents}

Preface

Part 1

Introduction

1. LCA within developing and emerging economies....................................11

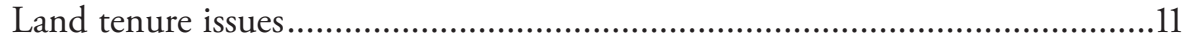

Environmental vs. economic development concerns .....................................13

Most developing and emerging countries are located in the tropical zone......13

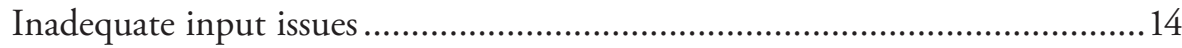

Research and development priorities and capacities .......................................15

2. The purpose of this operational guide ………......................................17

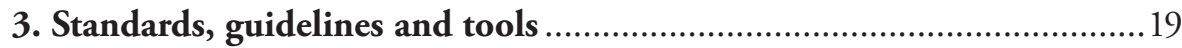

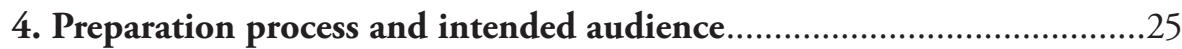

Part 2

Agri-food LCA in developing and emerging contexts

5. State of the art of agri-food LCA

6. Specific challenges for agri-food LCA in developing and emerging contexts

Diversity of agri-food systems due to specific natural conditions

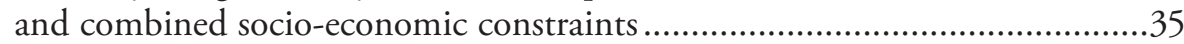

Data gaps on the systems to be characterized................................................ 36

Varying awareness and capacities of stakeholders ........................................... 39

7. Established and emerging initiatives................................................... 43 


\section{Part 3}

Overcoming the challenges for robust agri-food LCA in developing and emerging economies

8. Co-designing the study with stakeholders .................................... 49

Overview of the approach .............................................................. 49

Critical analysis of the demand, constraints and avoidance strategies ............ 51

The community of the study.......................................................... 54

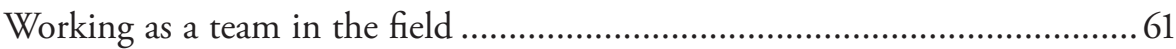

Management of ethics and rights for stakeholders...................................66

System boundaries, typologies and sampling strategies............................ 71

9. Building life cycle inventories...................................................... 79

Foreground data collection............................................................. 79

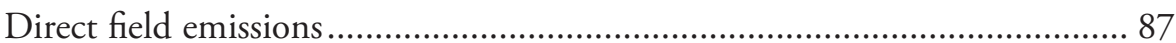

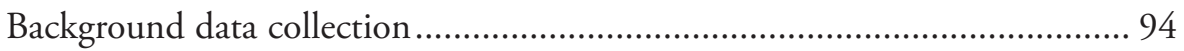

Quality management and critical review (CR) .................................... 95

10. Performing impact assessment .............................................. 97

Overview of available and recommended sets of LCIA methods ................. 97

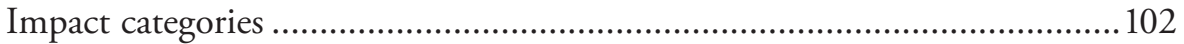

11. Interpreting the results for each stakeholder category .................... 103

Accounting for uncertainty in LCA studies............................................ 103

Comparing results with previous studies ............................................ 111

Sharing and communicating results to support decisions .........................112

\section{Part 4}

Conclusions and moving forward

\section{Part 5 \\ Appendices}

\section{A. Guidelines / ISO Norms: a brief overview.}

ISO, 2006. ISO - 14040:2006 - Environmental management - Life cycle assessment - Principles and framework, Environmental Management.

ISO, 2006. ISO - 14044:2006 - Environmental management - Life cycle assessment - Requirements and guidelines. Geneva. 
B. Commonly used direct field emission models.

C. LCA resources 126

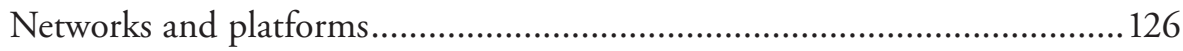

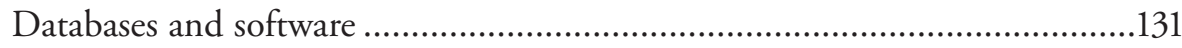

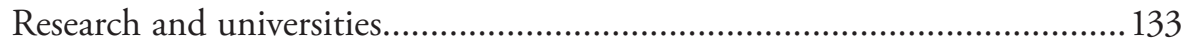

D. Data collection and confidentiality: check list and points of vigilance 135

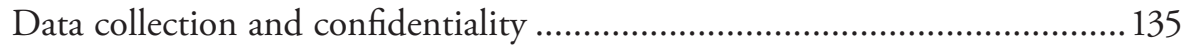

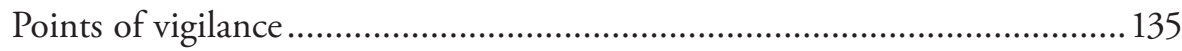

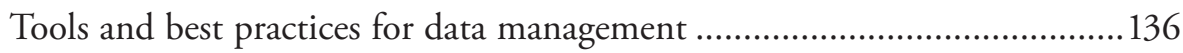

E. Recommendations for designing a sampling protocol according to PAS 2050-1.

F. Best practices for agri-food LCAs, at the system level 138

G. Free tools to model field emissions for LCI ................................ 143

Emission models online ................................................................. 143

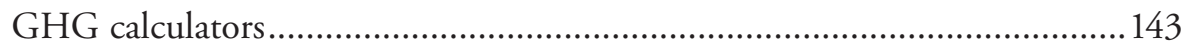

H. Detailed guidance on impact categories ................................... 144

Global Warming or Climate Change impact............................................ 144

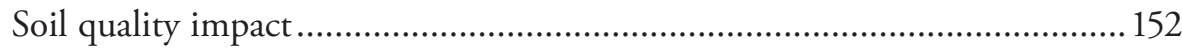

Human toxicity and ecotoxicity ................................................. 158

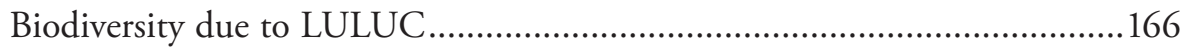

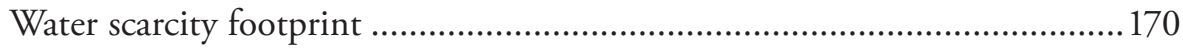

I. LCIA methods recommended by the Life Cycle Initiative

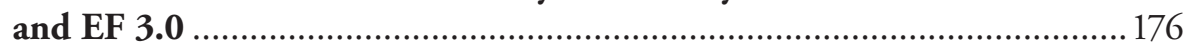

J. Detailed guidance on the use of the qualitative assessment of data in LCA according to the European PEFCR Guidance (EC 2018) ...........178

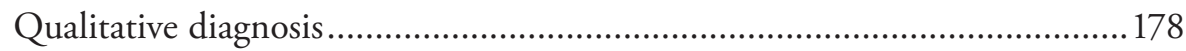

Uncertainty approximation ...................................................... 180 
K. How to display LCA results while avoiding bias due to

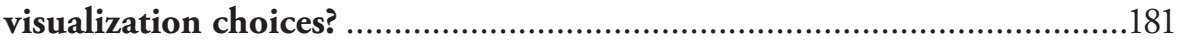

Refer to "useful ink" concept .......................................................................181

Which type of graph is the most effective for most LCIA results?

(histograms)

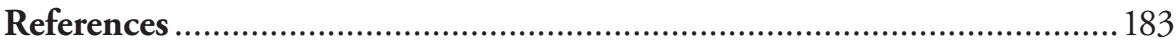

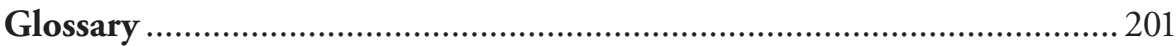

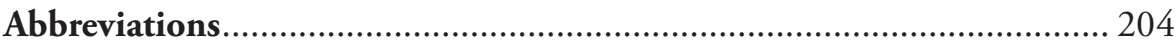

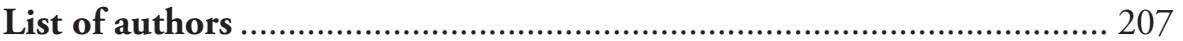




\section{Preface}

The application of LCA to agri-food systems in developing and emerging contexts remains limited, but the approach has considerable potential to support and guide their transition towards sustainable practices. The demand for LCA studies of agri-food systems in these contexts is increasing rapidly, and relates both to agrifood systems for export and for local markets. Agri-food systems in developing and emerging economies present key particularities combining socio-economic, pedoclimatic and environmental aspects, which can be summed up according to three main characteristics: a great diversity of production systems with little reliable data; highly specific natural contexts with little data, knowledge and tools for informing the inventory and impact assessment phases (especially for tropical systems); and varying awareness and capacities among stakeholders in relation to environment and environmental assessment.

These specificities pose important challenges for a reliable application of the LCA methodology, which will require a comprehensive answer. This guide takes the opposite view of the studies historically carried out remotely by Western consultancies on tropical agri-food systems in developing and emerging countries by promoting an approach based on fieldwork, designed with and for all stakeholders associated with the study.

Another original feature of this guide consists of its elaboration process based on a participatory and consensus-building approach to formalize actual field experiences from a panel of senior international experts on LCA in these contexts. This elaboration process included a web-based questionnaire covering all considerations of LCA studies completed by nearly 30 identified experts from around the world and supported a consistent formalization of their practices. Best practices were then discussed and agreed-upon through four dedicated workshops.

Unlike existing and numerous guidelines which are complementary to this guide, the present guide focuses on collaborative, ethical and operational aspects of LCA. It aims to help LCA practitioners successfully engage in this exciting adventure of undertaking LCA studies for agri-food systems in developing and emerging contexts. The guide also presents the most up-to-date and appropriate models to perform the inventory and impact assessment in these contexts and make clear recommendations on all components of the study.

The core content of this guide is complemented by a substantial corpus of appendices to provide LCA practitioners with more detailed information. 



\section{Part 1 \\ Introduction}

Claudine Basset-Mens, Angel Avadí, Cécile Bessou, Ivonne Acosta-Alba, Yannick Biard, Sandra Payen 



\section{1 \\ LCA within developing and emerging economies}

Developing and emerging economies are defined by Ghemawat and Altman (2016) as countries, regions and economies that are not fully industrialized, in socio-economic terms, generally showing an average low to middle income and high inequality of income distribution. According to various international references (UN, FAO, etc.), those countries may include least developed countries (LDC) and low and middle-income countries $\left(\mathrm{LMIC}^{1}\right)$. The application of life cycle assessment (LCA) for environmental assessment in these contexts is still very limited (Hou et al. 2015), especially in Africa (Karkour et al. 2021). The scarce existing studies were generally commissioned by international or developed country-based institutions, or were carried out in the context of research activities financed from abroad. Recently, a growing interest is exemplified by some locally driven initiatives and emerging LCA networks (Bjørn et al. 2013). Political and social conditions influence the capacity of agri-food stakeholders i.e. in agriculture (including livestock), aquaculture, fisheries and food processing - to adopt new social or technical innovations. Such conditions may affect both the implementation of LCA and the use of final LCA results. Some specificities of developing and emerging contexts embedding potential consequences on LCA implementation and uptake are briefly presented in the following sections.

\section{Land tenure issues}

Land tenure issues have strong implications on the possibility of improving agricultural systems. Land ownership and decision-making processes on communal or private land use do not have the same implications; thus, land tenure issues should be identified before further analysis. Several governance rules were set since

1. The list of LDC and LMIC is regularly updated: https://www.oecd.org/dac/financing-sustainable-development/development-finance-standards/daclist.htm. The transition criteria across OECD country categories are described here: https://www.oecd.org/dac/transition-finance-toolkit/LMICto-UMIC.pdf 
the end of colonialism (Focus on land in Africa (FOLA) 2018), but they are still failing to adequately consider property rights and customary land (Veit 2013). The FOLA website (https://www.wri.org/data/rights-resources-interactive-map) provides an overview of property rights issues and an interactive map of national experiences pertaining to land and natural resource rights.

In many developing countries, national land reforms have generated inequality of access, with poor land access for women under state laws and customary arrangements. Encroachment onto indigenous peoples' territories and common property resources such as protected areas are increasing due to economic and commercial pressures (UN-Habitat 2019). The Global Land Tool Network (https://gltn.net/) presents land access initiatives, while the World Database on Protected Areas (https://www.protectedplanet.net/) lists and classifies protected areas; both address these issues on the global scale.

In Asia-Pacific, around 80\% of farming households are small-scale farmers. The main challenges in this region (where 13 of the world's 23 megacities are located) regarding land access include economic transformation with growing inequality (increasing level of urbanization, private large-scale land acquisitions), vulnerability of women and indigenous people, and environmental degradation (UN-Habitat 2015).

Latin America has the highest inequality of land distribution compared with the rest of the world, and this remains a key unresolved historical issue on the continent (OXFAM 2016). The concentration of land ownership and land-grabbing are strongest in Argentina, Brazil, Dominican Republic, Mexico, Chile, Colombia, Nicaragua and Uruguay (Jarroud 2016). For instance, in Dominican Republic, the agrarian revolution has not been completed, leaving a considerable part of agricultural land with no formal property titles. In 1997, about $36 \%$ of private land was used by owners with no official title. In countries where public investment is low, this lack of clear land tenure rights may prevent investments for better agricultural development (Tejada de Walter and Peralta Bidó 2000).

Other issues related to secure land access may hamper sustainable land use development. In Colombia, for instance, conflicts between the government and armed groups, which have driven refugee migrations between regions, have had a major impact on Amazonian agriculture. Raising cattle has been considered a valuable option within uncertain contexts, since livestock is a "mobile" agricultural asset. Now, improving livestock systems, e.g. with enhanced permanent pasture quality or silvo-pastoralism, could only be developed under peace conditions and with substantial support from companies, universities and research centres (Estrada and Holmann 2008). 


\section{Environmental vs. economic development concerns}

In contexts where the economy is becoming increasingly industrialized, and sometimes quickly, another key aspect relates to the potential trade-offs between economic development and environmental protection ${ }^{2}$. Growth-oriented strategies usually focus first on increasing production, often through conventional systems rather than more environmental-friendly practices. A related aspect may be the low environmental awareness of local populations, due to low levels of education and knowledge about the environmental pressures of socio-economic activities. Additionally, sometimes the lack of proper law enforcement may lead to misappropriation of funds allocated to development priorities due to corruption or insufficient field control when dealing with environmental protection laws (e.g. legislation protecting natural reserves). The environmental Kuznets curve highlights that environmental degradation increases with economic development until a difficult-to-predict (Bernard et al. 2015) tipping point is reached, and then starts to decrease (Du and Xie 2020). However, this model has been challenged based on evidence that some developing economies are also addressing environmental issues, and that the prevalence of conflicts and the quality of institutions are more important drivers (Stern 2004; Kinda 2015; Sarkodie and Strezov 2018).

\section{Most developing and emerging countries are located in the tropical zone}

Most developing and emerging countries are located in the tropical zone (in-between the two tropics), although not exclusively. The tropical zone can host extreme climate conditions, from humid to very arid climates. The history of those very contrasted climates has led to highly contrasted pedoclimatic conditions, with sometimes heavily weathered soils, very arid areas or areas facing regular floods, etc. In most extreme contexts, the development of agricultural activities has long been hampered by extreme events and the lack of proper infrastructure to enable resilient development. Nonetheless in some humid tropical zones, soil and climate conditions may also provide optimal conditions for faster crop rotations and even more frequent harvests per year on the same field compared to temperate climates (Table 1.1). Such diversity in natural conditions has obviously led to a unique range of adaptation strategies and broad diversification of practices. In such optimal conditions, where the soil has been protected by the natural vegetation, there is also critical competition for land between agri-food systems and still pristine environments with a high biodiversity (e.g. the agricultural and livestock frontier expands in the South American Amazonia at the

2. In Africa and Asia, for instance, the increase in cocoa production for export is based on expanding surfaces, whereas in Latin America it is based on increasing yields driven by management improvements (Arvelo Sánchez et al. 2017). 
expense of rainforest and Pantanal biomes; the cotton-growing frontier expands in Sahel areas at the expense of savannah systems). Such competition has led to land conflicts, imbalances in ecosystems and support for the development of more resilient agricultural development pathways.

Table 1.1. Pedoclimatic factors influencing temperate and tropical agriculture.

\begin{tabular}{lll}
\hline Factors & Temperate agriculture systems & Tropical agriculture systems \\
\hline Climate & Four seasons with winter rains & Dry vs. wet season(s) with heavy rainfall events \\
& Lower humidity & Higher humidity \\
& Lower temperature & Higher temperature \\
\hline Soil & Higher natural fertility & Lower natural fertility \\
& Higher organic matter & Lower organic matter \\
& Lower decomposition rate & Higher decomposition rate \\
& Lower leaching & Higher leaching \\
\hline
\end{tabular}

Sources: Hartemink (2002); Six et al. (2002).

The specific soil and climate conditions, combined with the diverging long-term evolution of socio-technical agricultural systems, have led to a wide range of agrifood systems, both in terms of practices in fields (as well as in ponds and seas for fish and seafood products i.e. "blue foods", Gephart et al. 2021) and in terms of food processing and value chain organization. The evolving socio-technical systems have been influenced by many factors, including colonialism, governmental instability, development funds, population growth rates, etc. Compared to more industrialized contexts, the combination of complex tropical conditions and precarious socio-economic contexts - with no safety net such as mutualized risk management within Europe - has led to a lack of standardization of agri-food systems such as that observed today in many countries (e.g. among European countries). From past shifting cultivation to sedentary intensive systems, very diversified agri-food systems co-exist still today in tropical and emerging countries, which will have implications for the application of LCA.

\section{Inadequate input issues}

The environmental impacts of agri-food systems in developing and emerging contexts are often influenced by underperforming or inadequate inputs (e.g. homemade aquafeed, over-fertilization, pesticides designed for another crop, highly polluting fuels, etc.). In many cases, producers use these inputs because there are no suitable or economically interesting alternatives, or because they do not have enough knowledge on available and feasible alternatives. For instance, African small-scale horticulture farmers often use pesticides designed for cotton or other cash crops (Avadí et al. 2020b). Many Peruvian fishmeal producers use heavy residual fuels instead of natural gas, because the gas pipelines simply do not reach them or are overloaded (Fréon et al. 2017). Many Zambian and Peruvian 
small-scale fish producers cannot afford commercial aquafeed, or its transportation to remote locations, and thus rely on homemade feed (Avadí et al. 2015, 2021). Most market vegetable producers in Benin over-fertilize their plots with manure and compost, mainly due to ignorance on the nutrient content of these organic inputs (Avadí et al. 2021a).

Moreover, benefiting from economies of scale is less widespread, especially in developing contexts, due to gaps in infrastructure (e.g. poor roads impede efficient transport, sparse irrigation infrastructure hinders controlled irrigation, and poor landing facilities increase vessels' fuel consumption and generate product losses).

\section{Research and development priorities and capacities}

Finally, in developing and emerging contexts, research and development priorities vary regionally depending on the development levels and invested resources, while globally, agri-food systems face new or tougher challenges related to worldwide trends and changes (Table 1.2).

Table 1.2. Trends and challenges in food and agriculture in developing contexts.

\begin{tabular}{ll}
\hline Trends & Challenges \\
\hline - Population growth, urbanization and ageing & - Sustainably improving agricultural \\
- Global economic growth, investment, trade & productivity to meet increasing demand \\
and food prices & - Ensuring a sustainable natural resource base \\
- Competition for natural resources & - Addressing climate change and intensification \\
- Climate change & of natural hazards \\
- Agricultural productivity and innovation & - Eradicating extreme poverty and reducing \\
- Transboundary pests and diseases & inequality \\
- Conflicts, crises and natural disasters & - Ending hunger and all forms of malnutrition \\
- Poverty, inequality and food insecurity & - Making food systems more efficient, inclusive \\
- Nutrition and health, including the & and resilient \\
connections among environment, agriculture & - Improving income earning opportunities \\
and infectious diseases of poverty & in rural areas and addressing the root causes \\
- Structural change and employment & of migration \\
- Migration and agriculture & - Building resilience to protracted crises, \\
- Changing food systems & disasters and conflicts \\
- Food losses and waste & - Preventing transboundary and emerging \\
- Governance for food and nutrition security & agriculture and food system threats \\
- Development finance & - Addressing the need for coherent and effective \\
& national and international governance \\
\hline
\end{tabular}

Sources: WHO 2013; FAO 2017a.

National agricultural research systems in developing countries in particular are usually understaffed and underfunded, thus a large proportion of agri-food research is carried out in cooperation with, or directly by, international institutions. For instance, the main global agricultural development research institution, the Consultative Group on International Agricultural Research (CGIAR), 
devoted $11 \%$ of its expenditure in 2008 to strengthening national agricultural research centres across the world, $8 \%$ to environmental protection, and under $50 \%$ to increasing productivity, plant enhancement and breeding, and research on production systems (Lele et al. 2010). Public agricultural research and development investment has increased worldwide in the last 40 years, notably in Latin America, Asia-Pacific and China. However, West Asian and African public investment has remained relatively low. The relevance of extension services (i.e. agri-food advisory) proved valuable in improving both agronomic performances and environmental protection (Lele et al. 2010). Unfortunately, these services show uneven coverage and efficiency, and often farmers remain isolated with no access to technical advice or capacity-building support. 


\section{2}

\section{The purpose of this operational guide}

This operational guide focuses on applying LCA to agri-food systems in a range of socio-economic contexts, from least developed to emerging economies, mainly within the tropics. Agri-food systems are defined as all systems providing food, fibre and bioenergy products based on agriculture, livestock, aquaculture and fisheries. This guide aims to provide solutions to overcome the specific issues found by LCA practitioners in developing and emerging contexts, by consolidating the knowledge from the literature and formalizing LCA practitioners' experience in these contexts. Feasible and practical solutions are preferred, namely those that are useful under severe resource constraints, but more sophisticated and resource-intensive solutions are also discussed.

Over the last two decades, LCA has become an essential framework for the environmental assessment of agri-food systems at various scales, from the cropping system to the rest of the value chain and even entire agricultural regions. Applying LCA to agri-food systems, is supported by a number of methodological developments and resources. These include dedicated guidelines for direct emission models, life cycle inventory (LCI) databases, life cycle impact assessment (LCIA) methods, sets of characterization and normalization factors, and multiple research initiatives aimed at overcoming unresolved issues ${ }^{3}$. Existing LCA resources, such as background inventory databases on technologies and practices or emissions models, are generally tailored to developed and temperate contexts, where LCA was first developed. Hence, the vast majority of LCA resources available nowadays represent production systems operating mostly in temperate and developed contexts, where large statistical and field measurement datasets were available to develop various models.

Putting LCA into practice for agri-food systems in developing and emerging economies is more recent and faces specific challenges, related to both the socio-economic and biophysical specificities of these contexts. As already mentioned, tropical agricultural systems can be highly diversified and complex (e.g. tropical

3. See a list of unresolved issues in LCA in Reap et al. (2008a,b). Some of these issues have been successfully addressed to date, but not all. 
agroforestry systems), while data is often missing to characterize this diversity and calibrate existing models, which have been calibrated for temperate conditions. Moreover, in the tropics some environmental issues may be particularly severe such as water deprivation, salinization, soil quality and biodiversity losses. They may require specific parameters in LCA (e.g. regional characterization factors (CFs) that are thus far mostly lacking for tropical zones). 


\section{Standards, guidelines and tools}

The international organization for standardization (ISO) 14040 and 14044 standards (ISO 2006a, b) describe the LCA methodology procedure. All subsequent standards, guidelines, databases and tools are ultimately based upon the ISO 14040/44 standard. ISO 14040/44 determine the four phases of LCA, namely goal and scope, inventory analysis, impact assessment, and interpretation; they also include the mandatory and optional elements of LCA. Appendix A (p. 121) presents an overview of the ISO norms 14040 and 14044.

The goal and scope phase demands particular attention as it determines the rules for the rest of the study (see study design in Chapter 8 "Co-designing the study with stakeholders"). See Table 3.1 for the exhaustive list of items that should be included in a goal and scope definition.

Table 3.1 Elements of the goal and scope definition according to ISO 14040 (verbatim from ISO 2006a).

\begin{tabular}{ll}
\hline Goal & Scope \\
\hline - the intended application & - the product system to be studied \\
- the reasons for carrying out the study & - the functions of the product system or, \\
- the intended audience, i.e. to whom & in the case of comparative studies, the systems \\
the results of the study are intended to & - the functional unit (FU) \\
be communicated & - the system boundary \\
- whether the results are intended to be & - allocation procedures \\
used in comparative assertions intended & - impact categories selected and methodology \\
to be disclosed to the public & of impact assessment, and subsequent \\
& interpretation to be used \\
& - data requirements \\
& - assumptions \\
& - limitations \\
& - initial data quality requirements \\
& - type of critical review (CR), if any \\
& - type and format of the report required \\
& for the study \\
\hline
\end{tabular}

Beyond ISO 14040/44, and the ISO 14020/25 standard describing the rules for LCA-informed environmental labels and declarations, several general guidelines 
were developed by various institutions to help practitioners implement the LCA framework according to best available practices and methods. Harmonization of LCA practices is a challenging endeavour given the flexibility in the LCA framework as described in the ISO standards, but also given the need to regularly update emission and impact modelling according to continuous scientific advances. A summary of existing guidelines, tools and databases is presented in Figure 3.1.

\begin{tabular}{|c|c|c|c|c|}
\hline & & Full LCA & & Partial LCA \\
\hline \multirow{3}{*}{$\begin{array}{l}\text { Frameworks } \\
\text { and ISO } \\
\text { standards }\end{array}$} & France & Europe & \multicolumn{2}{|l|}{ International } \\
\hline & & & ISO $14040 / 44$ & ISO 14067 (Carbon) \\
\hline & & & ISO $14020 / 25$ & ISO 14046 (Water) \\
\hline $\begin{array}{l}\text { General } \\
\text { guidelines }\end{array}$ & BPX2011-30-323-0 & ILCD Handbook & $\begin{array}{c}\text { Life Cycle Initiative } \\
\text { (GLAM) }\end{array}$ & $\begin{array}{c}\text { GHG Protocol } \\
\text { (Product Life Cycle } \\
\text { Standard) }\end{array}$ \\
\hline $\begin{array}{l}\text { Sector } \\
\text { guidelines }\end{array}$ & $\begin{array}{l}\text { BPX-30-323-15 } \\
\text { (for food) }\end{array}$ & $\begin{array}{l}\text { Food SCP } \\
\text { Round table }\end{array}$ & FAO LEAP Guidelines & $\begin{array}{c}\text { PAS } 2050 \\
\text { (food systems) }\end{array}$ \\
\hline & & ENVIFOOD Protocol & & \\
\hline $\begin{array}{l}\text { Sub-sector } \\
\text { guidelines }\end{array}$ & $\begin{array}{l}\text { AGRIBALYSE } \\
\text { methodological } \\
\text { report }\end{array}$ & $\begin{array}{c}\text { ecoinvent / WFLDB } \\
\text { methodological } \\
\text { reports }\end{array}$ & $\begin{array}{l}\text { AGRIBALYSE } \\
\text { methodological } \\
\text { report }\end{array}$ & $\begin{array}{c}\text { PAS 2050-1/2 } \\
\text { (horticultural and } \\
\text { seafood systems) }\end{array}$ \\
\hline $\begin{array}{l}\text { Product } \\
\text { Category }\end{array}$ & & $\begin{array}{c}\text { PEFCR } \\
\text { (food and drink) }\end{array}$ & $\begin{array}{c}\text { EPD PCR } \\
\text { (food and beverages) }\end{array}$ & ISO 22948 (CFP-PCR) \\
\hline & & & Hortifootprint CR & \\
\hline \multirow{4}{*}{$\begin{array}{l}\text { Databases } \\
\text { and tools }\end{array}$} & AGRIBALYSE v3.0 & ecoinvent & LEAP database & FAO EX-ACT \\
\hline & MEANS & Agri-footprint & EU LCDN/UN GLAD & FAO GLAM \\
\hline & YUKA & WFLDB & GFLI & FAO B-INTACT \\
\hline & & EF Base & Hestia & Blonk LUC tool \\
\hline
\end{tabular}

Figure 3.1. Non-exhaustive overview of LCA standards, general and sector-specific guidelines, and related tools around the world.

In this figure, one can measure the number of existing guidelines, tools and database. Partial LCA applies a life cycle approach but focusses only on one or a few environmental indicator(s) such as global warming potential (carbon footprint) or water deprivation (water footprint). BPX2011-30323-0 is a French standard describing the general requirements for the implementation of the LCA approach for the French eco-labelling program, for all products. BPX2011-30-323-15 is a French standard describing the specific requirements for the implementation of the LCA approach for the French eco-labelling program, for food products. AGRIBALYSE corresponds to the French reference environmental database for agricultural and food products. The MEANS (MulticritEria AssessmeNt of Sustainability) platform is the result of the decision of the French National Institute of Agricultural Research (INRAE), and since 2018 of the French agricultural research and international cooperation organization for development (CIRAD), to provide the scientific community with comprehensive and modular software for multi-criteria assessment of agricultural and agri-food systems. YUKA is 
an application for smartphones that allows scanning the labels of food and cosmetic products and provides a detailed information on their quality (nutritional for food) and attached health risks. The ecoinvent database provides well documented $\mathrm{LCl}$ process data for thousands of products, across product categories, helping LCA practitioners inform their background modelling. Agri-footprint is a LCl database, focused on the agriculture and food sector. HESTIA (Harmonized Environmental Storage and Tracking of the Impacts of Agriculture) is an online platform to enable the sharing of food sustainability data in a structured, open source and standardised way. The FAO EX-ACT: Ex-Ante Carbon-balance Tool accounts for GHG emissions covering the entire "Agriculture, Forestry and Other Land Use" (AFOLU) sector, including agricultural inputs, energy, infrastructure, management of organic soils, coastal wetlands, fisheries and aquaculture. The FAO B-INTACT makes use of various geo-referenced maps and tools to increase accuracy and account for the ecological value and biodiversity sensitivity of project sites. Blonk LUC tool: Direct Land Use Change Assessment Tool, allows calculating the GHG emissions associated to direct land use change.

The international reference life cycle data system (ILCD) handbook (EC-JRC 2010) was developed by the Institute for Environment and Sustainability in the European Commission Joint Research Centre (EC-JRC). The ILCD handbook provides guidance for good LCA practices in policy and business. This handbook comprises a set of documents that are in line with ISO 14040 and 14044, based on existing best practices - not on new methodological developments and provides recommendations established through a series of extensive public and stakeholder consultations. In parallel, the European Council invited the Commission to "develop a common methodology on the quantitative assessment of environmental impacts of products, throughout their life-cycle, in order to support the assessment and labelling of products". Building on the analysis of seven product-specific methodologies of environmental footprinting (including the ILCD handbook), the EC-JRC developed guidelines for this common European environmental footprint (EF) methodology (EC-JRC 2013) regarding products (Product EF - PEF) and organizations (Organisation EF - OEF). Since its first release in 2013, the PEF/OEF guidelines have gone through a pilot phase (2013-18) and a transitional phase since 2019 (https://eplca.jrc.ec.europa.eu/ EnvironmentalFootprint.html), resulting in the continuous publication of (sector) PEF Category Rules (PEFCR). PEFCR compete with the ISO-compliant product category rules/type III environmental declarations (ISO 14025) produced by the international Environmental Product Declaration - EPD system (https:// www.environdec.com/home).

More specific and strict prescriptions are easier to draw up at the sector and product category level in close consultation with all stakeholders. As a follow-up of the PEF initiative and with inputs from JRC, the Food Sustainable Production and Consumption Roundtables co-supervised by the European Commission and food companies finalized in 2012 and tested in 2013 the ENVIFOOD protocol (Food SCP RT 2013), i.e., harmonized guidelines for evaluating environmental impacts of food products. The food sector was thus the first sector with specific rules to apply the PEF guidelines. In May 2018, an accepted draft of PEFCR guidelines applying to more sectors was published (EC 2018). In this document, LCA practitioners can find clear technical specifications for an LCA applied to particular sectors such as agriculture and which address specific issues 
such as biodiversity. At the French level, a similar initiative was launched as part of the government's Grenelle law no. 2009-967 involving representatives of all stakeholders to harmonize requirements to implement LCA for all products. Requirements were further specified for the food sector in a dedicated report called BPX-30-323-15 (AFNOR 2012). Application to the agri-food sector was carried out within the AGRIBALYSE project (Koch and Salou 2014, 2016) and provided the backbone to the current French Agence de l'environnement et de la maitrise de l'énergie (ADEME) AGRIBALYSE LCI database. Revisions of the LCA-based EF requirements are underway in France. The smartphone application YUKA, which originally presented detailed nutritional information on foods, has begun presenting environmental information partially based on LCA studies (AGRIBALYSE 3) via an eco-score and as part of an environmental labelling experiment (https://yuka.io/eco-score/).

In complement to these initiatives, in 2014, the EC-JRC launched the Life Cycle Data Network (LCDN) to provide "a globally usable infrastructure for the publication of quality assured LCA datasets from different organizations" (https:// eplca.jrc.ec.europa.eu/LCDN/). It also aims to host and share data packages in line with the PEF/OEF framework. The European LCDN somewhat overlaps with the UN GLAD initiative (see Chapter 7 "Established and emerging initiatives").

For the LCA of livestock products, FAO has been leading the consensus-building process. Launched in 2012, the FAO Livestock Environmental Assessment and Performance (LEAP) partnership programme established ten Technical Advisory Groups on the application of LCA in the following sectors: animal feeds, poultry, small ruminants, large ruminants and pigs, as well as on the following focus topics: nutrient cycling, water, soil carbon sequestration, biodiversity and ecosystem services. The LEAP programme involves over 300 experts from academia, governments, industries and non-governmental organizations and has so far produced a series of background and guidance documents that are available on its website (http://www.fao.org/partnerships/leap/en/). Although the LEAP reports propose some case study-based illustrations and occasionally a tiered approach to apply more or less complex methods depending on data availability, the guidelines remain general and mostly theoretical. They do not provide practical methods based on field experiences in developing countries or cover other important aspects such as partnership or ethics.

Over the last few years, the number of guidelines, tools and databases for agrifood LCA studies and data has increased dramatically (see, for example, the World Food LCA Database - WFLDB (Nemecek et al. 2014, 2020) or the Agri-footprint LCI database (Blonk Consultants 2014, 2019)). All these databases provide very detailed methodological reports describing precise choices, methods and data for LCA studies for a wide range of agricultural products. The WFLDB has a global coverage with the objective of representing at least $50 \%$ of the global market in mass for each product from the main exporting countries. However, 
many of these inventories rely heavily on assumptions and secondary data. The Agri-footprint database has also a global coverage but it is predominantly built on statistical/top-down rather than on system-level bottom-up data. Input data and yields for cropping and animal systems are based on pre-existing primary or secondary data and rarely rely on dedicated field studies.

All these general or sector-specific guidelines constitute key reference documents for all LCA practitioners including those working in developing or emerging contexts. However, they are either very general, or tailored to developed contexts and certain specifications are not applicable in developing contexts. For instance, the recommended sampling procedure from PEFCR implies that statistical data exist on the studied systems to define homogeneous sub-populations, whereas this is generally not the case in tropical developing contexts. Furthermore, for guidelines including products from developing countries (e.g. the WFLDB), data are largely based on existing literature references and do not guide LCA practitioners with respect to practical aspects such as field data collection, stakeholder participation, partnership or ethics. The present guide intends to be very specific in terms of both the specificities of the contexts explored and the practical solutions for LCA practitioners. 



\section{4 \\ Preparation process and intended audience}

This operational guide is the result of combining an array of feedback from LCA experts who have carried out comprehensive studies in developing countries. Experts from CIRAD, King Mongkut's University of Technology, INRAE, Indonesian Institute of Sciences, Stockholm University, WorldFish, Pontificia Universidad Católica del Perú, University of Oxford, Wageningen University, UNEP, FAO, and independent experts with recognized expertise in LCA studies in developing contexts have been involved. All these LCA experts have expertise on agri-food systems in Africa, Asia, Latin America and the Caribbean, including crops (such as citrus, mango, strawberries, banana, sugar cane, pineapple, market vegetables, green beans, coffee, cocoa, rice, cassava, cotton, palm oil), livestock (beef, fish, milk) and bioenergy products.

First, all identified experts (around 40) were invited to complete an online questionnaire to consistently formalize their experience on key aspects of implementing LCA in agri-food systems in developing contexts (29 answers received).

Second, all experts were invited to a series of four workshops to share their experiences and develop consensual recommendations. The four workshops were held between May and June 2019 with the following topics:

- Workshop 1: Building and communicating with stakeholders: Expectations, partnerships, confidentiality, ethical aspects and restitution

- Workshop 2: Inventory: Sampling and representativeness issues, data collection, field emissions

- Workshop 3: Impacts: LCIA methods depending on the study and certain important and complex impact categories such as land use, water, toxicity and ecotoxicity, biodiversity, eutrophication

- Workshop 4: Validation and interpretation: Data quality system, critical review (CR), sensitivity and uncertainty analyses

The guide covers the main aspects of conducting LCA studies in these contexts, considering not only scientific and methodological bottlenecks, but also organizational, legal, partnership and ethical constraints. This guide seeks to provide 
practitioners with advice and tools to understand and anticipate the pitfalls linked with these specific contexts, which will ultimately help improve the quality of their studies. In terms of study objects, this operational guide is broadly centred on LCA of agri-food systems in developing contexts, as previously defined, including different system boundaries depending on the goal and scope of each study. In a non-exhaustive way, the feedback collected from experts specifically dealt with LCA studies on crop production, animal husbandry, fisheries, aquaculture and food processing.

This operational guide is primarily intended for practitioners carrying out LCA studies with on-site data collection in developing and emerging contexts. It aims to enable practitioners to:

- understand the specificities of conducting a comprehensive LCA study in these areas;

- identify the most appropriate existing LCA methodological recommendations, considering up-to-date scientific results;

- prepare for frequently encountered field constraints to develop adapted and/ or fall-back strategies;

- improve the quality and reliability of the final results;

- ensure the completion of the LCA study when facing constraints external to the study itself; and

- optimize the impact of the study by improving communication on its objectives, data collection and results according to the audience.

This guide is more specifically aimed at experienced LCA practitioners who are new to the implementation of LCA in developing/emerging countries, or who need to become familiar with the specificities of applying the conceptual framework to such areas and agricultural productions. 


\section{Part 2 \\ Agri-food LCA in developing \\ and emerging contexts}

Claudine Basset-Mens, Angel Avadí, Cécile Bessou, Ivonne Acosta-Alba, Yannick Biard, Sandra Payen 



\section{5}

\section{State of the art of agri-food LCA}

Despite two decades of continuous methodological, data and tool development and improvement, the practice of LCA still faces several challenges. These challenges can be classified according to the main associated limiting factors, namely: methodological bottlenecks, data and tool availability, and financial shortages. Given the iterative LCA approach, these challenges are all highly interdependent. Methodological LCA challenges are numerous. Common ones include the choice of functional units (FUs), the delineation of system boundaries (e.g. inclusion of capital goods, end-of-life scenarios), cut-off criteria, allocation strategy, and the selection of impact categories. The LCIA methodology is generally based on linear simple models that do not properly account for complex site-specific mechanisms. The selection of impact categories thus requires a good understanding of underlying impact characterization methods and their limits regarding the system to be assessed as well as recent scientific developments.

These issues are exacerbated in agri-food LCA because results are known to be highly sensitive to methodological choices. For instance:

- For LCA of crops and livestock, the most common physical property used as FU is mass (e.g. a fixed amount of product), yet it does not capture quality attributes of agri-food products, such as their nutritional value.

- The impact of land use is also still poorly accounted for in LCA, which means trade-offs between production and land-use impacts are poorly assessed. This issue is exemplified when comparing conventional and organic cropping systems (Meier et al. 2015; Biermann and Geist 2019; Knudsen et al. 2019). The combined use of mass (e.g. $1 \mathrm{~kg}$ of product, protein or other substance of interest) and area units (e.g. 1 ha of agricultural land) can result in a more comprehensive assessment of contrasted systems (van der Werf et al. 2009; Salou et al. 2016).

- Another key element when studying agricultural systems is that the crop rotation must be considered for more realistic modelling of long-term amendment impacts. Current practice often includes at least the preceeding and successive crops (including intermediate crops) to the system's boundaries (van Zeijts et al. 1999; Koch and Salou 2016). Recent research has proposed approaches for including the full rotation and crop interactions into agricultural LCA. See for 
instance Brankatschk and Finkbeiner (2015) for a review of historical approaches and Goglio et al. (2017) for a full-rotation method.

- The allocation of impacts among agricultural co-products (e.g. grain and straw) definitely affects results, as shown when comparing AGRIBALYSE and ecoinvent processes for straw; AGRIBALYSE v1.3 (Koch and Salou 2016) assigns zero impacts from cereal production, while ecoinvent 3.5 (Nemecek et al. 2011a, b) assigns part of the agricultural impacts.

Applying LCA to agri-food systems entails further challenges due to the intrinsically variable nature of systems (Notarnicola et al. 2017) that are impacted not only by technological drivers, like industrial systems, but also by natural mechanisms. For instance, fisheries exploit fish stocks whose state and evolution are affected by fisheries and natural weather patterns (e.g. the El Niño Southern Oscillation (Bertrand et al. 2020)) and biological drivers (e.g. inter-decadal abundance regime shifts) (Thatje et al. 2008; Ayón et al. 2011). Agriculture and aquaculture depend on biophysical and geo-bio-chemical mechanisms, as well as on pedoclimatic conditions. Food processing requirements (e.g. energy, chemicals, water) are largely driven by the biophysical characteristics of the raw materials, which are highly variable. Moreover, agri-food systems are generally quite sensitive to management, which can differ greatly and lead to extremely variable performances. The LCA modelling of agri-food systems, and especially the inventories, requires careful considerations of the diversity within studied systems and the numerous biophysically driven aspects.

Suitable models are needed to estimate emissions from agriculture and aquaculture. These emissions mainly consist of direct field emissions of nutrients (e.g. leaching of nitrates and phosphorus $(\mathrm{P})$ and nitrogen $(\mathrm{N})$ losses from agriculture; $\mathrm{N}$, methane $\left(\mathrm{CH}_{4}\right)$ and $\mathrm{P}$ emissions from fish production systems, etc.) and pesticides, whose experimental measurement is highly resource-intensive and mostly unfeasible for time-limited or remote LCA studies. Among these models, multiple alternative approaches were developed for agricultural emissions, whereas fewer are available for aquaculture emissions (e.g. Cho and Kaushik 1990; Wang et al. 2012). Agriculture-oriented emission models are often aggregated into sets and described in agricultural inventory databases guidelines, such as ecoinvent (Nemecek and Schnetzer 2012), World Food LCA database (Nemecek et al. 2015) or AGRIBALYSE (Koch and Salou 2016). These models are "simple" ones, based on empirical equations. Other models created for non-LCA purposes are also being used for LCA. These models range from relatively simple ones, such as Indigo-N (Bockstaller and Girardin 2010; Bockstaller et al. 2021), to complex dynamic soil-plant/agro-ecosystem models, such as STICS (Brisson et al. 2003), with higher data requirements and a steep learning curve (Figure 5.1). LCA practitioners tend to use the simplest emission factors and empirical equations, such as those proposed by the Intergovernmental Panel on Climate Change (IPCC), FAO, etc. (Bouwman et al. 2002a, b; Roy et al. 2003; De Klein et al. 2006; Hergoualc'h et al. 2019). 


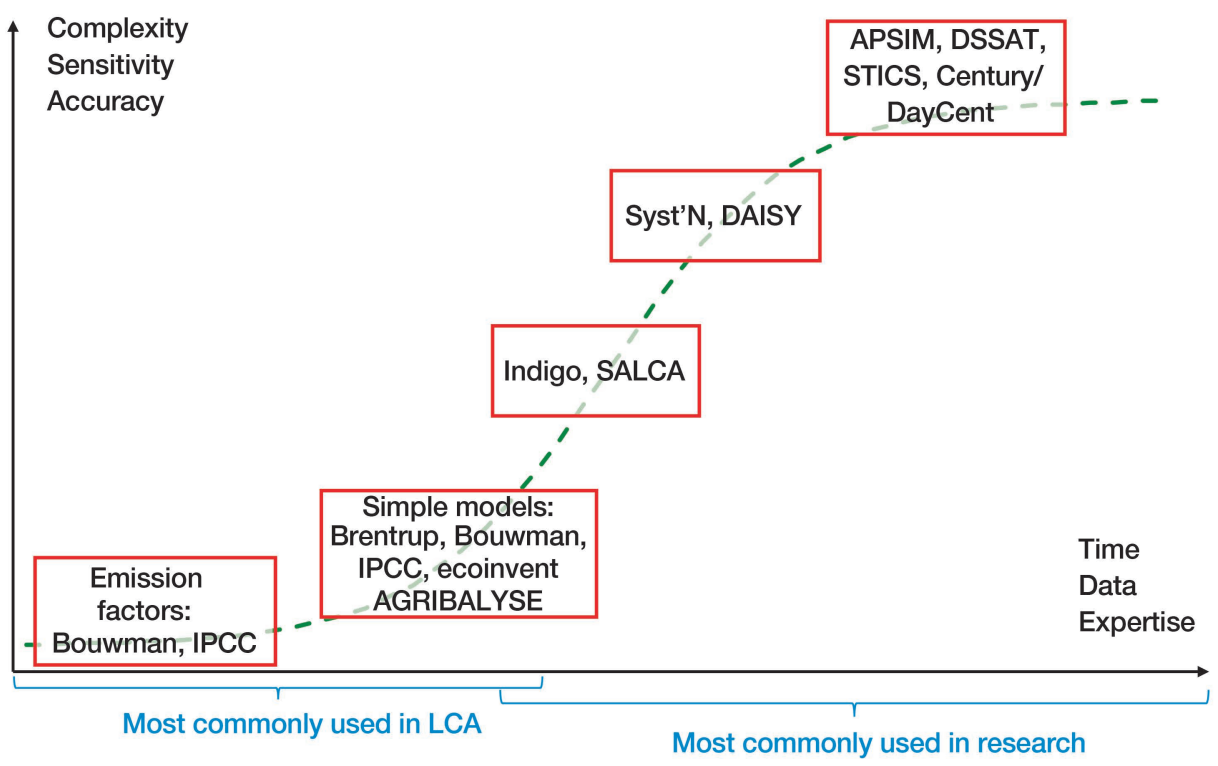

Figure 5.1. Complexity continuum of models computing direct field emissions. Source: adapted from Avadí et al. (2022).

Regarding the estimation of field emissions of pesticides, 100\% of the applied dose is still meant to be emitted into the soil in most cases, including within the most commonly used LCI databases such as ecoinvent and WFLDB. However, as part of an international consensus-building initiative led by the Danish Technical University, new recommendations and a web-based and updated version of the PestLCI model (Birkved and Hauschild 2006; Dijkman et al. 2012; Fantke 2019) have been recently developed, and should enable estimating the distribution of pesticide emissions into the different environmental compartments depending on application conditions (practice, soil, climate). Additionally, the dynamiCROP model (Fantke and Jolliet 2016) can be used to estimate the fraction taken up by the harvested part of the crop and subsequent exposition and impacts on consumers. Using the PestLCI consensus webtool, Gentil-Sergent et al. (2021) recently provided pesticide primary emission fractions for a panel of pesticide application scenarios in tropical conditions, taking account of specific crop growth stages, foliar interception and drift curves.

Specific impact categories of great relevance for agri-food systems are still under development or their modelling lacks consensus among practitioners. These categories include land use and related considerations on modelling biogenic carbon and soil quality, water deprivation and salinization, biodiversity, and terrestrial ecotoxicity (Notarnicola et al. 2017).

The main challenges for agri-food LCAs are summarized in Box 5.1, Box 5.2 and Box 5.3, for agriculture, seafood, and processing, respectively. 
In the specific context of seafood (i.e. fisheries and aquaculture, whether marine or not) LCA, various methodological and data limitations of LCA hinder the completeness of and comparability among studies (Avadí et al. 2018). These limitations have been addressed by researchers, and options are available to overcome them (Box 5.2).

\section{Box 5.1. Challenges for agricultural LCA (A. Avadí, C. Basset-Mens, CIRAD)}

Critical challenges for agricultural LCA to improve the quality and usefulness of LCA results: - Lack of operational methods to capture the diversity of farming systems in field sampling procedures.

- Lack of consensual approaches to deal with agriculture multifunctionality (including various issues related to allocation among rotational crops, within multi-cropping systems, etc.). - Lack of universally valid direct and indirect field emission models, for all agriculturally relevant emissions, under contrasted pedoclimatic conditions.

- Lack of suitable terrestrial ecotoxicity models.

- Lack of suitable models to account for agricultural impacts on soil quality, including biodiversity and salinization.

\section{Box 5.2. Challenges for seafood LCA (A. Avadí, CIRAD)}

Critical challenges for seafood (fisheries and aquaculture) LCA, to improve quality and usefulness of LCA results:

- Inclusion of fisheries management concerns and related impact categories (e.g. discards, by-catch, seafloor damage, biotic resource use, biomass removal impacts on the ecosystem and species).

- Data availability and data management: capture data, fuel-use data, aquafeed data, uncertainty data.

- Lack of CFs for waste emissions into the ocean, such as bilge water, lubricating oils and certain toxic molecules used in antifouling paints.

- The relation between LCA and seafood certifications. Seafood LCA guidelines were found to have either failed to include all relevant concerns or have yet to be widely applied by the industry (i.e. a consolidated set of practices is not widely applied by practitioners).

\section{Box 5.3. Challenges for food processing LCA (T. Tran, CIRAD)}

Critical challenges for food processing LCA to improve the quality and usefulness of results:

- Allocation of energy, water and chemical expenditures among interconnected and/or partially overlapping industrial processes within a factory producing multiple products.

- Limited background data for packaging materials. Such data are often required to model tin and aluminium cans, glass and plastic containers, woven plastic fabric/bags, etc. in the foreground.

- Flows of both input materials or energy, and by-products are often not monitored, especially waste water and solid by-products with no residual economic value; hence the difficulties for quantitative estimation of these flows. This is particularly true and critical for artisanal food processing chains that can be very diversified and based on "local recipes". - Trade secrets can make factory managers reluctant to share data on their operations. Sometimes, concerns may be addressed by anonymizing or averaging data.

- In the case of small-scale factories, how do practitioners estimate the number of factories to survey to reach a representative sample? 
For proposed solutions to overcome these challenges, see Chapter 9 "Building life cycle inventories" and Avadí and Vázquez-Rowe (2019a, b). These challenges are further analysed in the following sections in relation to developing contexts. 



\section{6 \\ Specific challenges for agri-food LCA in developing and emerging contexts}

All the general challenges described for the LCA of agri-food systems are even more critical in developing and emerging contexts. Three main constraints cover most critical challenges:

- a great diversity of production systems with little reliable data;

- highly specific natural contexts with little data, knowledge and tools for informing the inventory and impact assessment phases (especially for tropical systems);

- stakeholders' varying awareness and capacities in relation to the environment and environmental assessment.

\section{Diversity of agri-food systems due to specific natural conditions and combined socio-economic constraints}

As described in Chapter 1 (section "Most developing and emerging countries are located in the tropical zone"), highly diversified agri-food systems still co-exist in tropical developing and emerging countries. Their levels of complexity and performance may be subdivided in three mainstream groups, although not exclusively and with great variability levels across and within groups:

- traditional production systems based on small family farms, often partially for household consumption and "organic" by default;

- input-intensive production systems based on large farms and often dedicated to export;

- urban and peri-urban production systems to feed ever-expanding cities, operating in highly constrained conditions with a generally excessive and inappropriate use of chemical and organic inputs.

In terms of LCA modelling, tropical contexts generate specific issues. Most existing direct emission models used in LCA were calibrated for field conditions of crops growing in temperate environments (practices, soil characteristics, temperature, rainfall, etc.). Hence, their validity domain pertains to the conditions for which they were initially calibrated. It is notably true for the Swiss model suite SALCA 
(Swiss Agricultural LCA) used in ecoinvent, which encompasses the modelling of all primary field emissions, e.g. nitrogen, phosphorus and trace element emissions, while relying on field data collected in Switzerland only. Other commonly used empirical models for nitrogen and carbon compounds are the IPCC guidelines (IPCC 2006, Volume 4, Chapter 11). These guidelines are regularly updated to account for state of the art. For instance, in the latest version (IPCC 2019), models from Stehfest and Bouwman (2006) or Cardinael et al. (2018) were updated. But the coverage of tropical conditions in the background datasets is still limited (Bouwman et al. 2002c). Existing direct field emission models were not designed - or calibrated - to properly consider specific tropical conditions nor developing and emerging contexts, i.e. the pedoclimatic conditions or the substantial variability in practices (e.g. the high diversity of field inputs, agroforestry systems, etc.) (Table 6.1, more details in Appendix B p. 122). This issue was also recently demonstrated for pesticide emission models by Gentil et al. (2019) and for N emission models by Avadí et al. (2022). Other process-based models exist, such as APSIM (Holzworth et al. 2018), STICS (Brisson et al. 2003) and combinations of models (Constantin et al. 2015; Lammoglia et al. 2017), that make it possible to calibrate the models to very specific site conditions. However, calibrating process-based models requires specific expertise and extensive datasets. Moreover, such models are not available for all cropping systems, nor can all process-based models model the field emissions in a mechanistic way.

The same limitations apply to impact assessment models which are either too generic or valid only for temperate conditions. For instance, Gentil et al. (2019) highlighted in their review the lack of validity of ecotoxicity data for tropical species that show a specific sensitivity to the exposure to pollutants. Avadí et al. (2022) demonstrated that direct field nitrogen emissions modelling is to date not well adapted to tropical conditions, organic fertilization, or short-cycle crops such as market vegetables.

\section{Data gaps on the systems to be characterized}

Agri-food systems in developing and emerging countries are somewhat represented in LCA literature, especially field crop commodities exported worldwide, but on a limited scope compared with more industrialized agri-food systems. Aquaculture in developing and emerging countries focuses, for instance, on different species than those raised in developed ones, and different types of systems are used. The aquaculture systems and species in developing and emerging contexts, despite representing the bulk of global production (FAO 2016, 2018a, 2020a), are much less represented in LCA literature than systems and species exploited in industrialized countries. A similar situation applies to fisheries, where the vast majority of fisheries modelled with LCA are found in industrialized countries or operated by international firms (Avadí et al. 2018). 





Moreover, in developing and emerging contexts, public databases are not as systematic as in industrialized countries. Therefore, data on agricultural activities and production systems are not exhaustively available, or not available at all $^{4}$. Depending on the country, the administrative resources at governmental level, the political stability and the decentralization level, databases may be more or less complete, reliable or accessible. The reasons are multiple, but a common limiting factor is the level and regularity of public funding for data collection. When funds are intermittent, production data may be estimated instead of measured (based on expected or theoretical yields, which are usually overly optimistic), or collected at different subnational levels with varying levels of detail and accuracy (Box 6.1). Furthermore, required data is often not publicly available, but it may be accessible upon request (in person, and accompanied by a suitable reference/ introduction) at specific government offices. It is almost always impossible to have access to complete and reliable agricultural databases without acting in situ and having the right local contacts.

Visits within the country to institutional offices, farmers' associations and field operators (those in charge of production and processing), are critical to identify where data is available and how representative it is according to LCA data quality criteria (technologically, temporally and geographically).

\section{Box 6.1. Availability and quality of statistical data in developing and emerging countries (A. Avadí, CIRAD)}

In developing and emerging countries as different as Ecuador (agriculture), Peru (wild caught anchovy), Zambia (farmed tilapia), Côte d'Ivoire and Benin (vegetable market gardening), it has been observed that:

- Subnational statistics were very detailed in some cases and very basic in others.

- The national central statistics office combined data differing in quality and age, and database documentation was sometimes incomplete.

- Government officers declared lacking the funding for detailed and regular data collection.

- Some data were not combined or published.

- Due to political reasons, some data stopped being published or were even removed from public websites.

This is especially crucial since the lack of systematic databases may also hide a huge diversity in production systems which complicates data collection. In many developing and emerging contexts, specific and variable soil and climate conditions combined with diverse socio-economic contexts have led to an extreme diversification of production systems. In developing and emerging countries, this was probably exacerbated in many situations by the lack of means to massively

4. There are notable exceptions, such as that of Ecuador, where very detailed agricultural data at the farm and parcel level are publicly available and anually updated by the Ministry of Agriculture: https://www.ecuadorencifras.gob.ec/estadisticas-agropecuarias-2/ 
invest in inputs and machinery, paving the way to more original and diversified management practices.

Another situation, affecting certain developing and emerging economies, is the doctoring of production statistics. With fisheries, for instance, certain countries including China and Myanmar are believed to under- or over-report catches (Pauly and Zeller 2017).

Moreover, informal trade is not included in official statistical systems. The informal economy is known to be dynamic and easily adapt to market variations (Benjamin et al. 2014). According to the World Bank, the informal economy represents the majority of economic activity and employment in least developed countries. In (lower and upper) middle income countries, even if the existence of an informal economy is known, determining its size and assessing it is difficult. National experts often consider that micro and small informal businesses belong to a small sector that evolves or disappears when demand decreases. However, in some examples such as Colombian milk, despite more than half of it still being produced by informal farmers, this product represents around $25 \%$ of the agricultural gross domestic product (GDP) (Vega 2018). This reality affects LCA studies, since specific sectors are only partially represented if only official statistical data are considered. The operations of these informal producers might also be different due to small investment capacity.

The World Bank has developed a database on informality, estimating the proportion of the informal economy per country (http://www.enterprisesurveys.org/ data/exploreTopics/Informality). This resource should nonetheless be used with caution, just as an estimation, as the agricultural sector features specific issues regarding informality (e.g. informality in the rural sector, family businesses).

\section{Varying awareness and capacities of stakeholders}

In contexts were security and food security can be high priorities, stakeholders and the population rarely have the same level of awareness about environmental issues. Although life cycle thinking has spread throughout the world since its early development in the 1980s, there is still a gap among world regions in terms of LCA capacity building and applications. Particularly in developing countries, in areas where capacity building resources are limited, few stakeholders are aware of the methods and even fewer are able to apply LCA. To tackle this issue and enable the global use of credible life cycle knowledge by private and public decision-makers, the UN Environment Life Cycle Initiative has been implementing a roadmap with quantified targets towards 2022. Among those targets, providing capacity building worldwide and a solution to access all interoperable LCA databases are milestones being pursued through collaboration platforms in Africa, Asia, and Latin America. Under the Life Cycle Initiative, ecoinvent leads 
a project ${ }^{5}$ that aims to establish national LCI databases in several developing and emerging countries.

The varying awareness regarding LCA objectives and challenges may be exacerbated in countries where life cycle thinking is not widespread, and LCA not extensively applied. A diverse range of stakeholders may be involved in an LCA study, and can be classified according to four groups (sometimes overlapping): commissioners and decision-makers, stakeholders directly involved in the agrifood system, facilitators who may or may not be directly involved in the agri-food system, and experts carrying out the LCA of the agri-food system. Both LCA knowledge and interest in LCA results may vary considerably across these stakeholder groups, although they are tightly connected for LCA application. Likewise, knowledge and expectations can vary greatly among stakeholders within each of these groups. The greatest challenge for a commissioned LCA study thus lies in managing multiple expectations, which may be conflicting (Box 6.2).

\section{Box 6.2. When key players of the agri-food system boycott the LCA study (C. Basset-Mens, CIRAD)}

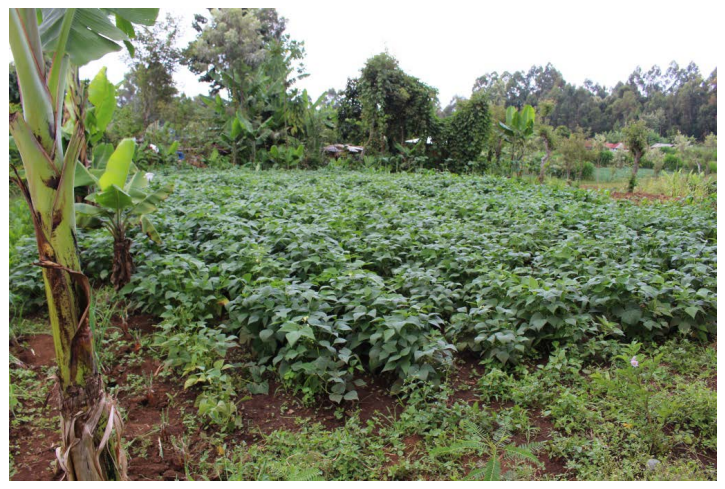

As part of an LCA study for fresh French beans produced in Kenya for the EU market and commissioned by the European Union's Directorate-General for International Cooperation and Development (DG-DEVCO, now the department for International Partnerships), certain key industry stakeholders had refused to meet the LCA and local experts or collaborate in data collection. The reason given was that EU was not legitimate nor welcome to come and control the fresh French bean value chain after fifty years of high regulatory and sanitary constraints leading to major perceived difficulties by the value chain operators and farmers. Often, such tensions can be relieved by face-to-face efforts to explain the work and diplomacy supported by local experts. However in this particular case, despite all the talent and effort of the local expert to convince them, these stakeholders did not accept to be part of the study, which had implications on the representativeness of the data collected for the study and its final results.

On one hand, LCA practitioners are usually well aware of the data needs of the LCI, the existing LCIA methods, and the overall potential and limits of LCA when interpreting the results. On the other hand, some commissioners may be

5. Development of National LCA Database Roadmaps and further development of the Technical Helpdesk for National LCA Databases (https://www.lifecycleinitiative.org/ call-for-proposals-development-of-national-lca-database-roadmaps/). 
too demanding or overly optimistic in terms of conclusions and applicability of LCA results. In particular, means in terms of funds, work force or time allocated by the commissioners may not be appropriate to carry out the LCA in satisfactory conditions. Stakeholders directly involved in the agri-food system or the facilitators may play a key role in enabling access to data. It is thus critical to know what their roles and expectations are to anticipate how these factors may affect data quality (see Chapter 8 section "Critical analysis of the demand, constraints and avoidance strategies"). 



\section{Established and emerging initiatives}

Several initiatives have emerged to overcome LCA challenges in developing and emerging contexts. In Asia, Africa and Latin America, networks of major producers of primary resources (i.e. commodities such as minerals, cotton or soya) are being structured by local (e.g. national environmental organizations such as Fundación Chile (https://fch.cl/en/)) and external (e.g. international development organizations such as UN Environment) stakeholders (Quispe et al. 2016). Worldwide, several initiatives and networks are emerging to support the life cycle thinking approach (local, regional and global). We have attempted to identify the known existing LCA networks based on available sources (scientific and grey literature, online research and LCA forum discussion list). Bjørn et al. (2013) identified around a hundred initiatives among which 29 were considered as networks. The authors mapped and characterized these networks according to their structure and activities. Global initiatives and communities also record regional, national and other LCA networks, for instance (https://www.lifecycleinitiative. org/networks/life-cycle-networks/) and the Forum for Sustainability (https:// fslci.org/regional-networks/).

As of April 2021, we found nine international and regional initiatives and 32 national networks or platforms (Table 7.1). At least eight websites were no longer available or appear inactive while other initiatives were just emerging. The detailed list of networks is available in Appendix C (p. 126). The stability and permanence of those national networks seems to be inconstant. In further work, it would be interesting to understand the main challenges they faced and to update the list at least annually. Scientific publications are correlated to the formation of LCA networks and their continental distribution. A vast majority of networks are located in Europe and the United States, but some operate in Africa, the Middle East and Central Asia. In those regions, non-governmental organizations (NGOs) are more represented in these networks than in developed countries. In developing and emerging contexts, major actors in LCA networks are academia and industry, with a varying presence of government authorities and NGOs. LCA networks are context dependent. Out of six networks in developing and emerging economies, few work with LCA software and communicate through websites, but when compared with 
networks based in developed economies, they host more conferences and open seminars, thus raising awareness (e.g. the biannual CILCA conference, organized by the pan-Latin American Red Iberoamericana de Ciclo de Vida (https://rediberoamericanadeciclodevida.wordpress.com/).

Table 7.1. Networks, platforms and initiatives identified by regions and sub-regions.

\begin{tabular}{|c|c|c|}
\hline LCA network/platform type & Geographical scope & Initiatives by region/countries \\
\hline International & Global & 3 \\
\hline \multirow[t]{5}{*}{ Continental networks } & Africa & $1^{*}$ \\
\hline & Asia & $1^{*}$ \\
\hline & Europe & $2^{*}$ \\
\hline & LAC & 1 \\
\hline & North America & 1 \\
\hline \multirow{5}{*}{$\begin{array}{l}\text { National networks } \\
\text { or platforms by continent }\end{array}$} & Africa & 1 (Uganda) $^{* *}$ \\
\hline & Asia & $\begin{array}{l}7 \text { (China, India, Indonesia, Japan, Korea } \\
\text { Malaysia Thailand) }\end{array}$ \\
\hline & Europe & $\begin{array}{l}14 \text { (Denmark, Estonia*, Finland, France } \\
\text { (3), Germany*, Hungary, Italy, Poland*, } \\
\text { Spain*, Switzerland, Turkey, UK) }\end{array}$ \\
\hline & America & $\begin{array}{l}6 \text { (Argentina, Brazil, Chili*, Colombia*, } \\
\text { Ecuador, Mexico, Peru, US) }\end{array}$ \\
\hline & Oceania & 2 (Australia, New Zealand) \\
\hline
\end{tabular}

${ }^{*}$ website inactive or not fully accessible; ${ }^{* *}$ no website available.

Africa remains the region with the least representation in networks. The only regional network was the now inactive ALCANET initiative (Ramjeawon et al. 2005). Although the African networks are not very visible on the internet, they may still continue to emerge, such as the Uganda network created in 2018. Nonetheless, LCA is not a common research tool among the African research community (Box 7.1).

There are national LCI database initiatives, especially from developed and emerging countries outside Europe and North America, which could inspire developing countries to build their own. For instance, IDEA is a process-based Japanese database (http://idea-lca.com/?lang=en), AusLCI is the Australian National LCI database (http://www.auslci.com.au/), and emerging economies such as China, Brazil, Peru and Thailand are continuously building their national LCI databases. In December 2020, ecoinvent released the version 3.7.1 of its database (updated as 3.8 in 2021), which includes many seafood and agriculture (crops and livestock) inventories from developing and emerging countries. However, there is a significant time lag between the release dates of the latest version of the 
database, its implementation in reference LCA software (often six months to a year later), and its standard use by the practitioner community: in the first half of 2021, many scientific LCA publications are based on ecoinvent versions 3.5 or 3.6, published in 2018 and 2019, respectively. Curated lists of LCI data, both free and fee-based, are available through the Global LCA Data Access (GLAD) network (https://www.globallcadataaccess.org/) and openLCA Nexus (https:// nexus.openlca.org/databases).

\section{Box 7.1. LCA in Africa (A. Avadí, C. Basset-Mens, CIRAD)}

The reasons for the lack of penetration of LCA in Africa are multiple. Among them, capacity building limitations by universities and experts as for disseminating the concepts and language of LCA play a major role, together with LCA's traditional focus on the product-service, which evolved from a context of overconsumption and which is not necessarily valid in Africa (Ramjeawon et al. 2005). Moreover, almost no LCA background data is available for African contexts, while in the specific field of agri-food, direct field emission models adapted to tropical conditions are lacking; this further hinders the development of LCA on the continent. In a recent review, Karkour et al. (2021) found around 200 papers on LCA in Africa among which agriculture appeared as the sector receiving the most attention, with 53 articles (predominantly commissioned by non-African institutions). The number of articles related to LCA have increased in recent years. However, the coverage of LCA studies among African countries is highly uneven, with South Africa (Brent et al. 2002), Egypt and Tunisia being where most of the research was conducted. The authors highlighted remaining challenges for LCA in Africa, such as the need to establish a specific $\mathrm{LCl}$ database for African countries or a targeted valid LCIA method. A recent and ongoing programme by the European Commission's department for International Partnerships is performing sustainability assessments (including LCA for the environmental dimension) of several agri-food supply chains in developing and emerging regions, including some located in Africa: the Value Chain Analysis for Development - VCA4D programme (https: / / europa.eu/capacity4dev/value-chain-analysis-for-development-vca4d-).

National and regional initiatives are spreading and provide a breeding ground for new LCA studies in the tropics and emerging contexts. There should be mutual interests in contributing to and benefiting from such networks and databases, notably when preparing an LCA study from an office rather than in the field or when helping to disseminate the final results. Conducting an LCA study abroad is quite challenging and local or neighbouring networks may be very useful to avoid pitfalls and better plan for the fieldwork.

Facing challenges in conducting agricultural LCA in tropical and emerging contexts requires a good understanding of local issues and available solutions. In the next chapters, we provide detailed guidelines from designing the study to communicating the final results to harness the most useful information from any agricultural LCA conducted in the tropics and/or emerging contexts. 



\section{Part 3}

\section{Overcoming the challenges for \\ robust agri-food LCA in developing and emerging economies}

Claudine Basset-Mens, Angel Avadí, Cécile Bessou, Ivonne Acosta-Alba, Yannick Biard, Sandra Payen, Patrik Henriksson, Shabbir Gheewala, Joël Aubin, Edi Iswanto Wiloso, Jessica Hanafi, Anthony Benoist, Thierry Tran 



\section{8 \\ Co-designing the study with stakeholders}

The goal and scope of design is a critical first step in LCA. Key elements of the ISO 14040/44 standard should always be considered when defining goal and scope (see Appendix A p. 121). Depending on the situation, this first step may be carried out by the LCA practitioner alone or with the collaboration of stakeholders. In the following sub-sections, we describe a complete co-design approach for an LCA study.

\section{Overview of the approach}

Based on our field experience, we designed an approach to help LCA practitioners organize their LCA study with the best chance of success and build long-lasting and fruitful partnerships (Figure 8.1). In this approach, a first loop of exchanges with the commissioner (i.e. the stakeholder from whom the study originates and who defines the terms of reference) occurs, and the LCA practitioner may reject the proposal if all important conditions are not met. The study might take place in highly complex situations or the commissioner might have unrealistic requirements or not provide sufficient means. We illustrate such conditions with some real situations from the field in our "deal-breaker situations" scheme (Figure 8.2). Once realistic conditions are negotiated with the commissioner and an explicit contract is signed, we recommend designing and formally validating in a dedicated report the goal and scope of your study with the commissioner. This will help make sure that the commissioner and the practitioner agree on common and realistic achievements, and provide a clear roadmap for the LCA study.

Next, one essential part of the study will consist in building operational interactions with all stakeholders: this is what we call the "community" of the study. It is therefore of paramount importance to analyse and understand the expectations and constraints of each member of this community and to develop a strategy to work with them. Depending on the study conditions, the work may also be organized in synergy with other experts; either local technical experts or experts from other disciplines. Finally, before starting the actual data collection, as part 
of the study goal and scope, the system boundaries need to be fine-tuned and a typology for the studied systems must be delineated to define the best possible sampling protocol and be able to answer the questions raised by the commissioner.

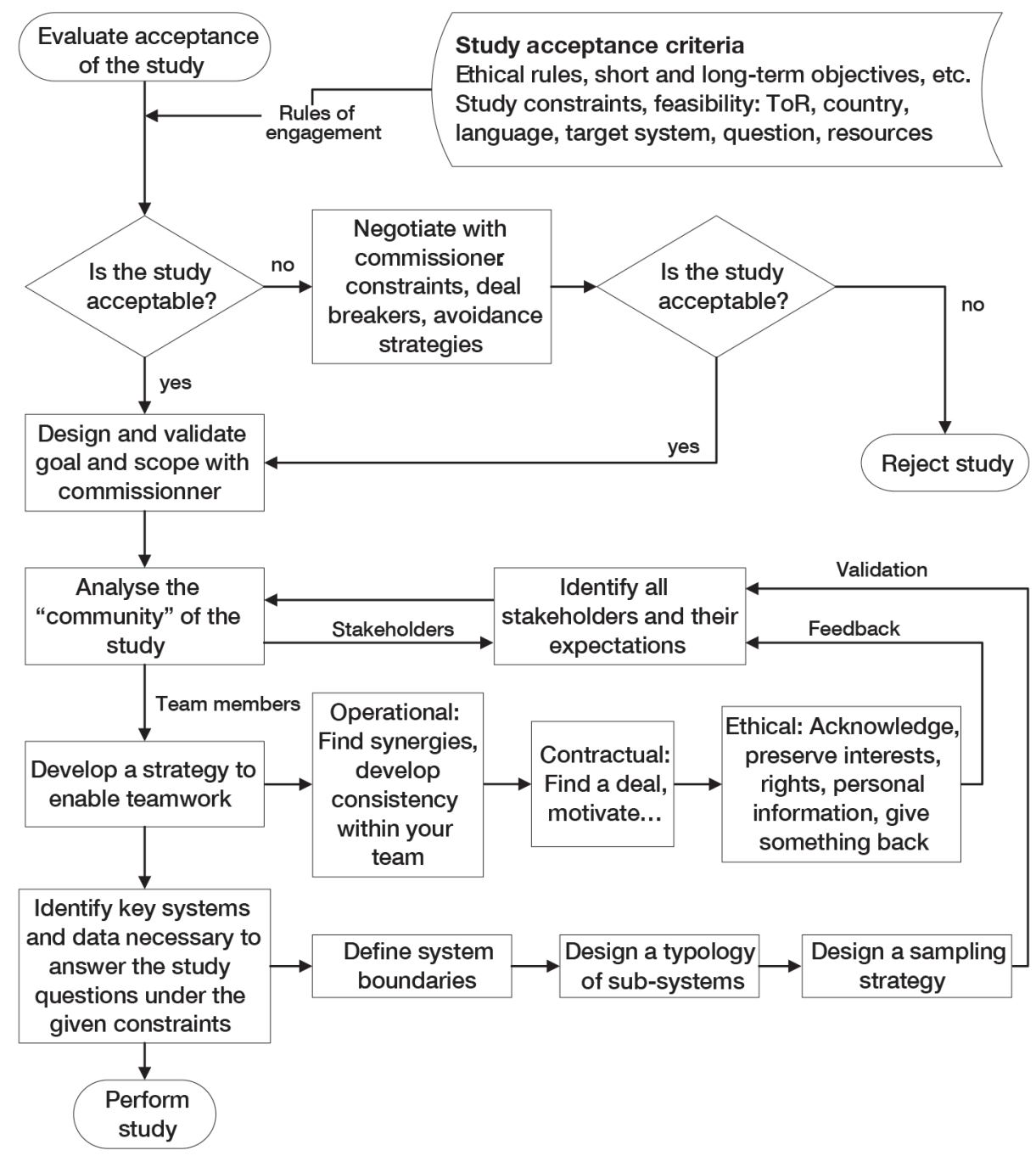

Figure 8.1. Overall approach to organize the LCA study with the different stakeholders in the best possible conditions (ToR: terms of reference). 


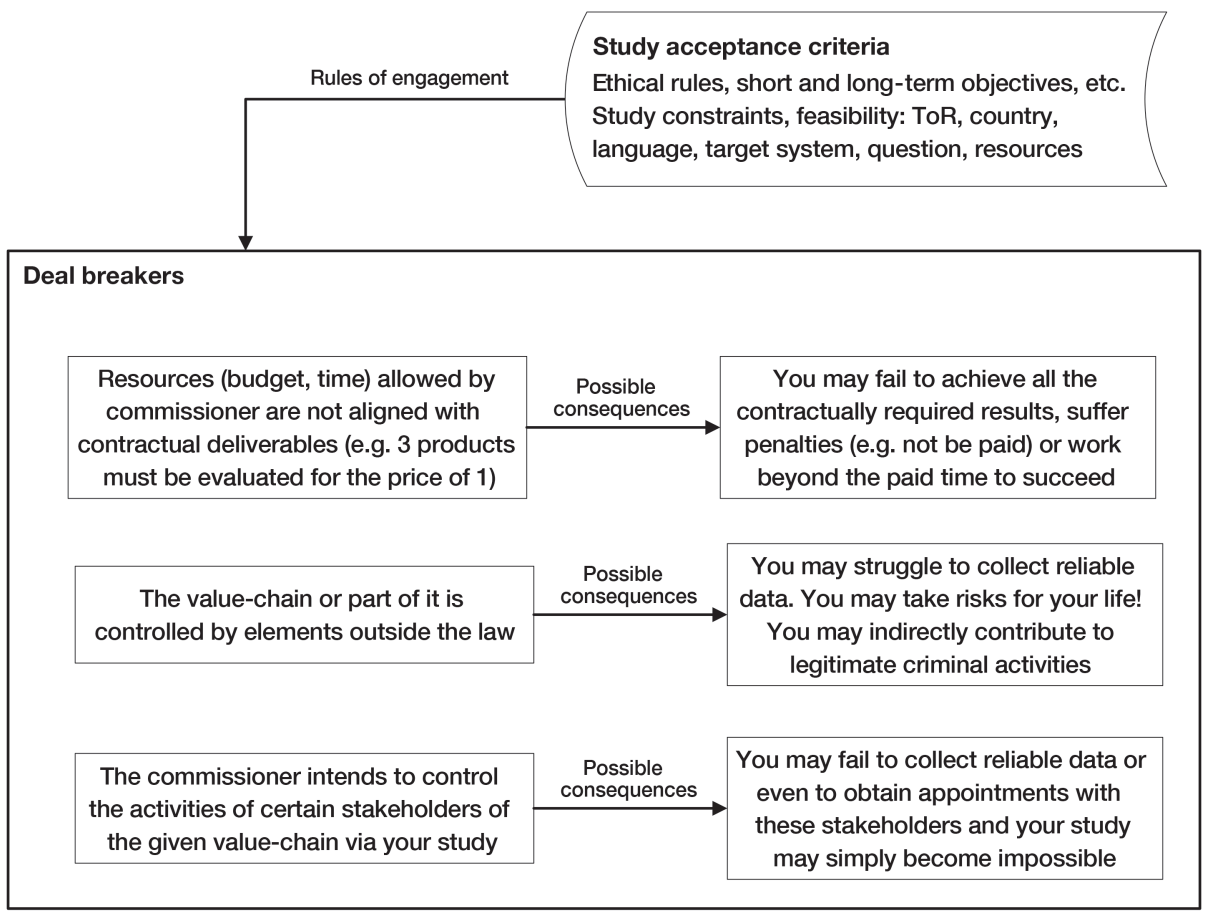

Figure 8.2. Deal-breaker situations: some examples from the field.

\section{Critical analysis of the demand, constraints and avoidance strategies}

Before starting a study, it is necessary to analyse the demand, i.e. the detailed terms of references, and assess its feasibility. The most important conditions are: - resources allocated in terms of time, money, and access to data are adapted to the study objectives;

- the context of the study, especially that the actual commissioner and study objectives are transparent;

- the country of the study should not face important security issues (e.g. war)

In Table 8.1 and Table 8.2, main LCA study constraints are reported and adaptation strategies are provided. Table 8.1 focuses on constraints more directly related to the initial conditions of the study as determined by the commissioner's objectives, which should be clarified as much as possible before the study begins. The commissioner may or may not be the sponsor, but is considered to be the stakeholder deciding on the means allocated to the study.

Table 8.2 indicates more scenarios depending on the expectations and constraints of further stakeholders throughout the study. All other aspects including data availability and system complexity might be challenging but should be possible 
to address with adequate organization and the right partnerships. This is what our guide aims to demonstrate and support.

Table 8.1. Clarification of commissioners' constraints and expectations to be handled ahead of the LCA study.

\begin{tabular}{|c|c|c|}
\hline $\begin{array}{l}\text { Main constraints and/ } \\
\text { or expectations of } \\
\text { commissioner }\end{array}$ & $\begin{array}{l}\text { Avoidance and adaptation } \\
\text { strategy }\end{array}$ & Practical implementation \\
\hline $\begin{array}{l}\text { The commissioner } \\
\text { wants quick results and/ } \\
\text { or is not aware of LCA } \\
\text { complexity: not enough } \\
\text { time or resources are } \\
\text { allocated to the LCA } \\
\text { practitioner in the } \\
\text { terms of reference } \\
\text { Or } \\
\text { The commissioner } \\
\text { or another affiliated } \\
\text { beneficiary expects } \\
\text { unrealistic outputs } \\
\text { from the study such as } \\
\text { the decision he or she } \\
\text { should make (see Box }\end{array}$ & $\begin{array}{l}\text { Clarify in advance the needs } \\
\text { for a proper LCA study. } \\
\text { Clarify in advance the limits } \\
\text { regarding potential LCA } \\
\text { coverage, data completeness } \\
\text { and representativeness. } \\
\text { In all cases, after negotiations } \\
\text { and the study, issue a } \\
\text { reminder to put final results } \\
\text { into perspective with initial } \\
\text { context and means. }\end{array}$ & $\begin{array}{l}\text { Ahead of study start, propose a presentation } \\
\text { to the commissioner on LCA methodology } \\
\text { with an example of necessary datasets and } \\
\text { explanation about result consistency and } \\
\text { quality. It is key to find suitable ways to } \\
\text { explain the importance of the constraints } \\
\text { and to detail the methodological challenges } \\
\text { faced by the practitioner. } \\
\text { Propose an inception mission ahead of the } \\
\text { actual study, without a set engagement for } \\
\text { carrying out the study, in order to gather } \\
\text { concrete field information to justify either } \\
\text { the narrowing of study objectives to fit } \\
\text { the proposed means or to negotiate better } \\
\text { alignment among the study scale, allocated } \\
\text { means and potential scope for the outputs. }\end{array}$ \\
\hline
\end{tabular}

8.1 and Box 8.2)

Lack of transparency on who the commissioner is and what the expected outcomes are
Clarify in advance the study context, i.e. the commissioner's expectations and intended use of LCA outputs.
Check the study terms of references to know who the designated parties are and make sure you are properly introduced to all potential commissioner levels. Make sure objectives are clearly defined in the study terms of references and/or the LCA study contract.

Lack of objectivity from Explain in advance what the commissioner who "good" or "bad" results could be; stress issues of trade-offs; exemplify how all of these can be useful to improve the production systems.

Clarify in advance the publication policy to make sure that results can be made public independently from initial expectations. If the LCA is meant to be used for a public comparison with other products or published results, anticipate the need for a peer-review as required by the ISO standard.
Provide feedback and showcase success stories of LCA.

Make sure the publication policy is clearly stated in the contract.

Propose a "non-responsibility" clause in the contract for the practitioner, if the LCA results are not used properly (not in agreement with the study validity domain) and/or results are modified.

Make sure that a budget is allocated for an external ISO-compliant LCA review when the objective is to publish the LCA results compared with previously published LCA results. 


\begin{tabular}{|c|c|c|}
\hline $\begin{array}{l}\text { The commissioner } \\
\text { and one or more } \\
\text { stakeholders are bound } \\
\text { by contractual or } \\
\text { funding relationships } \\
\text { that complicate } \\
\text { the collection of } \\
\text { information }\end{array}$ & $\begin{array}{l}\text { Clarify in advance potential } \\
\text { contractual relationships } \\
\text { between the commissioner } \\
\text { and other stakeholders. } \\
\text { Clarify in advance the } \\
\text { commissioner's objectives } \\
\text { (link with the constraint on } \\
\text { "lack of transparency"). }\end{array}$ & $\begin{array}{l}\text { Make sure objectives are clearly defined } \\
\text { in the study terms of references and/or } \\
\text { the LCA study contract. } \\
\text { Discuss with the commissioner the potential } \\
\text { implications of his/her relationships with } \\
\text { the stakeholders regarding potential issues } \\
\text { on data collection, etc. Depending on the } \\
\text { outputs, ask for transparent information } \\
\text { communicated to relevant stakeholders on } \\
\text { the study objectives (e.g. through mails } \\
\text { to stakeholders with a copy to the LCA } \\
\text { practitioner). }\end{array}$ \\
\hline
\end{tabular}

\section{Box 8.1 Expectation management in Zambian aquaculture study (A. Avadí, CIRAD)}

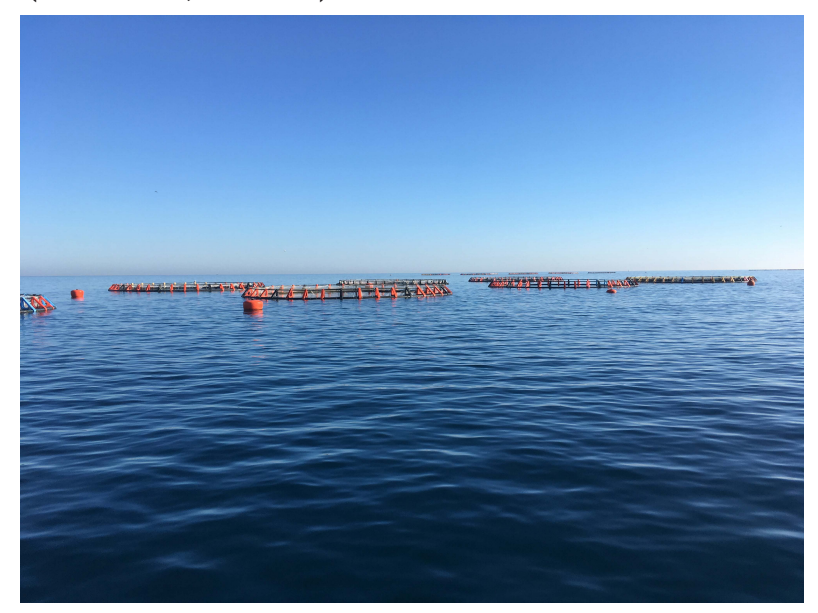

In the context of the VCA4D project on Zambian aquaculture, certain stakeholders such as the local European community (EC) Delegation and the Zambian government (Ministry of Fisheries) expected direct advice on where to invest in the supply chain (e.g. priorities). The experts explained that the purpose and scope of the study was to describe the current supply chain situation, and to evaluate the consequences of investing in each element of the value chain, but not to recommend specific investments. Therefore, the project team's role was to inform and support their decision-making, not to make decisions.

Project data brief: https://europa.eu/capacity4dev/value-chain-analysis-fordevelopment-vca4d-/wiki/207-zambia-aquaculture 


\section{Box 8.2. The notion of "environmental sustainability" from a LCA perspective (Y. Biard, CIRAD)}

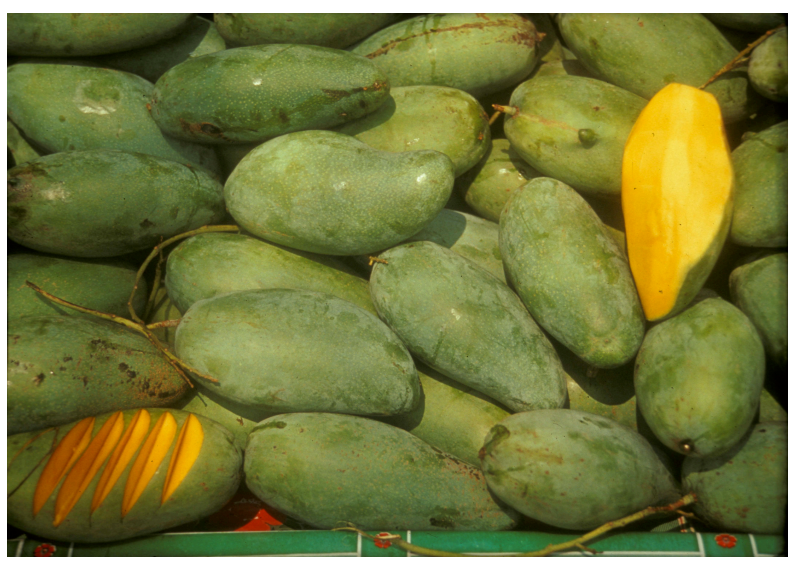

The study carried out on the mango commodity chains in Burkina Faso was one of the first studies of the VCA4D programme. At that time, the question explicitly formulated by DG DEVCO and Agrinatura was: Are these commodity chains sustainable?

With regard to LCA, the question had to be reformulated, to make it clear to the sponsor that the word "sustainable" is a non-prescriptive word and does not include anything quantitative. As such, LCA could not answer yes or no to the question asked, but could provide data and information on the potential impacts of each sub-sector.

Second, these potential impacts could be benchmarked by comparing the values obtained for the mango commodity chains with those of other agricultural commodity chains, or even other sectors of the Burkina Faso economy, although as a non-predictive cross-view given the unmatched functions.

The detailed synthesis of the study is freely available online via the following link: https: / / europa.eu/capacity4dev/value-chain-analysis-for-development-vca4d-/wiki/ 202-burkina-faso-mango

\section{The community of the study}

An LCA study involves many stakeholders with whom the practitioner must exchange information and data (Figure 8.3). Stakeholder categories include:

- the commissioner (public or private, individual or institutional, etc.);

- local experts who cooperate with your study;

- local institutions (e.g. ministries);

- actors involved in the value chain to be interviewed (producers, processors, carriers, retailers, who can be industrial players or smallholders, etc.);

- actors involved indirectly (local authorities, statistics offices, central decision-makers, etc.);

- sometimes observers from the civil society (NGOs, academics, consultants, etc.).

The quality of the LCA depends substantially on the quality of the data collected, which in turn depends on the willingness from stakeholders to share information and data, and from their potential direct interest in participating, since doing so requires time. It is paramount to make sure that expectations and constraints related to stakeholders are well understood and managed to the fullest extent 
possible. We differentiated two main situations that influence interactions between the LCA expert and the community of the study:

- a situation where the LCA expert is local;

- a situation where the LCA expert is a foreigner.

For each situation, we proposed a formalization of the expectations from the various stakeholders (Figure 8.3). The commissioner (or funder) orders and pays for the study. This stakeholder must have clear expectations and requirements. As already mentioned, the LCA practitioner must explain clearly what an LCA study can and cannot do and negotiate with the commissioner to ensure adequate conditions to produce realistic deliverables. In the country of the study, all stakeholders have their own expectations. Local institutions may seek useful information and support for decision-making as well as more personal recognition as individuals. Local experts may expect financial benefits, future projects, visibility or publications. Farmers might hope for some technical advice and future subsidies based on the study results. Processors and exporters might expect favourable feedback on their businesses, etc. All along the value chain, the stakeholders must manage their day-to-day activities and will need to see a benefit in contributing to the study.

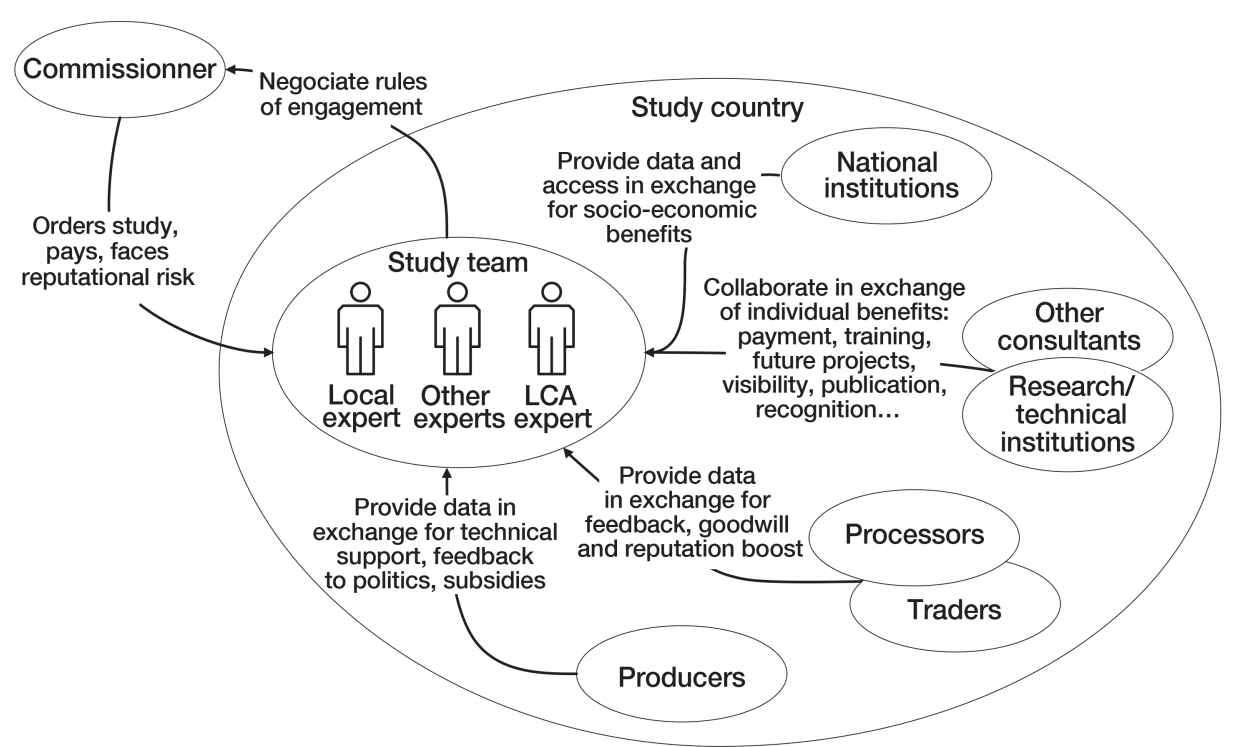

Figure 8.3. Community of the study and stakeholder expectations: the LCA expert may be local or a foreigner. The main difference between the two situations is that when the LCA expert is a foreigner, she or he will need to collaborate with a skilled local expert who can facilitate meetings with the relevant contact and ensure proper social usages and language. 
Overall, the golden rules to ensure good working conditions with stakeholders are: listening skills, transparency, awareness raising, explaining, respect, trust, protection of interests and sensitive data. These main rules are presented and illustrated in Figure 8.4.

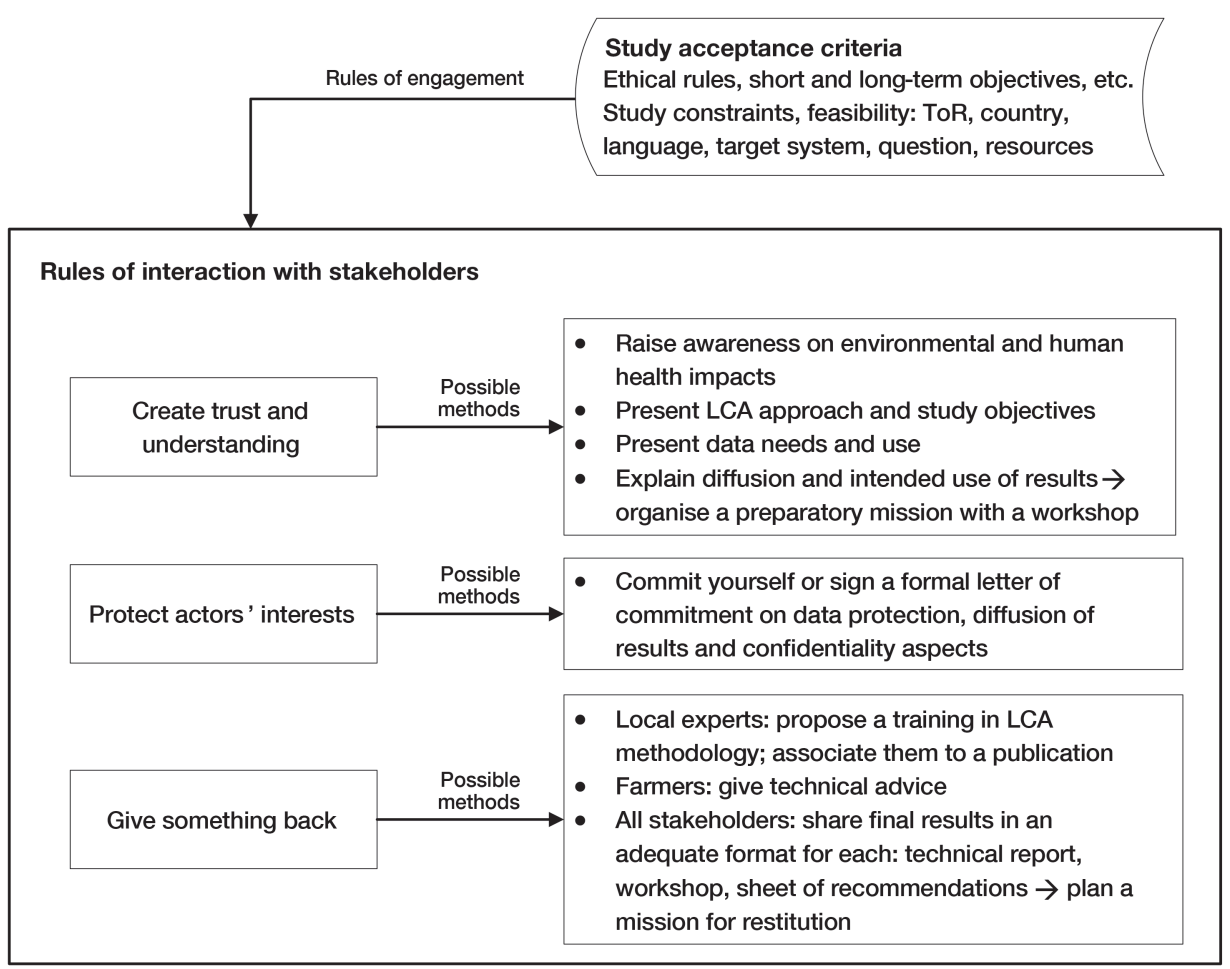

Figure 8.4. Golden rules of interactions with stakeholders.

Some stakeholders might fear drawbacks or reputational risks from the study, or simply see it as a waste of time with no foreseeable benefits. It is impossible to make an exhaustive list of all potential situations and expectations. However, we did list the main situations and proposed ways to avoid obstacles and ensure positive collaboration with stakeholders and effective data collection (Table 8.2). Ideas are not listed by stakeholder type, as one constraint may be faced by several stakeholders. Instead, they are listed by type of constraint and/or expectation. Avoidance and adaptation strategies may still depend on the stakeholder. Generally speaking, it is important to remain attentive to the actual willingness of the local partners and stakeholders. Some may prefer very official interactions while others may feel uncomfortable signing formal agreements. Local expert advice is of great help in determining the most suitable ways of collaborating with each stakeholder. 


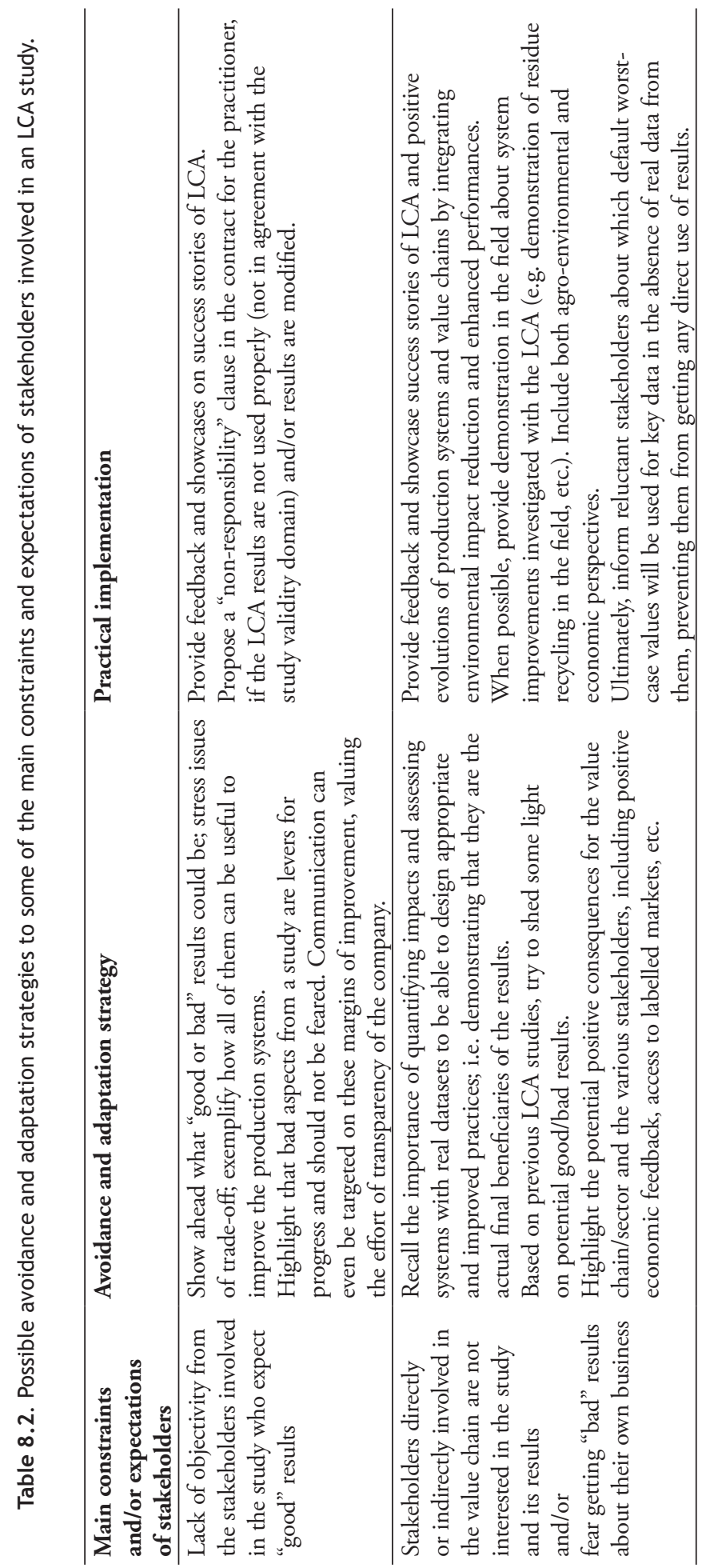




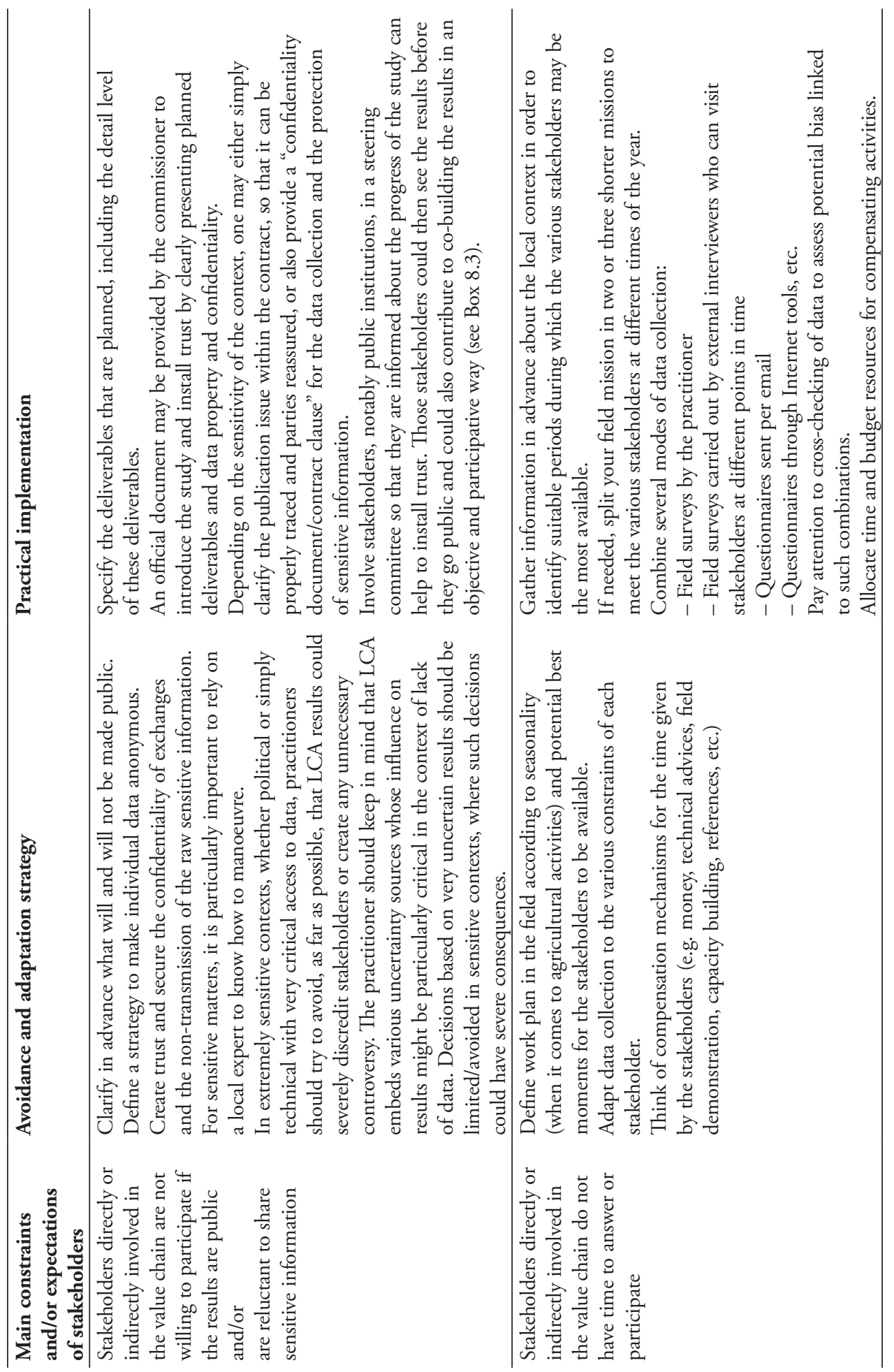




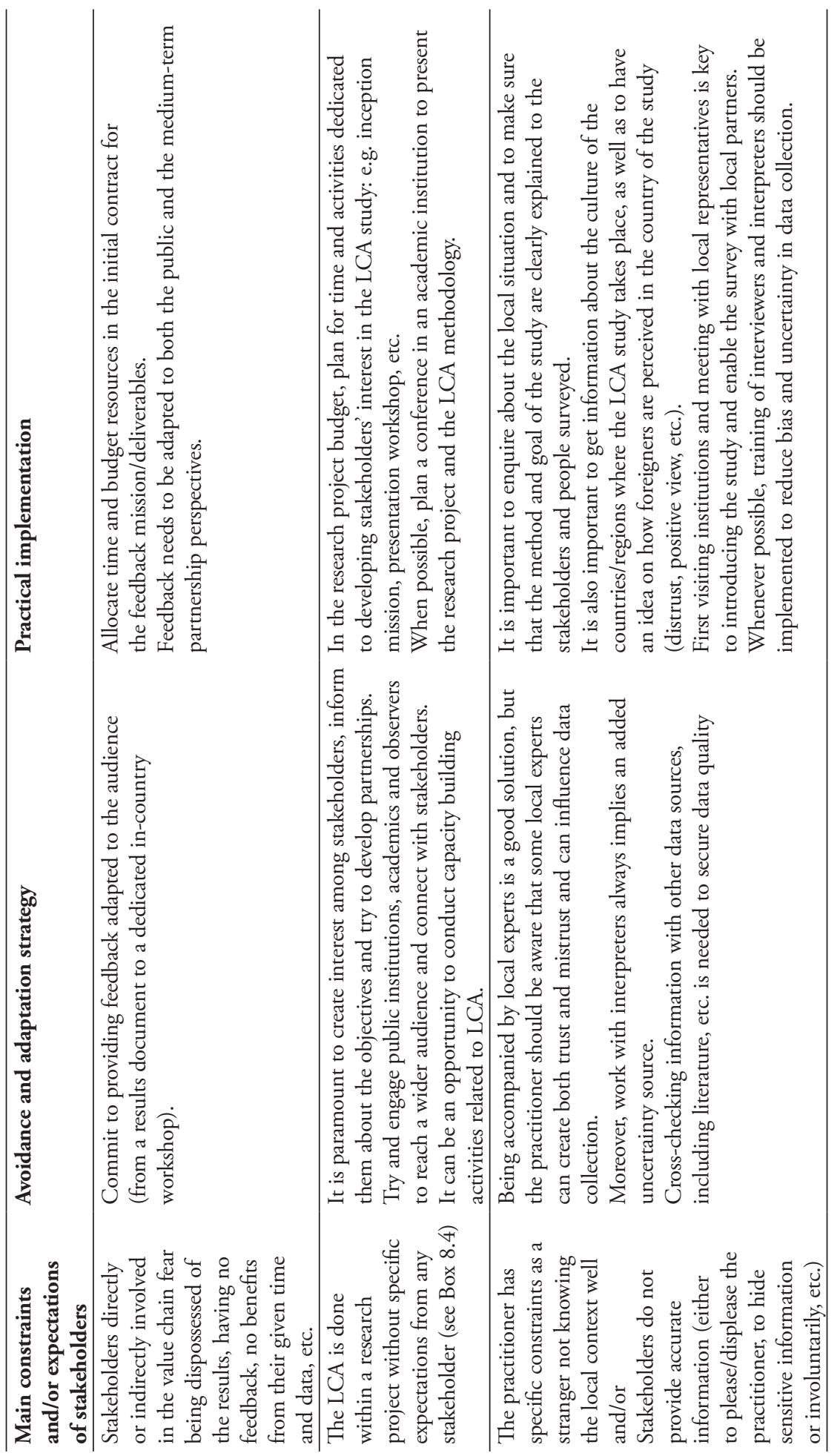




\section{Box 8.3. Sustainability assessment of sugarcane biorefiner- ies to enhance the competitiveness of the Thai sugar industry (S. Gheewala, King Mongkut's University of Technology Thonburi, Thailand)}

Thailand is one of the world's leading sugarcane-producing and sugar-exporting countries where this industry is relatively mature. However, there is relatively little scientific information on the sustainability of the sugarcane supply chain considering all environmental, economic and societal aspects. This study aimed to assess the sustainability of sugarcane biorefineries in Thailand in view of environmental, economic and social hotspots (Gheewala et al. 2016; Silalertruksa et al. 2017).

To monitor and steer the overall work and support dissemination and further implementation of research results into policy, an advisory committee was officially assigned through the National Science and Technology Development Agency (NSTDA) by engaging the relevant stakeholders in the sugarcane value chain, including government bodies, industry players, the cane growers association and researchers. The government sector included the Office of the Cane and Sugar Board (Ministry of Industry), Office of Agricultural Economics (Ministry of Agriculture and Cooperatives), Department of Alternative Energy Development and Efficiency (Ministry of Energy), Ministry of Science and Technology, and the Thailand Greenhouse Gas Management Organization. The private sector included representatives from the sugar mills and ethanol companies, as well as the sugarcane growers association. In addition to the advisory committee, a technical committee from various research institutes provided technical advice to the research team, verified the sustainability assessment method and results, and provided recommendations.

\section{Key Partners}

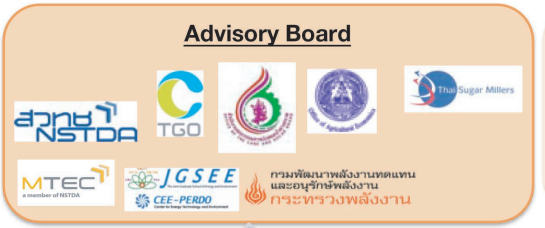

Role \& Responsibility

- Monitor and steer the overall work and ensure results are correct

- Recommend for sustainability indicators

- Support dissemination and further implementation of research results to policy

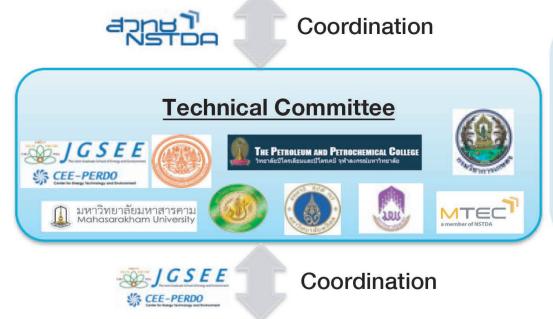

Role \& Responsibility

- Technical consultation to research team

- Verify sustainability assessment method \& results

- Provide recommendations on measures for enhancing competitiveness of industries

- Regularly report the work progress and result to the Advisory Board

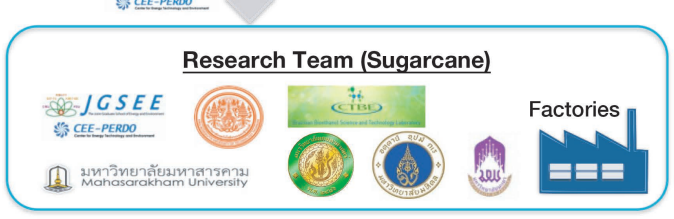

Role \& Responsibility

- Study on sustainability assessment

- Data collection and analysis

- Report results to technical committee

- (Factory team) support on data

collection, field trip arrangement and regular meeting 


\section{Box 8.4. Expectation management in a research study: coffee in Colombia (I. Acosta-Alba, EvaLivo)}

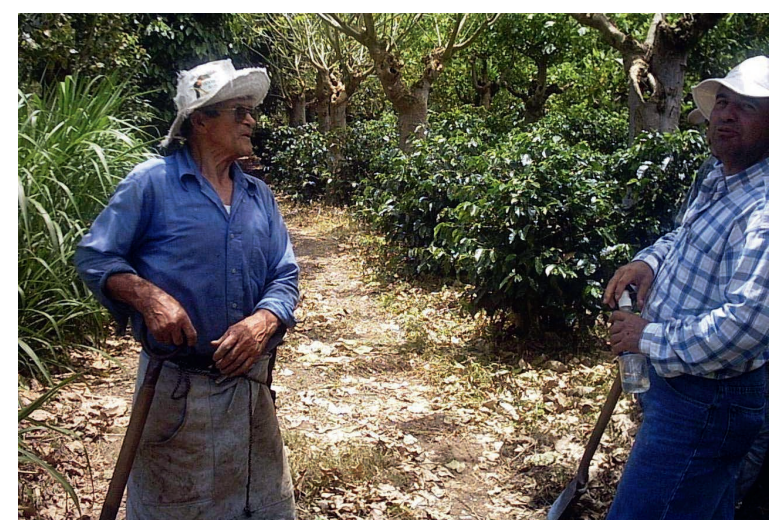

In the context of a postdoctoral research project, an LCA of farms was carried out including all the crops and livestock of coffee producers in Colombia (Acosta-Alba et al. 2020). The participative research enabled several field visits and trust development with farmers who were actively participating in other research projects. A launch meeting was held to explain the LCA's expected outcomes to partners and farmers. In the beginning, partners and farmers did not understand why different researchers asked the same questions. After explaining the level of detail needed for LCA, farmers were more receptive. The multicriteria nature of LCA was also warmly welcomed by academic and technical partners. A participative workshop was organized with farmers to ask them about the main environmental issues for them, and to share the LCA results. They were very satisfied to have the full picture including off-farm impacts of coffee production. Meetings and discussions with researchers resulted in the LCA study being introduced into a larger methodological framework for co-designing climate-smart farming systems with local stakeholders (Acosta-Alba et al. 2019; Andrieu et al. 2019).

\section{Working as a team in the field}

\section{How to best organize fieldwork}

Figure 8.5 summarizes important steps to best organize fieldwork, especially for foreign LCA experts. The first step is the preparation of the study before the data collection in the field. It is crucial to document the product system to be assessed, the region and the value chain sufficiently in advance for the proposed solutions to be appropriate and achievable. When the LCA expert is a foreigner, relying on a national or regional expert is a huge asset to quickly identify key stakeholders, inconsistent or reliable data sources, etc. Language mastery and understanding the local culture and specific constraints such as administrative difficulties, etc. by at least one member of the team is a second compulsory element. It is particularly important when the studied systems include small-scale producers to establish quality contact with them. This will also help identify and gain data from potentially important actors who only can speak in local dialect or language (Box 8.5, Box 8.6). 


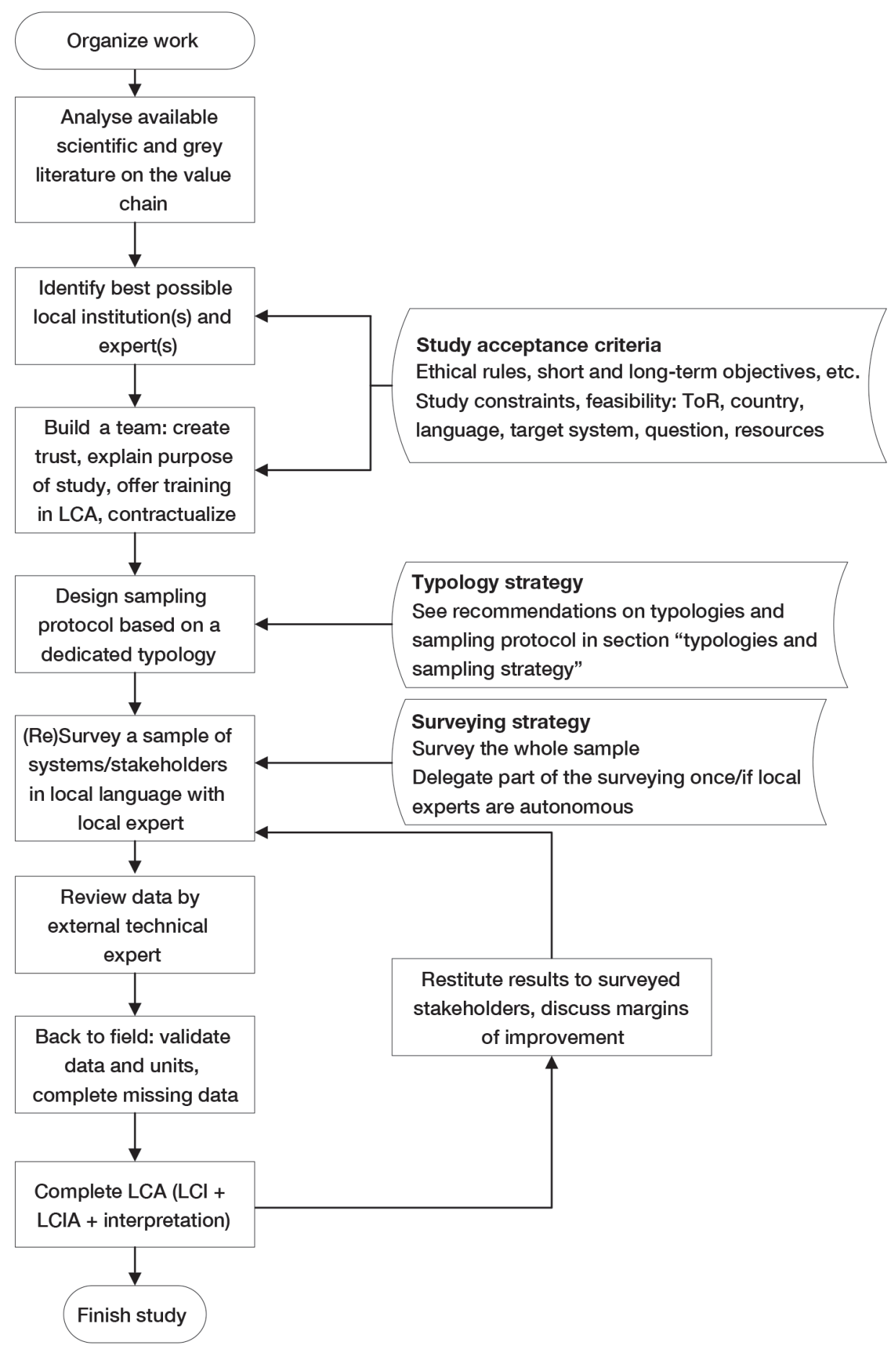

Figure 8.5. Recommendations for optimal fieldwork organization for foreign LCA practitioners. 
Box 8.5. Study of the Malian value chain of artisanal continental fisheries in Mali, linguistic and cultural barriers (I. Acosta-Alba, EvaLivo)

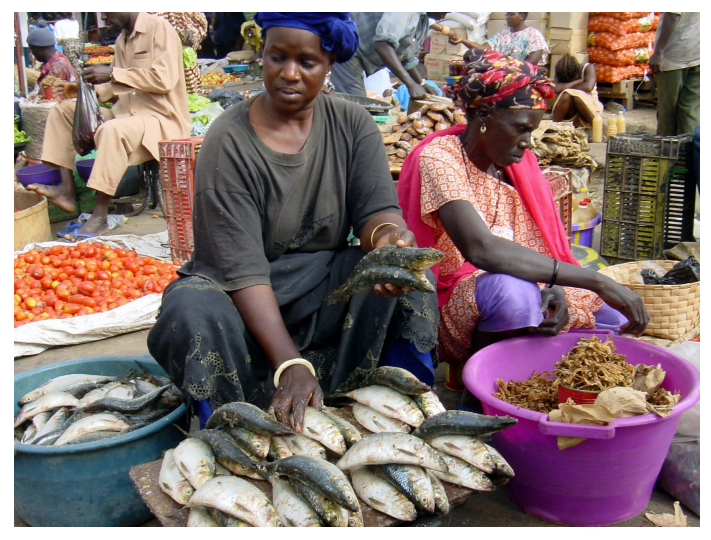

In Mali, more than half of the fish caught is processed into smoked fish mostly by the fishermen's wives. To limit travel within the country because of security risks, a workshop was organized in one of the main fishing areas. Actors were invited to participate; more than 50 participants attended. The seats were occupied by the men while the women remained seated next to them on the floor. Men understood French and spoke Bambara unlike the women who spoke only Bambara. In general, fishermen's wives are more familiar with the quantitative data about fished yield, the allocation between consumption and sales, the prices, the quantities of wood, the technical aspects of smoking and even the prices of fishing equipment because their sales partially finance them. Without an experienced translator and a female interlocutor on the team, the critical access to the data and knowledge from the wives would have been impossible.

\section{Box 8.6. Gender division of labour and direct access to the peo- ple concerned - mango from Burkina Faso (Y. Biard, CIRAD)}

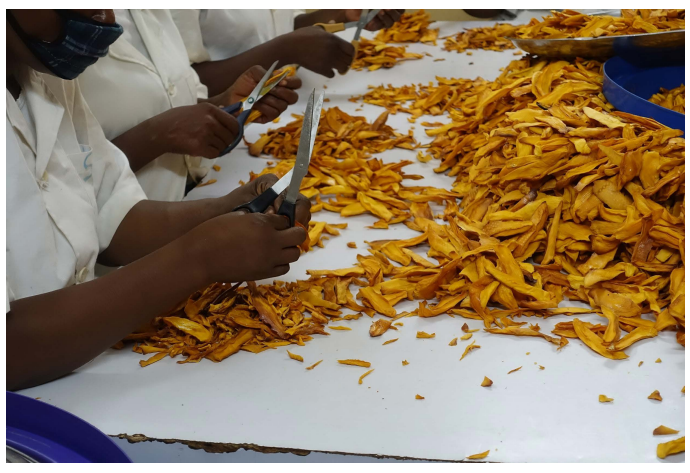

The dried mango sub-sector particularly involves women, especially for fruit preparation tasks (selection and washing, peeling and cutting, and packaging). Meanwhile, oven management and permutation of mango slices racks are mainly carried out by men. Depending on the information to be collected and the associated technical activities, it is important to be able to identify the right people, if possible in the language used in practice to coordinate the work in an operational manner, in this case the Dioula language.

The detailed synthesis of the study is freely available online via the following link: https: //europa.eu/capacity4dev/value-chain-analysis-for-development-vca4d-/wiki/ 202-burkina-faso-mango

\section{How to best work as part of a multidisciplinary team}

If the LCA study is part of a sustainability study including environmental, economic and social evaluations of a common system or value chain, a common and 
efficient working method must be adopted. This is especially important when it comes to designing a consistent protocol and interacting with stakeholders. However, in projects subject to time constraints, the presence of several experts in the field to understand and collect data from the systems studied can be difficult to organize and the actors interviewed may feel uncomfortable. All experts should clearly explain their specific objectives to the team and try to build bridges and develop synergy as much as possible. We summarized our field experience in Figure 8.6. When surveying stakeholders, the multidisciplinary team should not hesitate to split into two sub-teams: a "social" team (including a local expert and the social expert) and a "technical" team (including a local expert, the economist and the LCA expert) and meet specific key people in the organization or company. The team may organize turns if all members must discuss with the same people to avoid creating competition for asking the questions and confusion for the people surveyed.

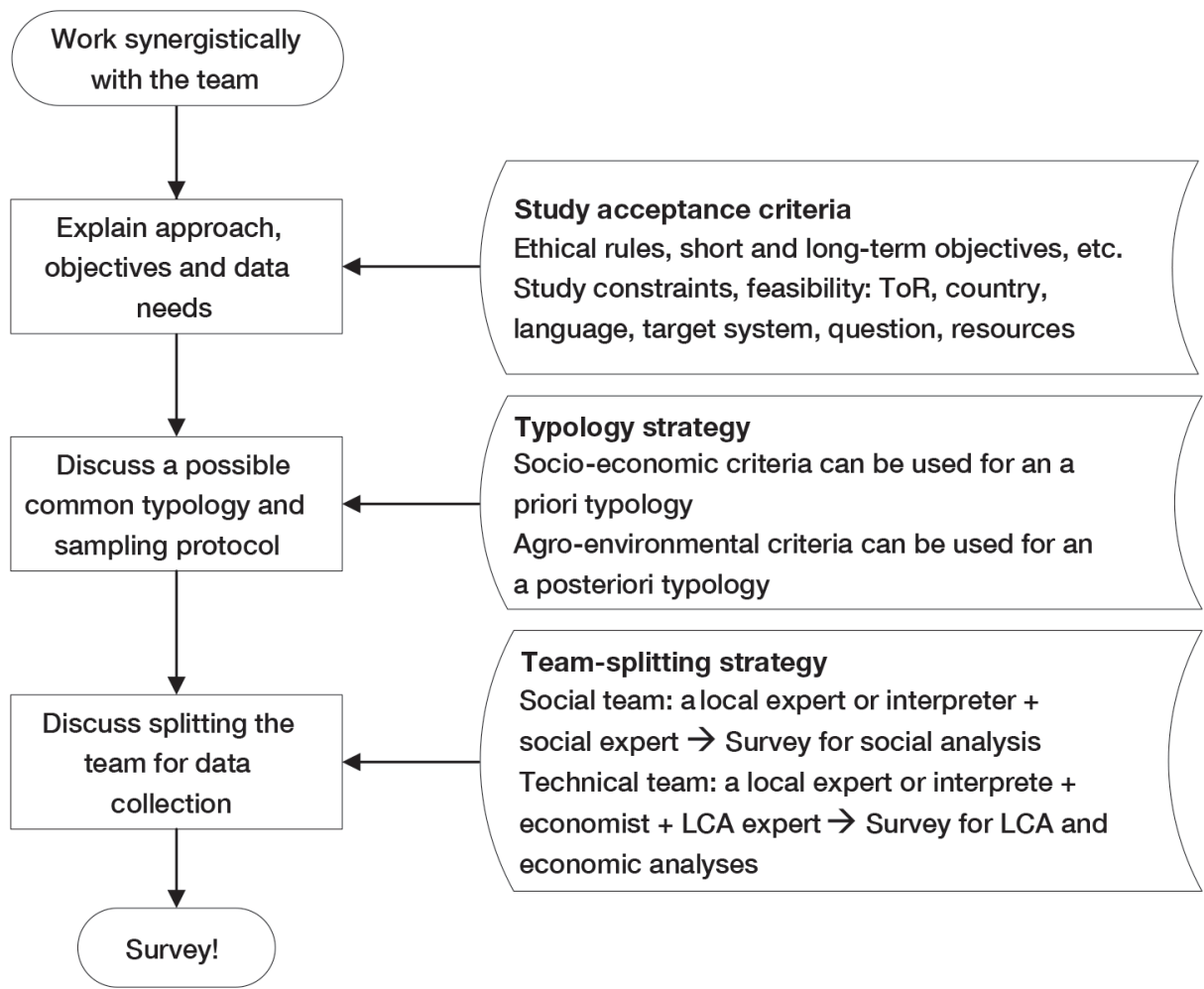

Figure 8.6. Recommendations for optimal fieldwork as a multidisciplinary team.

When the LCA expert works with an economist, part of the data collection can be mutualized. Indeed, both analyses have a common need for detailed data from all operations and products used. Therefore, it is crucial to have a common definition of the system, as previously mentioned. With sociologists, it is also 
possible to find anchorage points for mutualized data, especially when focusing on working conditions and food production and consumption patterns.

If LCA is not part of a sustainability assessment, support from a technical expert of the studied system is always recommended. The technical expert can be the local expert or another expert such as an agronomist for a given cropping system or a technical expert of aquaculture or livestock production. The technical expert can play a key role in identifying the right partners and experts in a given country on a specific product system. He or she can provide valuable input to design the protocol and when validating the field data, thereby identifying potential inconsistencies in a dataset, anomalies or mistakes and guide the validation effort among the stakeholders in the field (see Chapter 9 section "Foreground data collection").

\section{Management of ethics and rights for stakeholders}

This section is mainly based on the European legal and institutional frameworks with explicit references to them, particularly where European regulations have spread and influenced jurisdictions in other geographical areas of the world. However, a complementary analysis would be needed to adapt to countries whose legal development is based on other frameworks such as the common law-based systems (UK, US, Australia, etc.), which differs significantly on copyright issues from these European frameworks.

\section{Data and database legal framework}

According to the harmonized European legal frameworks, a "single data unit" is not protected by law. However, it is possible to limit its dissemination, use or exploitation by a contract (data availability contract, confidentiality contract, exploitation contract, etc.). It is also possible to disseminate it and make it available to the scientific community in particular, while indicating conditions for reuse and citation and respecting an embargo period if necessary.

However, some data may be subject to specific protection by intellectual property rights, such as photos and videos that may be protected by copyright. In this case, the data cannot be used freely without the written permission of the author, who should have prior consent from any people who are filmed or photographed. In the context of data collection for LCA, photos and videos can be very useful, especially for easily collecting technical information on devices and infrastructure (technical data sheets, model numbers) but also for scanning monitoring documents. Special care must therefore be taken with this data and permission must be obtained prior to their use in a study.

A database can be protected by two types of mechanisms: copyright as a creative/ original work and/or by a sui generis database right. These two types of protection are presented in Box 8.7. 


\section{Box 8.7. The two mechanisms of database protection (Y. Biard, CIRAD)}

- "The rules of international law - Berne Convention, the WTO/TRIPs Agreement and under the WIPO Copyright Treaty (WCT), original and creative databases enjoy copyright protection as literary works."

- "The Directive $96 / 9 /$ EC on the legal protection of databases, which creates a specific property right for databases that is unrelated to other forms of protection such as copyright. This new form of sui generis protection applies to those databases, which are not 'original' in the sense of an author's own intellectual creation ('non-original' databases), but which involved a substantial investment in their making."

Source: European IP Helpdesk (https://www.iprhelpdesk.eu/home)

These two types of rights only apply to the arrangement of data - neither database copyright nor the sui generis right create an additional protection for the individual elements of the database.

\section{Questions and recommendations on data}

When setting up the LCA study, there are key questions about data collection, as well as at the end of the project regarding the use of the data. We prepared the following checklist with the main questions to be addressed by the LCA practitioner (Box 8.8).

\section{Box 8.8. Questions directed to the LCA practitioner (as "you") when designing the study and preparing data collection}

1. Will you be using existing databases? Can you trace back their origin? Is it possible to identify the producer? Do you have permission to reuse these databases (structure and content)?

- The use of the main reference $\mathrm{LCl}$ databases is foreseen and indicated in the conditions of use of these databases. However, this question becomes very important if you plan to mobilize other databases (such as on inputs).

2. For the development of your own databases, especially in files external to the LCA software you use, do you plan to extract from third-party databases (content)?

- If so, do you have the authorization to perform these extractions?

- If not, you must formally request such authorization.

3. Will you produce an original database (structure and content) with several partners?

- In this case, a co-production contract must be drawn up and the rights and obligations

of each party with regard to the database during and after the project must be defined.

- This may be the case in particular when quantitative or semi-quantitative surveys are planned in connection with a typology of systems. These questions must be addressed as soon as the study starts, as they should be explained to your partners and contacts. 4. Will you use existing datasets?

- If yes, are these datasets covered by a contract (partnership agreement, confidentiality agreement, service agreement, license agreement, other)?

- If they are covered by a contract, check the conditions of use in the contract.

5. What is the purpose of the data and databases resulting from the project? Open data? Valuation through expertise? Paid licenses for restricted access databases?

- Whenever possible, it is strongly recommended to discuss these points with the partners at the start of the project. 
At the end of the LCA study, it is important to revisit these elements to verify that what is planned for the dissemination or exploitation of LCA results is in line with what was originally agreed with all stakeholders. The first step is to check what is included in the partnership or consortium agreement regarding the use of the data or databases produced. The best tool to manage data is called a data management plan (DMP), which is presented in Box 8.9.

\section{Box 8.9. A DMP: a convenient tool to manage the data of a LCA project (Y. Biard, CIRAD)}

A DMP is a tool to help scientists manage their data within a project. Writing a DMP at the beginning of a project allows for the implementation of good data management practices, facilitates exchanges between partners and saves time for the publication and reasoned sharing of data at the end of the project. This document is increasingly required by most funders.

The drafting of a DMP makes it possible, among other things, to:

- implement good data management practices and documenting data,

- guarantee the quality of research and the production of reliable and understandable data,

- contribute to the transparency, scientific integrity and reproducibility of research,

- reduce the risk of data loss or non-reusable data,

- clarify the roles, responsibilities and rights of each contributor,

- anticipate legal, ethical or technical problems,

- ensure the security of personal, sensitive or strategic data,

- facilitate the sharing of data within the collective,

- predict the needs and costs to generate, process, store and share data,

- respond to donor demand.

The return on investment is the simplification of subsequent recovery work since these data will be ready to be deposited in a data warehouse, published, and reused.

Here is a list of free tools for creating a DMP:

- DMPonline (Digital Curation Centre - UK): https://dmponline.dcc.ac.uk/

- Easy.DMP (EUDAT European data infrastructure): https://easydmp.eudat.eu/

- DMPTool (University of California Curation Center - US): https://dmptool.org/

- ezDMP (Interdisciplinary Earth Data Alliance 2011): https://ezdmp.org/index 
In Figure 8.7, the data flow and data transformation mapping in the DMP of the LCA-CIRAD platform is presented for information. Appendix D (p. 135) proposes a checklist to help LCA practitioners account for confidentiality in their inventory.

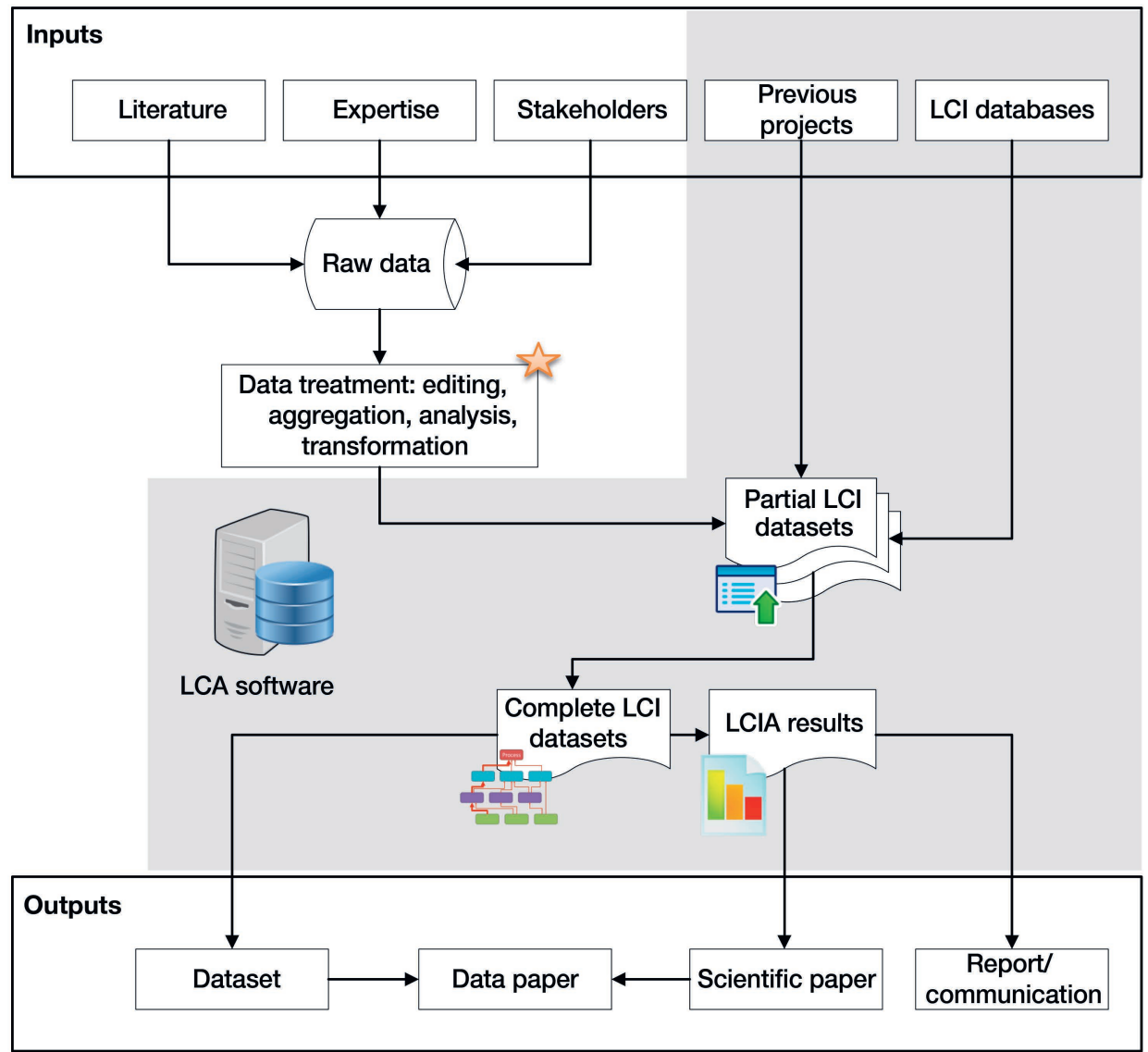

Figure 8.7. Data flow and data transformation mapping identified in the DMP of the LCA-CIRAD platform.

\section{A closer look at personal data protection}

The General Data Protection Regulation (GDPR) is a European regulation applicable since 25 May 2018. This regulation aims to strengthen the protection of personal data and has inspired substantial developments regarding their protection in other countries around the world. Indeed, it applies to any company operating in the EU and to any company outside the EU that processes data on European citizens.

The production of LCIs generally does not require personal data, which is why LCA is generally not directly concerned by this legal framework. However, for specific cases where personal data is required, a generic template was created (Box 8.10). This template must be adapted (parts in square brackets are to be completed 
using the explanations below) and integrated in full to any form used either for internal or research purposes. It may be inserted directly within consent forms.

In general, for an LCA study carried out as part of a scientific project, raw personal data may be retained, in paper or electronic form, for the duration of the project and the time required for publication. Beyond that period, the data must be deleted or anonymized on all media (personal computers, external hard drives, databases, etc.).

\section{Box 8.10. Personal data template (Y. Biard, CIRAD)}

The information collected [on this form / ...] is processed by [DATA CONTROLLER] as data controller, in order to / for the research project ... [PURPOSE $\left.(S)^{1}\right]$. This data processing operation is based on [LEGAL BASIS ${ }^{2}$.

Your personal data is stored only for [RETENTION PERIOD ${ }^{3} /$ the necessary duration to achieve said purpose(s)], without prejudice to applicable regulation. It is destined to [INTERNAL RECIPIENT] and can be transferred to [EXTERNAL RECIPIENT ${ }^{4}$ ].

In accordance with Regulation (EU) 2016/679 (GDPR), you are entitled the rights of access, modification, erasure and portability (when applicable) of your personal data, and of limitation and opposition of its processing, with the right to withdraw your consent at any time. You can claim those rights writing to our Data Protection Officer. You also have a right to submit a complaint directly to the appropriate data protection Supervisory Authority.

${ }_{1}^{1}$ PROCESSING PURPOSE(S): The processing purpose is the reason why personal data need to be collected and processed, and what are the planned use for it.

${ }^{2}$ LEGAL BASIS: GDPR allows processing operations on personal data when justified by one of six legal bases:

- Specific, informed, and unambiguous consent of the data subject, which must be given freely and prior to the processing (for instance, collecting sensitive data such as health data is normally subject to the person's consent)

- The necessity of the processing operations in order to satisfy a contract or precontractual steps taken at the request of the data subject

- The compliance of the data controller with a legal obligation that requires it

- The necessity to protect the vital interests of the data subject or another natural person

- The necessity of the processing in order to accomplish a task carried out in the public interest, or as regards the official authority of the controller

- The necessity for the purposes of the legitimate interests pursued by the controller or a third party, provided said interests are not overridden by the interests or fundamental rights and freedoms of the data subject (for instance, the protection of minors' personal data)

${ }^{3}$ RETENTION PERIOD: In accordance with the principle of minimization, personal data must not be retained any longer than necessary to accomplish the determined purpose or comply with legal obligations. A retention period must therefore be defined, informed, and implemented.

${ }^{4}$ RECIPIENT AND DATA TRANSFER: Whenever personal data are bound to be transferred outside of Europe, complementary obligations apply.

\section{Ethical dimension and scientific integrity}

Respect for the privacy of respondents, the intellectual property of the data mobilized, and the quality and integrity of the data are part of a broader definition 
of the ethical dimension of data management. The European Code of Conduct for Research Integrity identifies four fundamental values: responsibility, respect, honesty and reliability. ${ }^{6}$

When applied to primary data collection required to perform LCA, it is clear that developing strong partnerships is one of the cornerstones of the working method. The approach, based on mutual trust between partners, aims to build up LCA win-win situations: partners in developing countries build their capacity in LCA methodology and are well informed about the implications of the study on which they are collaborating, while an LCA practitioner can benefit from the best existing data on agricultural systems in these contexts and deliver reliable LCA studies for all parties. This approach requires taking into account ethical and legal considerations on the collection and use of LCI data with different partners presented above.

The LCA-CIRAD team decided to go further than the legal framework, putting more emphasis on trust and partnerships in their set of ethical rules, acknowledging the fact that strong partnerships are particularly important in the context of LCI data collection and sharing. The details of the implementation of this data quality charter were published in the proceedings of the LCA Food conference (Biard et al. 2016) and its main rules are described in Box 8.11.

\section{Box 8.11. Main rules of CIRAD's ethical charter (Y. Biard, CIRAD)}

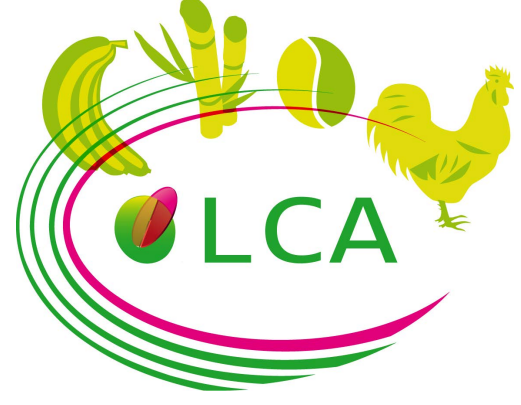

The charter is based on two pillars: the quality of the relationship with the partners and scientific development. No data dissemination is allowed without considering the impact this could have on the interests or reputation of the partners and their relationship with LCA-CIRAD or CIRAD as a whole. The dissemination of datasets for direct commercial exploitation to strict dataset buyers is not a strategic priority for CIRAD.

These principles are specific to CIRAD and its long-term partnership strategy. LCA practitioners are free to establish their own policy, taking into account the imperatives of the project as well as their institution's strategy. This policy should then be explained in a document that summarizes commitments with regard to the datasets collected from third parties. If the dissemination of the full LCI dataset or LCIA results is required, those conditions should be thoroughly explained to partners right from the beginning of the study. Partners' validation of such conditions should be written out to the fullest extent possible in the collaboration agreement. Moreover, if external demands for LCI datasets or LCIA results

6. https://www.allea.org/wp-content/uploads/2017/05/ALLEA-European-Code-of-Conduct-forResearch-Integrity-2017.pdf 
arise after the end of the project, the further long-term impact on the relationship with the partners must be considered in addition to the contractual clauses concerning the data dissemination agreed at the beginning. The scientific team leader is generally perceived as the most convenient decision-maker to exercise the sui generis right. She or he is encouraged to decide based on the advice from practitioners who worked on the concerned data. The data dissemination timeframe can include an embargo period, i.e. a delay to allow for scientific publication, provided that all partners agree.

An effective way to strengthen the trust and cooperation between partners is also to include, right from the initial project design, activities dedicated to LCA capacity building in the studied regions. This helps partners fully understand the ins and outs and potentially contribute to the LCA building itself rather than act only as data providers. This entails building medium- or long-term partnerships offering LCA trainings at novice and expert levels as well as specific trainings on LCA database quality management systems.

\section{System boundaries, typologies and sampling strategies}

To finalize the co-design of the study with stakeholders, a clear definition of the system boundaries and typologies associated with a transparent sampling strategy in accordance with the goal and scope of the study is crucial.

\section{System boundaries}

A key component of the goal and scope definition is the setting of system boundaries, coupled with cut-off criteria. In the case of a single system LCA, the limits of the system are usually straightforward to define, and several approaches for cut-off criteria exist. For instance, typical cut-off criteria include a mass or an economic threshold, but more elaborate approaches such as cumulative contribution to impacts have been proposed (e.g. Fréon et al. 2014b). A generalized practice in LCA consists of excluding certain inventory items (typically infrastructure) under the assumption that their contribution to impacts, per FU, is marginal. This practice is risky, as stated in Suh et al. (2004): "many excluded processes have often never been assessed by the practitioner, and therefore, their negligibility cannot be guaranteed". Nonetheless, in many situations, a system type is well known and there is consensus on key inventory items that should be considered (see Chapter 9 section "Foreground data collection", and especially Figure 9.1).

Even if the system boundaries are pre-defined, the data collection stage may inform refinements, as unforeseen sources of emissions for atypical systems may be discovered only by visiting them and interviewing the local stakeholders. Refinements through iterative loops are often needed in LCA and must be anticipated in terms of time allocation for the study. 


\section{Typologies and sampling strategy}

The level of representativeness is linked to the goal and scope definition. Published LCA studies tend to exaggerate their representativeness in the very title (e.g. soybeans from Brazil), potentially misguiding readers when the study is actually representative of only a fraction of the whole system. LCA users should also be aware that LCI at country level available in databases, such as the WFLDB, also are too often not representative of very diversified systems, especially for tropical agriculture in developing and emerging countries. The conscientious LCA practitioner should choose a title fitting to the study's representativeness, e.g. specifying a type of agricultural system or a representative area.

Except in rare occasions, such as when the study is intended for pedagogic or research purposes, designing a representative sample of individuals of the studied population/product system may be a prerequisite. This is especially true when the scope of the study includes several typical systems, a regional or national scope, and if various systems ought to be compared regarding their environmental impacts. The feasibility of defining and surveying a representative sample of individuals will depend on both internal characteristics of the studied population, such as its size, variability and heterogeneity, and external parameters including the question asked and the resources allocated but also the knowledge and data available on the studied system.

A typical approach consists in classifying several systems into types, by means of a typology, in order to make comparison among types of systems rather than among individual systems or to account for the internal diversity of the studied population. The construction and use of a typology is based on the key assumption that systems belonging to different types are (i) homogeneous within a type, and (ii) sufficiently different among types to the extent that environmental impacts (or their key drivers) are also sufficiently different. Comparisons based on typologies require careful uncertainty management and understanding of the intrinsic variability among systems.

Typologies can be established a priori or a posteriori to the first field mission. If the addressed question is "Are the environmental impacts across pre-defined product system types significantly different?", the LCA study and sampling protocol will be based on an a priori typology relevant to these pre-defined types. If the addressed question is "What are the key drivers explaining the environmental impacts of a given product system?" then the sampling protocol could be based on a priori expert-based typology and cross-referenced with a posteriori typology using principal component analysis (PCA) and clustering if possible.

According to Bélières et al. (2017) the creation of typologies requires both theoretical and practical knowledge. Several approaches can be used for a priori typologies such as:

- structural-based typologies based on means of production;

- functional-based typologies based on the chain of decision-making by the farmer; 
- performance-based typologies, although this criterion is often coupled with the previous two typologies;

- analytical typologies, which are constructed from the selection of discriminating indicators whose information comes from the farms themselves;

- statistical typologies;

- expert-based typologies; and

- mixed typologies.

According to our field experience there is often a mix of approaches depending on the goal of the project, time, resources, and available data. To build a typology, for instance of agricultural systems or fish farming systems, various criteria should be considered, including the existence of legal, administrative or ad hoc classifications of systems based on previous experiences or documents. Examples of a priori typologies:

- crop systems may be segregated into field crops vs. prairies vs. perennial crops, or into conventional vs. organic, or into open-field versus greenhouse production; - animal systems are often classified depending on farming conditions and time spent in the building or in the open air;

- cattle systems are often classified into dairy vs. suckler systems;

- fishing fleets are generally divided into segments based on dominant fishing gear, target species or holding capacity;

- aquaculture systems are usually separated into land-based and water-based or intensive vs. extensive, or by size (which is often correlated with management intensity);

- for all product systems, a technical typology can be combined with a spatial typology accounting for the different regions or soil and climate conditions of production.

If such an a priori typology is retained, its validity should be confirmed by comparing the overall difference in environmental impacts among types. Other, more complex approaches are available for building typologies, including the use of statistical tools such as PCA (e.g. Avadí et al. 2016; Abdou 2017; Basset-Mens et al. 2019).

Criteria and recommendations for typology construction, based on key drivers of environmental impacts per agri-food system category, are summarized in Table 8.3. Although the existence of a legal, de facto or expert-based typology can be highly valuable in designing a sampling protocol in an LCA study, it should always be cross-checked and validated by the field experience, as illustrated in some of our case studies (see Box 8.12, Box 8.13, Box 8.14). In particular, the importance and the performance of the informal sector are often underestimated (or denied) by official typologies and knowledge. 


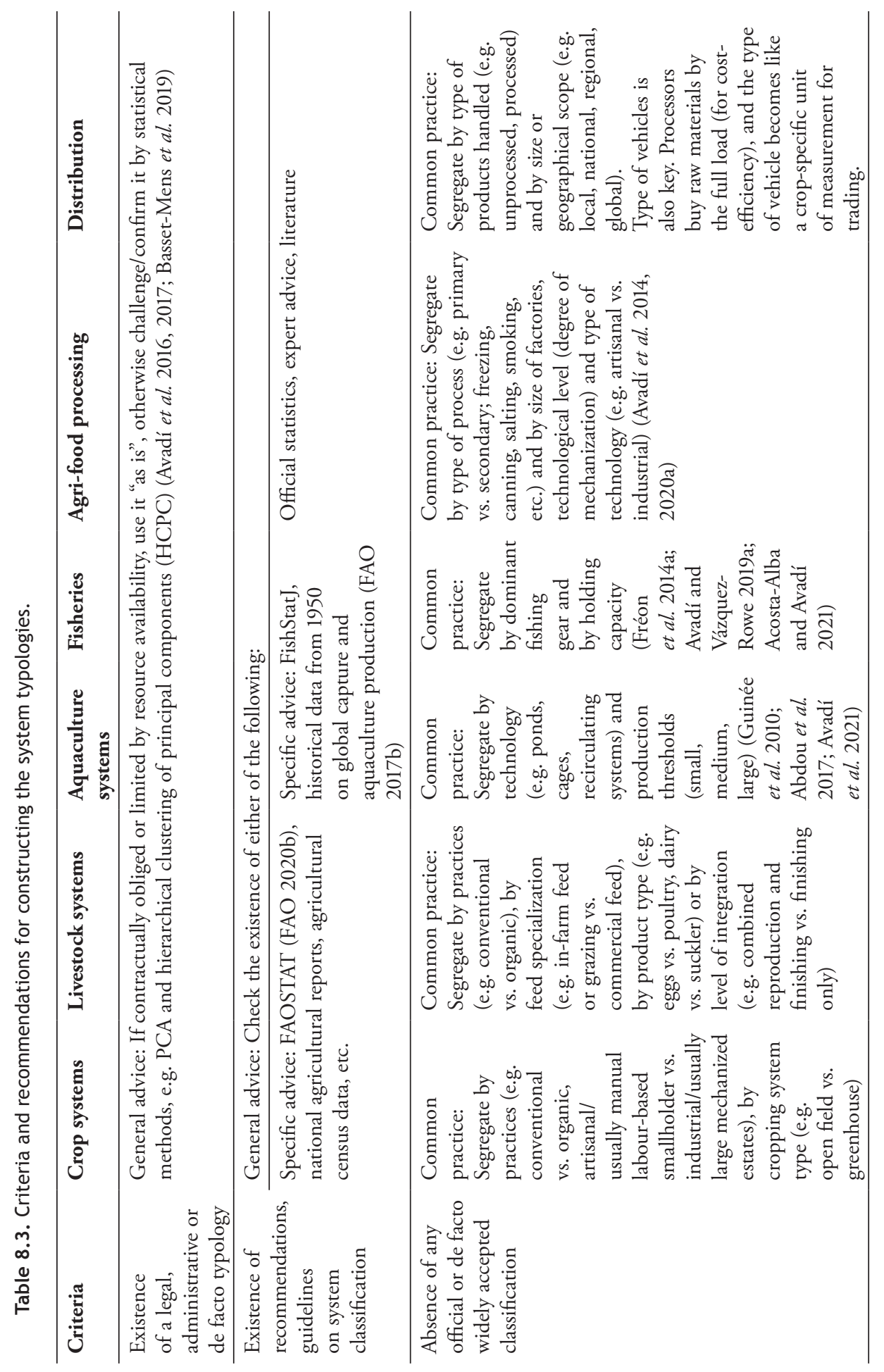




\section{Box 8.12. Milk value chain in Colombia: an example of important produce categories omitted by existent typologies based on local extension services (I. Acosta-Alba, EvaLivo)}

In developing countries, the share of informality can be very high even for export products. Often, this informality is a source of unawareness and preconceptions about the real importance of some actors even when surveying local extension services within the country. In Colombia, a study on the milk value chain and processed products was carried out in 2016. During discussions with partners and technical services about the producers' typology, the choice of excluding the milk produced by the informal sector was recommended. The suggestion was in particular for smallholders having no official records nor technical monitoring since they were considered as not economically sustainable and fated to disappear. However, during the field interviews, experts from producers' cooperatives estimated the informally produced and marketed milk at around $40 \%$ of total Colombian milk and $80 \%$ of total Colombian milk was produced by small farmers having fewer than 15 animals. After several field visits, which confirmed the importance of small producers, this type of producers was modelled on the basis of a few interviews to at least represent them within a dedicated scenario.

\section{Box 8.13. Fishing value chain in Mali: an example of the importance of iterative fieldwork to catch the occasional fishers (I. Acosta- Alba, EvaLivo)}

In Mali, the fisheries value chain was particularly difficult to model. Official fishing data do not correspond to the reality of this sector. Only $1 \%$ of artisanal fishermen have a fishing license. This fact is known by state services, who correct fishing volumes and rate the self-consumption to account for this. A relevant and acknowledged typology of fishermen exists since the 1970s. Given the travel difficulties linked to the security conditions in the country, the experts had a limited data collection period and the system definition was based on the official typology. However, after discussions and interviews on the ground, it turned out that the fishing activity, formerly reserved for traditional professional fishermen, had become very widespread and that now "everyone fishes". These occasional and opportunistic "new" fishers caught about 30\% of Malian fish. This category of fishermen could not be thoroughly surveyed due to the lack of time and they had to be modelled in a very simplistic scheme. This illustrates the interest of iterative fieldwork.

\section{Box 8.14. Study of the Dominican Republic value chain for pro- cessed mango: bias from systems and products identified by spon- sors and partners (I. Acosta-Alba, EvaLivo)}

A type of bias can arise when defining the system, even by actors from the field. For example, in the Dominican Republic, during an evaluation of processed mango, the regional variety criolla was described by the sponsors and technical partners as negligible for the study. The production was described as "palos de mango en el patio" (a few trees in private gardens). However, after interviews with the main industry players in the country, it turned out that only this variety was used at industrial level. Sourcing and production are little known and very different to commercially grown varieties which focus on export varieties for fresh fruits based on the taste demanded by importing countries (United States, European countries, Japan). Despite the difficulty, it was possible to find farmers who produced the criolla mango and to include it in the analysis. 
Figure 8.8 presents recommendations on sampling protocol design following the choices regarding the extension of systems to be studied and their typology. Depending on the constraints associated with the LCA study, the number of achievable samples may vary considerably, and the robustness of the study's conclusions may vary accordingly. In a context of limited resources (time, money), only limited sampling may be possible, and thus the heterogeneity among systems and within a system may be considerable. The level of heterogeneity can be determined by expert opinion, as local experts usually have a good idea of it. For instance, in Africa, smallholder pond systems farming herbivorous fish, or smallholder crop systems producing staple foods such as maize or tubers or commodities such as cotton, tend to be rather homogenous (regarding practices and yields) within each country. If the scope of the LCA study is regional or value-chain oriented, the representativeness of sampling is key.

Many sampling strategies exist. They may include random or non-random selection of actual production units which will be based either on snowballing sampling or random sampling designs. Snowball sampling represents non-probability sampling where individuals are recruited by experts or between themselves based on their acquaintances, while in simple random sampling of a given size, all individuals have an equal probability of being selected. In Appendix E (p. 137), a table from PAS 2050-1 is provided with sample sizes depending on the population size, with or without grouping into types. However, these sample sizes are indicative and will be influenced by the constraints of the study.

Alongside sampling strategies, building virtual representative production units can constitute an effective strategy (Vayssières et al. 2011; Avadí et al. 2016, 2020a, b, 2021). A virtual representative production unit is a scenario designed to represent a given type. They are widely used in LCA, especially when the goal is to compare system types. An alternative to the use of these virtual representative production units is to use a real individual system that is very representative of each type. When a solid typology exists, these representative individuals may have been previously identified and are called paragons. 


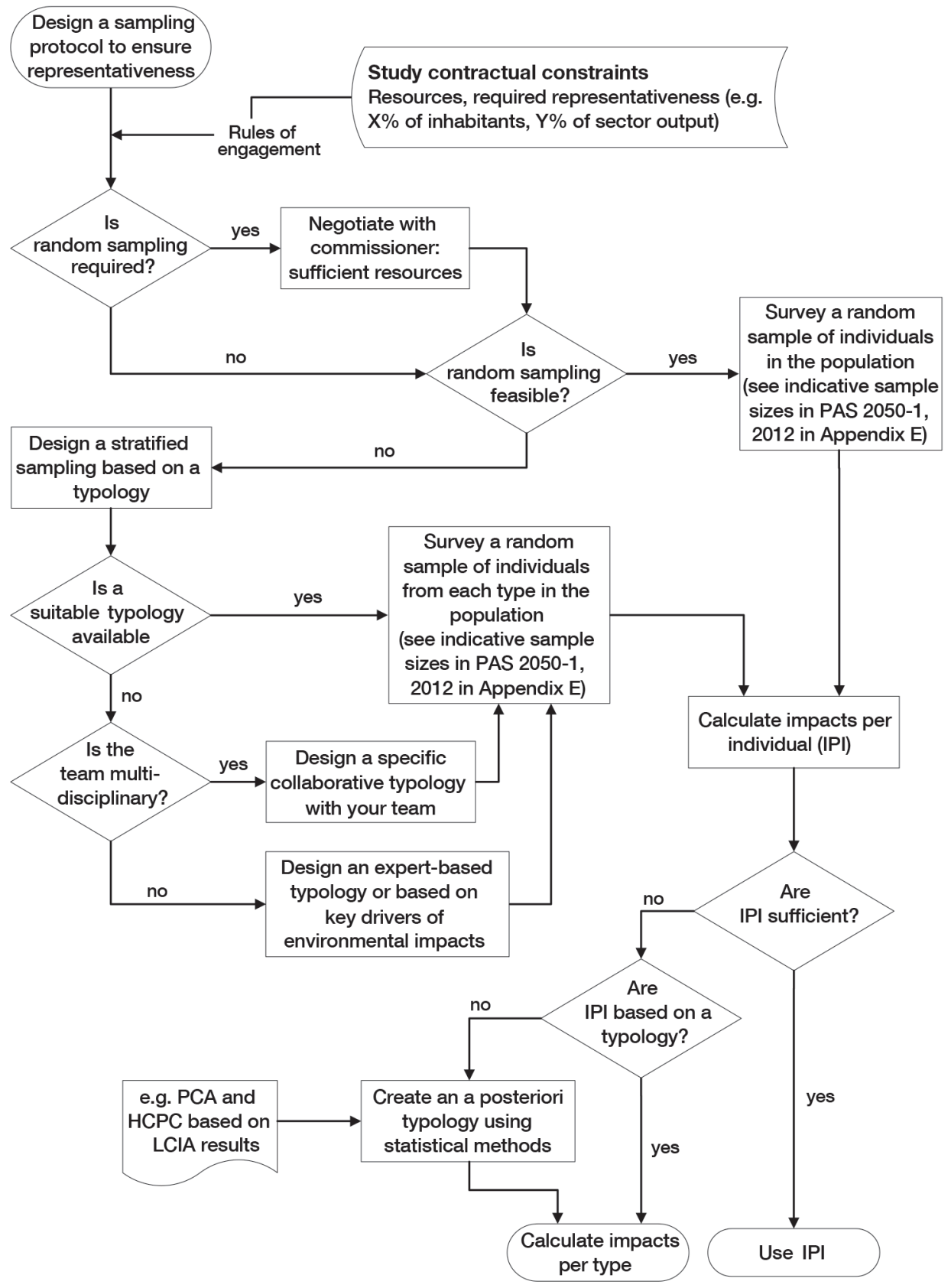

Figure 8.8. Recommendations for designing the sampling protocol. 



\section{9 \\ Building life cycle inventories}

Once the study is properly designed, all important flows in the studied systems or system types need to be estimated with the most reliable data possible. It is important to distinguish between foreground and background data collection since these two types of data require completely different collection strategies.

\section{Foreground data collection}

\section{Key data to collect}

In principle, all foreground data (i.e. the data describing the system of interest to the LCA study) should be compiled and modelled into LCI.

In practice, and following the 80/20 Pareto principle, it is much easier to compile the bulk of the data than the remaining few details, some of which may well be key contributors to impacts.

Therefore, over the last three decades of LCA practice, ad minima lists of key inventory items were compiled for most agri-food systems. The main contributors to impacts in the agriculture sector (see Appendix F p. 138), except for land use change in the tropics, are usually the use of fertilizers, the use of pesticides, animal feed and manure management. When performing LCA of aquaculture and fisheries, a number of sector-specific considerations should be included, as described in Appendix F3. The main contributors to impacts in the seafood sector are usually fuel consumption in fisheries and feed provision in aquaculture. When post-harvest stages take place on the farm (e.g. pulping and drying of coffee), a separate section should list the technical processes, quantities of water, energy and inputs used as well as the fate of waste and co-products. Generally speaking, the conversion factors and yields in products of each important process will play a critical role in the eco-efficiency of the studied product. Eco-efficiency can be defined as the ability of a system to deliver a function while minimizing its impacts on the environment. For instance, the feed conversion ratio, which is the number of kilograms of feed needed to produce one kilogram of animal product (meat or milk), should be estimated with a high level of precision and include uncertainty data in the LCA study of animal products.

Figure 9.1 below provides key parameters for an LCI questionnaire by product category. 


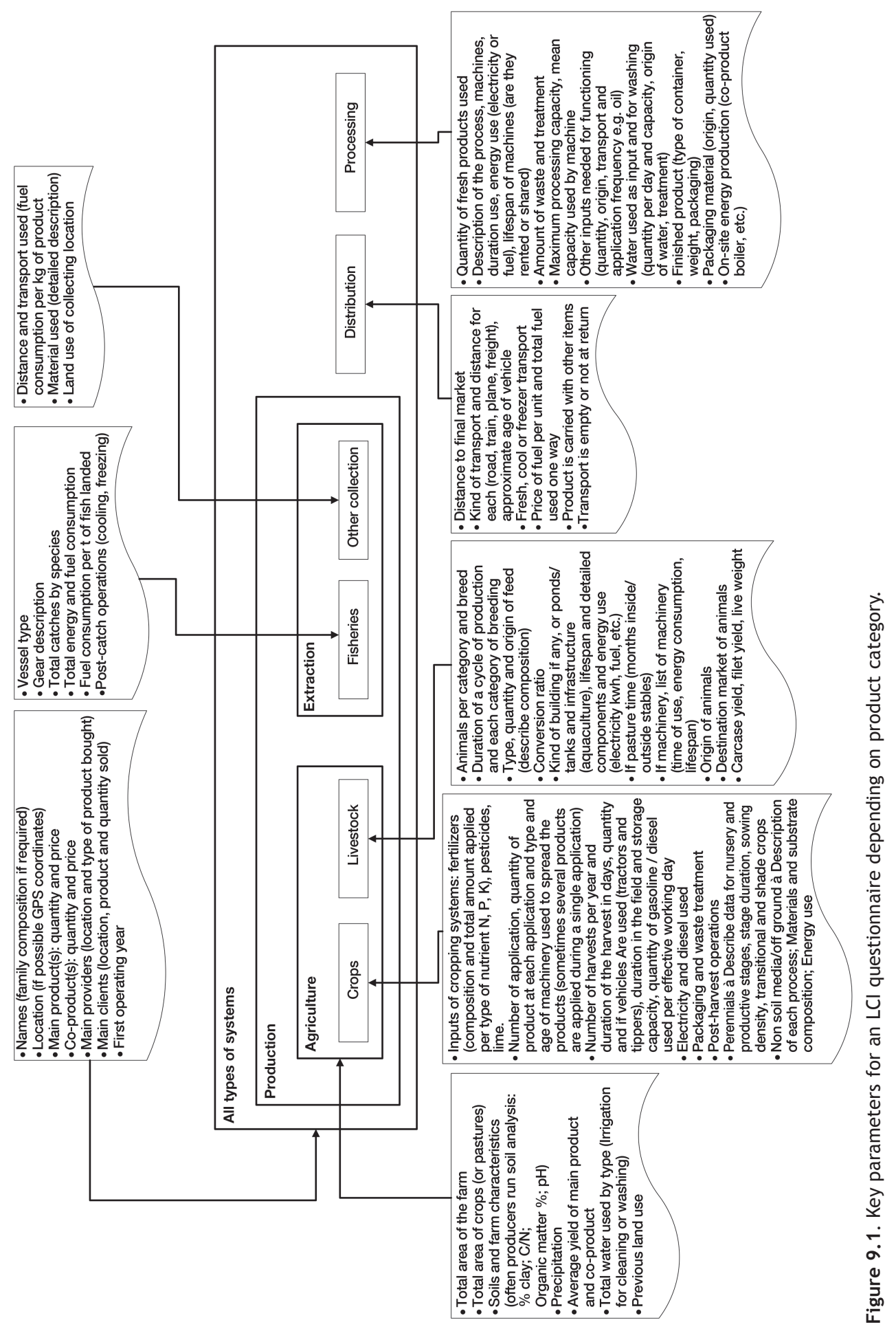




\section{Temporal aspects}

Of course, the temporal dimension is a key factor in collecting representative data. All agri-food systems have important variability over time and these variations should ideally be captured in LCI datasets. Agri-food systems are exposed to climate variations and potentially extreme events that continuously and sometimes deeply affect their performances. It is therefore paramount to consider several years in data collection. In areas where extreme events are regular, such as hurricanes on the Atlantic coast of the Caribbean islands and Central America or El Niño/La Niña phenomena (Bertrand et al. 2020), their frequencies and impacts should be investigated in greater detail. Likewise, water availability or scarcity are also deeply influenced by seasons, which will be critical when studying seasonal crops or crops with several harvests per year. In the case of perennial crops, it is also paramount to account for the whole perennial cycle, since partial modelling, based on single years for instance, can severely bias the LCA results (Bessou et al. 2013; Bessou et al. 2016).

Overall, the basic temporal variability should be accounted for by adapting the data collection protocol to each system type: at least three seasons/year for each studied system, at least all phases of perennial crops should be modelled, and each phase should use either a typical year or an average of three to five years. Recommendations for the modelling of perennial crops in LCA are summarized in Bessou et al. (2013) and further updated in Basset-Mens et al. (2018).

If the studied system is located in a region with regular extreme events, for instance occurring once or twice over three years, this major disturbance should also be modelled in the LCA, either by designing scenarios with and without these extreme events to show a range of situations or by designing an average scenario taking account of the regular destruction of the infrastructure and production in the system performance.

\section{How to design a $\mathrm{LCl}$ questionnaire}

Questionnaire design is very important. The questionnaire must include information on the means of production and the operations of the farm. Questions may be more open-ended if the interviewers conduct the surveys themselves or closed questions if data collection is delegated. On farms, it is necessary to have the details of the crops in space (area, density of sowing, intermediate crops) and the crop rotations in time (length of the crop cycle, crop before and after and if the same sequence is repeated over time), and non-productive and productive periods must always be differentiated.

Next, the cultivation operations must be detailed, indicating the quantities and types of inputs for each. The data must be collected according to one specific period, generally a productive cycle. This period should be well defined because the quantities will be expressed per area, per unit of product and per unit of time. The questionnaire and the questions on the day of collection should be asked in the units commonly used by the actors. To save time during the interview, the 
data will be converted afterwards. Ideally, knowledge on the various local common units should be gathered early in the survey timeframe to anticipate potential errors and cross-checking in the field. It might be important, for instance, to verify the volumes of commonly used recipients such as empty tomato cans. For animal production, it is important to distinguish the categories of animals, their management (time in the building, diet) and the management of excreta. Figure 9.2 shows recommendations for designing LCI questionnaires. In addition to details on farm operations, it might also be necessary to collect extra data that are input variables for emission models and cannot be found in the literature (e.g. slope, existence of a buffer zone etc.). The list of these particular data will obviously need to be properly prepared before going into the field for the survey.

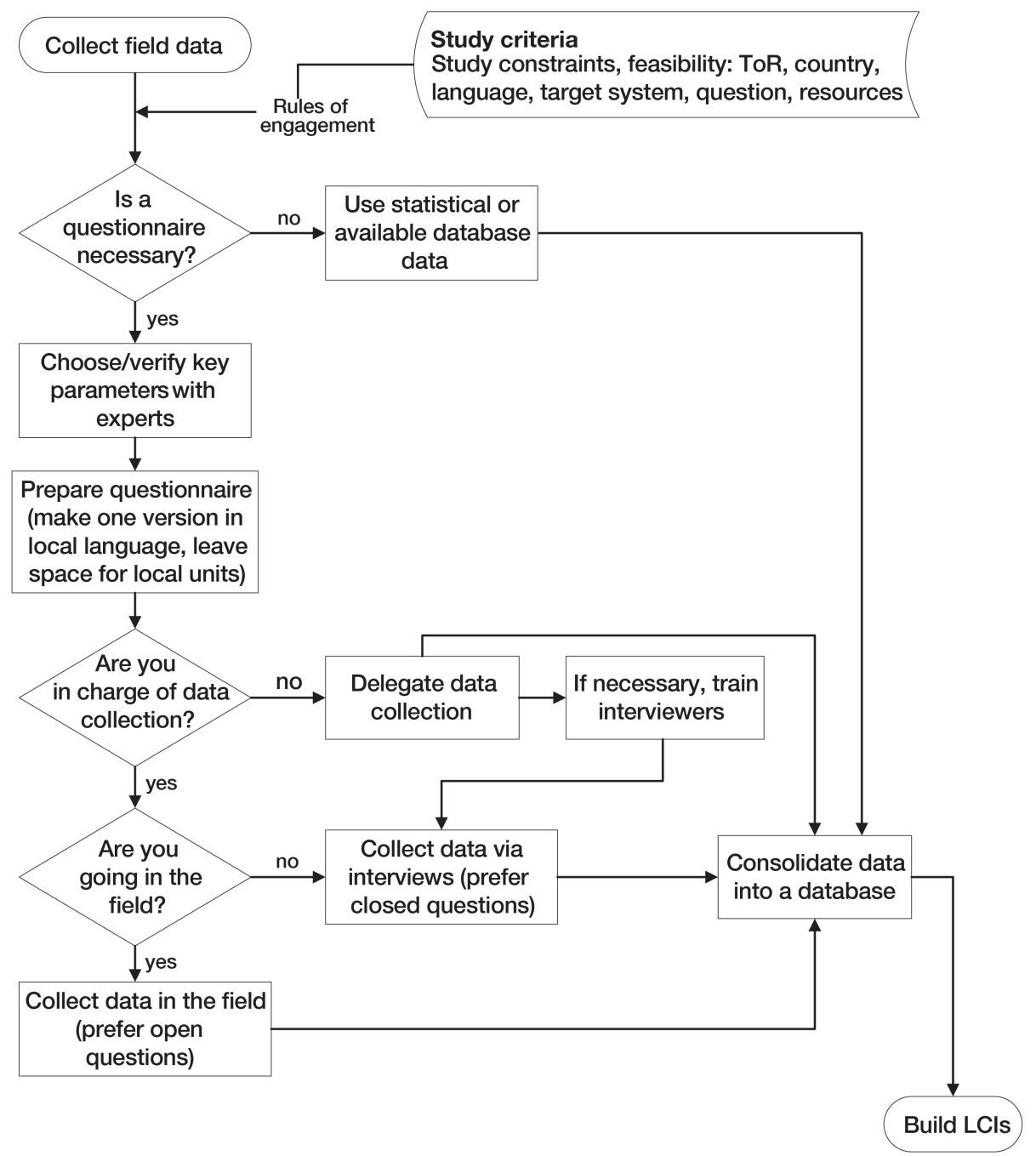

Figure 9.2. Recommendations to design a questionnaire for $\mathrm{LCl}$ field data collection. 


\section{How to best collect reliable data at field level}

In LCA studies for agri-food systems in developing countries, foreground data need to be collected directly in the field. Collecting reliable data at field level requires specific skills and a proper organization. Based on our field experience, we formalized our recommendations of best practices on surveying stakeholders (Figure 9.3).

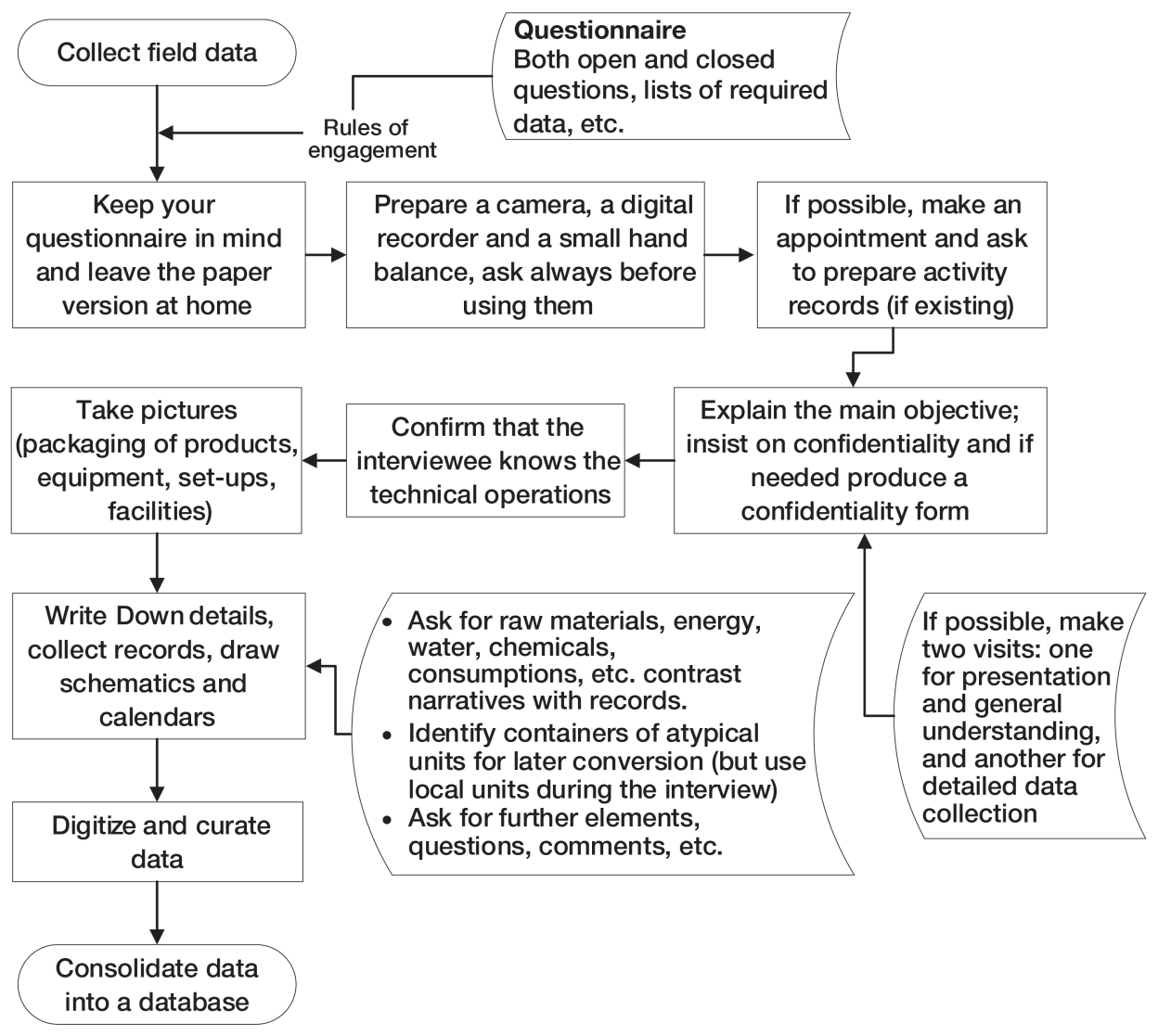

Figure 9.3. Key steps and recommendations to collect reliable data from the field.

Fieldwork has enabled us to see that trust is a fundamental factor in any exchange of information, as much for connecting with actors as for obtaining quality data. When the LCA experts conduct their own data collection, having a paper questionnaire may lead the discussion exclusively to the questions in the established order. Often, the person surveyed stares at the paper, which can limit the discussion. We obtained the best results when the questionnaire was hidden in the expert's pocket and notes were written down in an empty notebook while having coffee, tea or other regional traditional drinks and trying to make the speaker comfortable.

During an LCA study, we ask about every detail of the activity. Put yourself in the person's shoes and imagine a complete stranger coming into your home and 
asking you questions about everything you do... If you do not understand why and how the data are going to be used, would your answers be reliable?

To facilitate discussions during a field visit, we recommend to start by introducing yourself and talking about the goal of the study, then taking a tour of the place (farm or industry) with, when authorized, a camera, a digital recorder and a small hand balance. However, using recording devices may make some people less comfortable. The practitioners need to be attentive to their actual willingness to be recorded or not since this might affect the content of the discussion. It is also useful to verify the information with different questions, for example asking for plant density per hectare and yield per tree, then asking for yields per hectare. For animal products, the quantity of feed and product must be asked and at another point the concept of the conversion ratio must be discussed. An example of surveys is available in Box 9.1.

\section{Box 9.1. VCA4D study of pineapple and mangoes in Dominican Republic, working in a multidisciplinary team (I. Acosta-Alba, EvaLivo)}

During VCA4D studies, there is a mandatory field mission for the whole team (economist, sociologist and environmental expert). During several interviews, the method that best allowed the understanding and collection of data was to start the discussion by presenting the goal of the study, introducing the team and talking about the confidential nature of the data that will be collected (a confidentiality agreement can even be signed). The visit then started and we asked about the history of the activity during the tour. Taking pictures is a good opportunity to ask questions and to observe key details (empty packaging of used products that are not always mentioned, machinery, the brands and types of machinery to obtain the power and consumption described on the engines, etc.).

Field observation makes it possible to note details that the actors do not consider important, such as the plots on which the first non-productive years of mangoes, plantain banana or cassava crops are often planted. For pineapple, the construction of infrastructure linked to cropping (paths, mounds, drainage) is a stage which requires the use of heavy machinery and where $30 \%$ of the surface is kept as a nursery for reproduction. While the productive period lasts 18 months, if the establishment of the crop and the nursery are taken into account, the land is rented for a period of three years.

After the first conversation, the interviewee was more comfortable and we asked for a quiet place to sit down and continue with more specific questions. Sitting allows easier taking of notes and better concentration. When farm records exist, they can be consulted at that time. To resume the discussion, if time permits, it is possible to continue by drawing a plan of the farm if there are distant plots. Then, the interviewee can describe technical itineraries by unrolling the work calendar and each technical intervention describing products used and their application each month of the year. Since most of the steps were already described during the visit, the questions can be more concrete. This entry is also helpful in addressing input quantities and costs, as well as key labour issues, especially when operations are manual.

With regard to industrial players, a discussion with the manager or director on the history of the company, followed by a visit led by the production manager and a discussion with the quality and purchasing manager were valuable sources of information. Carrying out the interviews in this way made it possible to combine the information and to validate it by cross-checking the data. 


\section{How to best delegate data collection}

Data collection is a key step in obtaining reliable data. When it is necessary to delegate data collection for whatever reason (time, cost, large samples), the preparation phase will be longer. Setting up the tool used for data collection (Excel spreadsheet, questionnaire) and training interviewers are time-consuming processes. It is also important to provide enough time for data formalization: translation when surveys are conducted in the language of the country, information systematization and database creation to be sufficiently precise in the questions to avoid errors. Training interviewers in LCA principles by doing at least one survey test with them is a way to ensure better data. It is also key to train interviewers on all the possible sources of uncertainty related to the data and on the need to cross-check and validate data onsite. It is essential that reviewers provide sufficient information on the origin and level of confidence of each piece of data in the questionnaire or Excel spreadsheet used for the survey.

\section{How to validate and complete datasets}

As previously discussed, the reliability of the data is the result of multiple actions throughout the data collection process. Here, we propose a summary of these steps that aim to make this dataset as reliable as possible (Figure 9.4). The possible sources of uncertainty attached to field data are numerous. People may wish to please the interviewers, or they may not trust them and not want to give them their actual data. They may not keep formal records of their practices and forget what they did. They may have used what they had at hand to measure the inputs they apply, such as the cap of a bottle for a pesticide and the interviewer will need to estimate the corresponding quantity in international units. As already demonstrated, it is important to validate as much information as possible while still in the field to secure the data. It is advised to ask for invoices for all purchased or paid inputs if the farmer does not know the amount of a given input. Plots should be visited since they will reveal the actual situation of the crop (e.g. crop associations, slope of the land, etc.). Active ingredients and formulas of fertilizers should be checked by looking at the packaging of inputs, while certain containers should be weighed to convert their capacity into international units. Pictures can be taken, after getting explicit agreement from the farmers, to remember. While still in the field or just after (e.g. once back at the hotel), the origin of each figure, the way it was estimated, and its level of confidence must be reported as precisely as possible in the survey file.

Once back at the office, the dataset should be cleaned up and submitted for critical review (CR) by an external technical expert to check orders of magnitude, units, and consistency across data. It is also important to compare it with existing literature references or datasets. This will help identify aberrant values and gaps that can be asked about again or checked back with the surveyed stakeholder either during a second mission or by email or a phone conversation. Remaining data gaps should 
then be filled based on expert advice and the literature or by proxies. Finally, while creating new processes in the LCA software, the metadata for each piece of data should be reported as precisely as possible, including origin of the data, method of estimation/calculation, representativeness, and reliability. The data quality management system proposed by Weidema and Wesnæs (1996) or another more personal system can be used as long as the overall data quality is properly described.

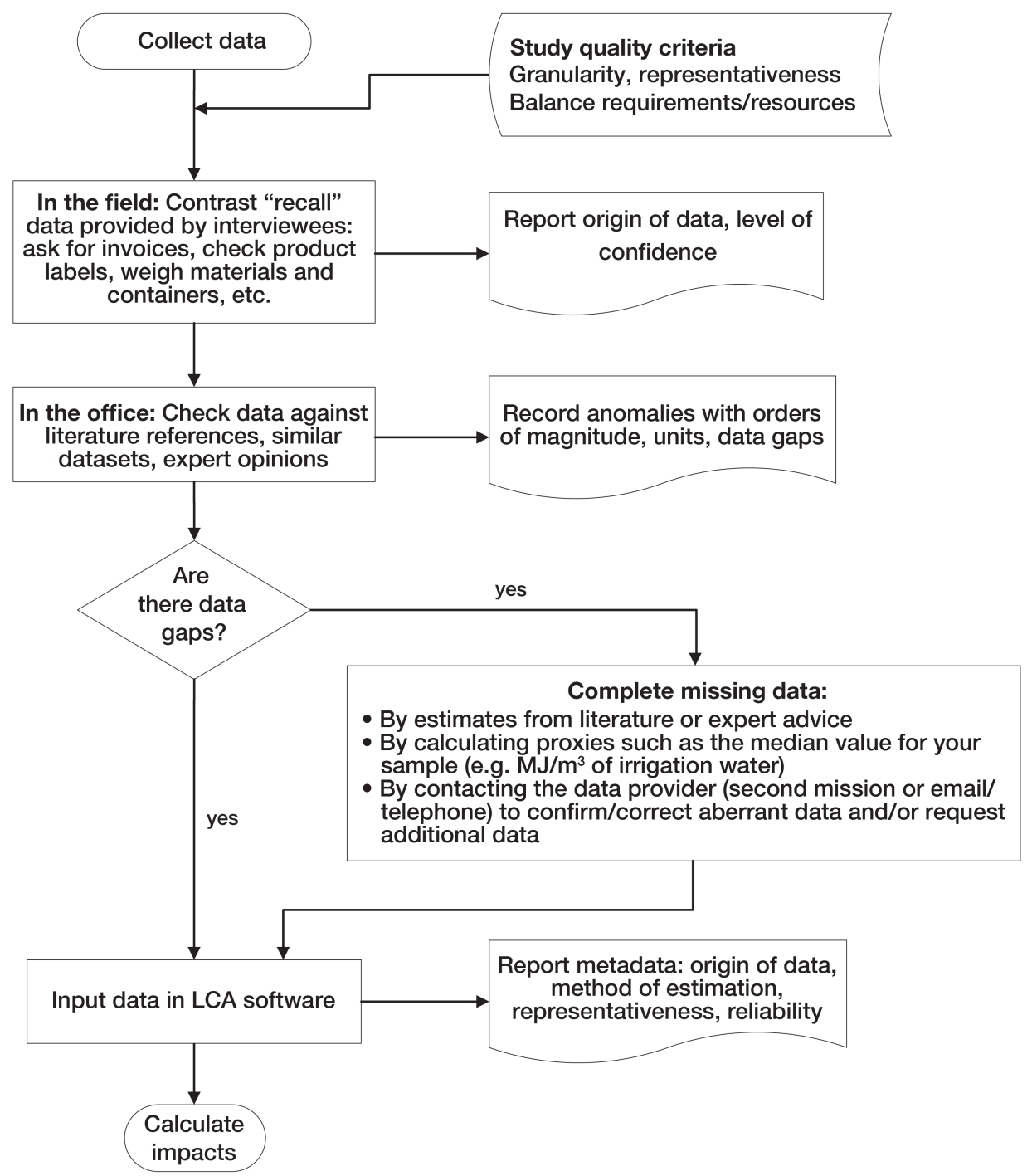

Figure 9.4. Recommendations on data quality management at all steps of the data collection and reporting process. 


\section{Horizontal averaging of unit processes data}

Averaging data might seem straightforward, but is subject to several decisions that can greatly influence results. One might want to model each sample separately (one LCI dataset per site), but this easily becomes impractical in LCA models. Thus, most datasets need to be averaged to a certain extent, but this raises its own set of challenges. For example, one might be faced with several datasets that represent vastly different scales of production. Production practices might also vary, and one needs to determine if sets of farming practices can be considered as one production practice or if they must be divided into several (e.g. tillage and non-tillage agriculture). Rather than predefined divisions, such as geography or crop, the LCI data should be organized according to what is most relevant for the study. For example, a crop cycle (spring or autumn) might have much larger influence on the LCI data than the region of farming. In other cases, scales of production or farming practices might result in the most relevant criteria. These aspects also relate to typology, which was described in Chapter 8 section "System boundaries, typologies and sampling strategies".

Averaging data among diverse actors can be done on the basis of production volume or representativeness (Henriksson et al. 2013). This can be done either in one LCI dataset (e.g. weighting the inputs to the outputs of farms), or with regards to what the study seeks to represent (e.g. based upon production practices). In this context, it is important to reflect upon the goal and scope of the study. As mentioned in Chapter 8 section "System boundaries, typologies and sampling strategies", LCA studies tend to imply broad representation (e.g. soybean production in Brazil), while the primary data often only represents a few farms in one province. For many agricultural commodities it makes better sense to break up the unit processes related to distinct production practices and conform to a title that better represents the actual study area (e.g. tillage and non-tillage soybeans from Mato Grosso).

\section{Direct field emissions}

Agri-food systems feature direct emissions associated with practices, which should be estimated by way of models (as it is generally too resource-intensive to measure them) and included in the LCIs. Direct emissions are often among the top contributors to environmental impacts depending on the system type and category. Soilless cropping systems (e.g. algae, vertical farming, hydroponics, etc.) do not present critical risks of emissions to the soil, except in relation with the management of crop and other residues. The most important (in terms of contribution to impacts) direct emissions per major agri-food category are summarized in Table 9.1. In Appendix G (p. 143), a list of free tools to model field emissions for $\mathrm{LCI}$ is provided. 


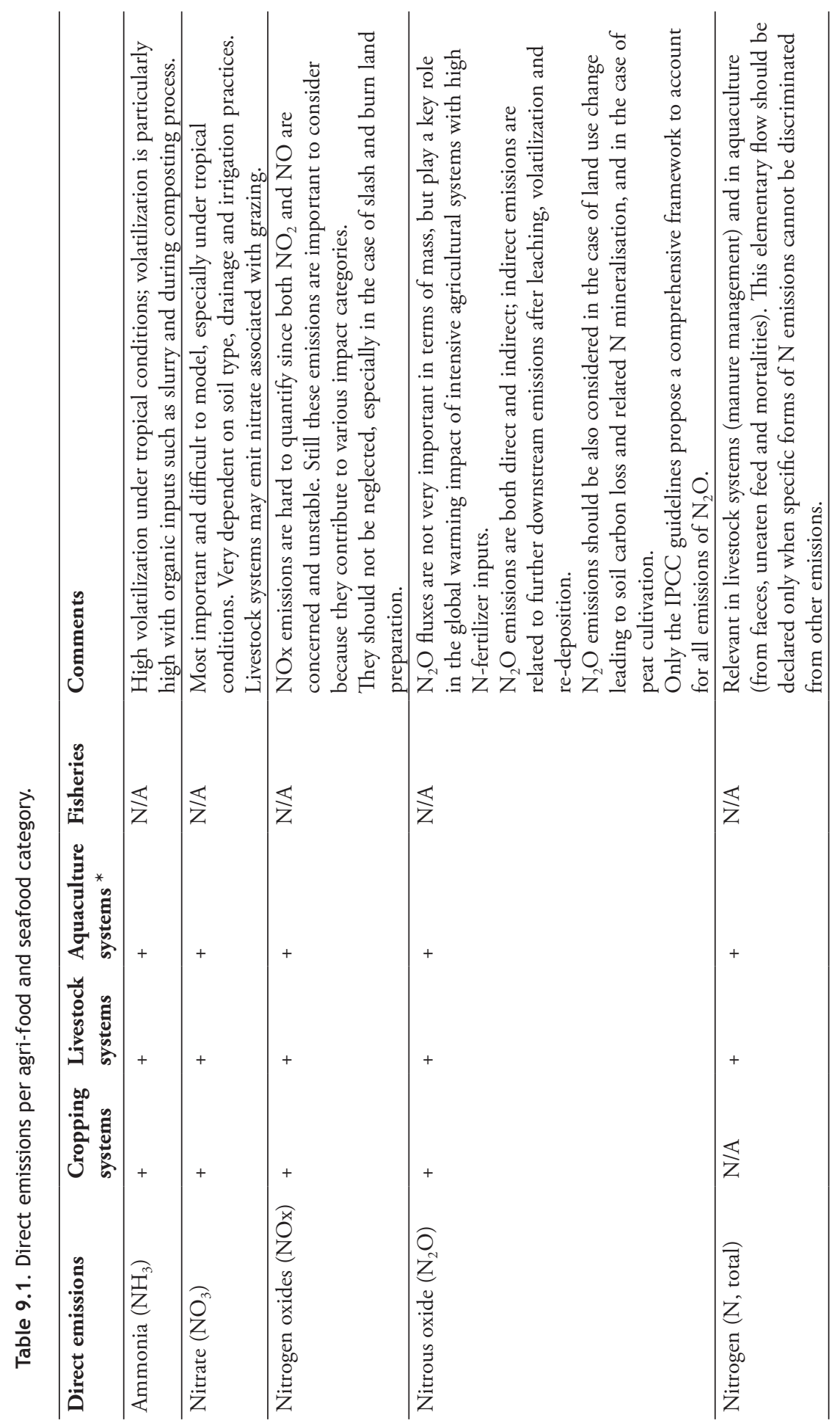




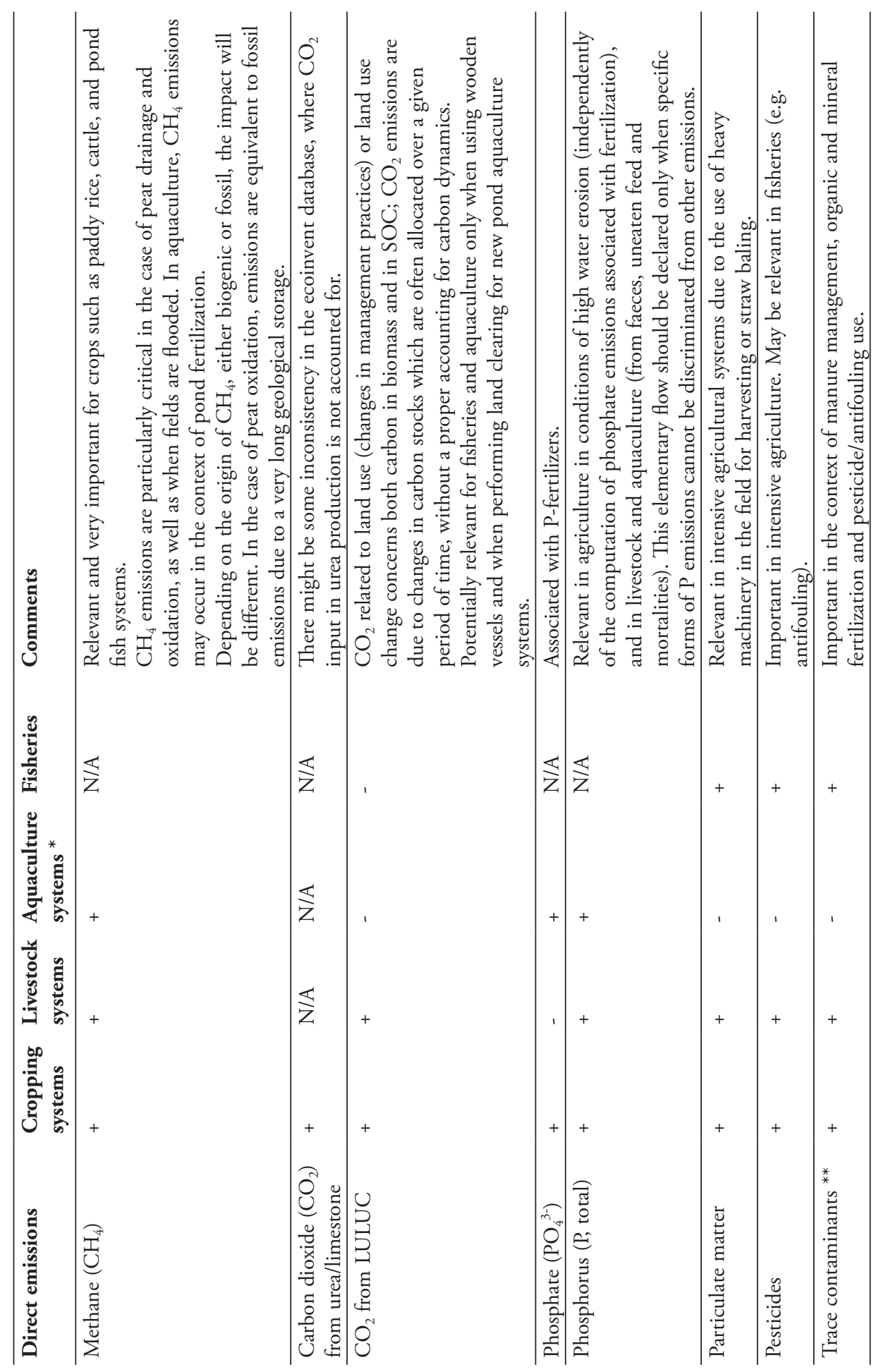




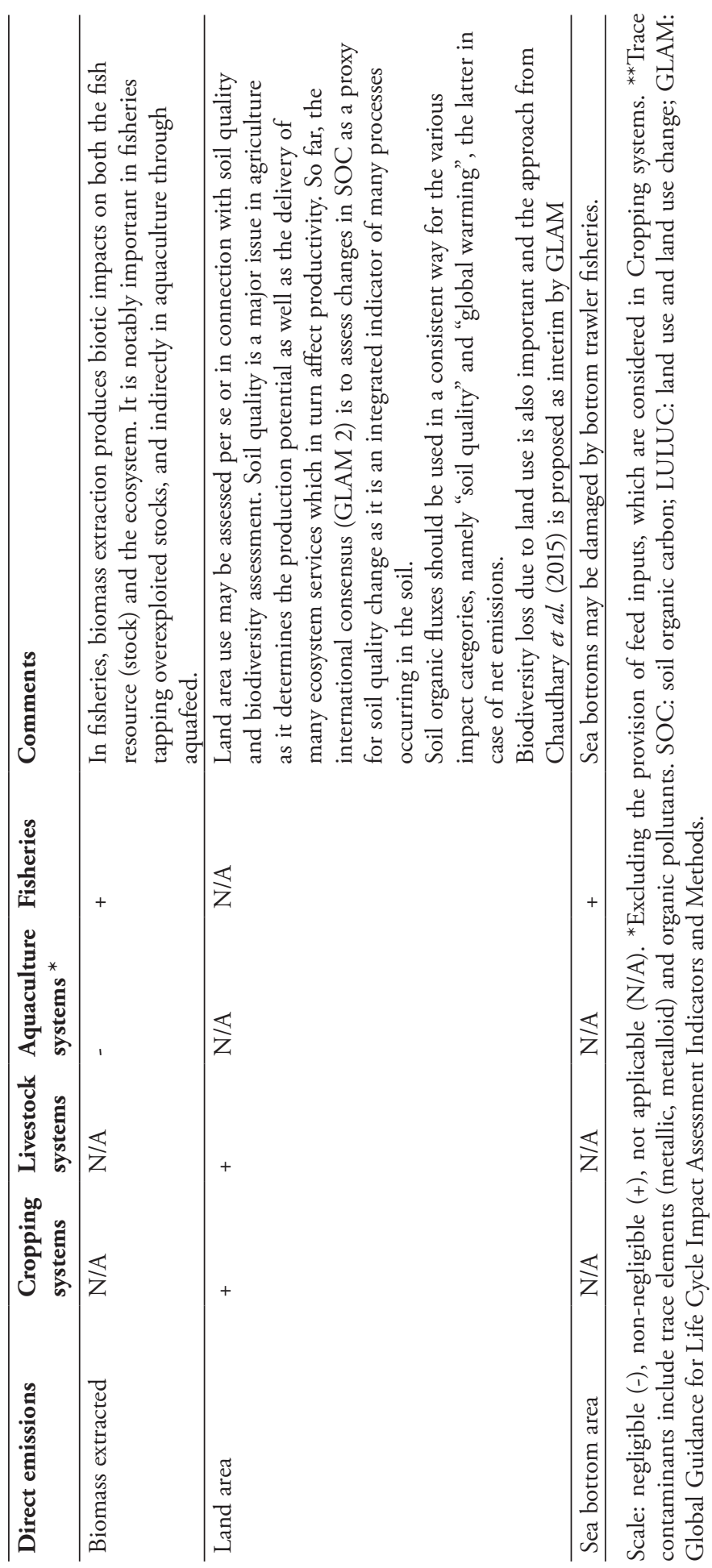


Various models are available to estimate direct emissions from agriculture, featuring varying levels of complexity, accuracy and data requirements. Recently, some of the main model sets used in agricultural LCA - ecoinvent (Nemecek and Schnetzer 2012), World Food LCA database (Nemecek et al. 2015) and AGRIBALYSE (Koch and Salou 2016), which are all described in Appendix B (p. 122) - were sometimes limited regarding their suitability to model nitrogen emissions in contrasting agricultural situations (Avadí et al. 2022). Regarding the suitability and choice of a model, several criteria must be taken into account with regard to both model performances and the data availability to run the model. There are also challenges in ensuring overall consistency, whether among the different models applied for various emissions or with regard to other considered processes that are often modelled with ecoinvent. The decision tree proposed in Figure 9.5 only applies to nitrogen compounds but could be adapted to other compounds should more models be available. It is meant to aid the decision-making process and emphasize where to find further resources. Additionally, in Table 9.2 we present several model recommendations for various field emissions.

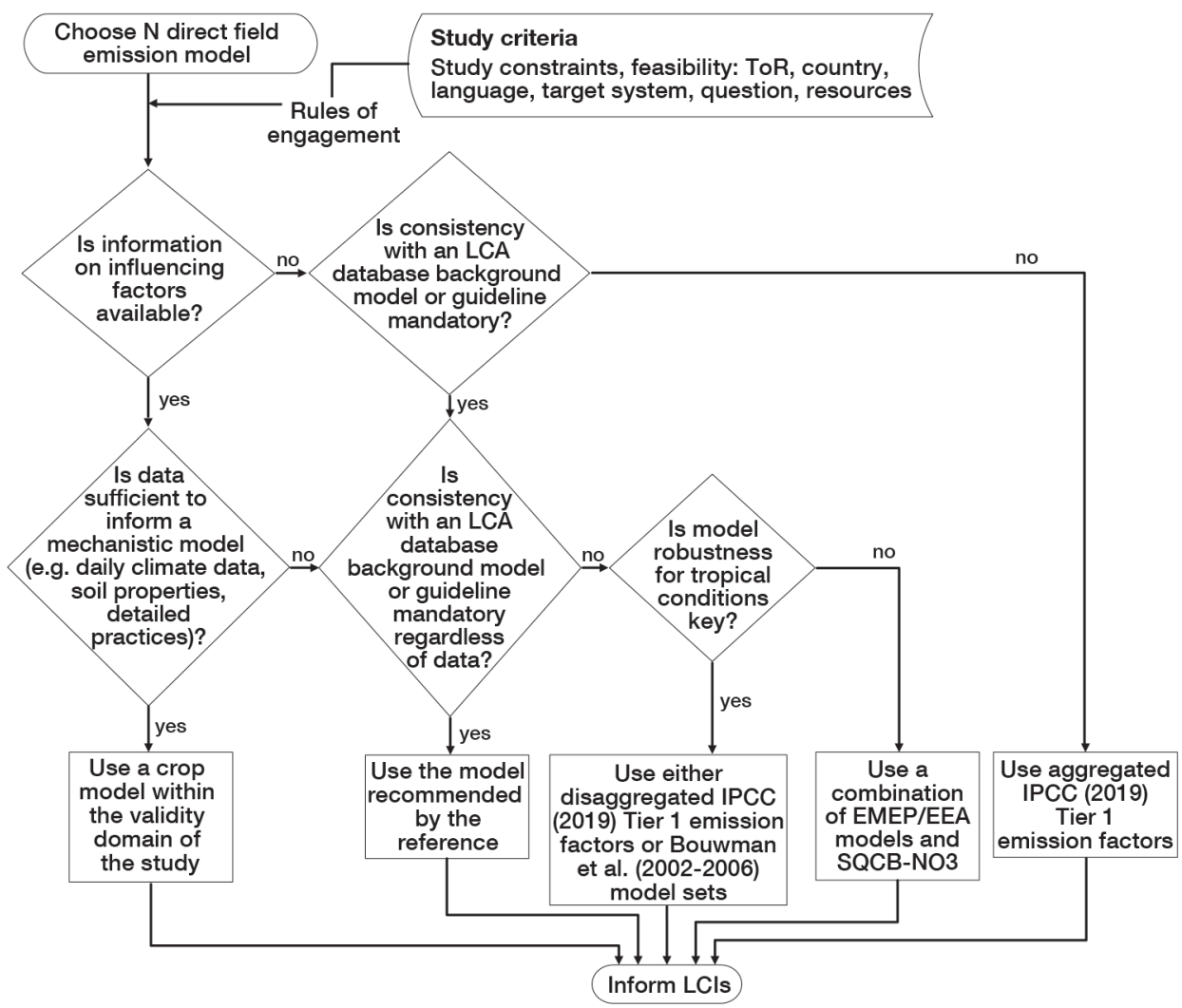

Figure 9.5. Decision tree to guide the model choices for nitrogen $(\mathrm{N})$ field emissions (see also Table 9.2). 


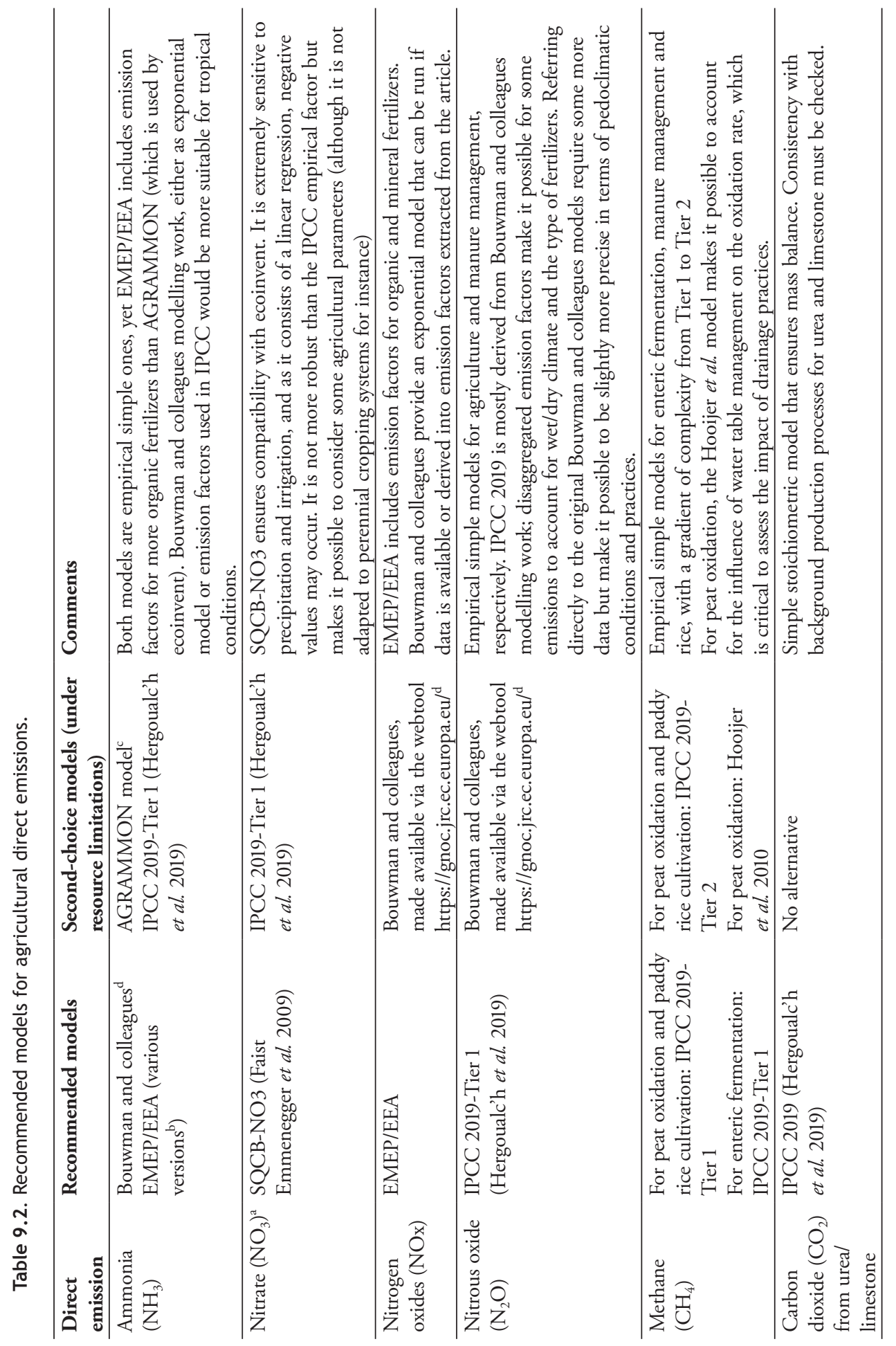




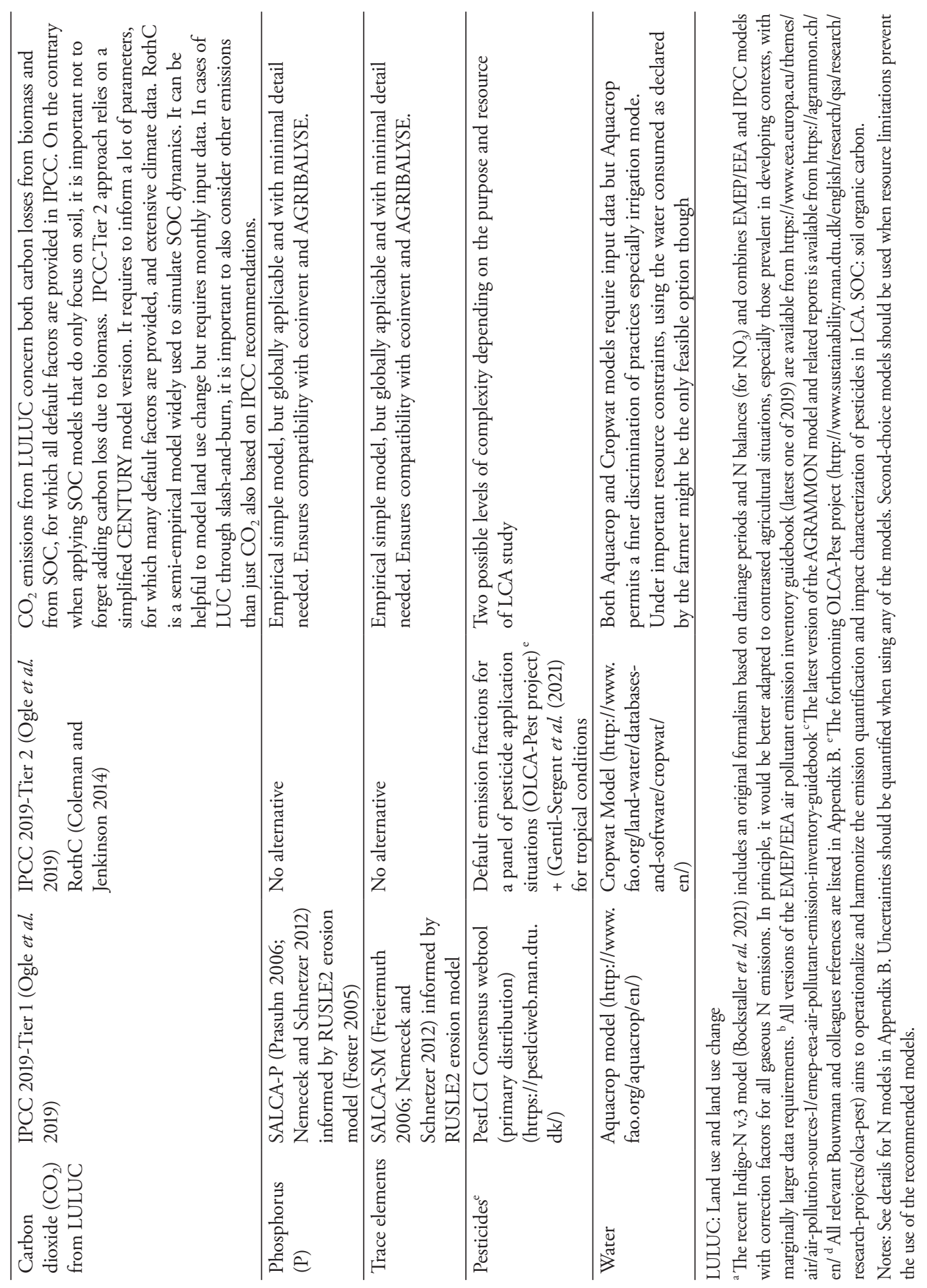




\section{Background data collection}

More often than not, parts of the inventory will have to be obtained from background databases such as ecoinvent, ILCD, World Food LCA Database or other commercial LCI databases. These background data typically include "background" processes representing the provision of energy, packaging, infrastructure and other industrial inventory items.

A unit process dataset contains at least:

- one reference product (which is the main output flow);

- metadata containing description and documentation of the dataset, including a description of sources and the modelling approach to create the dataset;

- a list of all relevant intermediate exchanges, "from" and "to" the technosphere, often referred to as "processes" by practitioners;

- a list of all relevant elementary exchanges, "from" and "to" the environment.

Especially under resource constraints, practitioners may be in the situation where they will not be able to model key inventory items that would normally belong to the foreground, such as the production of on-farm organic fertilizers or industrial feeds. In those cases, database processes would be necessary, but for full disclosure (as some of these items may be key system elements, with a large weight in the whole system's impacts) practitioners should always list all assumptions made and proxies used in the form of an explicit table listing the data sources used in the inventory. The following list offers some hints on how to perform background data collection and chose proxies:

- If grid electricity for the specific country or location of interest is not available from ecoinvent or another suitable commercial database, the national energy or electricity mix is usually obtainable from government reports (as listed, for instance, in http://iea.org). The practitioner can then construct a tailored grid electricity process, such as by combining different types of energy generation available in the databases in the proportions representative of the national energy mix.

- This approach can be replicated with regard to the use of water resources, in particular to establish a localized mix of the different origins of the water used, whether renewable or fossil.

- A similar approach may be applied to construct processes representing industrial products, such as packaging and other metal, glass, fibre, wood or plastic products (e.g. fishing gear, greenhouses, etc.).

- The use of agricultural machinery for certain agricultural operations is available in AGRIBALYSE, on a per hour basis.

- Various types of agricultural, industrial and agro-industrial infrastructure are available in ecoinvent, AGRIBALYSE and other databases. Infrastructure includes buildings, key industrial equipment such as boilers and pumps, fishing gear, aquaculture infrastructure, fishing vessels, etc.

- Pesticides and chemicals in general should be modelled in terms of their active substances, some of which are available in ecoinvent. When a specific substance 
is not available, at least the substance group, as defined in PubChem (https:// pubchem.ncbi.nlm.nih.gov/), would be available. Please note though that only some pesticides are readily characterized by the most common toxicological impact methodologies.

- Animal feeds and especially aquafeeds are particularly difficult to model, because most commercial producers do not disclose the exact formulation of their products nor the origin of raw materials. One should ideally seek to include feed producers as part of the primary data collection. When this is not an option, educated guesses based for instance on import/export data (available, among other resources, via TradeMap, https://www.trademap.org/) would be necessary to determine the likely source of feed ingredients. Literature, technical reports and dedicated websites (https://feedtables.com/; https://www.feedipedia.org/content/ feed-databases) can be used to reconstruct the feed formulations based on the declared nutrient contents, if the few feeds available in ecoinvent, AGRIBALYSE and other databases are not suitable as direct proxies.

- Transport - expressed in terms of tonne-kilometre $(\mathrm{tkm})$ - is modelled in databases following for instance freight capacity, EURO standards and assuming good road conditions. As in developing contexts transportation means very often do not comply with international standards, and an important proportion of roads are not in mint condition (e.g. Bove et al. 2018), transport of goods should be carefully modelled and proxies used should be considered as underestimations.

- If key inventories are missing and if the practitioner want to quickly find out if they are available in certain commercial, free or paid databases, the openLCA Nexus platform can be used to do a search (https://nexus.openlca.org/).

\section{Quality management and critical review (CR)}

If the framework of the LCA project or the expertise allows it (in particular if this has been planned and anticipated in the DMP), all or part of the product datasets may be distributed, according to different modalities, via supply agreements, licence agreements or open data. In any case, this prospect of future dataset release adds requirements in terms of metadata management when building LCIs.

When the results of the LCA study are intended for public communication, a CR must be implemented. In this case, before starting the study, confidentiality agreements giving access to data for the CR procedure should be drawn up in addition to a budget and time allocation if the reviewer is an external expert, which seems preferable. The CR elements are also useful at the end to check if all steps of the study were reasonably fulfilled. According to technical specification ISO/TS 14071 (2016), the main objective of the CR procedure is to ensure that the LCA is consistent with the ISO standards (principles of ISO 14040:2006 framework and with the directives and requirements of ISO 14044:2006 standard). The ISO/TS 14071: 2016 was updated in 2019. The final report shall cover all the elements of the CR. An interesting document (dated but still relevant) 
which details CR steps is the review by Weidema (1997), which was partially adapted in this section.

The steps of a CR are: identification of the expert leading the CR (including a self-declaration of independence and skills), description of support given for CR, an appraisal on conformity of LCA with ISO standards, including scientific and technical validity and transparency and consistency of the study. Finally, the CR might include suggestions for improving the methodology and finally the limitations identified in relation to the objectives of the study. Table 9.3 summarizes main elements for the appraisal on conformity of LCA with ISO standards, including scientific and technical validity and transparency and consistency.

Table 9.3. Main elements for the appraisal on conformity of LCA with ISO standards including scientific and technical validity, transparency and consistency.

\section{Consistency with these international} standards: Main points in goal and scope

- Functions of the studied product systems

- FU

- Systems to be studied

- System boundaries and criteria used in establishing system boundaries and the justification of these criteria

- Allocation procedures
Data used are appropriate and reasonable in relation to the objectives of the study

- Reference unit in relation to which the environmental exchanges are calculated

- Geographical representativeness

- Applied technology/the technological level

- Period during which data has been collected

- Source of the data, how data have been collected and how representative they are, and the significance of possible exclusions and assumptions

- Assumptions used on the source of fuels and electricity mix shall be clearly stated and justified - Validation procedure used

- CR of the inventory analysis

- Check calculations

\section{Results and interpretation}

\section{used to perform LCA}

Scientific and technical validity of methods

- Transparency in characterization and CFs

- Weighting methods and operations

- System comparability assessment

- Interpretation of the results according to the objective and scope of the study; interpretation must include data

- Quality assessment of data and sensitivity analysis 


\section{0}

\section{Performing impact assessment}

In this part of the guide, we propose decision keys for the choice of the most appropriate LCIA methods, an overview of recommended LCIA method sets, a brief analysis of their validity for developing contexts, overall uncertainty and operationality, and finally, a specific focus on important impact categories for agri-food LCA, often showing non-consensual approaches.

\section{Overview of available and recommended sets of LCIA methods}

LCIA method development is an ongoing endeavour, from the very beginnings in the early 1990s to the most recently released models in 2019-20, as depicted in Figure 10.1. More recent models have increasingly focused on spatialization of impact assessment.

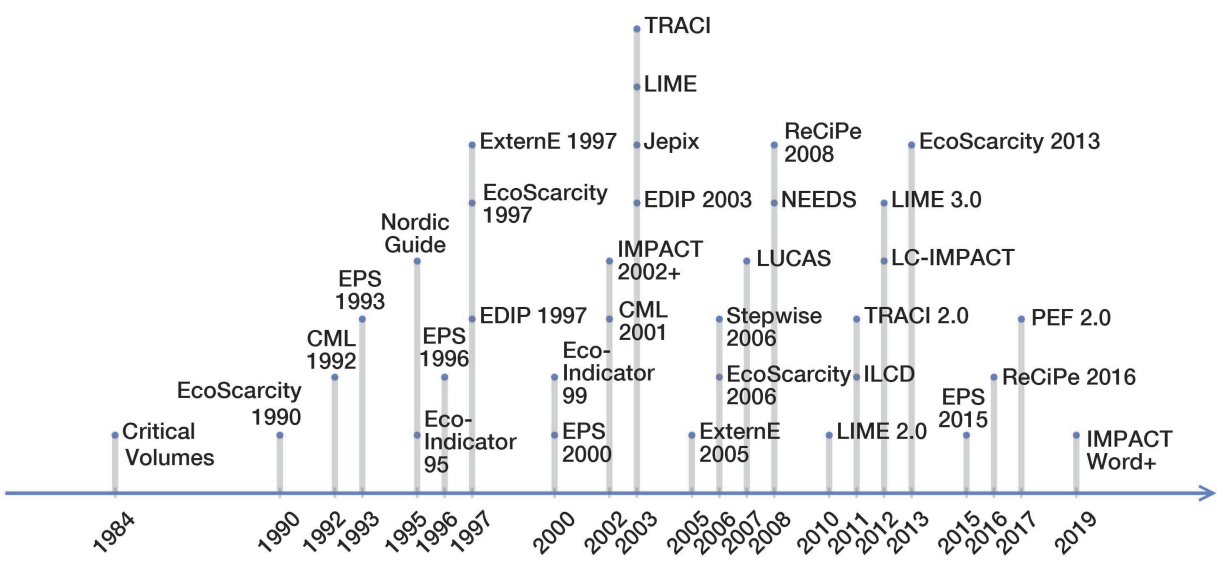

Figure 10.1. Timeline ${ }^{7}$ of LCIA method development. Source: https://github.com/BenPortner/ lca-methods-timeline

7. The EF method 3.0 published for use during the EF transition phase, was published in november 2019, and available in SimaPro from June 2020. 


\section{A multi-parameter and complex choice}

The choice of an LCIA method or an overall LCIA method set depends on multiple parameters and is complex for LCA practitioners. This choice will include both scientific considerations, compliance with the commissioner's expectations and needs and resource constraints for the study (including, for instance, the availability of LCIA methods in LCA software).

From a scientific point of view, all important environmental impacts should be covered for the studied system while several of them do not benefit from consensual and operational methods yet (see specific focus in section "Impact categories" and Appendix H p. 144). The chosen method should ideally rely on the state-of-the-art knowledge and model, be valid in the studied context, not have large uncertainties, but also be operational (e.g. available in LCA software). In many cases, it should also allow acceptable comparisons with existing references to help benchmark and interpret the results for decision-makers. From a commissioner standpoint, it might be expected to obtain a simple and aggregated overview of the results to simplify the interpretation of the results and the decision-making process. Finally, depending on the resources allocated to a project or study, it might simply be impossible to explore refined solutions for modelling LCIA impacts. In Figure 10.2, we propose some decision keys to choose an LCIA method set taking account of the study constraints.

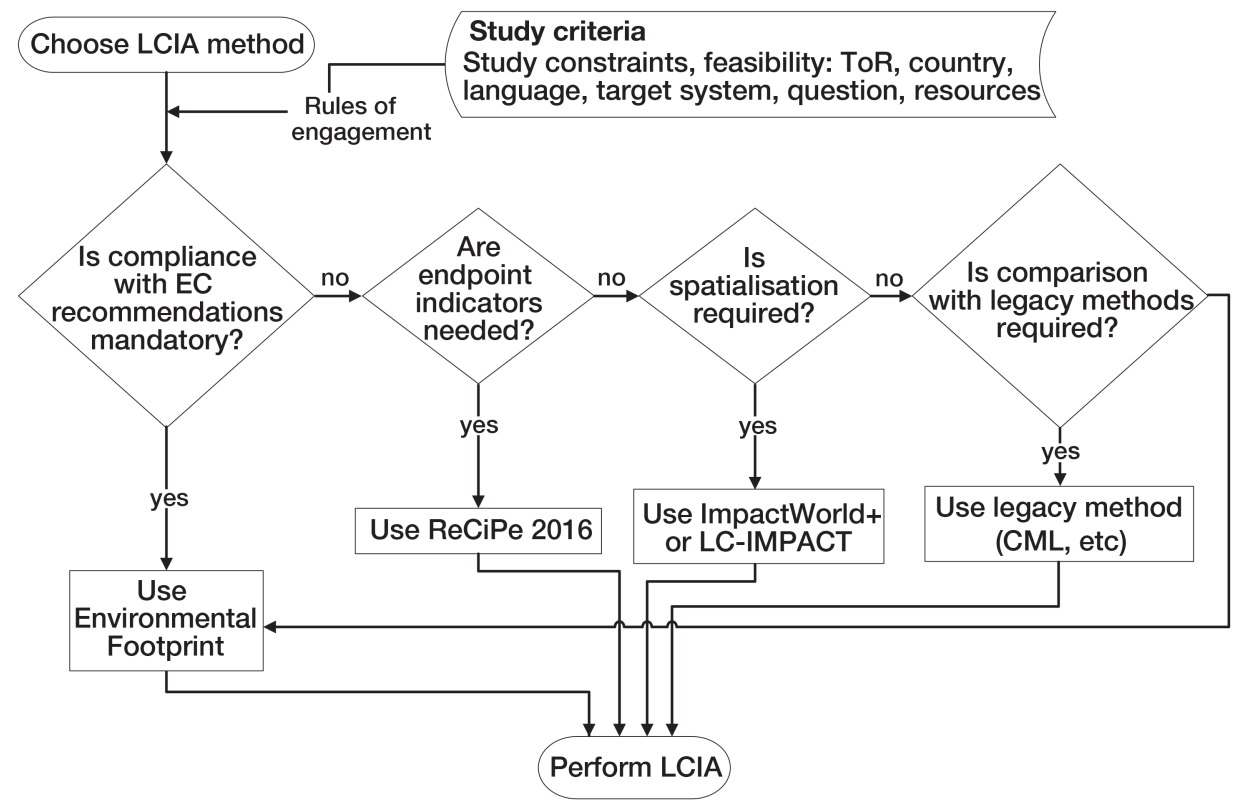

Figure 10.2. Which LCIA method set should be chosen (and why)? 


\section{An important and complex "offer"}

Developing LCIA models constitutes an old but still topical challenge within the LCA scientific community that gave rise to an intense and still highly active scientific production. Several authorities at both international and European levels are involved in critically analysing this immense corpus of scientific production, coordinating consensus-building efforts and making recommendations for LCA practitioners. The main institutions coordinating the provision of guidance on LCIA are the Institute for Environment and Sustainability in the EC-JRC, in cooperation with the Environment DG and UN Environment.

As mentioned in Chapter 3, the JRC first developed the ILCD handbook series of recommendations covering all aspects for conducting an LCA (EC-JRC 2011) (https://eplca.jrc.ec.europa.eu/). The LCIA guides provide requirements for assessing the emissions and resource consumption associated with a product in terms of impacts on the environment, human health, and resource depletion. In 2013, the European Commission established the PEF and OEF, or more generally EF framework to contribute to "Building the Single Market for Green Products Facilitating Better information on the environmental performance of products and organisations COM/2013/0196". The common methods to measure and communicate the life cycle environmental performances for PEF and OEF, have been defined in a specific EU recommendation (2013/179/EU) to fulfil the requirements of the EF scheme. Compared to the ILCD scheme (EC-JRC 2011), in the EF scheme some LCIA methods have been completely changed, while others have been fine-tuned or unchanged. The EF scheme only recommends methods at midpoint level while ILCD also recommended endpoint methods. The EF framework is currently in its third version: EF 3.0.

Table 10.1 presents an overview of LCIA methods recommended for some key impact categories for agri-food LCA studies in the LCIA method sets from the Life Cycle Initiative (UNEP 2016, 2019) and EF 3.0 (Zampori and Pant 2019), as well as the methods used in ReCiPe 2016 (Huijbregts et al. 2016), IMPACT World+ (Bulle et al. 2019) and LC-IMPACT (Verones et al. 2020). IMPACT World+ (http://www.impactworldplus.org/en/), an update of IMPACT 2002+, LUCAS and EDIP, is a recently released LCIA method set offering an updated midpoint-damage framework, spatially-resolved impact categories and a subdivision between short-term and long-term damages for long-term impact categories. LC-IMPACT (https://www.lc-impact.eu/) is a newly proposed method providing CFs at the damage (endpoint) level for 11 impact categories, seven of which include spatial differentiation (no midpoints are included). The goal of this method was to consolidate the latest modelling developments scattered in the scientific literature. Appendix I (p. 176) presents the full lists of LCIA methods recommended by EF 3.0. 
Table 10.1. Methods, indicators and references behind recommended LCIA method sets for some of the most important impact categories for agri-food LCA studies.

\begin{tabular}{|c|c|c|c|c|c|}
\hline & $\begin{array}{l}\text { Life Cycle } \\
\text { Initiative (GLAM) }\end{array}$ & EF 3.0 & ReCiPe 2016 & IMPACT World+ & LC-IMPACT \\
\hline \multicolumn{6}{|l|}{$\begin{array}{l}\text { Water } \\
\text { scarcity/stress }\end{array}$} \\
\hline Midpoints & $\begin{array}{l}\text { AWaRe (Boulay } \\
\text { et al. 2018) }\end{array}$ & AWaRe & $\begin{array}{l}\mathrm{m}^{3} \text { consumed/ } \\
\mathrm{m}^{3} \text { extracted }\end{array}$ & AWaRe & N/A \\
\hline $\begin{array}{l}\text { Human } \\
\text { health }\end{array}$ & $\begin{array}{l}\text { (Motoshita et al. } \\
\text { 2014) }\end{array}$ & & $\begin{array}{l}\text { (Pfister } \text { et al. } \\
\text { 2009) }\end{array}$ & (Boulay et al. 2011) & $\begin{array}{l}\text { (Pfister } \text { et al. } \\
\text { 2009) }\end{array}$ \\
\hline $\begin{array}{l}\text { Ecosystem } \\
\text { quality }\end{array}$ & N/A & & $\begin{array}{l}\text { (Pfister et al. } \\
\text { 2009; Hanafiah } \\
\text { et al. 2011) }\end{array}$ & $\begin{array}{l}\text { Terrestrial: (van } \\
\text { Zelm et al. 2011), } \\
\text { Freshwater: } \\
\text { (Hanafiah et al. } \\
\text { 2011), Thermal } \\
\text { pollution: (Verones } \\
\text { et al. 2010) }\end{array}$ & $\begin{array}{l}\text { (Verones et al. } \\
2017 \text { ) }\end{array}$ \\
\hline \multicolumn{6}{|c|}{ Eutrophication } \\
\hline Midpoints & $\begin{array}{l}\text { Freshwater: } \\
\text { (Helmes et al. 2012) } \\
\text { Marine: (Cosme } \\
\text { et al. 2017) }\end{array}$ & \multirow{2}{*}{$\begin{array}{l}\text { Freshwater } \\
\text { and marine: } \\
\text { Struijs' } \\
\text { Chapter } 6 \\
\text { in RECIPE } \\
2008 \\
\text { (Goedkoop } \\
\text { et al. 2009) }\end{array}$} & $\begin{array}{l}\text { Freshwater: } \\
\text { (Helmes et al. } \\
\text { 2012) } \\
\text { Marine: N/A }\end{array}$ & $\begin{array}{l}\text { Freshwater: } \\
\text { (Helmes et al. } \\
\text { 2012) } \\
\text { Marine: (Roy et al. } \\
\text { 2012) }\end{array}$ & N/A \\
\hline $\begin{array}{l}\text { Ecosystem } \\
\text { quality }\end{array}$ & $\begin{array}{l}\text { Freshwater: } \\
\text { (Azevedo et al. } \\
\text { 2013a, b) } \\
\text { Marine: (Cosme } \\
\text { et al. 2017) }\end{array}$ & & $\begin{array}{l}\text { Freshwater: } \\
\text { (Azevedo et al. } \\
\text { 2013a, b) } \\
\text { Marine: N/A }\end{array}$ & $\begin{array}{l}\text { Freshwater: } \\
\text { (Tirado-Seco 2005; } \\
\text { Helmes et al. 2012) } \\
\text { Marine: (Roy et al. } \\
\text { 2012) }\end{array}$ & $\begin{array}{l}\text { (Helmes et al. } \\
\text { 2012; Azevedo } \\
\text { et al. 2013b; } \\
\text { Scherer and } \\
\text { Pfister 2015) }\end{array}$ \\
\hline $\begin{array}{l}\text { Toxicity and } \\
\text { ecotoxicity }\end{array}$ & $\begin{array}{l}\text { Generic scientific } \\
\text { recommendations } \\
\text { (USEtox } \\
\text { recommended) }\end{array}$ & $\begin{array}{l}\text { USEtox } 2.1 . \\
\text { (Rosenbaum } \\
\text { et al. 2008) }\end{array}$ & $\begin{array}{l}\text { USES-LCA } 2.0 \\
\text { (Van Zelm et al. } \\
\text { 2009) }\end{array}$ & $\begin{array}{l}\text { Parameterized } \\
\text { version of USEtox } \\
\text { for continents }\end{array}$ & $\begin{array}{l}\text { USEtox 2.1. + } \\
\text { (Rosenbaum et al. } \\
\text { 2015b; Fantke } \\
\text { and Jolliet 2016) }\end{array}$ \\
\hline $\begin{array}{l}\text { Biodiversity } \\
\text { due to } \\
\text { LULUC }\end{array}$ & $\begin{array}{l}\text { (Chaudhary et al. } \\
\text { 2015)* }\end{array}$ & N/A & $\begin{array}{l}\text { (de Baan } \text { et al. } \\
\text { 2013; Elshout } \\
\text { et al. 2014); } \\
\text { combination of } \\
\text { absolute species } \\
\text { loss at the local, } \\
\text { regional, and } \\
\text { global scale, } \\
\text { using species.yr }\end{array}$ & $\begin{array}{l}\text { (Curran et al. 2011; } \\
\text { de Baan et al. } \\
\text { 2013) }\end{array}$ & $\begin{array}{l}\text { (Verones et al. } \\
\text { 2019, 2020); PDF } \\
\text { (global scale) }\end{array}$ \\
\hline Soil quality & $\begin{array}{l}\text { SOC deficit } \\
\text { potential (Brandão } \\
\text { and Milà i Canals } \\
\text { 2013)+ erosion } \\
\text { (RUSLE) (Foster } \\
\text { 2005) }\end{array}$ & $\begin{array}{l}\text { Soil quality } \\
\text { index based } \\
\text { on LANCA } \\
\text { (Beck et al. } \\
\text { 2010; Bos } \\
\text { et al. 2016) }\end{array}$ & N/A & N/A & N/A \\
\hline
\end{tabular}

*We recommend Chaudhary and Brooks (2018) instead, which is an update and extension of Chaudhary et al. (2015). SOC: soil organic carbon; GLAM: Global Guidance for Life Cycle Impact Assessment Indicators and Methods; PDF: potentially disappeared fraction. 


\section{What is the validity of state-of-the-art LCIA methods for developing contexts?}

Methods for global impact categories, such as climate change, are generally valid at the global scale. For impact categories dependent on local or regional conditions, the spatialization of CFs is key for applying LCA in tropical conditions and has received considerable attention in recent decades. This is the case for the AWaRe water scarcity indicator, which is fully spatialized. However, the use of spatialized CFs is complicated for LCA practitioners due to their absence from the most common LCA software. Furthermore, certain impact categories such as ecotoxicity reflect mostly the sensitivity of ecosystems and organisms in temperate conditions while the sensitivity of tropical organisms to various toxic compounds has very seldom been tested and is not reflected in available CFs (Gentil et al., 2019). Although the increasing spatialization of LCIA models constitutes an important step forward for applying LCA in tropical conditions, there is room for improvement in this regard to better account for the sensitivity of tropical organisms.

\section{What is the uncertainty attached to LCIA models and indicators?}

In the LCIA phase, uncertainty is due to the choice and characteristics of underlying models and the list of substances for which CFs are computed (Alyaseri and Zhou 2019; Cherubini et al., 2018). Model uncertainty, due to "the structure of and the mathematical relationships defining the models themselves (including models for deriving emissions and CFs used in impact assessment models)" (Bamber et al. 2020), cannot be reduced by LCA practitioners, but it should be understood. For instance, (eco)toxicity impact categories feature much higher uncertainty (expressed in terms of the order of magnitude of error in CFs) than impact categories such as climate change or eutrophication. This is due to the understanding and choice of modelling approaches used to represent the underlying environmental mechanisms. Practitioners should keep in mind that (model, parameter) uncertainty may vary with the position of an indicator in the causality chain linking emissions to damage indicators through midpoints. For a holistic consideration of uncertainty it is useful to compare the results of midpoints and endpoints, and if the conclusions change, a more thorough analysis should be made (Rosenbaum et al., 2018).

Certain authors have been able to include the uncertainty attached to LCIA models in uncertainty analyses of LCA results, such as illustrated for instance in Henriksson et al. (2015a) for climate change and in Henriksson et al. (2015b) for freshwater aquatic ecotoxicity. However, including the uncertainty due to LCIA models into the more commonly performed data uncertainty analysis to provide comparisons among alternative systems with an associated level of confidence remain complex for LCA practitioners.

All impact categories for which no consensus models exist (e.g. impacts on biodiversity) are particularly prone to important differences across model results. In principle, when a specific impact category features a large contribution to 
endpoints, it should be contrasted across methods, and the differences explained to the study commissioner.

\section{How operational is the use of LCIA models for LCA practitioners?}

The operationality of LCIA models is contrasted among impact categories, from the global warming potential (GWP) impact that has been available in the first releases of the LCA software and is regularly updated, to recent and spatialized LCIA models such as biodiversity loss due to land use and land use change (LULUC) and which are still completely absent from LCA software. As mentioned earlier, spatialized LCIA models could be of great relevance for LCA studies in developing countries but they are generally not supported by most common LCA software such as SimaPro. Spatialized CFs are available in the literature and should be downloaded and used in other tools such as Excel and GIS sofware, which makes their integration more complicated for LCA practitioners. Finally, there might often be some difference of versions between the LCIA models implemented in LCA software and those proposed by their authors (e.g. USEtox versions), which requires some careful checking.

\section{Impact categories}

Appendix H (p. 144) explains and illustrates the meaning of each impact category (e.g. global warming or climate change impact, soil quality impact, human toxicity and ecotoxicity, biodiversity due to LULUC, and water scarcity footprint), presents a digest of the state of the art on available methods, uncertainty aspects, and validity domains; proposes decision trees to help select among methods, describes operational aspects (included in LCA software), and provides general recommendations/warnings on the links between inventory flows and impact assessment in relation to software used. 


\section{1 \\ Interpreting the results for each stakeholder category}

LCA is a decision support tool and each stakeholder needs to understand and trust the results to be able to make sound decisions. In this part of the guide, we formalize our recommendations on the best ways to secure, compare, present and share LCA results for decision-makers.

\section{Accounting for uncertainty in LCA studies}

\section{Overview of all potential sources of uncertainty}

LCA results cumulate several sources of uncertainty that are often not estimated or made visible for decision-makers who would need to know how confident they can be on the values presented in an LCA study. As explained by Heijungs (2021): "After all, knowing the probability of making the wrong decision may affect the decision you make". Making large uncertainties visible around LCA result values can be disturbing but pretending they do not exist is also an extreme exaggeration of their precision. The challenge then is to be able to account for main uncertainties and reach a reasonable estimate of their robustness and degree of confidence.

Many authors formalized the various sources and types of uncertainty attached to LCA results (Huijbregts 1998a, b; ISO 2006b; Igos and Benetto 2015). Uncertainty can be attached to the parameters (input data), the choice and value judgement, and the models used. All of these components of the LCA calculation can be affected by all three sources of uncertainty, which can be summarized as reported by SCORE LCA (Igos and Benetto 2015; Igos 2018):

- First, systematic uncertainty (uncertainty) corresponds to imprecision linked to the experimenter, the measuring instrument or the method of estimation used (e.g. surveys). It corresponds to the error associated with the estimated value that is the difference between the measured value and the "true value" of the quantity that we are trying to measure. 
- Second, stochastic uncertainty (variability) comes from the estimation of the mean of a naturally variable parameter based on a sampling procedure.

- Third, epistemic uncertainty (unrepresentativeness) arises directly from a lack of knowledge about the data, models or rules describing a complex system.

Variability cannot be reduced but it can be better characterized. That is what is aimed by designing relevant typologies and appropriate sampling protocols over time, space and technology. Uncertainty can be reduced or eliminated with more or better data and knowledge. Depending on the origin of the uncertainty, one might prefer to talk about variance, dispersion, scatter or spread.

To test the separate influence of some methodological choices on results, such as choice of allocation factor, or different impact assessment methodologies, sensitivity analyses can be useful. Sensitivity analyses can help estimate how critical the uncertainty related to those choices may be, but they cannot quantify the propagation of the full uncertainty associated with all choices combined. Other uncertainty sources may be treated with a quantitative uncertainty analysis, such as by using Monte Carlo (MC) simulations.

In Table 11.1 we summarize some of the best-known sources of uncertainty related to LCA results. Many of these relate to previous sections of these guidelines. That said, we also acknowledge that there often are many unquantifiable and unknown sources of uncertainty in LCA. Moreover, many software programs have limitations with regards to accounting for all of these different sources, still enabling a set of distributions, using different uncertainty parameters (e.g. min-max, arithmetic standard deviations, or geometric standard deviations), and offering different ways of propagating results.

Table 11.1. Best known sources of uncertainty related to LCA results.

\begin{tabular}{lll}
\hline Source & Example of source of variance & Possible parameters \\
\hline Sampling framework & Biased samples & Hard to account for \\
\hline FU & Moisture content, edible yields & Best estimates \\
\hline Field emission models & Parameter uncertainty & $\begin{array}{l}\text { Model-specific or literature } \\
\text { estimates }\end{array}$ \\
\hline Fate of run-off & Unknown fate of N and P & Literature estimates \\
\hline Economic inputs & $\begin{array}{l}\text { Non-existent or inaccurate } \\
\text { record-keeping }\end{array}$ & $\begin{array}{l}\text { Variances calculated from } \\
\text { sample }\end{array}$ \\
\hline Food waste and loss & Fraction spoiled or lost & Best estimates \\
\hline CFs & Uncertain models or variable & $\begin{array}{l}\text { Impact assessment method- } \\
\text { specific variances or sample } \\
\text { of input data }\end{array}$ \\
\hline Unrepresentativeness & Old data, proxy data, etc. & Pedigree approach \\
\hline
\end{tabular}


Variance related to CFs varies from $\pm 50 \%$ for GWPs to orders of magnitude for toxicological potentials. These dispersions are, however, applicable to all types of LCA, and not unique to LCA in the context of developing or emerging economies. Thus, these guidelines will mostly focus on the dispersions related to LCI data.

\section{Detailed issues to deal with uncertainty within agri-food LCA in developing and emerging economies}

For agri-food LCA in developing and emerging economies, the collection of primary data in the field is generally the best (or only) option to perform an inventory of the studied system. However, record-keeping on quite diversified agri-food systems might be poor or non-existent in such contexts, which means that collected data may have a high uncertainty and larger samples are needed to capture the performance of a sector. As already detailed in Chapter 8 (section "System boundaries, typologies and sampling strategies") and Chapter 9 (section "Foreground data collection"), this emphasizes the importance of the different data collection stages, including the sampling framework, horizontal averaging of data, and sources of overall dispersion.

Conversely, in more industrialized countries, producers generally keep better records on their production processes and have more homogenous production practices, but they are also less willing to share due to corporate confidentiality. Much LCI data in industrialized contexts therefore only represent one or a few data points. This is also a reason why data quality ratings (DQRs) have become an accepted practice to quantify dispersions for these processes. The DQR is a scoring system for qualifying data in LCA studies that was first developed by Weidema and Wesnæs (1996) and has been further developed and used by all LCA database. This data quality-checking system is summarized in Chapter 11 (section "Best practice to account for uncertainty").

Given the generally larger variances in data describing practices in developing and emerging economies, distributions defined by primary data should always be prioritized over DQRs. While empirically derived DQRs have been useful in establishing variances for existent datasets, such as the ecoinvent LCI database (Ciroth et al. 2016), they are generally derived from datasets describing unit processes for a few specific sectors in quite industrialized countries with potentially little dispersion. It is, for instance, not uncommon for uncertainty ranges around LCI results to span an order of magnitude (Henriksson et al. 2018) (Table 11.2). Moreover, DQRs originate from the pedigree concept of post-normal sciences and therefore tend to quantify uncertainties not covered by traditional statistics (Van Der Sluijs et al. 2005; Henriksson et al. 2013), such as temporal correlation and completeness. DQRs should therefore be seen as complements, rather than substitutes, for traditional uncertainty parameters. 
Table 11.2. Examples of different sources of overall dispersions in processes in developing and emerging economies, defined by the protocol for horizontal averaging by Henriksson et al. (2013).

\begin{tabular}{|c|c|c|c|c|c|c|}
\hline $\begin{array}{l}\text { Unit } \\
\text { processes }\end{array}$ & Type & Flow & $\begin{array}{l}\text { Inherent } \\
\text { uncertainty, CV }\end{array}$ & $\begin{array}{l}\text { Spread, } \\
\text { CV }\end{array}$ & $\begin{array}{l}\text { Unrepresenta- } \\
\text { tiveness, CV }\end{array}$ & Overall \\
\hline $\begin{array}{l}\text { Giant river } \\
\text { prawn } \\
\text { Khulna, unit } \\
\text { process data }\end{array}$ & Primary & Electricity use & Assumed: 0.05 & 0.935 & 0.0283 & 0.937 \\
\hline $\begin{array}{l}\text { Giant river } \\
\text { prawn } \\
\text { Khulna, unit } \\
\text { process data }\end{array}$ & Primary & $\mathrm{NH}_{3}$, to air & 1.73 & & 0.0623 & 1.73 \\
\hline $\begin{array}{l}\text { Soybean } \\
\text { farming, } \\
\text { Brazil }\end{array}$ & Secondary & $\mathrm{N}$ fertilizers & Assumed: 0.05 & 1.02 & 0.0398 & 1.02 \\
\hline $\begin{array}{l}\text { Soybean } \\
\text { farming, } \\
\text { Brazil }\end{array}$ & $\begin{array}{l}\text { Secondary, } \\
\text { IPCC } \\
\text { emission } \\
\text { model }\end{array}$ & $\mathrm{N}_{2} \mathrm{O}$, to air & 0.63 & & 0.0283 & 0.63 \\
\hline $\begin{array}{l}\text { Groundnuts } \\
\text { (peanuts), } \\
\text { China }\end{array}$ & Secondary & P fertilizers & Assumed: 0.05 & 0.519 & 0.0283 & 0.552 \\
\hline
\end{tabular}

CV: coefficient of variation.

Beyond the uncertainty related to the dataset used to characterize a process unit, the structuring of the process tree also affects how variances and uncertainties must be handled. This variance exists at almost every node of the unit process dataset and is hard to aggregate in a meaningful way.

While we generally get our first impression on how unit process datasets should be structured from ecoinvent, the condensed unit process structure of ecoinvent is a product of avoiding cumbersome matrix calculations. For example, ecoinvent tends to include transportation as part of a unit process. In reality, transportation processes are better modelled as separate unit processes (Figure 11.1), which enables more flexibility, easier analysis of results, and more descriptive uncertainty parameters. Another example concerns the inclusion of food loss and waste, it may happen at most nodes along the value chain and can be more easily parameterized if the processes are not too aggregated. Similarly, it could be argued that the DQR should be implemented at each node in the unit processes dataset.

Moreover, covariances often exist among different parameters, such as nitrogen fertilizers and field emissions of $\mathrm{N}_{2} \mathrm{O}$ (Groen and Heijungs 2017). Implementing distributions or using circular flows (e.g. electricity used by power plants) can also result in inverted operators, where outputs turn into inputs. This is more common for processes with large variances. 

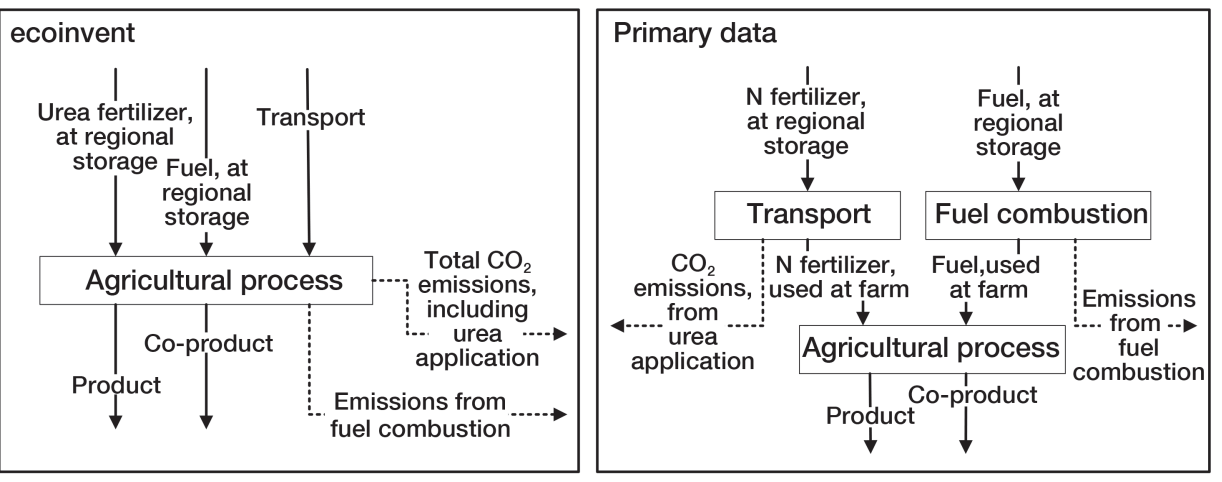

Figure 11.1. Unit processes dataset structure in ecoinvent database and as proposed in these guidelines.

\section{Best practice to account for uncertainty}

Depending on the LCA situation and constraints, various approaches are feasible to help feel reasonably confident with the conclusions of the LCA study. Some authors differentiated between non-comparative and comparative LCA studies in relation to the issue of managing uncertainty, arguing that non-comparative LCA studies can simply rely on more qualitative approaches while comparative LCA studies require a quantitative uncertainty analysis.

\section{Qualitative approaches}

For all LCA studies, qualitative approaches should be default options for dealing with uncertainty. They can consist of checking the validity of data for the goal and scope of the study and carrying out sensitivity analyses on key parameters.

\section{Data quality checking}

In LCA, data quality is key because it defines how well the data will fit with the LCA goal and scope. If the dataset is unsuitable, the LCA results may not provide any useful information on what the actual system impacts are. Distinction between primary and secondary data, typology for agricultural LCA, effort towards better field emission modelling, etc. all converge towards improving data quality to reduce uncertainty on the results. The closer the data is to the real system, the better the data quality.

There are two main ways to determine how close a dataset is to reality. First, statistical indicators can be calculated using mathematical means, but this requires a lot of information on the data distributions for both the sample and the whole population. Second, data quality can be approximated based on expert knowledge according to critical criteria in line with the LCA goal and scope. Given the difficulty in obtaining sufficient datasets in order to run statistical tests, data quality is mostly determined by qualitative means and uncertainty analysis is 
carried out based on estimated distributions of variables. Based on the pedigree matrix (Weidema and Wesnæs 1996), data quality scores can even be used to derive hypothetical distributions and kill two birds with one stone. However, such a transformation embeds an added layer of uncertainty.

The baseline qualitative approach of data quality relies on several criteria that are mostly common to the various approaches used in ecoinvent, PEF, etc. In the original LCA pedigree matrix, there were five quality criteria: (i) reliability; (ii) completeness; (iii) temporal correlation; (iv) geographical correlation; and (v) technological correlation (Weidema and Wesnæs 1996). In ecoinvent databases, which all include this pedigree matrix, a sixth criterion, "sample size", was added and retrieved depending on the version (no longer included in the version v.3.0). "Correlation" is understood as an adequacy between the data collected and the data needed to represent the studied system. In PEF, "representativeness" is used instead of "correlation" and reliability and completeness are embedded in a global "precision" criterion. Scores from one to five are defined by experts for each criterion, one being the highest quality score, five being the default value when no information on the data quality is available. The information needed to define the scores has remained both consistent and constant across ecoinvent versions (e.g., temporal thresholds have not changed): three, six, 10 and 15 years (Weidema and Wesnæs 1996; Ciroth et al. 2016). This qualitative information can be used in two non-exclusive ways: it can be aggregated in order to provide a qualitative assessment of the dataset, hence providing weighted perspectives on the potential outreach of LCA results (cf. qualitative diagnosis); or it can be translated into distribution laws providing mathematical translation of the information precision into value dispersions to be used in uncertainty analyses (cf. uncertainty approximation).

However, as mentioned earlier, for LCA studies in developing and emerging contexts, the use of data quality indicators to define distributions for foreground data does not seem appropriate.

The most detailed guidance on the use of the qualitative assessment of data in LCA is provided in the latest version of the European PEFCR Guidance (EC 2018) and is fully described in Appendix J (p. 178).

\section{Sensitivity analyses}

In addition to checking the validity of data for the goal and scope of the LCA study, it should always be possible to test the sensitivity of the results to important parameters and choices one by one. As recommended by the ISO norm: “... the interpretation shall include an assessment and sensitivity check of the significant inputs, outputs and methodological choices in order to understand the uncertainty of the results". A sensitivity analysis contributes to the robustness of LCA results and aids interpretation. Typically, the practitioner will test the sensitivity of the final results to the one-at-a-time variation of key parameters which are known to have a considerable contribution on impacts. We propose a list of key parameters per great agri-food category (Table 11.3) to support the selection of key variables. 
Table 11.3. Key parameters for sensitivity analyses depending on product system.

\begin{tabular}{|c|c|c|c|c|c|c|}
\hline Parameter & $\begin{array}{l}\text { Crop } \\
\text { systems }\end{array}$ & $\begin{array}{l}\text { Livestock } \\
\text { systems }\end{array}$ & $\begin{array}{l}\text { Aquaculture } \\
\text { systems }\end{array}$ & Fisheries & $\begin{array}{l}\text { Agri-food } \\
\text { processing }\end{array}$ & Distribution \\
\hline $\begin{array}{l}\text { Energy use (may } \\
\text { be expressed as } \\
\text { fuel use intensity) }\end{array}$ & - & $\begin{array}{l}+(\text { e.g. if } \\
\text { mechanized })\end{array}$ & $\begin{array}{l}+(\text { e.g. } \\
\text { recirculating } \\
\text { systems })\end{array}$ & + & + & + \\
\hline $\begin{array}{l}\text { Feed consumption } \\
\text { (may be expressed } \\
\text { as feed conversion } \\
\text { ratio) }\end{array}$ & N/A & + & + & N/A & N/A & N/A \\
\hline $\begin{array}{l}\text { Water } \\
\text { consumption }\end{array}$ & + & + & + & N/A & $\begin{array}{l}+(\text { e.g. in } \\
\text { water-scarce } \\
\text { areas })\end{array}$ & N/A \\
\hline $\begin{array}{l}\text { Fertilizer } \\
\text { consumption }\end{array}$ & + & N/A & - & N/A & N/A & N/A \\
\hline $\begin{array}{l}\text { Pesticide } \\
\text { consumption }\end{array}$ & + & - & - & N/A & $\begin{array}{l}\text { - (e.g. except } \\
\text { for cases } \\
\left.\text { described in }{ }^{a}\right)\end{array}$ & N/A \\
\hline
\end{tabular}

${ }^{a}$ It is not unusual for pesticides to be used as preservation treatment for certain artisanal processed products, such as smoked fish (Adeyeye and Oyewole 2016). Scale: negligible (-), non-negligible (+), not applicable (N/A).

\section{Quantitative approaches}

Quantitative uncertainty analyses are especially relevant for comparative LCA studies and are possible by using propagation methods. The most common propagation methods are MC sampling, Latin hypercube sampling, analytical uncertainty propagation and fuzzy interval arithmetic (Groen et al. 2014). Each of these have different strengths and weaknesses which should be considered, but MC sampling remains the most frequently used propagation method. While modern software can make use of the graphic processing unit and compute large sets of MC results in a short period of time, many LCA software still rely upon the central processing unit which results in longer computation times. This becomes cumbersome if one wants to run large sets of iterations for large unit process datasets. Thus, since there are no rules for a "sufficient number of iterations" (Heijungs 2019), the final decision often comes down to an arbitrary number. While the sample mean normally starts to conform around $100 \mathrm{MC}$ iterations, it comes down to the unit process dataset, so we recommend 1000 iterations (Groen et al. 2014). This said, it is important to highlight that resampled results only constitute arbitrary sample sizes and should therefore be approached carefully with confirmatory statistics (Heijungs 2019).

In practical terms, running MC simulation includes three steps:

1. The first step is to transform discrete input variables into stochastic variables by defining a probability distribution for them. In the LCA community, lognormal distributions are preferred, as negative results will not be generated during the 
propagation. It is important when using alternative distributions to make sure that the central value corresponds to the software algorithms. For example, most software expects the arithmetic mean as the central value for lognormally distributed data, as the point-value otherwise would deviate. Moreover, when normal distributions are extremely platykurtic (e.g. standard deviations > means), it is preferable to either limit the range of values used to build the normal distribution, or use triangular distributions, which guarantee that no incorrectly negative values would be possible. 2.Then, a random sampling of values among all input variables is performed (e.g. 1000 times), and for each set of values a result is calculated, progressively drawing the probability distribution of the result itself.

3. Finally, in the case of a comparison between systems A and B, null hypothesis significance testing can be done to check the significance of the difference. $A$ more relevant test could be to test the probability that the difference between $A$ and $B$ exceeds a given threshold, such as $20 \%$, which will give a clearer appraisal of the importance of the difference between $A$ and $B$.

For background data, probability functions can be based on DQR conversion while for foreground data, they should be based on statistical data from the primary data collected in the field. In some LCA software, there is a dedicated function to conduct uncertainty analyses, such as in the SimaPro software (v9.1.1.1).

Figure 11.2 summarizes some practical recommendations for conducting MC simulations.

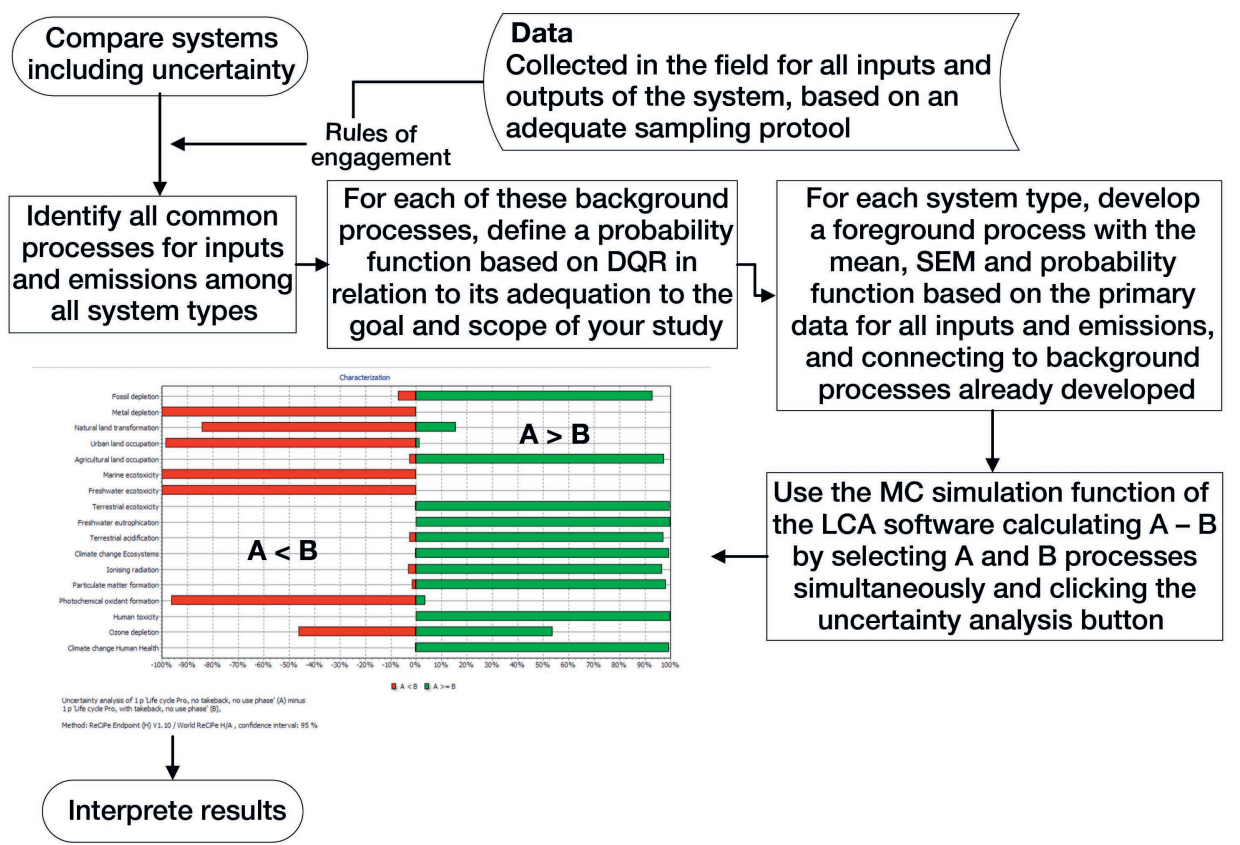

Figure 11.2. Practical recommendations for conducting $M C$ simulations with the SimaPro software. SEM: Standard error of the mean. For complementary instructions please refer to the SimaPro tutorial (Goedkoop et al. 2016). 
Generally, the objective is to compare the mean impacts between two system types. In this situation, the confidence interval should be defined using the standard error of the mean (SEM) of input data. If the objective is to compare the two populations, the confidence interval should be defined using the standard deviation (SD) of input data. If the SD is used for defining probability distributions, the result will be the probability that impact for $\mathrm{A}$ is greater than the impact for B. If the SEM is used, it will be the probability that the mean impact for $\mathrm{A}$ is greater than the mean impact for $\mathrm{B}$.

\section{Comparing results with previous studies}

Despite being discouraged by several authors and guidelines from doing so, LCA practitioners often compare their results with those from previous studies. Occasionally, they use clever strategies allowing them to recomputing third party results to have a common FU or to use the same LCIA Method, (e.g. Collado-Ruiz and Ostad-Ahmad-Ghorabi 2010). Recent meta-analyses on LCA studies for food products have been published on the basis of a solid methodology for harmonizing the assumptions and methods used among all reviewed studies (Poore and Nemecek 2018). Such rigorous reviews provide public stakeholders and consumers with key references on the environmental impacts of foods and can support adaptation of behaviours, as well as allow other scientific disciplines to integrate environmental information on products or services in a fairly accurate way.

However, as part of a given comparative LCA study under resource constraints, such comparison should be performed and interpreted with caution, because of the potential underlying differences in goals and scopes, assumptions, data sources and design decisions among studies. A priori, only the orders of magnitude of results from different studies should be compared as well as unambiguous rankings between scenarios when scenarios have been compared. When gross differences are found, they should be investigated to identify the causes: either an error or a valid explainable difference. In all cases, the versions of the databases used for the inventory must be strictly the same, as well as the impact assessment methods, in order to have relevant comparisons. When performing said comparisons, particular attention should be paid to aligning system boundaries, cut-off criteria, allocation strategies, background data sources, LCIA methods, and especially FUs. Sometimes previous studies are not sufficiently documented to attempt a recalculation based on a common and recent LCIA method, which would be ideal. At least common FUs should be used, which can often be accomplished by simple conversions (e.g. for crops, mass units to area units when yields are known). For livestock and seafood, comparisons may also be based on product yields, such as tonne of fat- and protein-corrected milk, tonne of live weight, etc. Intermediate indicators such as feed conversion ratios for fed livestock/aquaculture systems sharing common characteristics (e.g. technology, size, intensity) may also be used to compare systems. 
The fairest way to make this type of comparison is therefore often to have access to the complete LCI (if possible in unit version, with the individual processes), so as to be able to update old or obsolete underlying processes to their latest updated version. This will also enable impact calculations to be launched using the same LCIA method, which is strictly identical for all the scenarios being compared.

In addition, this recalculation will also make it possible to modify the process tree or process groupings in order to highlight relevant contribution analyses, whatever the scenarios studied.

\section{Sharing and communicating results to support decisions}

The results of an LCA study should be communicated to the different types of stakeholders in an appropriate way (Figure 11.3).

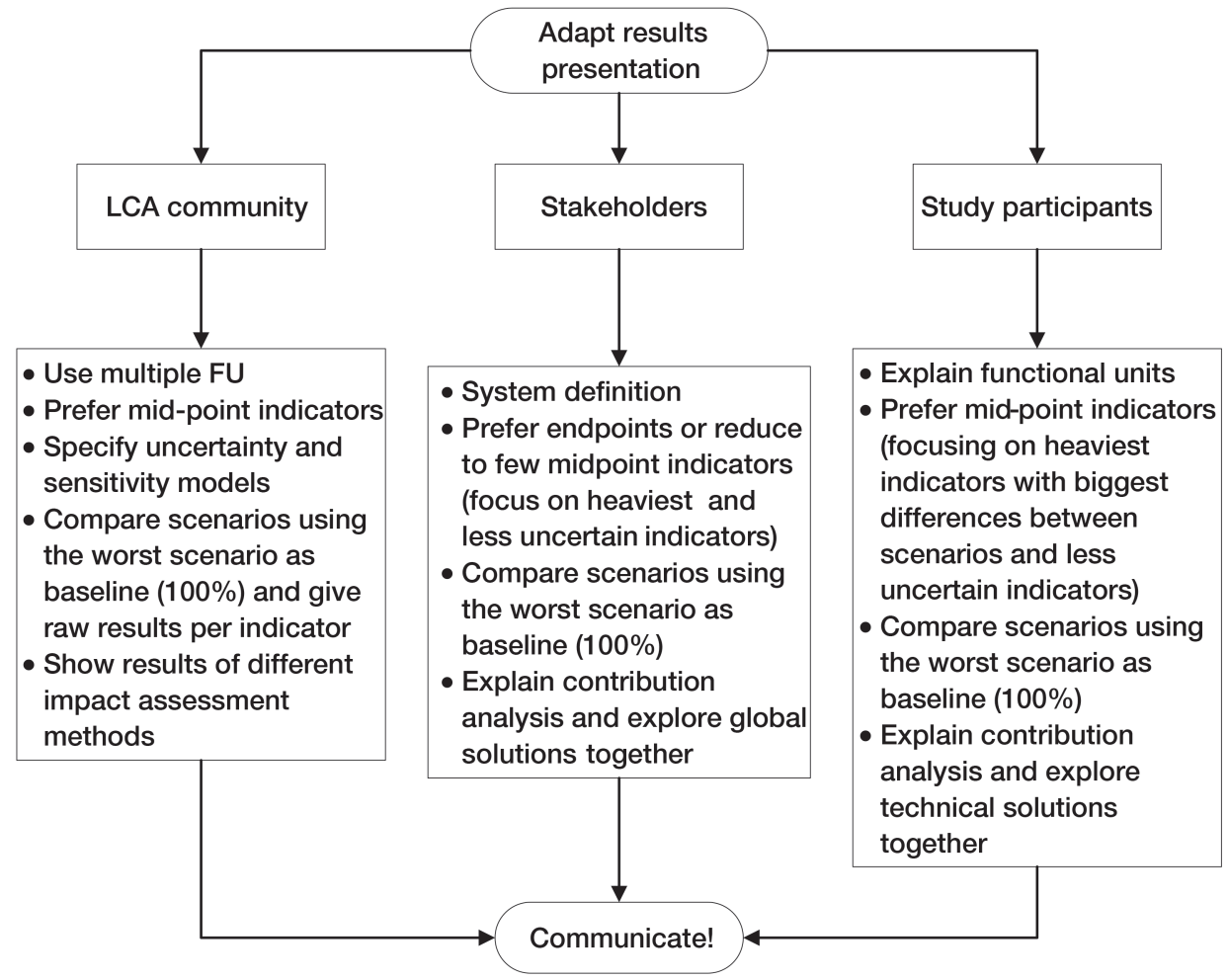

Figure 11.3. Adapting presentation of results to target audience.

LCA calculation results are multi-criteria and therefore by nature numerous at the midpoint level; it is nevertheless in this form that the scientific community shares its results to advance knowledge on environmental impacts. While midpoint tables and graphs are well understood by practitioners, this is generally not the case for non-practitioners. Particularly, for decision-makers and the general 
public, it is often more effective in the short term to produce simpler forms of specific results that are more intelligible for their level of knowledge than disaggregated midpoints. In the medium or long term, however, it is more relevant to increase the LCA literacy of interlocutors, notably through training.

The first level of simplification of the scientific results consists in using the endpoint results (damage on the three areas of protection: human health, ecosystems and resource scarcity), if the impact method allows it, which is not always the case. The most simplified level of results is to use the single score version, which aggregates all impacts into a single indicator.

The following is a list of tips for additional information to provide when presenting the results:

- If aggregated results such as the endpoint or single score have been used, make sure to always communicate the midpoint version in the appendix of the document as well. This is the standard version for communicating results in the scientific community.

- Provide simple and clear explanations of the sources of uncertainty in the results, as well as the key assumptions that have an impact. Confidence intervals should also be communicated.

- Provide the best available visualization options for decision-makers (see Appendix K p. 181 for options), and if possible the most response-oriented, in order to make the transfers and compromises between scenarios tangible if they exist.

Even at a midpoint level, identifying the best scenario from an environmental point of view is often complex because of the large number of environmental indicators to consider. To simplify comparisons of certain scenarios and to try to reach a simpler choice or communication of the results according to the audience, we propose using a procedure for analysing the results: a protocol to support the decision-making process, which is a structured and systematic procedure to eliminate minor indicators and focus on main differences, including their confidence intervals, based on the quantitative results obtained (Figure 11.4). Note that in a comparative LCA carried out according to ISO 14040/44, this procedure could not replace an in-depth analysis of impact indicators.

The proposed procedure is detailed in Guérin-Schneider et al. (2018) and consists in removing from the comparison certain categories of impacts based on simple, quantitative criteria derived from the calculated results. It is quite possible that the scenarios studied cannot be separated even at the end of the procedure. The decision must then be based on other criteria (social, economic, financial, technical, etc.). 


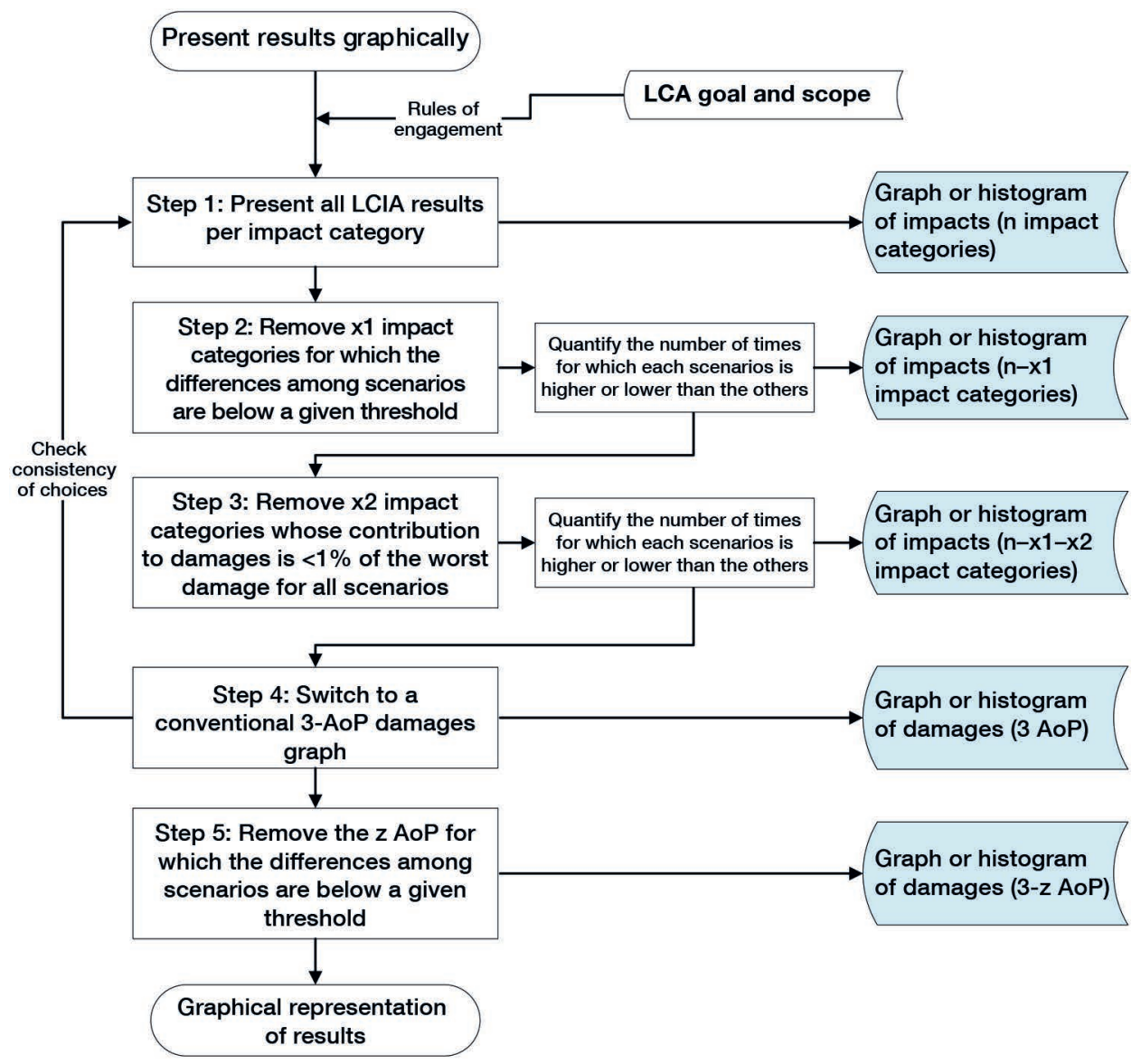

Figure 11.4. Protocol to support the decision-making process based on LCA results (adapted from Guérin-Schneider et al. 2018). Comparison of several scenarios (>2). 


\section{Part 4 \\ Conclusions \\ and moving forward}

Claudine Basset-Mens, Angel Avadí, Cécile Bessou, Ivonne Acosta-Alba, Yannick Biard, Sandra Payen 
Based on a participatory and consensus-building approach to formalize actual field experiences from a panel of senior international experts for agri-food LCA studies in developing and emerging contexts, this guide promotes an approach based on fieldwork and designed with and for all stakeholders associated with the study. The present guide insists on collaborative, ethical, operational and communication considerations and provides the most up-to-date and appropriate models to perform the inventory and the impact assessment in such contexts, making clear recommendations on all aspects of the study.

The most important recommendations of the guide are summarized below.

LCA practitioners should co-design and perform the study with all associated stakeholders:

- Clarify the study purpose and constraints; never accept a poorly designed or under-resourced study.

- Design and validate the goal and scope of the study with the commissioner.

- Analyse the community of the study as well as each stakeholder's expectations and potential fears; take time to explain, build trust, protect interests, and always give something back!

- Work on the field as a team with local experts and partners, other experts, and farmers.

- Take care when developing typology, the sampling strategy and the survey of data providers since this constitutes the foundation for the quality of your results.

LCA practitioners should use most adapted models for field emissions in tropical conditions taking account of their study constraints. The most important (in terms of contribution to impacts) direct emissions per great agri-food category are summarized and a decision tree is provided to support the selection of field emission models according to the study constraints. Recommended and second-choice models are provided for all important field fluxes. We propose a selection of best LCA practices for each major agri-food category, with an emphasis on the construction of LCIs, including recommendations on ad minima inventories and computation of direct emissions (see Appendix F p. 138). At system level, it is important to differentiate between non-productive and productive stages or results could be over- or underestimated.

Regarding impact assessment, an overview of available LCIA method sets is proposed and explained and a decision tree to help identify the most adapted sets of method for each study is provided. Detailed and up-to-date presentation and recommendation documents are also provided in Appendix H (p. 144) for the most important impact categories: climate change, soil quality, human toxicity and ecotoxicity, biodiversity due to LULUC and water scarcity.

Throughout the guide, data quality, variability and uncertainty is addressed at all levels: in the typology and sampling protocol design, in the relationships with data providers, in the checking and validation of data collected in the field and finally at the interpretation level, by identifying the main sources of uncertainty 
and integrating them into the final results. The whole approach being based on fieldwork with stakeholders, recommendations mostly focus on the accounting for uncertainty attached to unit process data.

Finally, specific recommendations are made on the best way to help each stakeholder understand, trust and take advantage of the results. This includes recommendations on the best practices for comparing, visualizing and interpreting LCA results in a transparent way.

The editors of this guide plan to continue updating and complementing their recommendations over time and present them on a dedicated website. 



$$
\text { Part } 5
$$

Appendices 



\section{Appendix A \\ Guidelines / ISO Norms: \\ a brief overview}

\section{ISO, 2006. ISO - 14040:2006 - Environmental management - Life cycle assessment - Principles and framework, Environmental Management}

This standard specifies the principles and framework for LCA by detailing the nature of the 4 stages of LCA (goal and scope, LCI, LCIA, interpretation). The document also covers the principles of communication and CR of LCA, and limitations.

This document does not describe in detail the practical and concrete implementation of LCA, nor the specific methodologies of each of its phases. However, it is a reference document that every practitioner must have read and know.

Chapter 3 from this norm, "Terms and Definitions", presents the key definitions used in LCA and referred to by the community of practitioners.

Figure 1 from this norm shows the interactions between the phases of LCA and lists examples of LCA applications, and is a classic figure used to present the different phases.

\section{ISO, 2006. ISO - 14044:2006 - Environmental management - Life cycle assessment - Requirements and guidelines. Geneva}

This standard specifies the requirements concerning the different phases of the realization of an LCA, by specifying what must be clearly explained in each one in methodological terms. This document also contains definitions of LCA reference terms.

Part 4 details the completeness and transparency requirements for conducting an LCA, and recalls as a preamble that there is no sound scientific basis for reducing or aggregating LCIA results into a single score. Precise explanations are given on the choice of the FU, the definition of the reference flow, the boundaries of the studied system, the modalities of choice of the cut-off criteria. The requirements in terms of data quality are also listed (data age, temporal relevance, geographical area, representativeness...). 


\section{Appendix B \\ Commonly used direct field emission models}

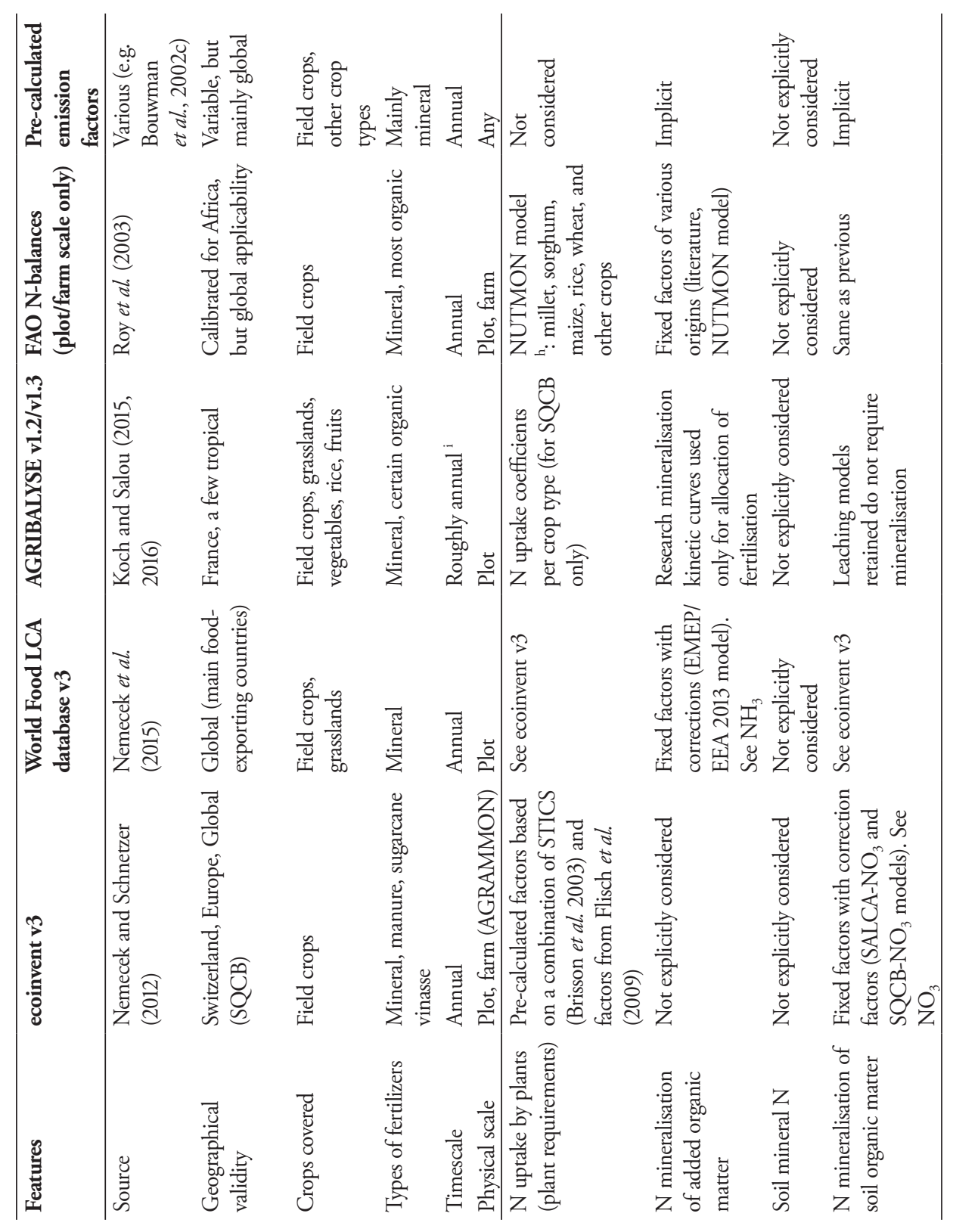




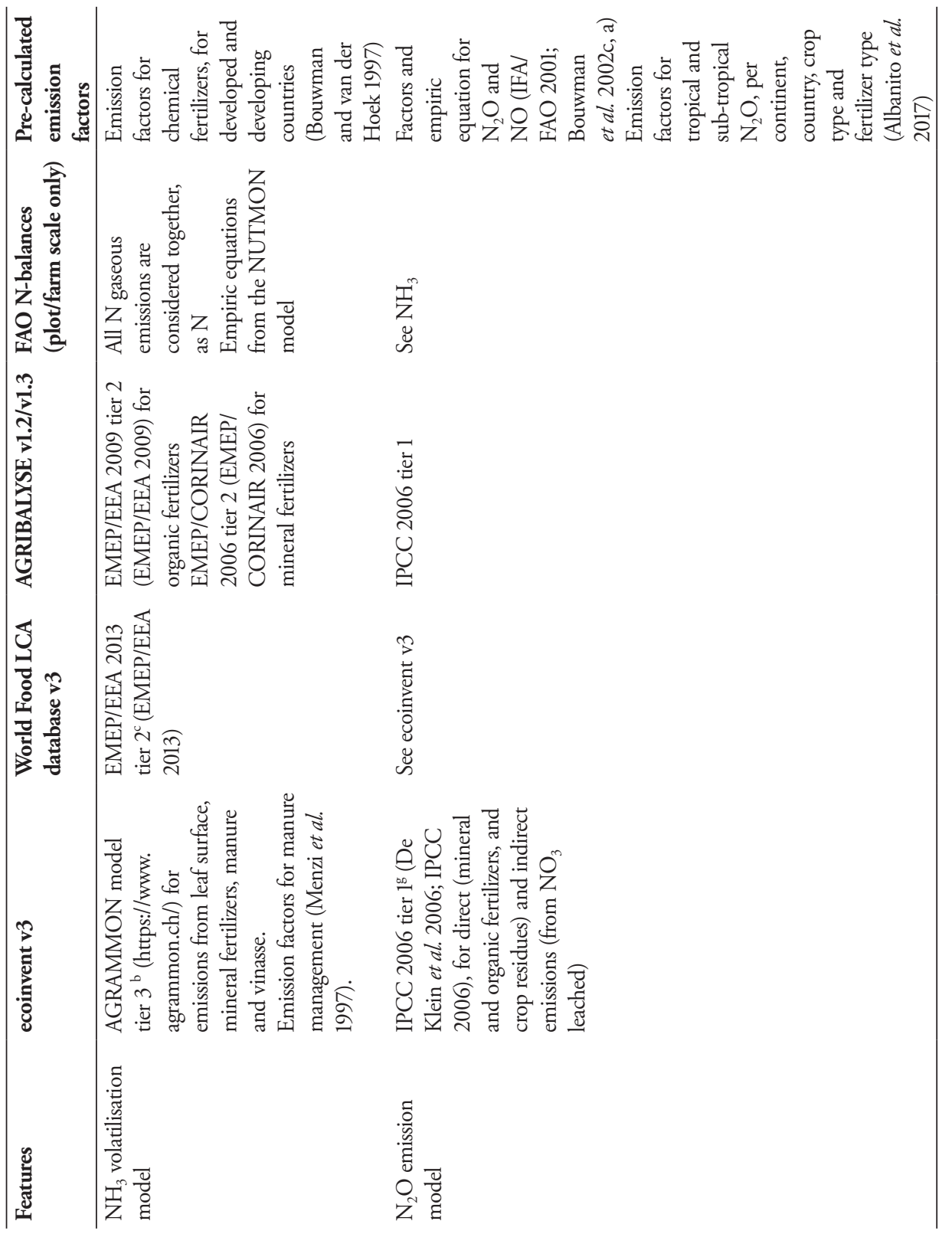




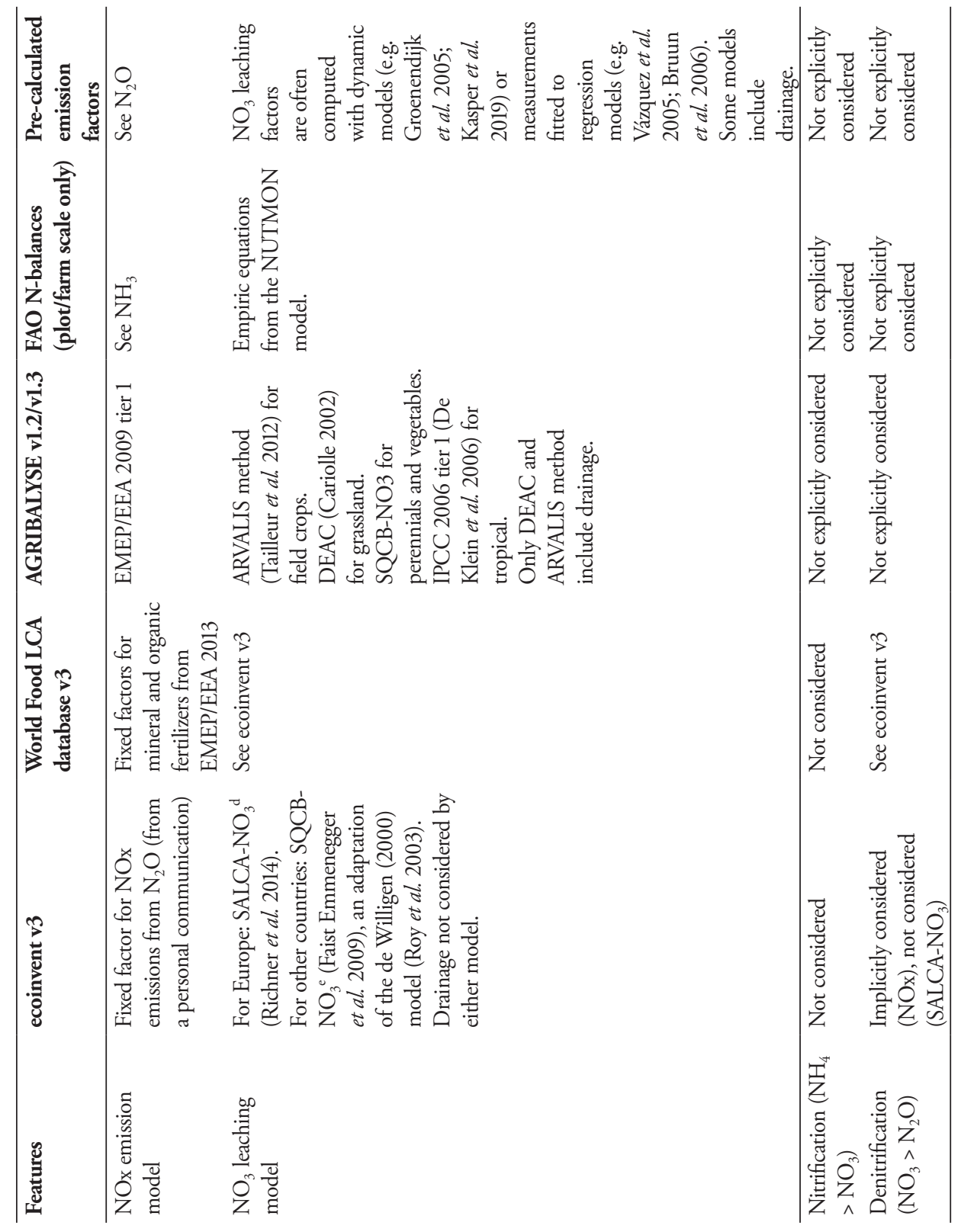




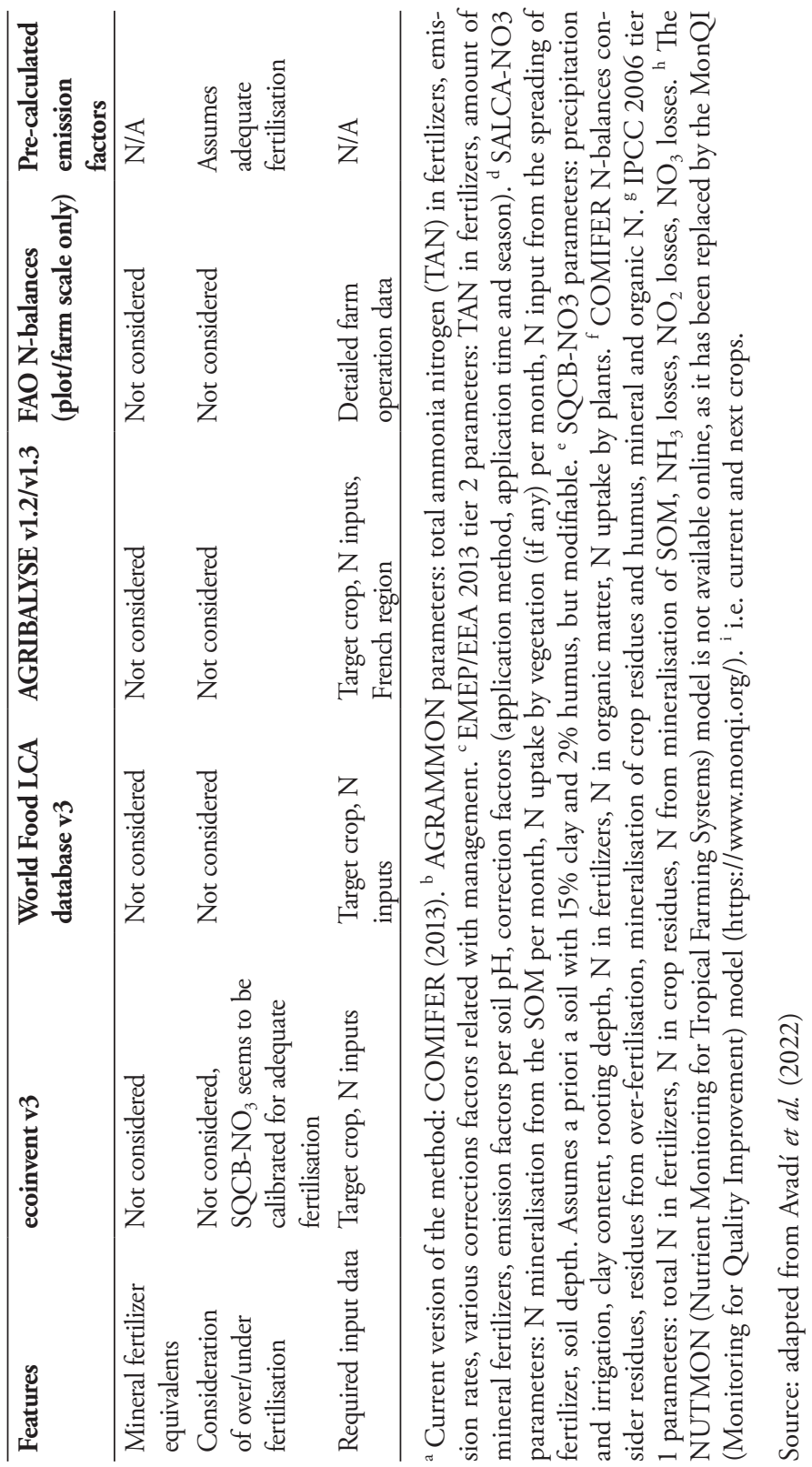




\section{Appendix C LCA resources}

I. Acosta-Alba, Evalivo

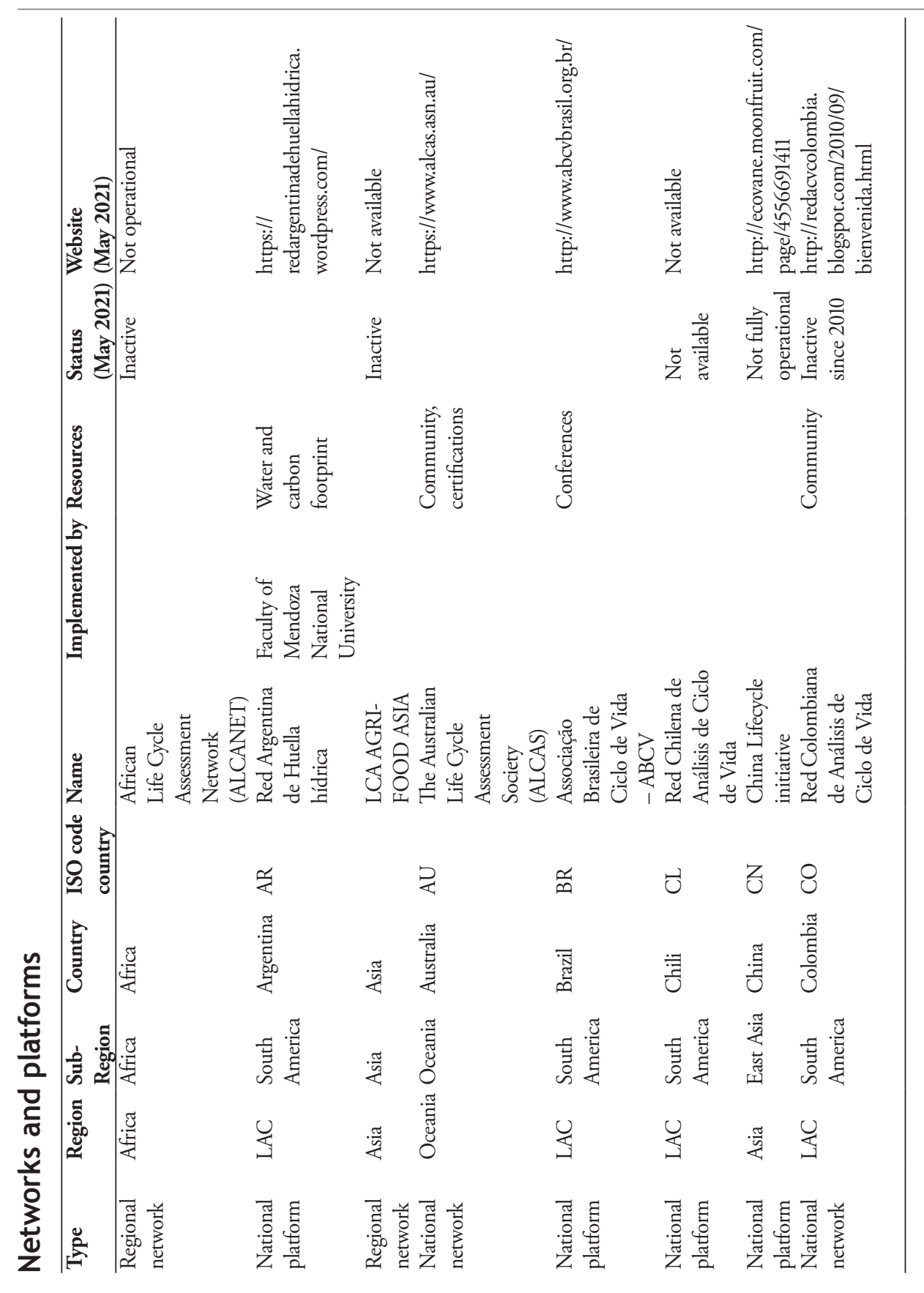




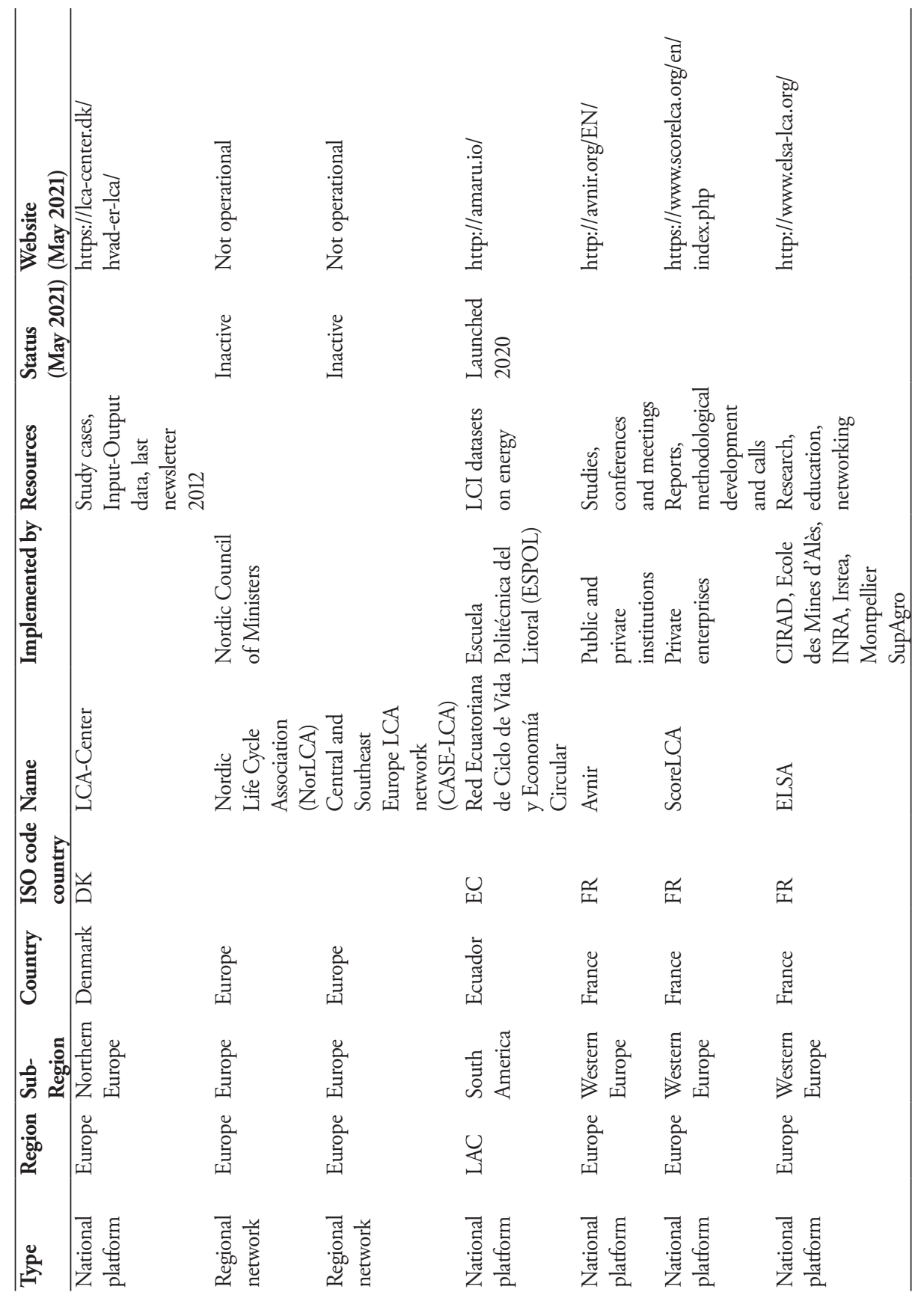




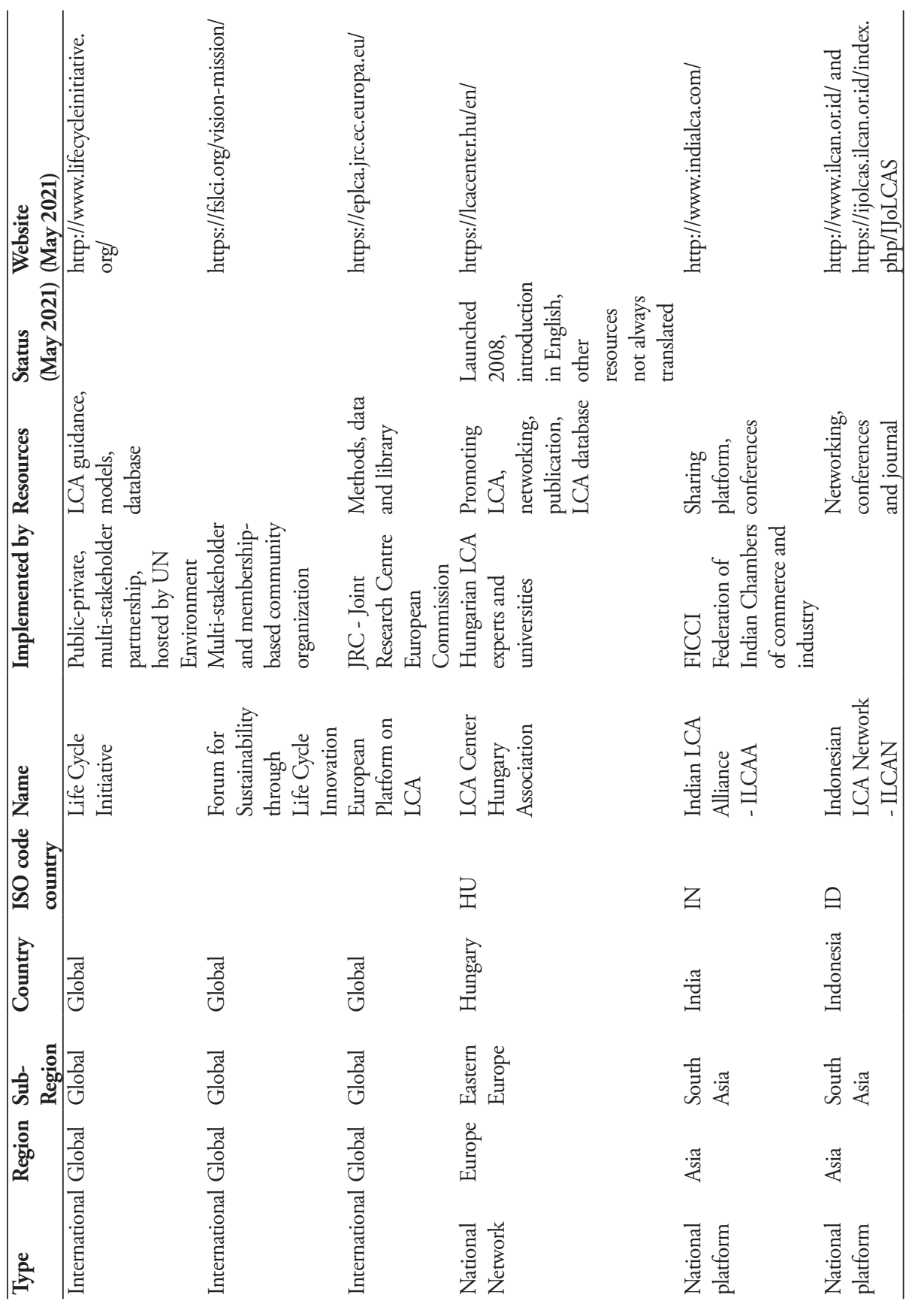




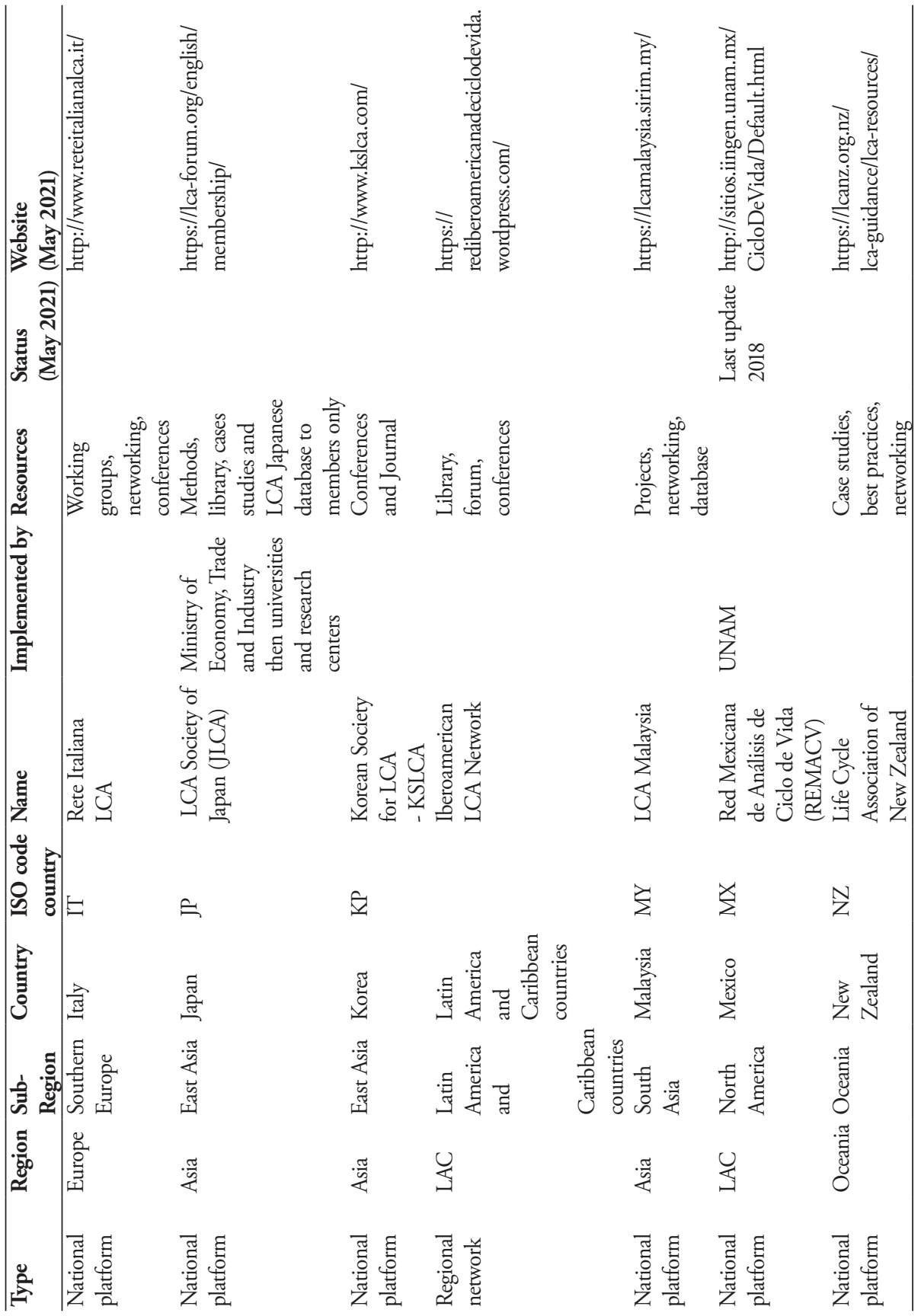




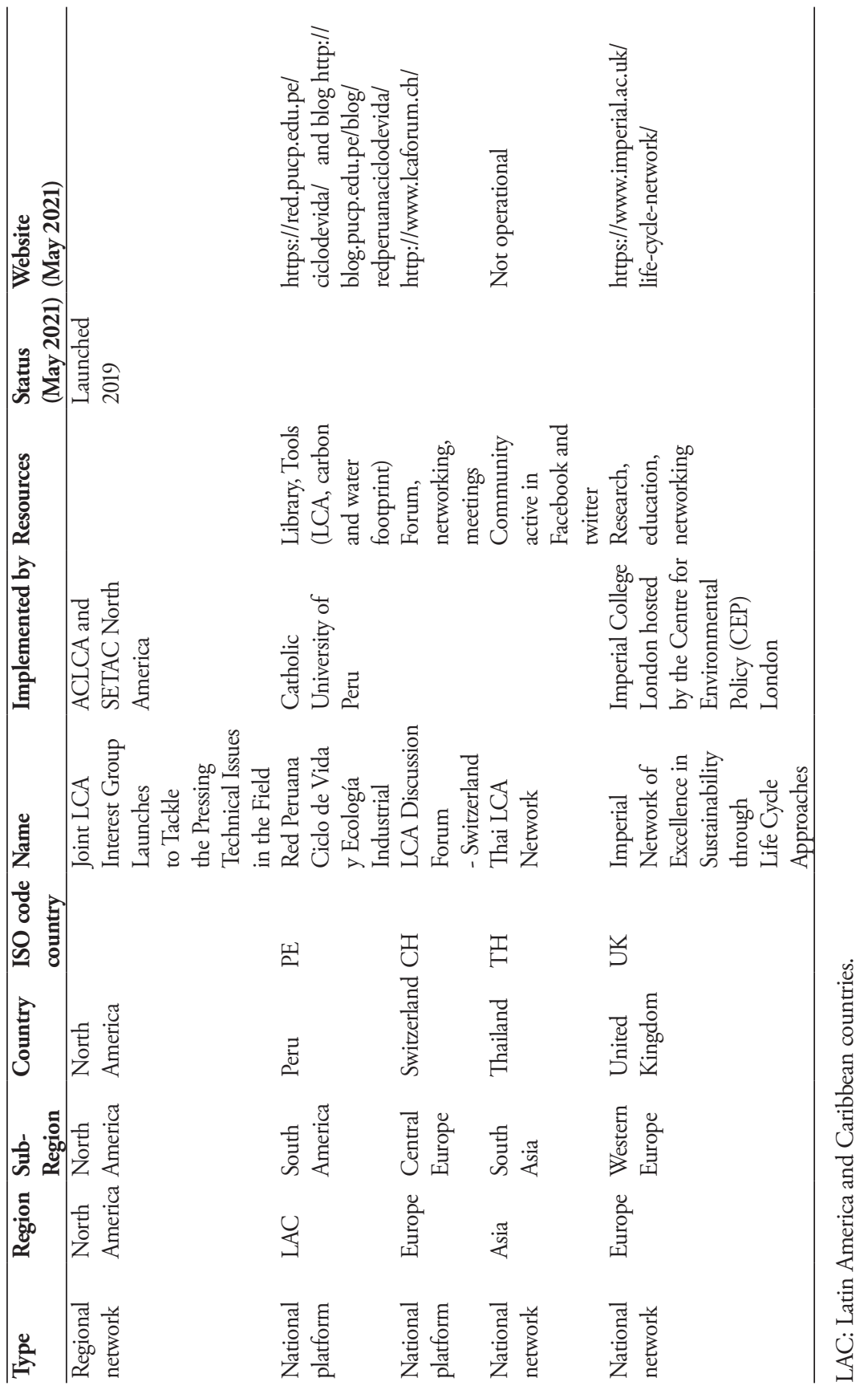




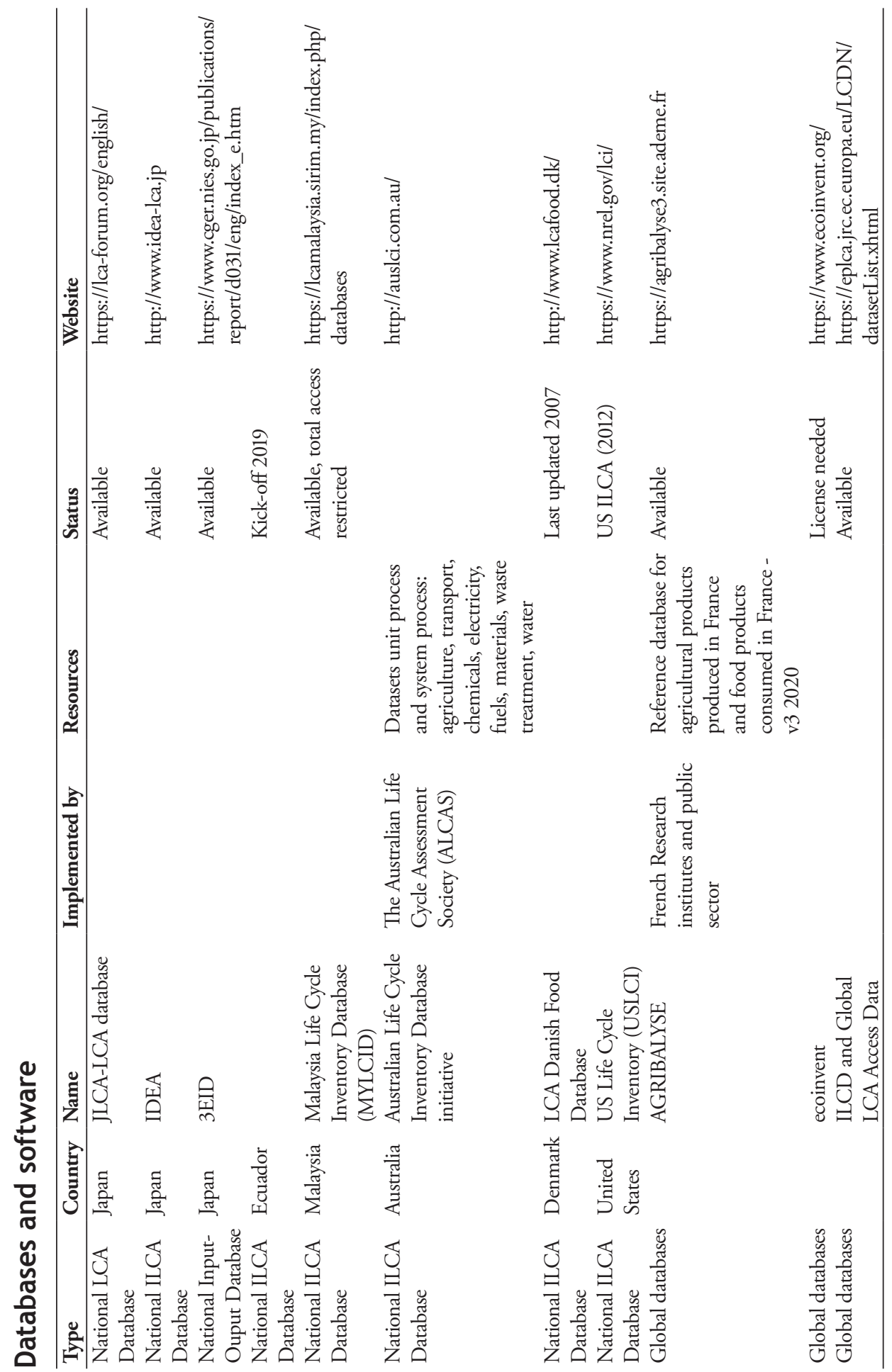




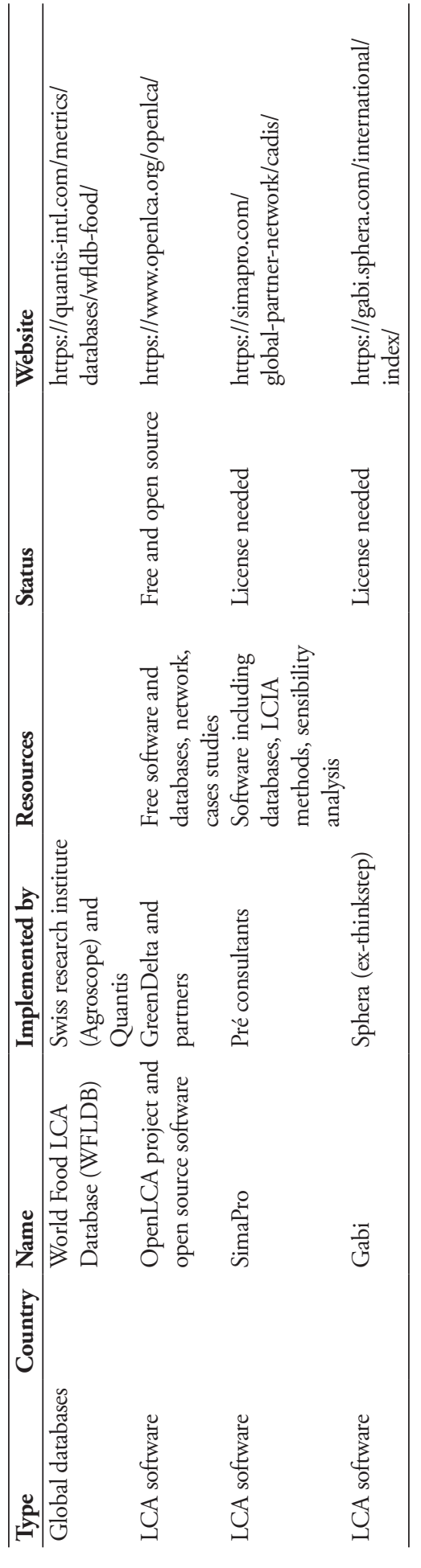




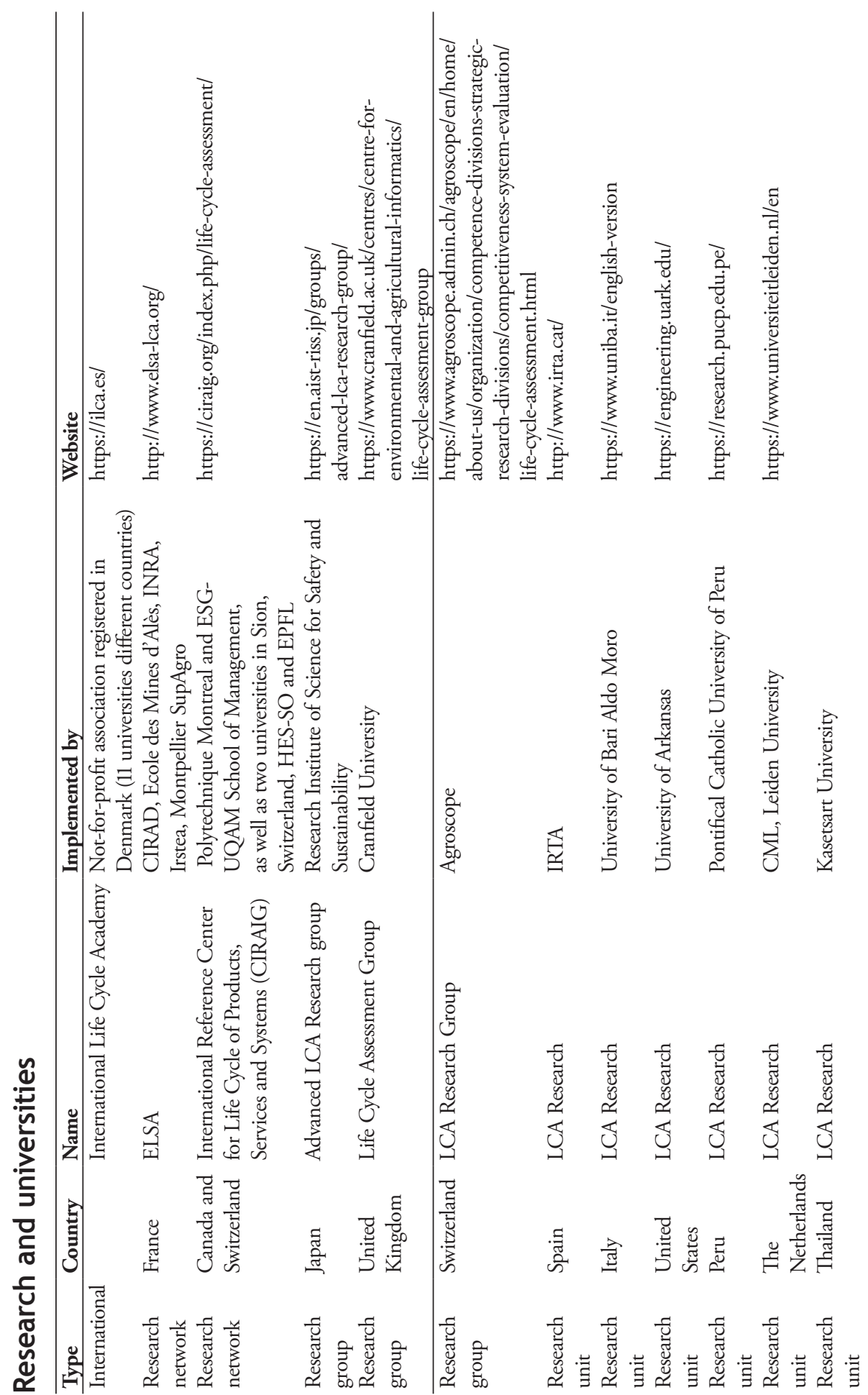




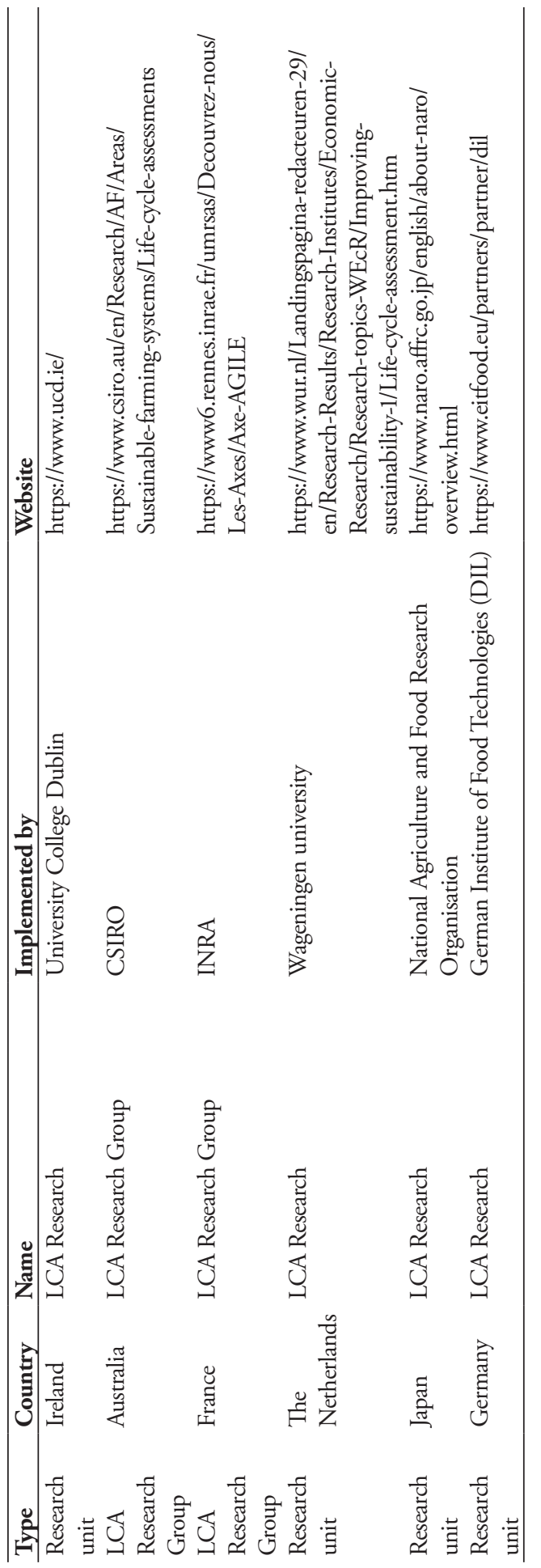




\section{Appendix \\ Data collection and confidentiality: check list and points of vigilance}

\section{Data collection and confidentiality}

Here is an operational checklist of questions to ask yourself when scoping your survey phase to conduct the LCI:

- Will you use existing databases, other than commercial LCI databases? Can you trace their origin? Is it possible to identify the producer?

- In developing your LCI datasets, do you plan to extract from third-party databases (other than commercial LCI databases)? If yes, do you have the authorization to perform these extractions? If not, it is necessary to ask for this authorization. - Will you produce a database (structure and content) with several partners for the realization of the LCIs? In this case, a co-production contract must be established and the rights and obligations of each partner on the database must be defined. - Will you be using existing datasets or structured LCI? If so, are these datasets framed by a license agreement? If so, check the terms of use in the agreement.

- Will you create datasets that are not arranged in a database? In this case, it is strongly recommended to foresee a license contract which will fix the conditions of diffusion, use, and exploitation.

- What is the purpose of the data and databases resulting from the project? Open data? valorization through expertise? licenses for restricted access to databases? If possible, it is strongly recommended to discuss these points with the partners at the beginning of the project.

\section{Points of vigilance}

Pay attention to the nature of the data you will use and produce:

- Personal data - beware of legal regulations concerning the management of personal data in the country where the study is carried out and where the data are processed (e.g. GDPR in EU)

- Confidentiality measures attached to the data

- The data protected by the intellectual property law

- The conditions for making the data available

and on project context:

- The permanence/longevity of the parties in a project (e.g. disappearance or change of status of a partner) 
Think about anticipating a disagreement during the project and the possible consequences on the data sets and databases (e.g. failure of a partner and consequences in terms of use rights on the co-produced data).

\section{Tools and best practices for data management}

A DMP is a tool to help manage data within a project. Writing a DMP at the beginning of a project allows to set up good data management practices, facilitates exchanges between partners and saves time for the publication and the reasoned sharing of data at the end of the project.

A DMP evolves over time. It is checked, reviewed and completed at different stages of the project. At a minimum: a first version at the beginning of the project, a second version at mid-term and a third at the end of the project.

The DMP answers the following questions:

- What types of data will be generated?

- What are the existing datasets that will be mobilized?

- What methodologies will be used?

- How will the data be described and documented?

- How will the data be exploited, shared and preserved?

- What legal and ethical framework will apply to the data?

- How will responsibilities be distributed?

Why write a DMP?

- Implementing good data management and documentation practices

- To guarantee the quality of research and the production of reliable and understandable data

- Contribute to the transparency, scientific integrity and reproducibility of research

- Reduce the risk of data loss or non-reusable data,

- Clarify the roles, responsibilities and rights of each contributor,

- Anticipate legal, ethical or technical problems

- Ensure the security of personal, sensitive or strategic data

- Facilitate data sharing within the group

- Anticipate the needs and costs of generating, processing, storing and sharing data

- Responding to the demand of donors.

The return on investment is the simplification of the subsequent work of valorization since your data will be ready to be deposited in a data warehouse, published and reused.

Free tools for creating DMP:

- DMP Online (Digital Curation Centre - UK): https://dmponline.dcc.ac.uk/

- Easy.DMP (Infrastructure européenne EUDAT): https://easydmp.eudat.eu/

- DMP Tool (University of California Curation Centre - US): https://dmptool. org/

- ezDMP (Interdisciplinary Earth Data Alliance 2011): https://ezdmp.org/index 


\section{Appendix E \\ Recommendations for designing a sampling protocol according to PAS 2050-1}

Source: BSi (2012).

\begin{tabular}{lllll}
\hline & \multicolumn{2}{c}{$\begin{array}{c}\text { Random sampling of growers - } \\
\text { without grouping }\end{array}$} & \multicolumn{1}{c}{$\begin{array}{c}\text { Sampling of growers after grouping } \\
\text { (for each group) }\end{array}$} \\
\hline $\begin{array}{l}\text { Total number of } \\
\text { growers }\end{array}$ & $\begin{array}{l}\text { Random sample } \\
\text { size }\end{array}$ & $\begin{array}{l}\text { Percentage } \\
\text { sampling rate }\end{array}$ & $\begin{array}{l}\text { Random sample } \\
\text { size }\end{array}$ & $\begin{array}{l}\text { Percentage } \\
\text { sampling rate }\end{array}$ \\
\hline 5 & 5 & $100 \%$ & 5 & $100 \%$ \\
10 & 9 & $90 \%$ & 9 & $90 \%$ \\
20 & 17 & $85 \%$ & 10 & $50 \%$ \\
30 & 23 & $77 \%$ & 10 & $33 \%$ \\
40 & 28 & $70 \%$ & 10 & $25 \%$ \\
50 & 33 & $66 \%$ & 10 & $20 \%$ \\
70 & 41 & $59 \%$ & 10 & $14 \%$ \\
100 & 49 & $49 \%$ & 10 & $10 \%$ \\
150 & 59 & $39 \%$ & 12 & $8 \%$ \\
200 & 65 & $33 \%$ & 14 & $7 \%$ \\
300 & 73 & $24 \%$ & 17 & $6 \%$ \\
400 & 78 & $20 \%$ & 20 & $5 \%$ \\
500 & 81 & $16 \%$ & 22 & $4 \%$ \\
1000 & 88 & $9 \%$ & 32 & $3 \%$ \\
5000 & 94 & $2 \%$ & 71 & $1 \%$ \\
\hline
\end{tabular}




\title{
Appendix F \\ Best practices for agri-food LCAs at the system level
}

\author{
A. Avadí, CIRAD
}

Box F1. Best practices for agricultural LCAs

\begin{tabular}{|c|c|c|}
\hline \multicolumn{2}{|c|}{ Challenges } & Best practices \\
\hline \multirow[t]{3}{*}{$\begin{array}{l}\text { Inclusion of } \\
\text { management- } \\
\text { related indicators }\end{array}$} & Land use change & $\begin{array}{l}\text { Model land use change associated with the studied system, } \\
\text { as carbon losses and impact on biodiversity could be significant. } \\
\text { See for instance WFLDB's use of "Land use change, [type of } \\
\text { crop], annualized on } 20 \text { years" per ha, which is included as an } \\
\text { input from nature in agricultural processes }\end{array}$ \\
\hline & $\begin{array}{l}\text { Changes in soil } \\
\text { quality }\end{array}$ & $\begin{array}{l}\text { Consider at least changes in SOC associated with land use change } \\
\text { and management changes (see Table 9.1) }\end{array}$ \\
\hline & $\begin{array}{l}\text { Effect of the crop } \\
\text { rotation on emissions }\end{array}$ & $\begin{array}{l}\text { Consider the whole crop rotation (or at least the previous and next } \\
\text { crops) regarding the allocation of direct emissions (see Table 9.1) }\end{array}$ \\
\hline \multirow{6}{*}{$\begin{array}{l}\text { Methodological } \\
\text { LCA challenges } \\
\text { in the agriculture } \\
\text { context }\end{array}$} & Selection of FUs & Contrast mass- and area-based FUs (Salou et al. 2016) \\
\hline & $\begin{array}{l}\text { Delimitation of } \\
\text { system boundaries }\end{array}$ & $\begin{array}{l}\text { - Include agricultural infrastructure and equipment, and their } \\
\text { maintenance } \\
\text { - Include on-farm manure management and organic fertilizer } \\
\text { storage. Consider non productive years for perennial crops, by } \\
\text { scaling the mean annual yield to the lifetime of the perennial system }\end{array}$ \\
\hline & Cut-off criteria & $\begin{array}{l}\text { Include ad minima inventories: fertilising and phytosanitary } \\
\text { inputs, irrigation, soil work, energy carriers, equipment and } \\
\text { infrastructure, direct field emissions, yields of products and } \\
\text { co-products. }\end{array}$ \\
\hline & Allocation strategy & $\begin{array}{l}\text { Contrast mass-, economic- and some density-based (e.g. nutrients, } \\
\text { digestible energy) allocation }\end{array}$ \\
\hline & $\begin{array}{l}\text { Selection of impact } \\
\text { categories }^{\text {a }}\end{array}$ & $\begin{array}{l}\text { - Select ad minima lists of impact categories: climate change, } \\
\text { eutrophication, acidification, etc. } \\
\text { - Include an assessment of impacts on biodiversity (Alkemade } \\
\text { et al. 2009; Jeanneret et al. 2014; Chaudhary and Brooks 2018) } \\
\text { - Include water footprints (Pfister and Bayer 2014; Boulay et al. } \\
\text { 2018) }\end{array}$ \\
\hline & Direct emissions & $\begin{array}{l}\text { Use models adapted to the specificities of the agricultural situation } \\
\text { under study (pedoclimatic conditions, type of crop, fertilisation } \\
\text { strategies), as detailed in Table } 9.1\end{array}$ \\
\hline \multirow{2}{*}{$\begin{array}{l}\text { Data availability } \\
\text { and data } \\
\text { management }\end{array}$} & Data gaps & Use data from reports, technical institutes, statistics, etc. \\
\hline & $\begin{array}{l}\text { Uncertainty } \\
\text { management }\end{array}$ & $\begin{array}{l}\text { - Data variability: create a typology of systems } \\
\text { - Data uncertainty: Horizontal averaging of unit process data } \\
\text { including estimates for uncertainty (Henriksson et al. 2013). For } \\
\text { comparative purposes, perform dependent sampling and pair-wise } \\
\text { comparisons (Henriksson et al. 2015b, a) }\end{array}$ \\
\hline
\end{tabular}

${ }^{a}$ Further details on biodiversity and water footprint methods are presented in Chapter 10. 
Box F2. Best practices for livestock LCAs

\begin{tabular}{|c|c|c|}
\hline \multicolumn{2}{|c|}{ Challenges } & Best practices \\
\hline \multirow[t]{2}{*}{$\begin{array}{l}\text { Inclusion of } \\
\text { management- } \\
\text { related } \\
\text { indicators }\end{array}$} & Land use change & $\begin{array}{l}\text { Grassland and crops of feed production for livestock have an } \\
\text { important impact over GHG balance. According to PAS 2050, } \\
\text { One-twentieth (5\%) of the total emissions from the land use } \\
\text { change should be included in the GHG emissions of products } \\
\text { in each year over the } 20 \text { years following the change in land use. }\end{array}$ \\
\hline & $\begin{array}{l}\text { Waste and } \\
\text { manure } \\
\text { management }\end{array}$ & Treatment type of animal dejections and their fate. \\
\hline \multirow{6}{*}{$\begin{array}{l}\text { Methodological } \\
\text { LCA challenges } \\
\text { in the livestock } \\
\text { context }\end{array}$} & Selection of FUs & $\begin{array}{l}\text { Contrast mass- and area-based FUs (Salou et al. 2016). Use fat and } \\
\text { protein corrected milk (Nguyen } \text { et al. 2013) }\end{array}$ \\
\hline & $\begin{array}{l}\text { Delimitation } \\
\text { of system } \\
\text { boundaries }\end{array}$ & $\begin{array}{l}\text { - Include agricultural infrastructure and equipment, and their } \\
\text { maintenance } \\
\text { - Include on-farm manure management and organic fertilizer } \\
\text { storage }\end{array}$ \\
\hline & Cut-off criteria & $\begin{array}{l}\text { Include ad minima inventories: feed provision, manure } \\
\text { management, energy carriers, equipment and infrastructure, direct } \\
\text { field emissions, yields of products and co-products. }\end{array}$ \\
\hline & $\begin{array}{l}\text { Allocation } \\
\text { strategy }\end{array}$ & $\begin{array}{l}\text { Contrast mass-, economic- and some density-based (e.g. nutrients, } \\
\text { digestible energy) allocation }\end{array}$ \\
\hline & $\begin{array}{l}\text { Selection } \\
\text { of impact } \\
\text { categories }^{\text {a }}\end{array}$ & $\begin{array}{l}\text { - Select ad minima lists of impact categories: climate change, } \\
\text { eutrophication, acidification, etc. } \\
\text { - Include water footprints (Pfister and Bayer 2014; Boulay et al. } \\
\text { 2018) }\end{array}$ \\
\hline & Direct emissions & $\begin{array}{l}\text { Use models adapted to the specificities of the livestock situation } \\
\text { under study (pedoclimatic conditions, type of livestock, feeding } \\
\text { strategies), as detailed in Table } 9.1\end{array}$ \\
\hline \multirow{2}{*}{$\begin{array}{l}\text { Data } \\
\text { availability } \\
\text { and data } \\
\text { management }\end{array}$} & Data gaps & Use data from reports, technical institutes, statistics, etc. \\
\hline & $\begin{array}{l}\text { Uncertainty } \\
\text { management }\end{array}$ & $\begin{array}{l}\text { - Data variability: create a typology of systems } \\
\text { - Data uncertainty: Horizontal averaging of unit process data } \\
\text { including estimates for uncertainty (Henriksson } \text { et al. 2013). } \\
\text { For comparative purposes, perform dependent sampling and } \\
\text { pair-wise comparisons (Henriksson et al. 2015b, a) }\end{array}$ \\
\hline
\end{tabular}

${ }^{a}$ Further details on water footprint methods are presented in Chapter 10. 
Box F3. Best practices for seafood LCAs

\begin{tabular}{|c|c|c|}
\hline \multicolumn{2}{|c|}{ Challenges } & Best practices \\
\hline \multirow{5}{*}{$\begin{array}{l}\text { Inclusion } \\
\text { of fisheries } \\
\text { management } \\
\text { concerns }\end{array}$} & Capture data & $\begin{array}{l}\text { Account for landings, discards, by-catch and on-board process } \\
\text { losses (Vázquez-Rowe et al. 2012) }\end{array}$ \\
\hline & Seafloor damage & $\begin{array}{l}\text { Account for at least distance trawled per FU (Nilsson and Ziegler } \\
\text { 2007) }\end{array}$ \\
\hline & $\begin{array}{l}\text { Biomass removal } \\
\text { impacts }\end{array}$ & Prefer less data-intensive indicators (e.g. Helias et al. 2018) \\
\hline & $\begin{array}{l}\text { Biotic resource } \\
\text { use }(B R U)^{\text {a }}\end{array}$ & $\begin{array}{l}\text { Calculate BRU (or a similar indicator of net primary } \\
\text { productivity appropriation) per FU (Avadí and Fréon 2014), } \\
\text { including all wild caught and agriculture-derived inputs to } \\
\text { processes assessed (applies also to aquaculture and seafood } \\
\text { processing) }\end{array}$ \\
\hline & $\begin{array}{l}\text { Management- } \\
\text { related indicators }\end{array}$ & $\begin{array}{l}\text { Complement LCA with indicators derived from and informing } \\
\text { fisheries management (e.g. Shin et al. 2010). Include when } \\
\text { possible data on stock assessment }{ }^{b}\end{array}$ \\
\hline \multirow[t]{6}{*}{$\begin{array}{l}\text { Methodological } \\
\text { LCA challenges } \\
\text { in the seafood } \\
\text { context }\end{array}$} & Selection of FUs ${ }^{\text {a }}$ & $\begin{array}{l}\text { - Fisheries: } 1 \text { mass unit of whole landed fish } \\
\text { - Aquaculture: } 1 \text { mass unit of whole produced fish at farm gate, } \\
1 \text { mass unit of edible portion at farm gate } \\
\text { - Seafood processing: } 1 \text { mass unit of final product, including } \\
\text { packaging; } 1 \text { mass unit of whole fish equivalent in product }\end{array}$ \\
\hline & $\begin{array}{l}\text { Delimitation } \\
\text { of system } \\
\text { boundaries a }\end{array}$ & $\begin{array}{l}\text { - Include capital goods (infrastructure, fishing vessels) and their } \\
\text { maintenance } \\
\text { - Include end-of-life in terms of material recycling and land use } \\
\text { change } \\
\text { - Model fate of by-products (e.g. on-board processing residues, } \\
\text { process water, excess heat) considering any raw materials they } \\
\text { substitute in their receiving treatment/valorisation process (e.g. } \\
\text { fish residues may partially substitute fresh whole fish in the } \\
\text { fishmeal industry) }\end{array}$ \\
\hline & Cut-off criteria & $\begin{array}{l}\text { Include ad minima inventories (Henriksson et al. 2012; Vázquez- } \\
\text { Rowe } \text { et al. 2012; Fréon } \text { et al. 2014b; Bohnes et al. 2018). } \\
\text { LCIs may be informed by indicators of efficiency, such as feed } \\
\text { conversion ratio for aquaculture and fuel use intensity for fishing } \\
\text { vessels. The use of antifouling substances should be included, } \\
\text { as it may have a large impact on biodiversity }\end{array}$ \\
\hline & Allocation strategy & $\begin{array}{l}\text { Contrast mass-, economic- and gross energy content-based } \\
\text { allocation; alternatively, treat it as choice uncertainty (Mendoza } \\
\text { Beltran et al. 2016) }\end{array}$ \\
\hline & $\begin{array}{l}\text { Selection of } \\
\text { impact categories }\end{array}$ & $\begin{array}{l}\text { - Select ad-minima lists of impact categories (Henriksson et al. } \\
\text { 2012; Vázquez-Rowe et al. 2012; Avadí and Fréon 2013; EC } \\
\text { 2018) } \\
\text { - Include seafood-specific impact categories (BRU, biomass } \\
\text { removal, etc.) }\end{array}$ \\
\hline & Direct emissions & $\begin{array}{l}\text { Aquaculture: nutrient budget modelling by means of mass } \\
\text { balances (including weight gain, feed, faeces and not consumed } \\
\text { feed, mortalities) to estimate direct emissions (e.g. Cho and } \\
\text { Kaushik 1990; Papatryphon } \text { et al. 2005) }\end{array}$ \\
\hline
\end{tabular}




\begin{tabular}{|c|c|c|}
\hline \multirow[t]{2}{*}{$\begin{array}{l}\text { Data } \\
\text { availability } \\
\text { and data } \\
\text { management }\end{array}$} & Data gaps & $\begin{array}{l}\text { - Reconstruction of missing data (e.g. fuel use) from economic } \\
\text { data (Fréon } \text { et al. } 2014 \mathrm{a}, \mathrm{b}) \\
\text { - Approximate missing values within a dataset by multiple } \\
\text { linear regression (Fréon } \text { et al. } 2014 \mathrm{a}, \mathrm{b} \text { ) } \\
\text { - Use models to calculate fuel use or seafloor area trawled from } \\
\text { fishing effort }\end{array}$ \\
\hline & $\begin{array}{l}\text { Uncertainty } \\
\text { management }\end{array}$ & $\begin{array}{l}\text { - Data variability: create a typology of systems (fishing vessels, } \\
\text { aquaculture farms) on the base of size or another defining } \\
\text { criterion (Fréon } \text { et al. } 2014 \mathrm{a}, \mathrm{b} \text { ), or even better by means of } \\
\text { statistical methods such as principal component analysis } \\
\text { (Abdou 2017) } \\
\text { - Data uncertainty: Horizontal averaging of unit process data } \\
\text { including estimates for uncertainty (Henriksson et al. 2013). } \\
\text { For comparative purposes, perform dependent sampling and } \\
\text { pair-wise comparisons (Henriksson } \text { et al. } 2015 \text { b,a) } \\
\text { - Data and choice uncertainty: Statistical or pseudo-statistical } \\
\text { methods for joint treatment (Andrianandraina 2015; Mendoza } \\
\text { Beltran et al. 2016) }\end{array}$ \\
\hline $\begin{array}{l}\text { Relation betwe } \\
\text { certifications }\end{array}$ & LCA and seafood & $\begin{array}{l}\text { Use full-fledged LCAs to provide environmental indicators } \\
\text { for and complement seafood certifications (Jonell et al. 2013) }\end{array}$ \\
\hline
\end{tabular}

${ }^{a}$ Anchoveta Supply Chains project (https://anchovetasc.wordpress.com/). For more details see Avadí and Vázquez-Rowe (2019b) and the upcoming PEFCR for marine fish for human consumption (E. Hognes, 04.2020, pers. comm.).

${ }^{b}$ Fisheries LCA would benefit from the inclusion of stock assessment data in support of the interpretation phase. Typical sources of stock assessment data include the International Council for the Exploration of the Sea (ICES, https://www.ices.dk/data/), Risk Assessment for Sourcing Seafood (RASS, https://www. seafish.org/risk-assessment-for-sourcing-seafood), the RAM Legacy Stock Assessment Database (https:// www.re3data.org/repository/r3d100012095), and reports by regional institutions dealing with aquatic resources exploitation such as the Fishery Committee for the Central Eastern Atlantic (CECAF) Stock Status Reports data collection (http://firms.fao.org/firms/en) for West African marine stocks and scientific reports such as Laë et al. (2003) for River Niger stocks. 
Box F4. Best practices for agri-food processing LCAs

\begin{tabular}{|c|c|c|}
\hline \multicolumn{2}{|c|}{$\begin{array}{r}\text { Challenges } \\
\end{array}$} & Best practices \\
\hline \multirow{6}{*}{$\begin{array}{l}\text { Methodological } \\
\text { LCA challenges } \\
\text { in the agro- } \\
\text { industrial } \\
\text { context }\end{array}$} & Selection of FUs & $\begin{array}{l}\text { Mass-based FUs including packaging, and } \\
\text { perhaps complementary FUs based on mass } \\
\text { of raw material equivalent (Avadí et al. 2014) }\end{array}$ \\
\hline & Delimitation of system boundaries & $\begin{array}{l}\text { - Include capital goods (infrastructure, main } \\
\text { equipment) and their maintenance } \\
\text { - Include end-of-life in terms of material } \\
\text { recycling and land use change } \\
\text { - Model fate of waste and by-products (e.g. } \\
\text { processing residues, process water, excess heat) } \\
\text { considering any raw materials they substitute } \\
\text { in their receiving treatment/valorisation } \\
\text { process }\end{array}$ \\
\hline & Cut-off criteria & $\begin{array}{l}\text { Include ad minima inventories: energy, energy } \\
\text { carriers, chemicals, yields and losses, packaging, } \\
\text { etc. (Pardo and Zufía 2012; Avadí et al. 2014). } \\
\text { In case of data paucity, model at least energy } \\
\text { and water consumption and waste generation } \\
\text { (Avadí 2020) }\end{array}$ \\
\hline & Allocation strategy & $\begin{array}{l}\text { Contrast mass-, economic- and some density- } \\
\text { based (e.g. nutrients, digestible energy) } \\
\text { allocation }\end{array}$ \\
\hline & Selection of impact categories ${ }^{a}$ & $\begin{array}{l}\text { - Select ad minima lists of impact categories: } \\
\text { climate change, photochemical smog, } \\
\text { eutrophication, acidification, toxicity, etc. } \\
\text { - Include water footprints (Pfister and Bayer } \\
\text { 2014; Boulay et al. 2018) }\end{array}$ \\
\hline & Direct emissions & $\begin{array}{l}\text { Consider direct waste emissions and especially } \\
\text { combustion fumes. Ideally, exhaust analyses } \\
\text { would be available, as mandated by legislation } \\
\text { in many countries. }\end{array}$ \\
\hline \multirow[t]{2}{*}{$\begin{array}{l}\text { Data availability } \\
\text { and data } \\
\text { management }\end{array}$} & Data gaps & $\begin{array}{l}\text { Use data from reports, technical institutes, } \\
\text { statistics, etc. The main agro-industrial value } \\
\text { chains (e.g. cacao, coffee, cotton, etc.) usually } \\
\text { publish national, regional or global assessments. }\end{array}$ \\
\hline & Uncertainty management & $\begin{array}{l}\text { - Data variability: validate value ranges based } \\
\text { on industrial expert opinion. } \\
\text { - Data uncertainty: Horizontal averaging } \\
\text { of unit process data including estimates for } \\
\text { uncertainty (Henriksson et al. 2013). For } \\
\text { comparative purposes, perform dependent } \\
\text { sampling and pair-wise comparisons } \\
\text { (Henriksson } \text { et al. 2015b, a) }\end{array}$ \\
\hline
\end{tabular}

${ }^{a}$ Further details on water footprint methods are presented in Chapter 10. 


\title{
Appendix G
}

\section{Free tools to model field emissions for $\mathrm{LCl}$}

\author{
C. Bessou, CIRAD
}

\section{Emission models online}

\section{IPCC models}

https://www.ipcc-nggip.iges.or.jp/public/2019rf/vol4.html

On the IPCC webpage, various tools are available either complete one (IPCC Inventory software) or disaggregated ones (Excel spreadsheets, without formulae though). Below are some useful links:

IPCC Inventory software: https://www.ipcc-nggip.iges.or.jp/software/index.html IPCC tool for estimation of SOC changes: https://www.ipcc-nggip.iges.or.jp/ public/gpglulucf/annex4al.html

IPCC worksheets to be completed with actual data and updated IPCC emission factors: https://www.ipcc-nggip.iges.or.jp/public/2006gl/vol4.html

Stehfest and Bouwman 2006 models for $\mathrm{N}_{2} \mathrm{O}$ emissions

https:/gnoc.jrc.ec.europa.eu/

\section{GHG calculators}

Cool Farm Tool (GHG/water/biodiversity indicators by Hillier et al. 2011, van Tonder and Hillier, 2014): https://app.coolfarmtool.org/account/login/

Carbon Calculation over the Life Cycle of Industrial Activities (Manchester Univ.): http://www.ccalc.org.uk/ccalc2.php 


\section{Appendix $\mathrm{H}$ \\ Detailed guidance on impact categories}

Global Warming or Climate Change impact

C. Bessou, CIRAD

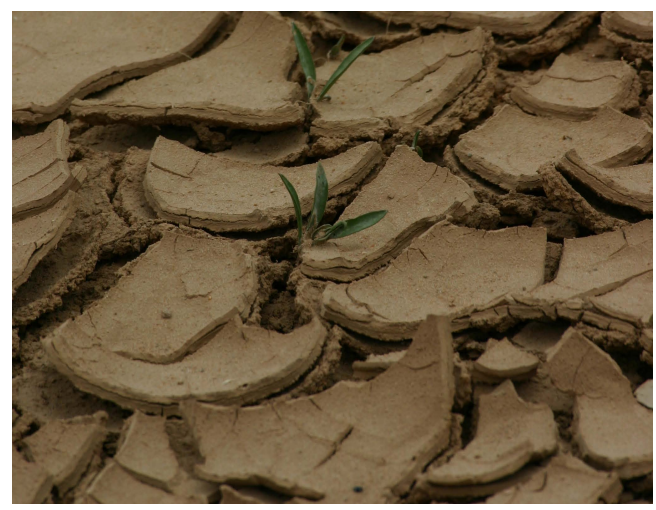

What is global warming about?

Global warming is an intensification of the natural greenhouse gas effect due to increased concentrations of greenhouse gases (GHG) in the atmosphere. GHG absorb and emit radiant energy within the infrared spectrum. The natural GHG effect maintains an average temperature on Earth around $15^{\circ} \mathrm{C}$ instead of $-18^{\circ} \mathrm{C}$. The GHG effect is hence necessary for most life on Earth. However, a significant and constant change in this average temperature can drastically change life conditions. Since the industrial era, and more definitely since the 1950s, GHG emissions have been exacerbated by human activities. As modelled and documented by the dedicated IPCC of scientific experts, given the current GHG emission levels, the global surface temperature increase by the end of the $21^{\text {st }}$ century is likely to exceed $1.5^{\circ} \mathrm{C}$ relative to the $1850-1900$ period. Such an increase will affect the ocean temperature, sea level and overall water cycle with increases in disparity between wet and dry regions, hence changing the climate (IPCC 2014). Anthropogenic GHG emissions come from the energy sector (35\%), the agriculture, forestry, LULUC (AFOLU) (24\%), the industry (21\%), transports (14\%), 
and buildings (6\%) (IPCC 2014). Almost half of the emissions from AFOLU sector are due to biomass destruction due to land use change. The other half is due to ruminant enteric fermentation $(35 \%)$, synthetic fertilizers $(20 \%)$, ruminant waste and manure management (18\%), energy (17\%) and paddy rice (10\%) (IPCC 2014). Given the significant contribution of agriculture to global warming, many LCA of agricultural products have focused on the global warming impact and attempt to provide improvement tracks towards climate change mitigation.

\section{State of the art on available methods, uncertainty aspects, validity domains}

Global warming is a global phenomenon whereby GHG emitted in various places and times are mixed up together in the atmosphere. This global scale fits well with the LCA framework that requires to integrate in a snapshot operations and emissions occurring at different places and times along the value chain. By essence, the validity domain of global warming assessment is global, unlike for more site-specific impacts such as eutrophication, where regional CFs are needed to narrow the validity domain to the relevant impact scale.

The modelling of global warming midpoint impact in LCA is the cumulative GWP due to all GHG emitted within the studied system boundaries. Calculation method consists, first, in inventorying all masses of GHG emitted per GHG type; second, summing their contributions to the overall radiative forcing (RF) according to each GHG RF relative to $\mathrm{CO}_{2}$. The result is given in $\mathrm{CO}_{2}$-equivalent $\left(\mathrm{CO}_{2 \mathrm{eq}}\right)$ per FU and represents the added RF, or enhanced GHG effect, due to the added GHG in the atmosphere per FU.

Main GHG emitted by the AFOLU sector are $\mathrm{N}_{2} \mathrm{O}$ (88\% of total anthropogenic $\mathrm{N}_{2} \mathrm{O}$ emissions), $\mathrm{CH}_{4}$ (47\% of total anthropogenic $\mathrm{CH}_{4}$ emissions), and $\mathrm{CO}_{2}(9 \%$ of total anthropogenic $\mathrm{CO}_{2}$ emissions). For more information on models available to inventory GHG emissions related to the AFOLU sector (see Chapter 9 section "Foreground data collection"). The RF and GWP of all GHG are regularly updated by IPCC, based on updates on radiative efficiencies and the modelling of the residence time of each GHG in various layers of the atmosphere against a given background $\mathrm{CO}_{2}$ concentration. The residence time, or the evolution of GHG concentrations in atmosphere over time, is influenced by various factors including physico-chemical reactions and sources-sinks equilibrium. The Bern carbon cycle model (Bern2.5CC; Joos et al. 2013) is used by IPCC to determine the $\mathrm{CO}_{2}$ response function, i.e. the increased RF due to a pulse of $\mathrm{CO}_{2}$ added to background concentration according to its decay over time. Absolute GWP (AGWP) are derived from the RF of each GHG that is integrated over a fixed time horizon $(\mathrm{H})$, i.e. a fixed decay period considered as a mean residence time for all GHG (Figure H1a). The AGWP of a given GHG over that of $\mathrm{CO}_{2}$ is used as the midpoint $\mathrm{CF}$ for a given GHG and expressed in $\mathrm{CO}_{2 \text { eq. }}$. Hence the GWP of a given GHG will depend on both the time horizon $(\mathrm{H})$ for the integration of the RF and its relative contribution to global RF compared to $\mathrm{CO}_{2}$. 
Going one step further down the cause-effect chain, the IPCC modelling of global temperature change potential (GTP) (Figure H1b) is then used in LCA to calculate the contributions of global warming to the endpoint damages. For example, in ReCiPe 2016 (Figure H2), endpoint damages are based on regressions between changes in temperature and, on the one hand, impacts on Human health as affected by increased risks of flooding and associated diseases (De Schryver et al. 2009), and on the other hand, impacts on species abundances as affected in both terrestrial (Goedkoop et al. 2009; Urban 2015) and freshwater ecosystems (Goedkoop et al. 2009; Hanafiah et al. 2011).
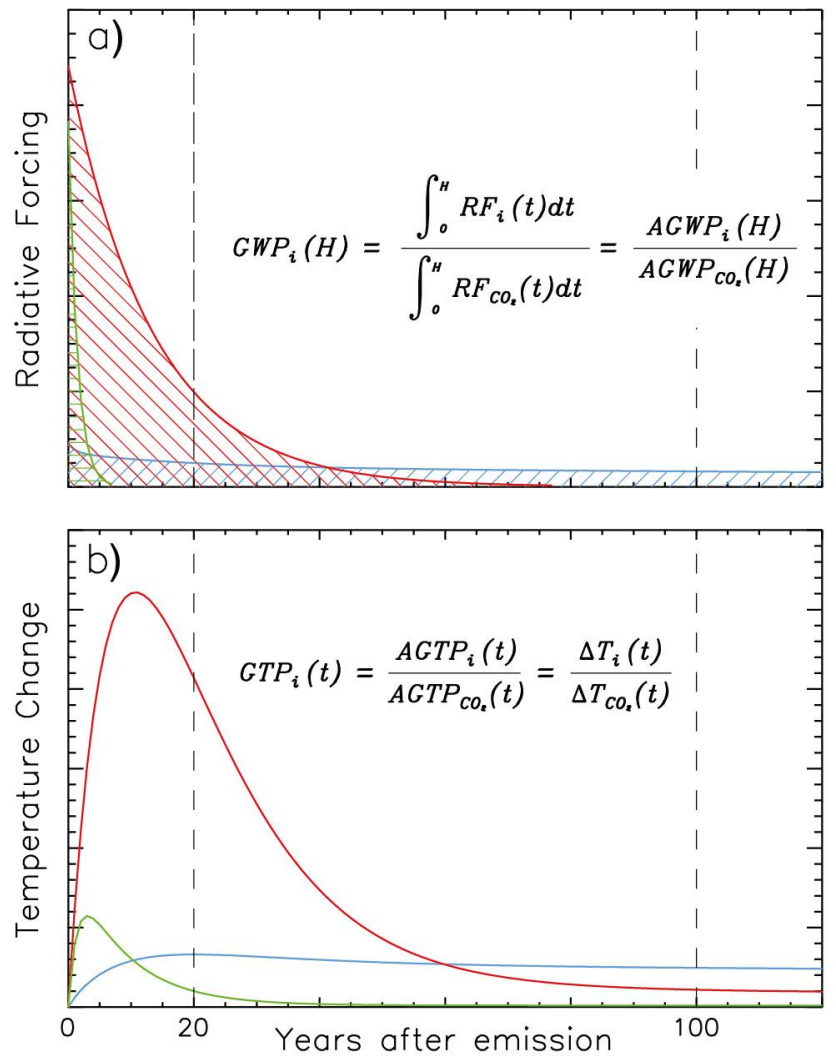

Figure H1. (a) The Absolute Global Warming Potential (AGWP) is calculated by integrating the radiative forcing (RF) due to emission pulses over a chosen time horizon; for example, 20 and 100 years (vertical dashed lines). The GWP is the ratio of AGWP for component i over AGWP for the reference gas $\mathrm{CO}_{2}$. The blue hatched field represents the integrated RF from a pulse of $\mathrm{CO}_{2}$, while the green and red fields represent example gases with 1.5 and 13 years lifetimes, respectively. (b) The global temperature change potential (GTP) is based on the temperature response at a selected year after pulse emission of the same gases; e.g. 20 or 100 years (vertical dashed lines). Source: IPCC (2013). 


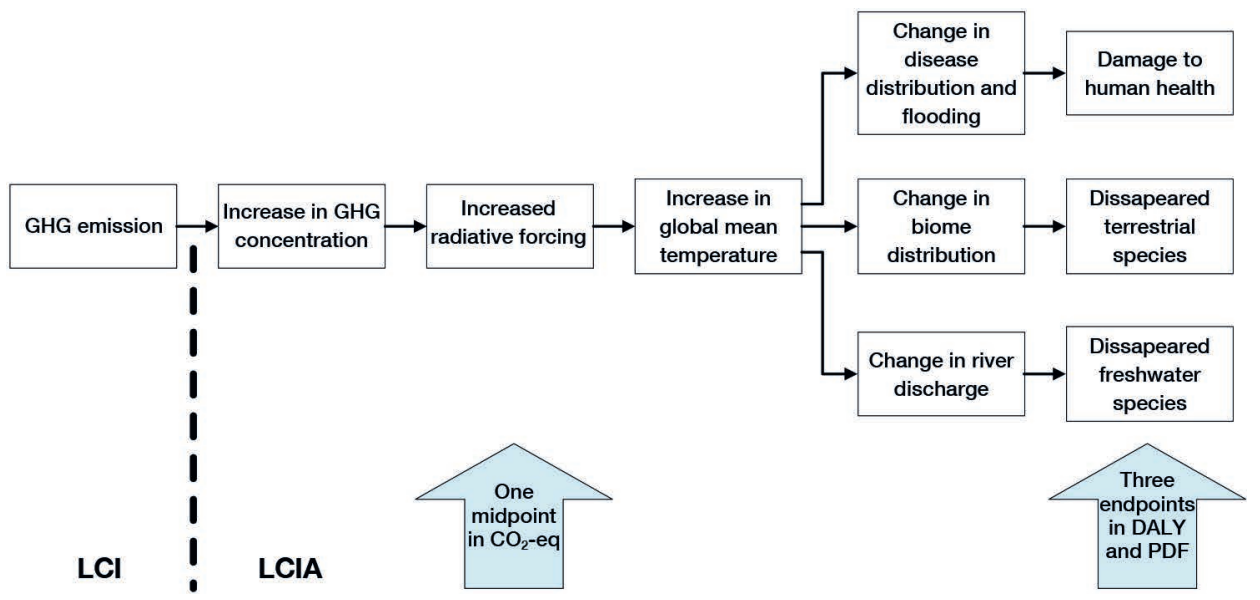

Figure H2. Modelling of midpoint and endpoints ( $\mathrm{LCIA}$ ) related to $\mathrm{GHG}$ emissions $(\mathrm{LCl})$ according to RECIPE 2016. Source: adapted from Huijbregts et al. (2016).

There are several sources of uncertainties in the modelling of both GWP and GTP. The first source of uncertainty is due to the incomplete accounting of all involved mechanisms, known and unknown. The second source of uncertainty relates to the choice of the time horizon that embeds uncertainty regarding future society choices and influenced mechanisms.

The uncertainties for global warming metrics of all GHG are determined by imperfections in the modelling of lifetime and radiative efficiency, being notably sensitive to the carbon cycle model, pulse size and background $\mathrm{CO}_{2}$ concentrations and climate. Moreover, not all indirect effects are known or modelled in a robust enough way to be accounted for. Compared to the previous GWP versions, indirect effects on $\mathrm{O}_{3}$ and stratospheric $\mathrm{H}_{2} \mathrm{O}$ due to $\mathrm{CH}_{4}$ were included, but the indirect effect of $\mathrm{N}_{2} \mathrm{O}$ on the RF of stratospheric $\mathrm{O}_{3}$ was not due to too large uncertainties (IPCC 2013).

The propagated uncertainty ranges were estimated to be $\pm 26 \%$ for $\mathrm{CO}_{2}-\mathrm{AGWP}_{100}$ or $\pm 40 \%$ for $\mathrm{CH}_{4}-\mathrm{GWP}_{100}$, for instance. For $\mathrm{GTP}_{100}$, those uncertainty ranges were higher, i.e. $\pm 75 \%$ for $\mathrm{CH}_{4}-\mathrm{GTP}_{100}$. Uncertainties for GTP are higher as the modelling is more complete towards causal effect and include the ocean heat uptake and climate sensitivity, further factors with embedded uncertainty (IPCC 2013). By construction, GWP and GTP are significantly different in terms of time accounting; GWP is integrated in time, whereas GTP is an endpoint metric based on temperature change for a given year. In both cases, nevertheless, "the time horizon has a strong effect on the metric values and the calculated contributions to warming" (IPCC 2013). 
Recommendations based on international consensus (e.g. by UNEP-SETAC GLAM)

The recommended consensual method for global warming midpoint impact is the used of IPCC GWPs as CFs. This method relies on robust modelling of main processes involved as carried out by an internationally recognized groups of researchers. Moreover the modelling outputs are revised every 4-5 years in order to account for changes in initial modelling conditions, which ensure the up-todate relevance of derived factors.

Metrics with carbon feedback included should be used as they are more consistent with the modelling of metrics related to $\mathrm{CO}_{2}$, the common denominator for other GHG metrics.

The default timeframe should be 100 years, i.e. GWP integrated over 100 years, as it was adopted by the United Nations Framework Convention on Climate Change and made operational in the 1997 Kyoto Protocol. There is no scientific argument for selecting 100 years compared with other choices, this choice is a value judgement whose influence on final results might be tested, should the LCA study particularly focus on prospective analysis of climate change.

Regarding the endpoint modelling, we recommend the ReCiPe 2016 method for mostly two reasons: (1) it makes use of the latest IPCC information on the GTPs; (2) it ensures consistency between midpoint and endpoint modelling, while making it possible to test the sensitivity to the time horizon considered as embedded in the three proposed social perspectives: individualist, hierarchist, or egalitarian.

\section{Operational aspects (included in LCA software)}

The global warming or climate change impact is an historical impact indicator in LCA and has been available in LCA software probably since their very first release. LCIA methods based on IPCC are available as single issue or embedded in more complete LCIA methods. CFs are updated regularly when new versions are released by IPCC and software updated. The list of up-to-date GWP CFs are provided in IPCC (2013): GWP and GTP with and without inclusion of climate-carbon feedbacks (cc fb) in response to emissions of the indicated non-CO2 gases (climate-carbon feedbacks in response to the reference gas $\mathrm{CO}_{2}$ are always included).

\section{General recommendations / warnings on links between inventory flows and impact assessment in relation to software}

GHG emissions are generally keyed in in LCA software as flows to the air; the sub-compartment does not play any role as the $\mathrm{CF}$ s integrate different atmosphere layers at global scale. Attention must be paid to calibrate emissions according to the molecular weights of the considered gases, as emission models commonly provide outputs with relation to the main molecular compound, e.g. $\mathrm{kg} \mathrm{N}-\mathrm{N}_{2} \mathrm{O}$ needs to be converted into $\mathrm{kg} \mathrm{N}_{2} \mathrm{O}$ by multiplying by $44 / 28$. 
In agricultural LCA, attention must be paid to the link between LULUC and GHG emissions. At LCI level, calculations based on IPCC Tier 1 stock-difference method, provide GHG flows over a given period of time defined to allocate the impact of change. In the case of land management practices, the change can occur over one year or more. In the case of land use change, the common timeframe for the impact allocation is 20 years or more, depending on the land uses considered. The 20-year timeframe is considered to be the minimum time needed for a new carbon stock equilibrium to be reached. Impact allocation can be linear uniform as applied in IPCC guidelines or linear digressive as recommended by ILCD. The time period and allocation methods should be made transparent and sensitivity analysis may be carried out on those parameters. Stocks and flows considered should encompass all pools affected (biomass above- and below-ground, soil organic carbon (SOC), etc.). $\mathrm{N}$ mineralisation should also be considered if land use change implies loss of SOC, since $\mathrm{N}$ will be decomposed together with the affected carbon in relation with the $\mathrm{C} / \mathrm{N}$ signature of decomposers. When applying IPCC and IPCC-derived methods, biogenic carbon loss or storage is attributed the same CF as for fossil carbon. Other methods propose other approaches (see next section).

Besides LULUC, there are other sources of biogenic GHG, notably $\mathrm{CH}_{4}$ emissions from waste water management due to the anaerobic decomposition of biogenic carbon compounds. Anaerobic ponds are quite common in the tropics where temperature is sufficient to ensure treatment efficiency with limited input costs. IPCC also provide guidelines to inventory GHG related to water treatment. Because $\mathrm{CH}_{4}$ has a higher GWP than $\mathrm{CO}_{2}$, it is important to ensure mass balance in the assessment and retrieve from the $\mathrm{CH}_{4} \mathrm{GWP}$ the contribution from the $\mathrm{C}-\mathrm{CO}_{2}$ within $\mathrm{CH}_{4}$ that is cancelled out by the fixation of atmospheric $\mathrm{CO}_{2}$ in the first place (2.75 $\mathrm{kg} \mathrm{CO}_{2} / \mathrm{kg} \mathrm{CH}_{4}$ based on molecular weights). In this case, the $\mathrm{CF}$ of biogenic $\mathrm{CH}_{4}$ shall be modified depending on the LCIA method selected and background assumptions on CF.

\section{Updated research propositions}

In recent years, many authors have explored ways to introduce more sophistication in the GWP calculation within the LCA framework in relation to two main aspects: the dynamics of GHG emissions and the accounting for biogenic carbon specificities in terms of global warming contribution. Both aspects were often connected at the origin of method development. Some recent studies propose comprehensive synthesis of the work published by those authors, highlighting common as well as divergent conceptual starting points (Figure H3) (Benoist and Bessou 2018; Breton et al. 2018; Brandão et al. 2019). 


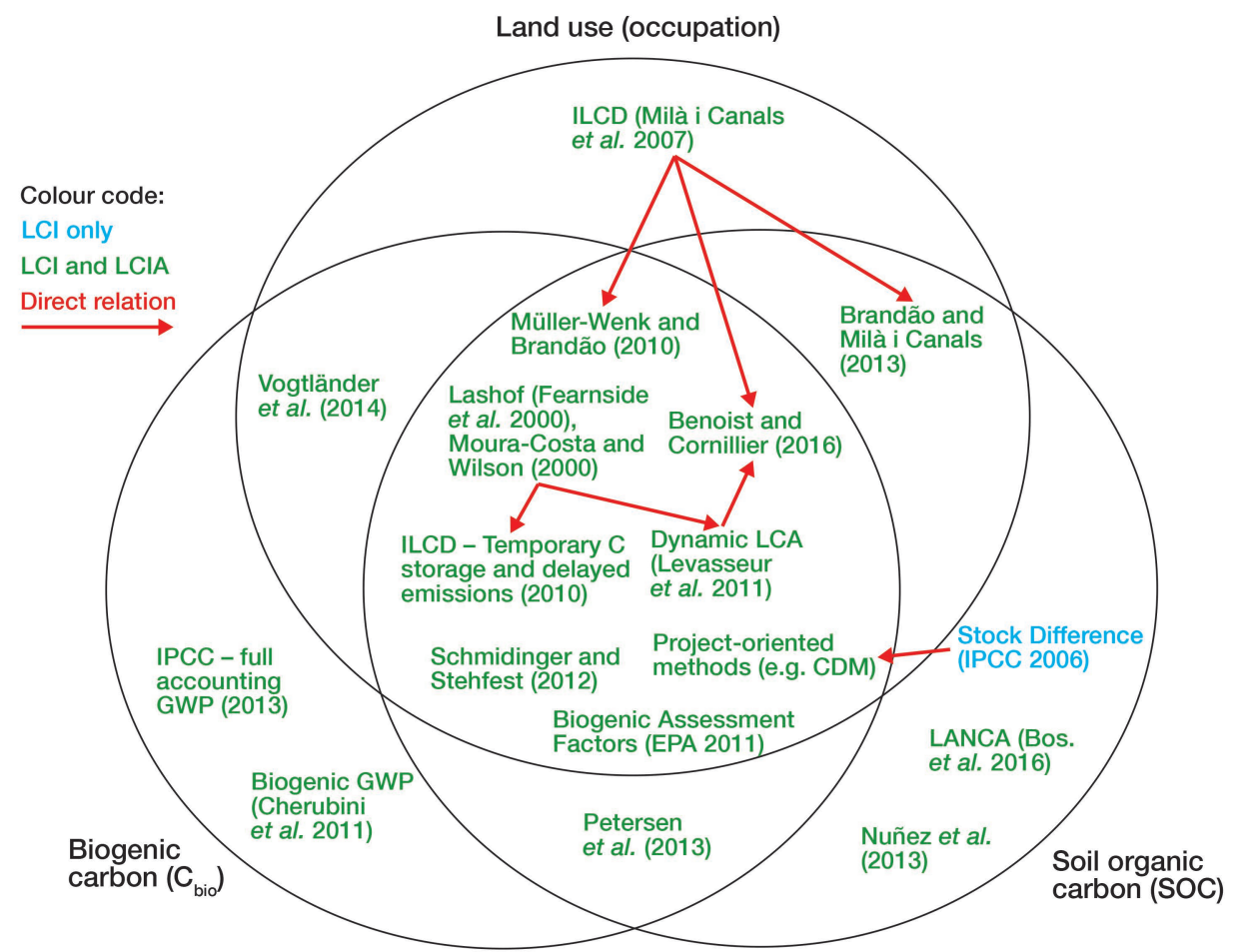

Figure H3. Mapping of methods linking biogenic carbon, soil organic carbon (SOC), and land use with climate change. Source: Albers (2019), adapted from Benoist and Bessou (2018).

First, some authors argue that the 100 -year time horizon is not consistently applied when using fixed $\mathrm{GWP}_{100}$, whereas emissions may occur at different time points along the value chain (e.g. Levasseur et al. 2012). The principle of dynamic LCA is to integrate varying GWP over the remaining time horizon from the emission point in time to the fixed 100-year horizon; the first emission considered within the system boundary is used to set this fixed 100-year horizon. This dynamic approach is interesting in the AFOLU sector in order to mimic better the dynamics of GHG uptake and release by plants depending on land use types and management practices. However, dynamic LCA is difficult to apply both for background processes where information on emission timing may not be available at all and for foreground processes as precise data from modelling work over several years may be needed. Furthermore, the change in the time integration is equally arguable from a consistency point of view. First, LCA snapshot by definition integrates all processes and fluxes in a virtual time point. Second, albeit the use of a 100-year horizon is more consistent with dynamic LCA as a fixed limit for all accounting, dynamic GWP imply that GHG emissions within the system occurring close to the 100-year limit would have a lower impact than those occurring at the beginning of the time period study. With fixed $\mathrm{GWP}_{100}$, the impact of a GHG is the same no matter when the GHG is emitted. The 
latter may be more consistent with the actual contribution of GHG to the global warming, especially for well-mixed long-lived GHG.

Second, somehow connected with the previous issue of emission timing that is critical for biosphere-atmosphere exchanges, some authors try to account better for the specificities of biogenic GHG emissions in the GWP calculation. In some articles, authors calculate biogenic GWP modifying the integration of the Bern carbon cycle model (e.g. Cherubini et al. 2011), which require many assumptions on the biosphere dynamics and climate functioning that somehow overlap with IPCC background work. Other authors have a more LCA practical approach and propose weighting of biogenic GWP compared to fossil GWP according to different residence times in the atmosphere (e.g. Müller-Wenk and Brandáo 2010). The latter approach is applied within the LCA land use framework and connect LCI fluxes on land use occupation and transformation to the global warming impact. Although this method relies on some simplified assumptions and extrapolated data on stocks and regeneration time for biogenic carbon, it bridges LCI and LCIA in the case of land use impact on global warming or climate change. Finally, in even more recent years, authors have worked on including the albedo contribution to global warming impact in LCA. Albedo can play an important role in global warming through changes in the reflectance of solar radiation and conversion of short wavelengths into long ones. The accounting for albedo effect within LCA has been made possible notably by recent works that provide keys to convert albedo effect into $\mathrm{CO}_{2 \text { eq }}$ (e.g. Bright et al. 2012). Moreover, the assessment of albedo effect through the analysis of land use change, i.e. compared to a reference, may be suitable to account for changes in albedo. Very recent works were based on remote sensing analysis to investigate albedo changes with relation to various crops, whose impacts can be complemented based on traditional agricultural LCA (e.g. Sieber et al. 2020). More work is still ongoing in order to account better for practices impacts (e.g. cover crop, afforestation, etc.) given that albedo changes may be seasonal (e.g. large snow effect) and complex to quantify. 


\section{Soil quality impact}

\section{Bessou, CIRAD}

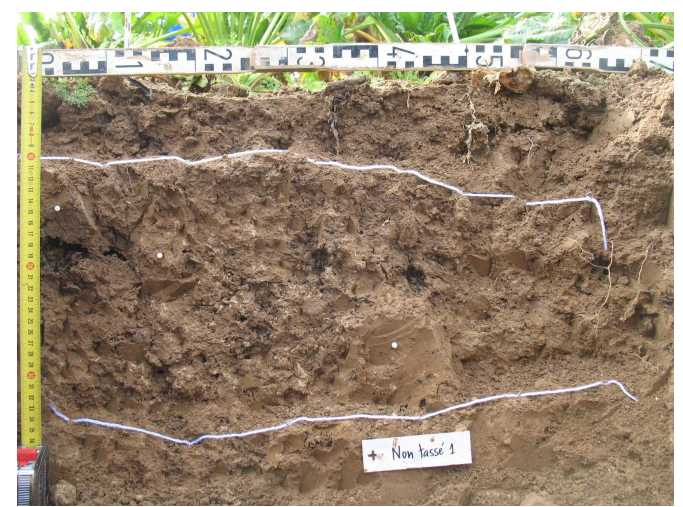

What is soil quality about?

Soil quality is a complex matter, whose definition has long been discussed. It was initially mostly related to fertility aspects, hence its suitability for agricultural purpose. By the end of the 90s, with the increasing awareness on environmental issues related to agricultural land use and the development of new knowledge on ecosystems, more comprehensive approaches of soil quality were developed. The current most common definition is: "Soil quality is the fitness of a specific kind of soil to function within its surroundings, support plant and animal productivity, maintain or enhance water and air quality, and support human health and habitation" (Karlen et al. 1997). Emphasis is put on both inherent properties of soil ("a specific kind of soil") and dynamic interactive processes (Larson and Pierce 1991). Following the metaphor of a complex living "organism", soil health is also used by some authors instead of soil quality. Soil quality is hence defined as the soil fitness for use (Patzel et al. 2000). It must be assessed in a sensitive and holistic way that accounts for both inherent properties and dynamic responses to management and resistance to environmental stress.

\section{State of the art on available methods, uncertainty aspects, validity domains}

Given its inherent complexity, soil quality cannot be measured directly. Instead, proxy indicators are commonly used. Various methods exist with different degrees of measurability and integration and there is little agreement on a harmonized framework (Nortcliff 2002). Within the LCA community, a preliminary consensus was reached in 2007 on a framework accounting for land use impact on soils (Milà i Canals et al. 2007) and derived approach to soil quality assessment (Koellner et al. 2013b, a). However, it is limited to SOC assessment and fails to 
assess distinct soil functions. The JRC European Platform on LCA's recent review on land-use and soil impacts in LCA showed that none of the existing methods is optimal, although various methods offer various interesting indicators (Table $\mathrm{H} 2$ ). Among key issues are the difficulties to find trade-offs between comprehensiveness in covering soil quality versus applicability, to decide on the indicators, and the needed detail level (Vidal Legaz et al. 2016). These difficulties persist due to the lack of a comprehensive framework addressing the inherent complexity of soil quality and the lack of model implementation in LCA.

As discussed by several authors, given our limited understanding of all mechanisms involved in soil quality, assessing the resulting soil functions instead of trying to model all mechanisms and actors behind may be the most efficient track to pursue in order to assess soil quality, at least in relative terms (Kibblewhite et al. 2008; Thoumazeau et al. 2019). In the latest UNEP-SETAC recommendations (UNEP 2016), emphasis was put on such an integrated approach of soil quality (Figure H4). Soil characteristics changes due to human intervention were linked with changes in four key soil functions (Kibblewhite et al. 2008) and ecosystem services further down the impact chain that are mostly conditioned by soil quality (Dominati et al. 2010; Adhikari and Hartemink 2016; Cowie et al. 2018).
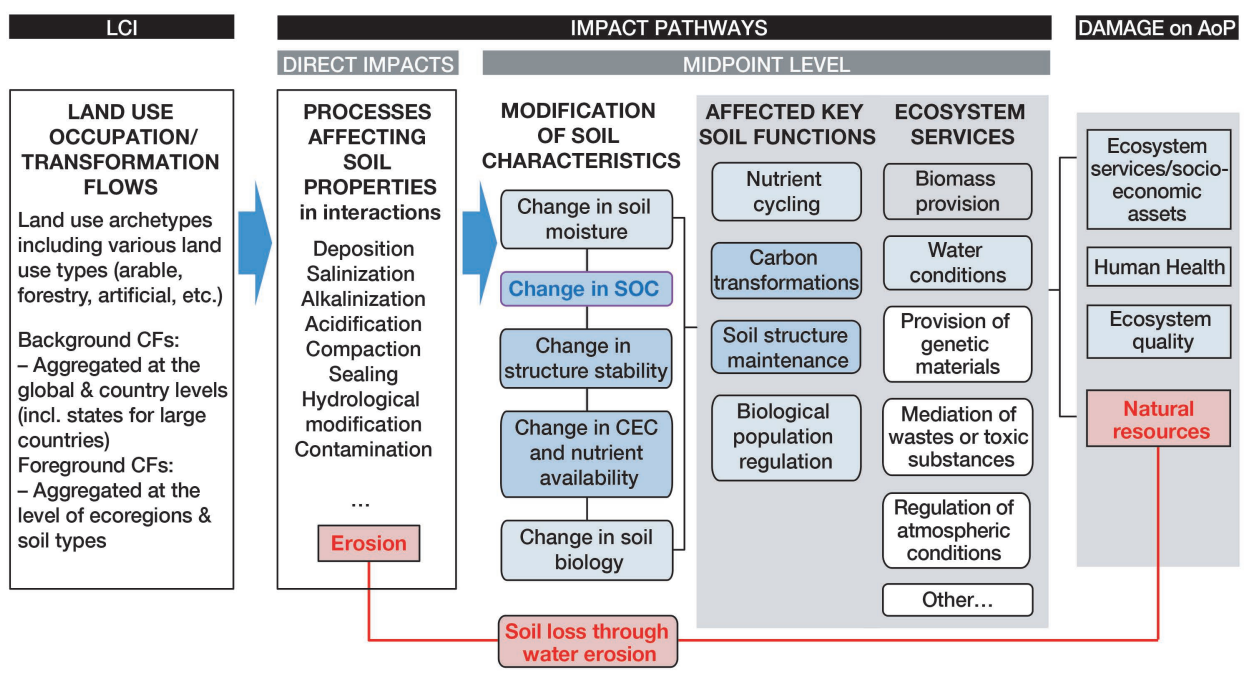

Figure H4. Impact pathway of land use impact on soil quality and soil loss through water erosion. Source: UNEP (2016). 


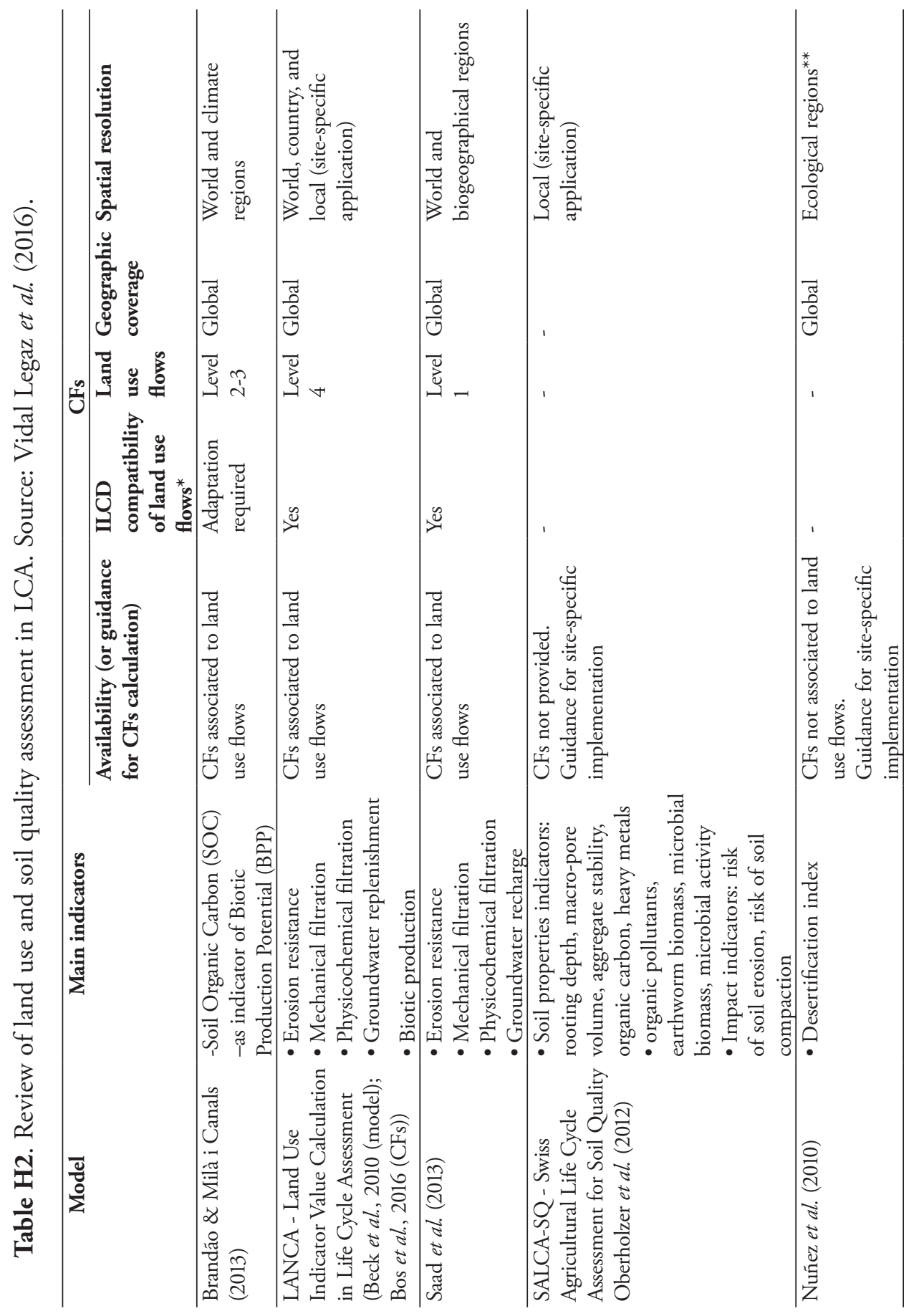




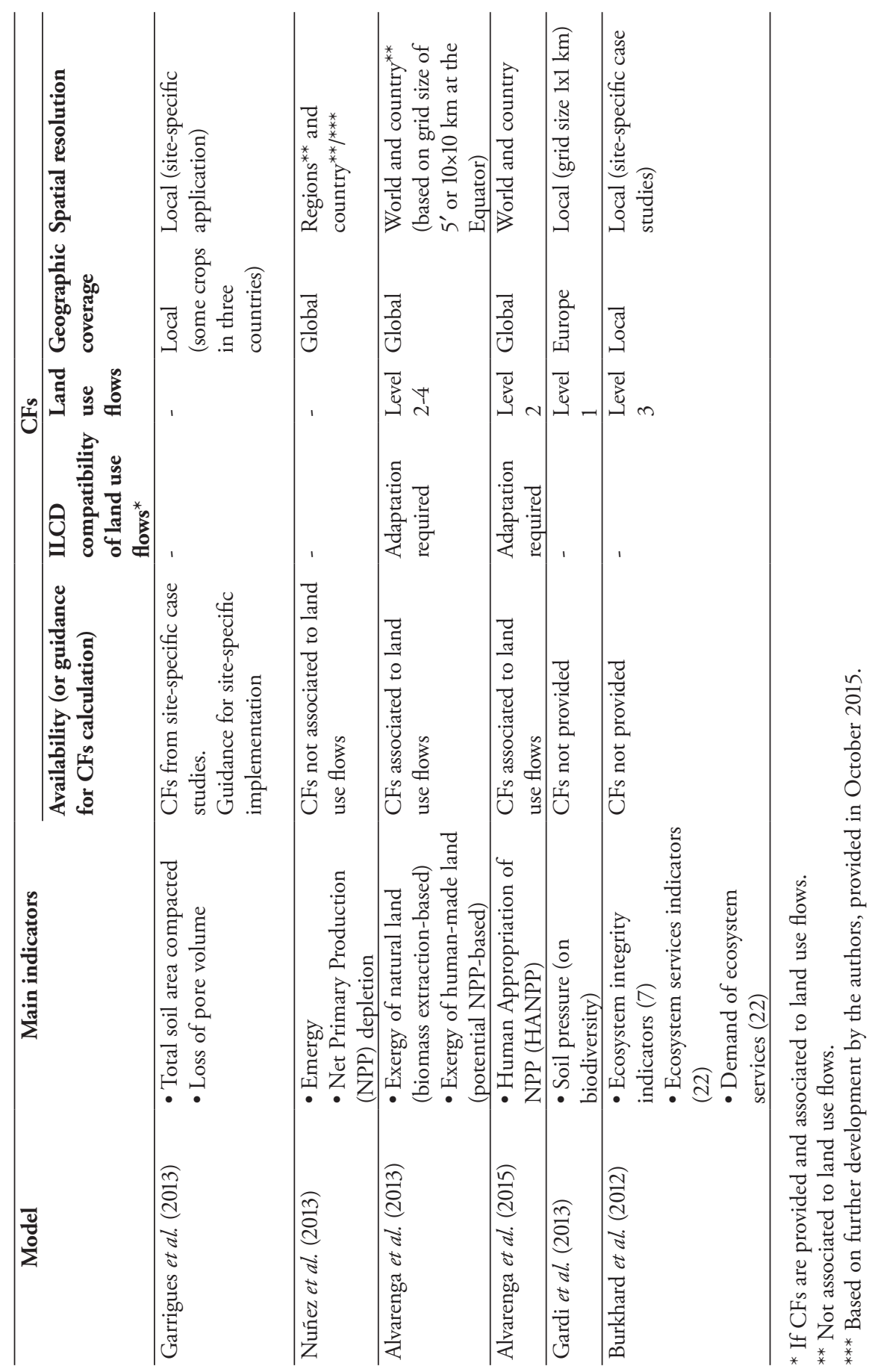




\section{Recommendations based on international consensus (e.g. by UNEP-SETAC GLAM)}

The JRC recommends the use of the LANCA model, which went through significant updates in the last two years. The latest version includes CFs fitting with the LCA land use framework for four to five indicators that can be aggregated and spatialized (De Laurentiis et al. 2019; Bos et al. 2020). The LANCA model provides, so far, the most detailed method to assess land use impact on soil quality in LCA.

The UNEP-SETAC Global Guidance for Life Cycle Impact Assessment Indicators and Methods (GLAM) Volume 2 recommends the use of SOC change as an integrated indicator of most affected soil functions and ecosystem services (e.g. Cowie et al. 2018). Compared to LANCA', SOC change provides a more aggregated information on soil quality as it results from the combination of many mechanisms by many soil actors as affected by various human interventions. It is hence less detailed but potentially more comprehensive than LANCA.

\section{Operational aspects (included in LCA software)}

Currently, within LCA software, only the LCIA method based on SOC change as proxy for soil quality indicator is implemented (Koellner et al. 2013b, a), notably within the ILCD method.

Although the LANCA model is not yet directly implemented in all LCA software, it is implemented in GABI software and updated and spatialized CFs were made available in the literature (previous numerical versions of $\mathrm{LANCA}^{\circ} \mathrm{CFs}$ were not freely available).

General recommendations / warnings on links between inventory flows and impact assessment in relation to software

With LCIA methods applying SOC change as a proxy for soil quality change within the LCA land use framework, there are various aspects to pay attention to. Current CFs implemented in software rely on IPCC data for SOC stocks worldwide. Those stocks depend on soil type and climate and are weighted according to land management. The LCA practitioner keys in flows in terms of land use occupied $\left(\mathrm{m}^{2} \cdot \mathrm{yr}^{-1}\right)$ and land used transformed $\left(\mathrm{m}^{2}\right)$ selecting in the implemented database the archetypes for the considered land uses. First, the practitioner must be aware of background assumptions in the IPCC SOC stocks used $(0-30 \mathrm{~cm}$ depth, considered management practices, etc.). Second, attention must be paid to the updates of those stocks and continuous improvement towards a more precise accounting for the impact of management practices (updates may take place every four to five years with a delay for the integration within LCA software). Finally, it is important to pay attention and test the influence of the reference use applied in the CFs calculation as it has a tremendous influence on the final impacts (Bessou et al. 2018). 
When applying LANCA ${ }^{\circ}$, LCA practitioner can use spatialized CFs for foreground processes or average country CFs for background processes. Despite recent updates in the model, it is important to keep in mind that background models use a lot of parameters such as "sealing factor" or "permeability class" and further pedotransfer equations that often rely on European databases and for which some of the background literature only is available in German.

\section{Updated research propositions}

In recent years, many authors have explored ways to introduce a more comprehensive and consistent approach to consider land use impacts on soil quality and ecosystem services (Alejandre et al. 2019; Othoniel et al. 2019; Rugani et al. 2019). 


\section{Human toxicity and ecotoxicity}

\section{Basset-Mens, CIRAD}

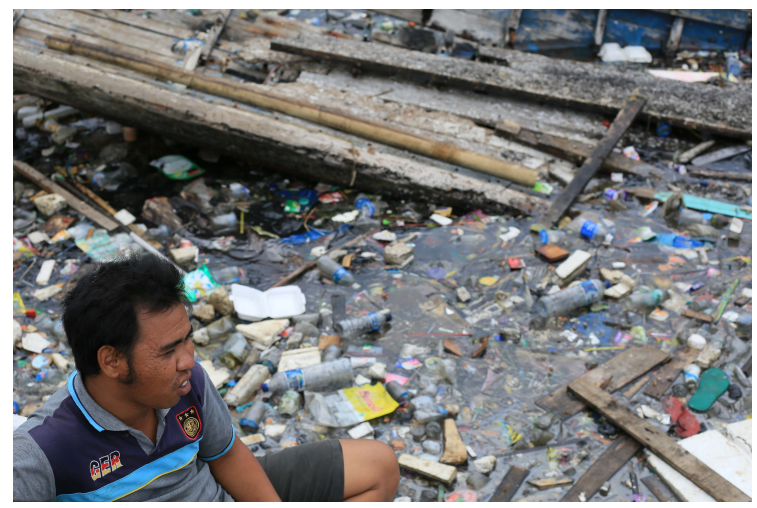

What are human toxicity and ecotoxicity about?

The potential of a chemical substance to cause harm (damage) to ecosystems and human health depends on its intrinsic properties (e.g., potency to induce a toxicity effect), the characteristics of organisms/humans, and the amount of time- and space integrated exposure of the organisms/humans in that compartment to the specific chemical. Human toxicity refers to the burden of disease attributable to exposure to chemical substances released throughout a product or service life cycle. To express damage on ecosystems, the potentially disappeared fraction (PDF) of species, a biodiversity-related metric for expressing damages on ecosystem quality, is commonly used.

\section{State of the art and recommended methods}

\section{LCI/LCIA models exist...}

Across the life cycle of products, thousands of pollutants can be inventoried and the modelling of their (eco)-toxicity impacts requires a consistent and integrative framework. Over the two last decades, several approaches have been proposed to assess the potential impacts of chemical substances on ecosystems and human toxicity in LCIA. Due to different equations and assumptions, these models lead to different results using different metrics and scales. To build consensus among the different modelling approaches, a global consensus model - USEtox - was designed (Hauschild et al. 2008; Rosenbaum et al. 2008). USEtox is the consensus model endorsed by the UNEP-SETAC Life Cycle Initiative for characterizing human and ecotoxicological impacts of chemicals emitted from product systems.

Among all chemicals emitted from an agricultural product systems, organic pollutants (e.g. pesticides) and trace elements are of particular concern. First, they can have major (eco)-toxicity impacts. Second, their emissions occurring at field level are dependent on local conditions of practices and environment and are complex to estimate. 
The pesticide life cycle inventory model PestLCI (Dijkman et al. 2012) estimates emission fractions to air, field soil, field crop, groundwater and off-field surfaces. Recently updated to PestLCI Consensus (Fantke et al. 2017), the model uses two levels of emission distributions. Initial (or primary) mass distribution covers initial processes within minutes after pesticide application, whereas secondary emission distribution also considers additional transport and degradation processes within a given period (by default 1 day) after application.

The dynamiCROP model was developed almost 10 years ago to account for impacts on human health due to ingestion of pesticide residues in the consumed product (Fantke et al. 2011). DynamiCROP was recently integrated for some parameterized scenarios into USEtox (Fantke and Jolliet 2016) and coupled with the pesticide emission model PestLCI Consensus (Gentil et al. 2020).

Metal-based pesticides such as copper, or trace elements such as those found in fertilizers, contain metal ions and cannot be characterized as organic substances. Characterizing metals requires to consider speciation and other metal-relevant characteristics (Dong et al. 2014). As described in Gentil et al. (2020), emission fractions for pesticides, which need to be characterized as metal ions, require a correction factor that accounts for the mass contribution of the metal ion to the overall mass of the emitted pesticide molecule. Currently, the dynamiCROP model is only modelling the fate in the crop of organic pesticides while the PestLCI model can only simulate the initial distribution of metal-based pesticides.

The state-of-the-art LCI/LCIA models available in LCA is presented in Figure H5.

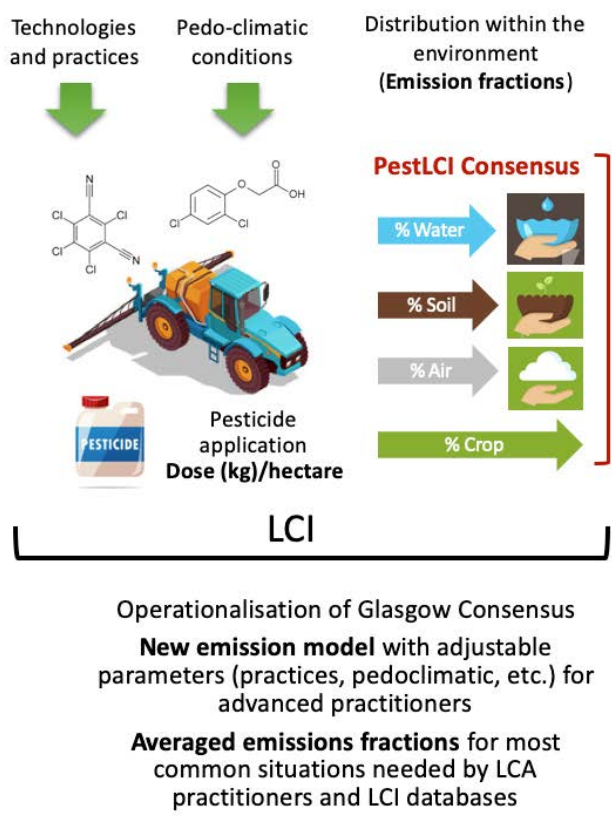

Resulting potential impacts (Characterisation factors)

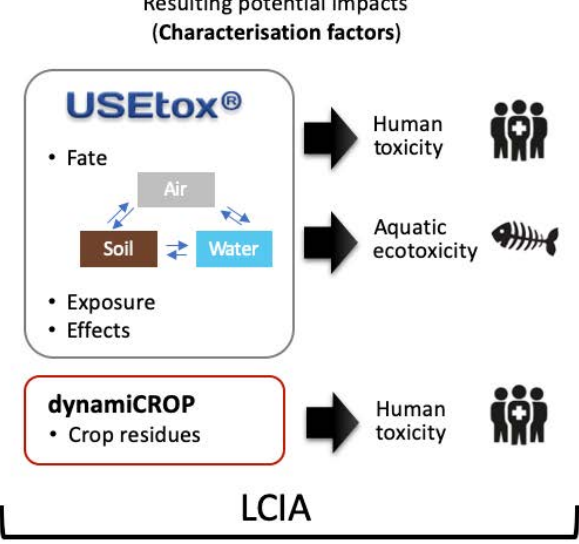

Figure H5. Advances from OLCA-Pest, InnovACV and Rivage projects. 


\section{But they are not used...}

Although these models exist, (eco)-toxicity impacts in general and in particular those due to pesticide and fertilizer applications are rarely accounted for in LCA studies (Perrin et al. 2014; Knudsen et al. 2019; van der Werf et al. 2020). An exhaustive and consistent evaluation of impacts due to pesticide applications remains complex. The issue of quantifying pesticide emissions in air/soil/ water without double counting of LCIA fate was discussed by (Van Zelm et al. 2014) and the Glasgow Consensus (Rosenbaum et al. 2015a) provided general recommendations regarding this issue but no operational guidance and tools for practitioners. When pesticide impacts are accounted for, default factors are used for field emissions, the most common assumption, as implemented for instance in ecoinvent and AGRIBALYSE agricultural inventories, being that $100 \%$ of pesticides applied are emitted to the soil. The PestLCI model has been seldom used by agronomists to support eco-design (Rouault et al. 2020). Furthermore, the dynamiCROP model is generally not used although ingestion can be the major pathway for human health impacts in certain LCA studies (Gentil et al. 2019, 2020). Regarding terrestrial ecotoxicity from multiple sources, including pesticides and fertilizers, the existing USEtox approach (for trace elements only) is not yet available in any LCA software, thus limiting its use by practitioners.

\section{A recent effort to operationalize $L C A$ of pesticides in temperate and tropical conditions}

In 2017, the OLCA-Pest (Operationalising Life Cycle Assessment of Pesticides https://www.sustainability.man.dtu.dk/english/research/qsa/research/researchprojects/olca-pest) project, funded by ADEME and coordinated by the Danish Technical University, was launched with the objective of helping practitioners to account for (eco)-toxicity impacts due to pesticides application in LCA studies. The InnovACV project, funded by ADEME Martinique and Cirad, and the Rivage project funded by the Martinique's European Regional Development Fund, complemented the OLCA-Pest project for tropical conditions. The main advances are summarized in Figure H6. PestLCI has been further advanced into the PestLCI Consensus web tool and a consistent coupling with both dynamiCROP and USEtox have been proposed by Gentil et al. (2020) as presented in Figure H6. All details for this combination of models can be found in the publication. Emission fractions have been calculated for a panel of pesticide application archetypes, including tropical scenarios, and can be directly used by LCA practitioners (see OLCA-Pest website and Gentil-Sergent et al., 2021). 


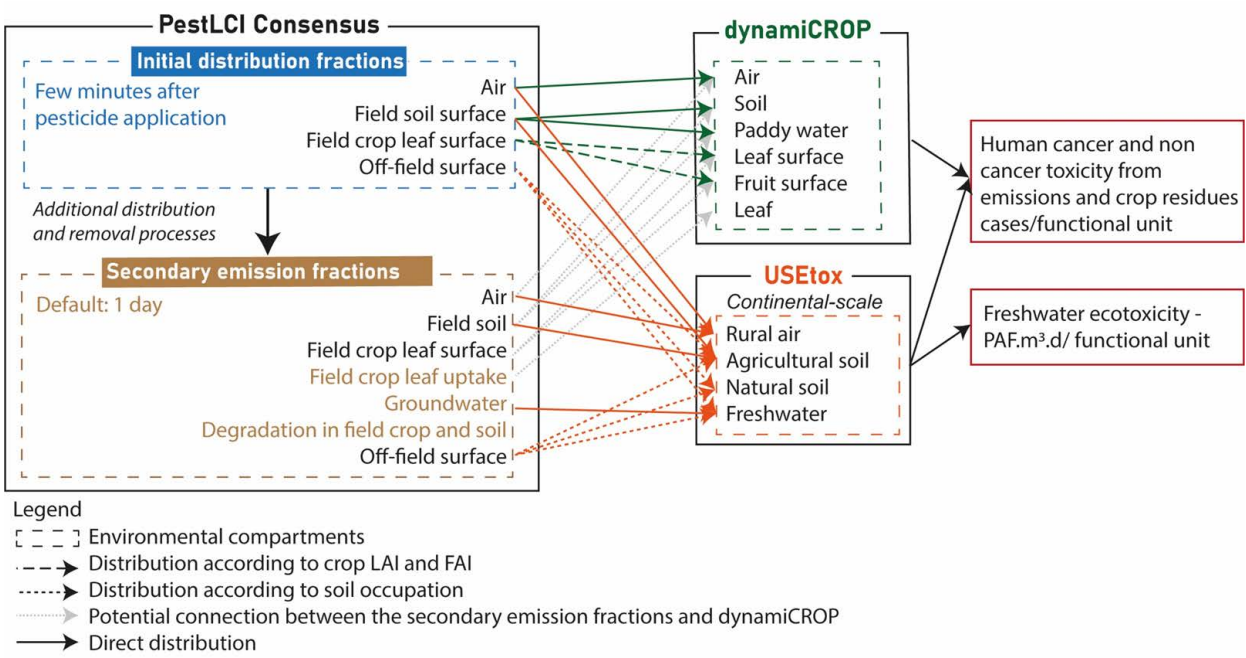

Figure H6. Connection of the emission compartments of PestLCI to those of dynamiCROP and USEtox according to the pesticide mass applied per $\mathrm{kg}$ of the harvested crop, adapted from Fantke (2019) by Gentil et al. (2020). LAI = Leaf Area Index, FAI = Fruit Area Index, PAF = Potentially Affected Fraction.

\section{Operational aspects}

USEtox recommended and interim CFs including fate, exposure, and effect parameters can be freely downloaded from the model website at: https://usetox. org/. Recent versions of the model are also available in LCA software such as SimaPro which currently proposes the version 2.02 of July 2016. However, LCA software cannot guarantee real-time updates of the model. Most updated CF must be directly downloaded from the model website.

The PestLCI webtool can be freely downloaded upon registration from https:// pestlciweb.man.dtu.dk/. A batch version has been developed to allow for multiple simulations of pesticide application scenarios. Furthermore, a new version of dynamiCROP with the coherent coupling with PestLCI is available on the web site model: http://dynamicrop.org/.

In complement to USEtox, CF from the new impact assessment method LC-IMPACT (Verones et al. 2020), which includes a formalism for the terrestrial ecotoxicity of trace elements described in Owsianiak et al. $(2013,2015)$, are available at https://lc-impact.eu/.

A general scheme is proposed in Figure H7, to help LCA practitioners evaluate the impacts due to pesticide emissions depending on their LCA goal and resources. 


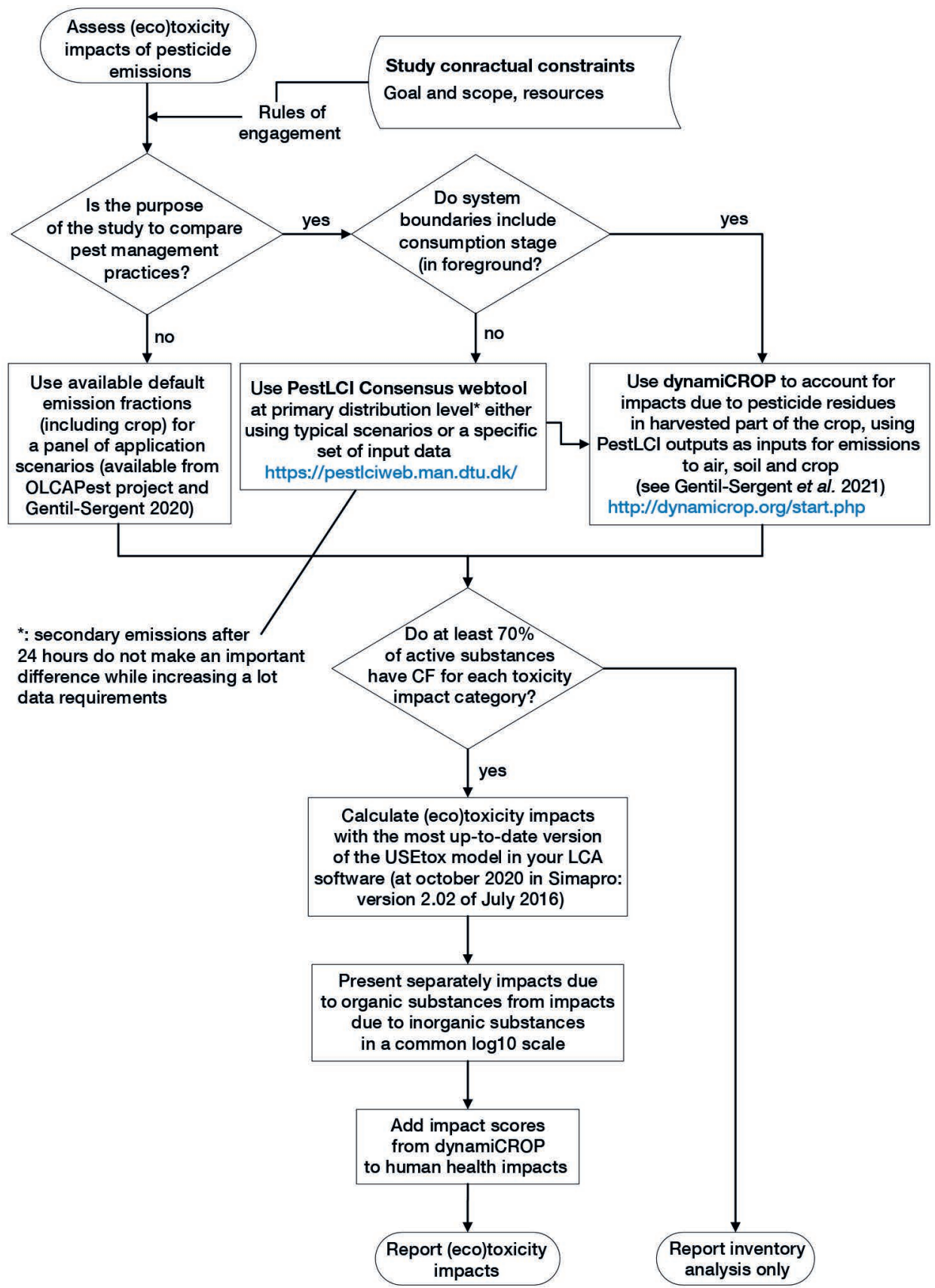

Figure H7. Overview of recommendations to account for impacts due to pesticide applications in LCA studies. 
As mentioned earlier, the initial distribution of pesticide applications at field level has been calculated through emission fractions to air, soil, crop and water, for a panel of pesticide application archetypes, including tropical scenarios, and can be directly used by LCA practitioners. For general archetypes of pesticide applications, details are available in D5.3 from the OLCA-Pest project (https:// www.sustainability.man.dtu.dk/english/research/qsa/research/research-projects/ olca-pest). In Table H3, crop classes and associated examples are proposed. It is important to note that the initial distribution is not dependent on climate and soil conditions. The crop and its development stage and the application technique constitute the most important parameters for the initial distribution. Access to default emission fractions for pre-defined archetypes of pesticide application should be shortly available on the OLCA-Pest project website. Tropical conditions can be found in Gentil-Sergent et al. (2021).

Table H3. Crop classes, examples within each class and central product classification (CPC) (extracted from D5.3 OLCA-Pest project).

\begin{tabular}{lll}
\hline Crop classes & Examples & CPC \\
\hline Berries & Strawberry, cape gooseberry, & $135,135-$ \\
Citrus fruit trees & Orange, lemon, lime, grapefruit, & $145,132,132-$ \\
Temperate fruit trees & Apple, apricot, peach & $13,134-, 1239,1315$ \\
$\begin{array}{l}\text { Tropical and sub- } \\
\text { tropical fruit trees }\end{array}$ & mango, guava, cherimoya, avocado & $13,1311,1316$, \\
Grapes/Vines & Grape & 133,1351 \\
Nuts & Almond, chestnut, hazelnut, pistachio \\
Oil-Bearing crops & Sunflower, rapeseed, soybean, peanut & $137,137-$ \\
Oil-Bearing trees & Palm oil, coconut, banana, plantain, & $14,14-, 144-, 1319$, \\
Other permanent crops & Coffee, cocoa, tea, cotton, tobacco & $146,1491,1313,1312$ \\
Paddy rice & Paddy rice & $161,162,192$, \\
Panicoideae & Maize, sorghum & 113 \\
Pooideae & Wheat, barley, oat, rye, quinoa, grass (cereals) (forage) & $11-, 119-, 1199$ \\
Pulses & Beans, lentils, peas, vetch, lupine, chickpeas, cowpea & $124,170-$ \\
Roots, tubers and bulbs & Potato, cassava, carrot, onion & $15-, 125-, 125,127$, \\
& & 194 \\
Vegetables fruit & Fruit solanaceae cucurbitaceae (passion fruit, lulo or & $122,122-, 123-, 124-$ \\
& Escuador's naranjille) & $12,121-, 129,1243$, \\
Vegetables leafy & Cabbage, lettuce, cauliflower, broccoli & 1919 \\
\hline
\end{tabular}

General recommendations / warnings on links between inventory flows and impact assessment in relation to software

When developing a new process as part of a lifecycle tree in an LCA software, compartments of emissions for chemical substances such as pesticides should be selected carefully so they actually match with the actual compartments with a $\mathrm{CF}$ 
in the model. When doing a full LCA study, certain active ingredients generally do not have yet a CF. Several options are possible:

1. Use the USEtox model to calculate a specific CF for the active ingredient using available pesticide database (see recommendations in D2.1 from OLCAPest project)

2. Check pesticide family and calculate and use a proxy for this family such as the geometric mean of all CFs for this family

3.If you cannot find the family of the chemical or cannot calculate a proxy, calculate and use the geometric mean of the other CFs for the pesticides used in the production system

4.In case you cannot either calculate a specific CF or a proxy for this chemical, at least report the percentage of pesticides characterized for the study. If this number is below $70 \%$, the toxicity results will be underestimated and should be taken with great caution.

As recommended by the UNEP-SETAC initiative, results should be presented separately for organic and inorganic molecules on a common log normal scale as illustrated for freshwater ecotoxicity in Figure H8 for open-field tomato in Martinique in Gentil et al. (2020).

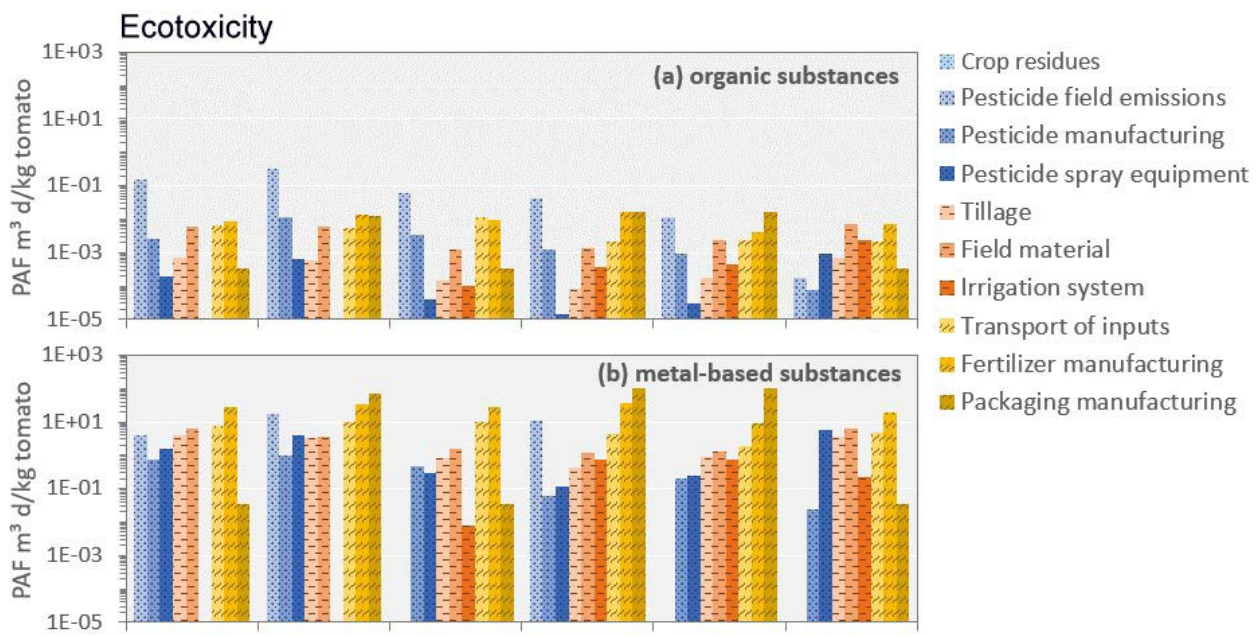

Figure H8. Ecotoxicity results for open-field tomato in Martinique presented as recommended by the UNEP-SETAC initiative (2016) (Gentil et al. 2020).

\section{Further research needs}

Although USEtox constitutes a consensual model for evaluating toxicity and ecotoxicity impacts in LCA, it still has margins for further improvement. The model does not evaluate local impacts on workers such as farmers nor on nearby residents. Many chemicals still do not have a $\mathrm{CF}$, including metabolites of parent compounds and biopesticides. The so-called "cocktail effect" in relation to the 
use of mixtures of pesticides and their accumulation in environmental compartments is not accounted for (Rizzati et al. 2016). A new indicator and dedicated modelling is also required for terrestrial ecotoxicity and for pollinator insects. USEtox to date estimates impacts on the human toxicity and freshwater aquatic ecotoxicity impact categories only. Except in the recent LC-IMPACT method (Verones et al. 2020), no formalism exists to date for terrestrial ecotoxicity of organic pollutants (such as present in most pesticides and organic fertilizers) within the USEtox framework.

Moreover, PestLCI Consensus also presents margins of improvement to better account for agricultural practices such as ground cover management and crop associations. The inclusion of those agroecological practices is key to compare properly conventional and agroecological cropping systems but will also require to model the secondary emission distribution (including water-related processes) in a consistent way with the USEtox model (Gentil-Sergent, 2020). 


\section{Biodiversity due to LULUC}

\section{Basset-Mens, A. Avadí, CIRAD}

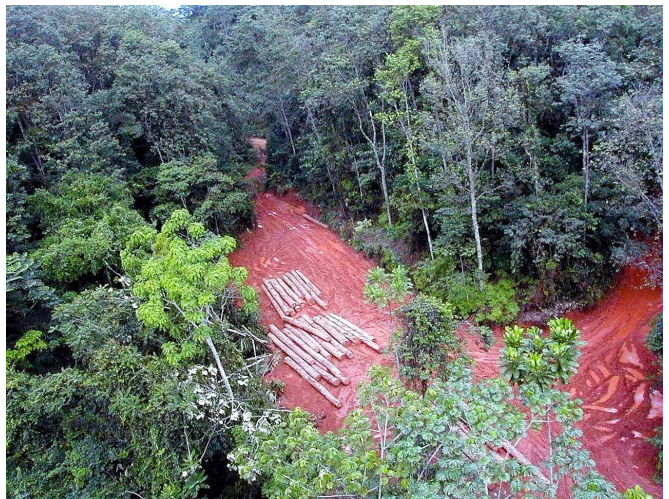

What biodiversity due to LULUC is about?

Land use represents one of the main drivers of biodiversity loss through loss and fragmentation of habitats. Land interventions such as transformation, occupation and land management and intensity constitute the main human drivers of the impact pathways toward biodiversity loss at the ecosystem quality area of protection level (Curran et al. 2016).

State of the art on available methods, uncertainty aspects, validity domains

Biodiversity loss due to LULUC is a quite ancient topic in LCA but has become one of the most important challenges for its operationalization and for decision-making on environmental protection in general. Extensive reviews on existing approaches to model biodiversity loss due to LULUC have been published in the literature (Curran et al. 2016; Winter et al. 2017). The Pellston workshop report from the UNEP-SETAC initiative GLAM makes a summary of these reviews (UNEP 2019). Complex impact pathways have been identified from the land intervention to the resulting impact on biodiversity loss at midpoint and endpoint levels. The most common pathway assessed across existing approaches is the direct, local degradation and conversion of habitats. Most current models are based on compositional aspects of biodiversity, namely species richness and species abundance. The ecoregion represents the most consensual spatial scale for the calculation of CFs and plants the most common taxon assessed across models.

\section{Recommended method}

No consensual method exists. The UNEP-SETAC initiative only recommended the method proposed by Chaudhary et al. (2015) as interim, since it has not been extensively tested and it is not fully satisfactory (UNEP 2019). In this approach, the potential species loss (PSL) from land use is proposed as indicator at regional 
scale. More precisely, it takes into account the effect of land occupation displacing entirely or partially the species on that land, the relative abundance of those species within the ecoregion, and the global threat level for the affected species. Five taxonomic groups are accounted for: birds, mammals, reptiles, amphibians, and vascular plants. They can be analysed separately or can be aggregated to represent the PDF of species. Land use types covered by the method include intensive forestry, extensive forestry, annual crops, permanent crops, pasture, and urban land. The reference state is a current natural or close to natural habitat in the studied ecoregion. This interim method is considered relevant to identify hotspots of biodiversity loss at the life cycle level of a product. However, being limited to six land use types, this indicator cannot differentiate alternative management practices such as agroecological practices versus conventional ones. More recently, Chaudhary and Brooks (2018) updated the CFs for PSL for the five taxa resulting from the five broad land use types under three intensity levels (minimal, light, intense use) in each of the 804 terrestrial ecoregions.

Chaudhary et al. (2015) is recommended as interim for application in general LCA studies. The approach from Chaudhary and Brooks (2018) constitutes an interesting alternative needing further testing for agri-food LCA studies, especially when the purpose is to differentiate different agricultural practices such as organic versus conventional.

\section{Operational aspects (included in LCA software)}

The method from Chaudhary and Brooks (2018) is not implemented in the LCA software such as Simapro, GaBi, Umberto and OpenLCA. To implement the method, the CFs presented in the supplementary material of the publication must be added in the LCA software manually by each user. An alternative consists in extracting the LULUC flows of the studied system from the LCA software into Excel and applying the CFs from the supplementary material of the publication.

\section{General recommendations / warnings on links between inventory flows and impact assessment in relation to software}

As mentioned above, the flows of LULUC exist in the processes in databases such as ecoinvent, but no characterization model allows converting these flows into impacts, at least in the most common LCA software, namely SimaPro, GaBi, Umberto, and OpenLCA (Lopes Silva et al. 2019). This calculation has to be done manually in Excel, $\mathrm{R}$, or another computing environment.

\section{Updated research propositions}

Among the growing body of alternative approaches, of which new ones are regularly presented in scientific conferences such as LCAFood (https://www6.inrae. fr/lcafoodconferencearchives/), an implementation/adaptation to LCA of the 
GLOBIO3 approach (Alkemade et al. 2009) has been recently proposed by FAO: the B-INTACT tool (FAO 2020c). B-INTACT complements other FAO tools commonly used in developing contexts, such as the EX-Ante Carbon balance Tool (EX-ACT) (Grewer et al. 2017) and the Global Livestock Environmental Assessment Model (GLEAM) (FAO 2018b).

B-INTACT considers six anthropogenic impacts on biodiversity, namely land use, climate change (representing a potential double-counting if combined with endpoint LCIA methods), atmospheric $\mathrm{N}$ deposition, disturbance by infrastructure, habitat fragmentation due to land use and infrastructure, and human encroachment. These impacts are segregated and calculated separately at nine sub-continental levels for seven land cover classes. This model uses the mean abundance of original species relative to their abundance in undisturbed ecosystems (MSA), corresponding to the concept of hemeroby (Taelman et al. 2016; Lindner et al. 2019), as the biodiversity indicator. To apply the model, a site under study is divided into homogenous land use patches, and then the MSA per type of impact multiplied by the affected area. A summary of CFs is provided in Table H4. 
Table H4. Collection of mean species abundance (MSA) values for LCA use, per type of land use. Each patch is assumed to feature only one land use.

\begin{tabular}{|c|c|c|c|c|c|}
\hline Naturalness & Land use & $\begin{array}{l}\text { Land use } \\
\text { (per patch) }\end{array}$ & $\begin{array}{l}\text { Infrastructure } \\
\text { (per patch) }\end{array}$ & $\begin{array}{l}\text { Fragmentation } \\
\text { (per site) }\end{array}$ & $\begin{array}{l}\text { Human } \\
\text { encroachment } \\
\text { (per site) }\end{array}$ \\
\hline $\mathrm{N}$ & Natural forest & 1.00 & Equation 1: & \multirow{18}{*}{$\begin{array}{l}\text { Equation 2: } \\
\text { MSA }_{\mathrm{F}}=(\mathrm{a}+(\mathrm{b}-\mathrm{a}) / \\
\left.(\mathrm{c}-\mathrm{d})^{*} \mathrm{~F}\right)^{*} \\
\text { proportion of } \text { natural }_{\text {in site }}+1^{*} \\
\text { proportion of } \\
\text { artificial in site } \text { if } \mathrm{F}<100 \rightarrow \\
\mathrm{a}=0.35, \mathrm{~b}=0.45, \\
\mathrm{c}=100, \mathrm{~d}=0 \text {; if } \\
100<\mathrm{F}<1000 \rightarrow \\
\mathrm{a}=0.45, \mathrm{~b}=0.65 \\
\mathrm{c}=1000, \mathrm{~d}=100 ; \\
\text { if } 1000<\mathrm{F}<10 \\
000 \rightarrow \mathrm{a}=0.65, \\
\mathrm{~b}=0.90, \mathrm{c}=10 \\
000, \mathrm{~d}=1000 ; \text { if } \\
10000<\mathrm{F}<100 \\
000 \rightarrow \mathrm{a}=0.90, \\
\mathrm{~b}=0.98, \mathrm{c}=100 \\
000, \mathrm{~d}=10000 \text {; if } \\
100000<\mathrm{F}<1000 \\
000 \rightarrow \mathrm{a}=0.98, \\
\mathrm{~b}=1.00, \mathrm{c}=1000 \\
000, \mathrm{~d}=100000 ; \\
\text { else }(\mathrm{a}+(\mathrm{b}-\mathrm{a}) / \\
\left.(\mathrm{c}-\mathrm{d})^{*} \mathrm{~F}\right)=1.00\end{array}$} & \multirow{18}{*}{$\begin{array}{l}\text { Equation 3: } \\
\text { if proportion of } \\
\text { cropland and urban } \\
>1.5 \% \text { then } \mathrm{MSA}_{\mathrm{HE}} \\
=0.85 \text {, else } \mathrm{MSA}_{\mathrm{HE}} \\
=1-((\text { proportion } \\
\text { of cropland and } \\
\text { urban } / 0.015)^{*}(1- \\
0.85))\end{array}$} \\
\hline $\mathrm{N}$ & $\begin{array}{l}\text { Lightly used } \\
\text { (i.e. logged) } \\
\text { natural forest }\end{array}$ & 0.70 & $\begin{array}{l}\mathrm{MSA}_{\mathrm{I}}= \\
\mathrm{AVG}[1- \\
((\text { length of }\end{array}$ & & \\
\hline $\mathrm{N}$ & $\begin{array}{l}\text { Moderately } \\
\text { used (i.e. } \\
\text { logged) semi- } \\
\text { natural forest }\end{array}$ & 0.85 & $\begin{array}{l}\text { infrastructure } \\
\left.\text { in } \mathrm{km}^{*} 2\right) / \\
(\text { patch area } * \\
\left.\left.100)^{*}(1-0.78)\right)\right]\end{array}$ & & \\
\hline $\mathrm{N}$ & Clear-cut forest & 0.50 & & & \\
\hline $\mathrm{N}$ & Managed forest & 0.30 & & & \\
\hline $\mathrm{N}$ & $\begin{array}{l}\text { Natural } \\
\text { grassland or } \\
\text { shrubland }\end{array}$ & 1.00 & & & \\
\hline $\mathrm{N}$ & $\begin{array}{l}\text { Grazed } \\
\text { grassland }\end{array}$ & 0.60 & & & \\
\hline $\mathrm{N}$ & Set-aside land & 0.90 & & & \\
\hline $\mathrm{N}$ & $\begin{array}{l}\text { Bare natural } \\
\text { areas, boreal/ } \\
\text { polar }\end{array}$ & 1.00 & & & \\
\hline $\mathrm{N}$ & $\begin{array}{l}\text { Extensive } \\
\text { agro-forestry }\end{array}$ & 0.50 & 1.00 & & \\
\hline A & $\begin{array}{l}\text { Degraded } \\
\text { grazed } \\
\text { grassland, } \\
\text { converted from } \\
\text { forest }\end{array}$ & 0.30 & Equation 1 & & \\
\hline A & Degraded land & 0.30 & & & \\
\hline A & $\begin{array}{l}\text { Extensive/ } \\
\text { subsistence/ } \\
\text { low-input } \\
\text { cropland }\end{array}$ & 0.30 & 1.00 & & \\
\hline A & $\begin{array}{l}\text { Intensive/high } \\
\text { input cropland }\end{array}$ & 0.10 & & & \\
\hline A & $\begin{array}{l}\text { Irrigated } \\
\text { cropland }\end{array}$ & 0.05 & & & \\
\hline A & Flooded rice & 0.30 & & & \\
\hline A & $\begin{array}{l}\text { Intensive } \\
\text { agro-forestry, } \\
\text { bioenergy crops }\end{array}$ & 0.30 & & & \\
\hline A & $\begin{array}{l}\text { Areas with } \\
>80 \% \text { built up }\end{array}$ & 0.05 & & & \\
\hline
\end{tabular}

$\mathrm{N}$ : natural area, A: artificial area, F: non-fragmented natural area (ha) in the studied site.

Sources: Alkemade et al. 2009; FAO 2020c. Criteria for identifying degraded lands are presented in Gibbs and Salmon (2015). 


\section{Water scarcity footprint}

\section{S. Payen, CIRAD}

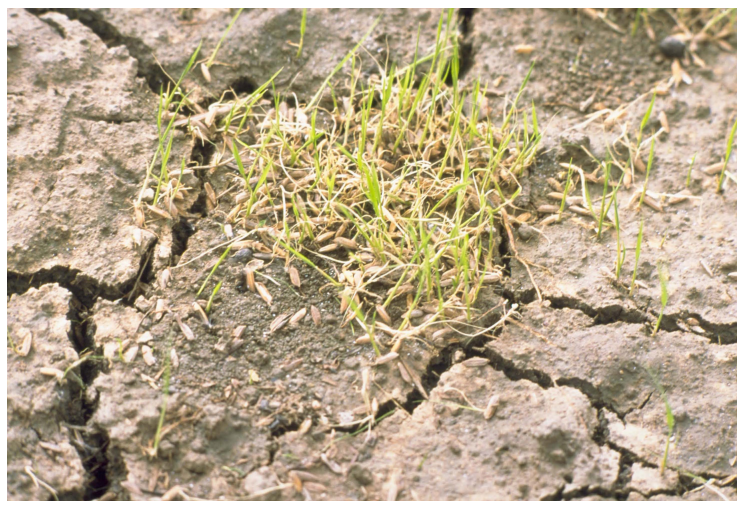

\section{What is a water scarcity footprint?}

The ISO 14046 standard (ISO 2014) and its practical guide (ISO 2017) are documents providing guidance and clear definitions of all aspects related to water footprinting. First, it is important to distinguish a water scarcity footprint from a comprehensive water footprint. In short, a water footprint is a "metric(s) that quantifies the potential environmental impacts related to water". Therefore, a comprehensive water footprint considers all impacts associated with water consumption and pollution. This includes water scarcity footprint as well as freshwater eutrophication, acidification and ecotoxicity impacts. A water scarcity footprint focuses on impacts due to reduced water availability from water consumption but do not address water quality.

Characterizing impacts from water consumption requires going beyond a simple volumetric measure (i.e. the inventory) by including relevant geographical and temporal dimensions.

\section{Inventory}

The inventory of a water scarcity footprint is based on a water balance, where the distinction between water withdrawal from water consumption is important. Almost all impact assessment methods rely on the volume and location of water consumed (through evapotranspiration, incorporation into product or transfer to another basin).

Figure $\mathrm{H} 9$ provides guidance on where to find water consumption data. Databases can be used for background activities such as fertilizer manufacture whereas estimating crop water use may require modelling. For details on how to estimate crop evapotranspiration and where to find data to run the models see Payen et al. (2018). 

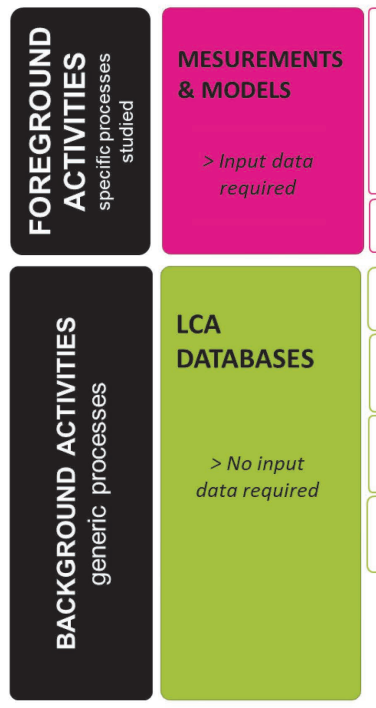

\begin{tabular}{|c|c|c|c|}
\hline $\begin{array}{l}\text { Crop model } \\
\text { Evapotranspiration } \\
\text { modelling } \\
\text { (see Payen et al. } 2018 \\
\text { for details) }\end{array}$ & \multicolumn{3}{|c|}{$\begin{array}{l}\text { Cropwat model: } \\
\text { > Discrimination of system main characteristics (e.g. average soil type) } \\
\text { > Better to use with input data on irrigation }\end{array}$} \\
\hline \multicolumn{4}{|c|}{ Ad hoc model, Measurements... etc } \\
\hline ecoinvent v.3 & $\begin{array}{l}10000+\text { datasets of products \& } \\
\text { processes from many sectors }\end{array}$ & $\begin{array}{l}\text { Based on Pfister et al. 2011, } \\
2014 \text { water database for crops }\end{array}$ & $\begin{array}{l}\text { With LCA } \\
\text { Software \$ }\end{array}$ \\
\hline AGRIBALYSE & $\begin{array}{l}2500 \text { agricultural } \& \text { food } \\
\text { products produced and/or } \\
\text { consumed in France }\end{array}$ & $\begin{array}{l}\text { Based on Ecoinvent for } \\
\text { background, Cropwat for } \\
\text { foreground }\end{array}$ & Available \\
\hline $\begin{array}{l}\text { World Food LCA } \\
\text { Database }\end{array}$ & $\begin{array}{l}2300+\text { datasets for } 120 \text { products } \\
\text { in } 56 \text { countries: food products, } \\
\text { food processing, transport... }\end{array}$ & $\begin{array}{l}\text { Based on Pfister et al. 2011, } \\
2014 \text { water database }\end{array}$ & $\begin{array}{l}\text { Available to } \\
\text { public soon }\end{array}$ \\
\hline Agri-footprint & $\begin{array}{l}\text { 5000+ products \& processes: } \\
\text { Crops, products from } \\
\text { processing, food products... }\end{array}$ & $\begin{array}{l}\text { Based on WaterStat (Mekonnen } \\
\text { and Hoesktra 2010) }\end{array}$ & $\begin{array}{l}\text { With LCA } \\
\text { Software \$ }\end{array}$ \\
\hline$\underset{\text { withdrawal }}{\mathrm{Q}_{\text {in }} \mathrm{I}}$ & $\begin{array}{l}\text { Differences in } \\
\text { consumption } \\
\text { or indirectly (C }\end{array}$ & water & \\
\hline
\end{tabular}

Figure H9. Finding data for the inventory of water consumption.

\section{State of the art on available methods}

Over the past 12 years, many impact assessment methods have been developed. Here we focus on methods that are widely applied, available in LCA impact assessment package (ReCiPe 2016, PEF, IMPACT World+) or recommended by the UNEP-SETAC (GLAM). These methods are detailed in Table H5, H6 and H7.

The most consensual midpoint indicator is the one developed by the WULCA group called AWaRe (Boulay et al. 2018). AWaRe stands for Available WAter Remaining and is recommended by the UNEP-SETAC and the European Commission. It aims to answer: "What is the potential of depriving another user (human or ecosystems) of water when consuming water in this area"? It is based on the "unused water remaining" calculated as the water available minus water demand for human and ecosystems. Impact score is expressed in $\mathrm{m}^{3}$ world equivalent and do not have any physical meaning since CF ranges from 0.1 to 100 (and not from zero to 1 like the Water Stress Index from Pfister et al. 2009). For example, a CF equal to 10 means there is 10 times less "unused water remaining" in this region than "average unused water remaining at world scale". The UNEP report (UNEP 2016) mentions a few limitations of AWaRe: a lack of discriminatory power in regions where demand is larger than availability and a large uncertainty associated with the estimate of environmental water requirement.

The Water Stress Index (WSI) from Pfister et al. (2009) has been widely applied and is still relevant. It presents the advantage of providing consistent indicators at both midpoint and endpoint levels. 
Table H5. Comparison of midpoint indicators for water scarcity footprint.

\begin{tabular}{|c|c|c|}
\hline MIDPOINT & Boulay et al. 2018 & Pfister et al. (2009) \\
\hline Midpoint indicator & AWaRe in $\mathrm{m}^{3}$ world-eq. & WSI in $\mathrm{m}^{3}$ eq. \\
\hline Characterization factor $(\mathrm{CF})$ & $\begin{array}{l}\text { CF based on the inverse of the } \\
\text { availability-minus-demand (AMD, } \mathrm{m}^{3} / \\
\mathrm{m}^{2} \cdot \text { month) } \\
\text { Demand = human and aquatic ecosystems } \\
\text { needs } \\
\text { Normalized with the reference flow } \\
\text { of the world weighted value }\end{array}$ & $\begin{array}{l}\text { CF based on a withdrawal } \\
\text { to availability ratio (WTA) } \\
\text { Withdrawal = by industry, } \\
\text { agriculture, and households } \\
\text { in watershed } \\
\text { Availability = Freshwater } \\
\text { availability in watershed }\end{array}$ \\
\hline Resolution & $\begin{array}{l}\text { Monthly, Annual } \\
\text { Subwatershed, region, country }\end{array}$ & $\begin{array}{l}\text { Monthly, Annual } \\
\text { Subwatershed, country }\end{array}$ \\
\hline Water use type & $\begin{array}{l}\text { Agricultural or non-agricultural, } \\
\text { Crop type, } \\
\text { Marginal or average activity }\end{array}$ & \\
\hline Used in/ Recommended by & $\begin{array}{l}\text { PEF, IMPACT World+, GLAM } \\
\text { (UNEP-SETAC) }\end{array}$ & Many publications \\
\hline
\end{tabular}

WSI : Water Stress Index.

Table H6. Comparison of human health endpoint indicators for water scarcity footprint.

\begin{tabular}{|c|c|c|c|}
\hline $\begin{array}{l}\text { ENDPOINT } \\
\text { HUMAN } \\
\text { HEALTH } \\
\end{array}$ & Motoshita et al. (2014) & Pfister et al. (2009) & Boulay et al. (2011) \\
\hline Endpoint indicator & $\begin{array}{l}\text { Malnutrition damages } \\
\text { in } \mathrm{DALY} / \mathrm{m}^{3}\end{array}$ & $\begin{array}{l}\text { Malnutrition damages } \\
\text { in } \mathrm{DALY} / \mathrm{m}^{3}\end{array}$ & $\begin{array}{l}\text { Malnutrition and } \\
\text { water-related diseases } \\
\text { damages in DALY/ } \\
\mathrm{m}^{3}\end{array}$ \\
\hline $\begin{array}{l}\text { Characterization } \\
\text { factor }(\mathrm{CF})\end{array}$ & $\begin{array}{l}\text { Impacts of reduced food } \\
\text { production due to a lack } \\
\text { of water for agriculture, } \\
\text { considering local scarcity and } \\
\text { economic adaptation capacity. } \\
\text { Combine food production } \\
\text { loss, food supply shortage } \\
\text { assessment and health } \\
\text { damage. }\end{array}$ & $\begin{array}{l}\text { Combine scarcity } \\
\text { indicator, agricultural } \\
\text { users' share of water use, } \\
\text { human development } \\
\text { factor for malnutrition, } \\
\text { per-capita water } \\
\text { requirements to prevent } \\
\text { malnutrition, damage } \\
\text { caused by malnutrition. }\end{array}$ & $\begin{array}{l}\text { Malnutrition from } \\
\text { water deprivation } \\
\text { for agricultural } \\
\text { users, fisheries, and } \\
\text { water-related diseases } \\
\text { associated with a lack } \\
\text { of water for domestic } \\
\text { use, due to water } \\
\text { degradation and } \\
\text { consumption }\end{array}$ \\
\hline Resolution & $\begin{array}{l}\text { Monthly, Annual Watershed, } \\
\text { Country }\end{array}$ & $\begin{array}{l}\text { Annual } \\
\text { Watershed, Country }\end{array}$ & $\begin{array}{l}\text { Annual } \\
\text { Watershed, Country }\end{array}$ \\
\hline Water use type & $\begin{array}{l}\text { Agricultural and non- } \\
\text { agricultural water use }\end{array}$ & & \\
\hline $\begin{array}{l}\text { Used in/ } \\
\text { Recommended by }\end{array}$ & $\begin{array}{l}\text { GLAM (UNEP-SETAC) with } \\
\text { a few adaptations }\end{array}$ & ReCiPe 2016 & IMPACT World+ \\
\hline
\end{tabular}

DALY: Disability Adjusted Life Years. 
Table H7. Comparison of ecosystem endpoint indicators for water scarcity footprint.

\begin{tabular}{|c|c|c|c|c|}
\hline $\begin{array}{l}\text { ENDPOINT } \\
\text { ECOSYSTEMS }\end{array}$ & Pfister et al. 2009 & $\begin{array}{l}\text { van Zelm et al } \\
2011\end{array}$ & $\begin{array}{l}\text { Hanafiah et al. } \\
2011\end{array}$ & $\begin{array}{l}\text { Verones et al } \\
2010\end{array}$ \\
\hline $\begin{array}{l}\text { Endpoint } \\
\text { indicator }\end{array}$ & $\begin{array}{l}\text { Impacts on } \\
\text { terrestrial ecosystems } \\
\text { in Species.yr }\end{array}$ & $\begin{array}{l}\text { Impacts on } \\
\text { terrestrial } \\
\text { ecosystems from } \\
\text { groundwater use } \\
\text { in PDF.m².yr }\end{array}$ & $\begin{array}{l}\text { Impacts on } \\
\text { freshwater fish } \\
\text { species in PDF. } \\
\mathrm{m}^{2} . \mathrm{yr}\end{array}$ & $\begin{array}{l}\text { Impact of } \\
\text { thermally polluted } \\
\text { water in PDF. } \\
\mathrm{m}^{2} . \mathrm{yr}\end{array}$ \\
\hline $\begin{array}{l}\text { Characterization } \\
\text { factor }(\mathrm{CF})\end{array}$ & $\begin{array}{l}\text { Vulnerability of an } \\
\text { ecosystem based on } \\
\text { the ratio of water } \\
\text { limited-net primary } \\
\text { productivity to } \\
\text { precipitation }\end{array}$ & $\begin{array}{l}\text { Effects of } \\
\text { groundwater table } \\
\text { lowering on the } \\
\text { species richness } \\
\text { of terrestrial } \\
\text { vegetation }\end{array}$ & $\begin{array}{l}\text { Change in } \\
\text { freshwater fish } \\
\text { species richness } \\
\text { associated with a } \\
\text { decrease of river } \\
\text { discharge due to } \\
\text { water consumption }\end{array}$ & $\begin{array}{l}\text { Fate factor = } \\
\text { residence time of } \\
\text { heat emissions in } \\
\text { the river, } \\
\text { Effect factor = } \\
\text { loss of species } \\
\text { diversity per unit } \\
\text { of temperature }\end{array}$ \\
\hline Resolution & $\begin{array}{l}\text { Annual Watershed, } \\
\text { country }\end{array}$ & Not regionalised & Watershed & Not regionalised \\
\hline $\begin{array}{l}\text { Used in/ } \\
\text { Recommended by }\end{array}$ & ReCiPe 2016 & IMPACT World+ & $\begin{array}{l}\text { ReCiPe 2016, } \\
\text { Impact World+ }\end{array}$ & Impact World+ \\
\hline
\end{tabular}

\section{Recommendations based on international consensus (UNEP-SETAC GLAM)}

At midpoint, the UNEP-SETAC recommends the application of AWaRe and a sensitivity analysis with a conceptually different method such as the WSI from Pfister et al. (2009) (UNEP 2016).

At endpoint, the UNEP-SETAC recommends addressing the impact pathway describing agricultural water deprivation and consequences on human health with the application of Motoshita et al. (2014) (slightly modified in the UNEP report from 2016). However, caution is recommended for interpreting results for food-producing systems. Indeed, can we consider malnutrition impacts when the system studied is actually producing food?

The indicators for ecosystems and resources damage categories were not yet mature for consensus (UNEP 2016).

\section{Operational aspects and general recommendations}

To satisfy the range of demands from LCA users in terms of specificity and applicability, AWaRe CFs have been developed at different spatial (country / subnational / watershed) and temporal (annual / monthly) resolutions. The aggregation of CFs from native resolution (monthly, watershed) to lower resolution (annual, country) is based on a consumption-weighted average, distinguishing agricultural from non-agricultural water use. This means that when the specific location or time of the water consumption is unknown, using aggregated CFs acknowledges that it is more likely to have happened in the watershed or during the month with the highest consumption. 
Crop-specific AWaRe CFs for 26 crops $^{8}$ were developed (at country level), to improve the accuracy of crop water scarcity footprint when no watershed level data are available (Boulay et al. 2019).

For case studies when the inventory represents a large amount of water in the watershed (i.e. non-marginal), average AWaRe CFs were developed (Boulay et al. 2020). Boulay et al. (2019) recommend to use sector-, or crop-specific CF if no watershed inventory-specific data are available. If specific data are available, selecting which CFs to apply can be supported by a simple decision tree (Figure H10):

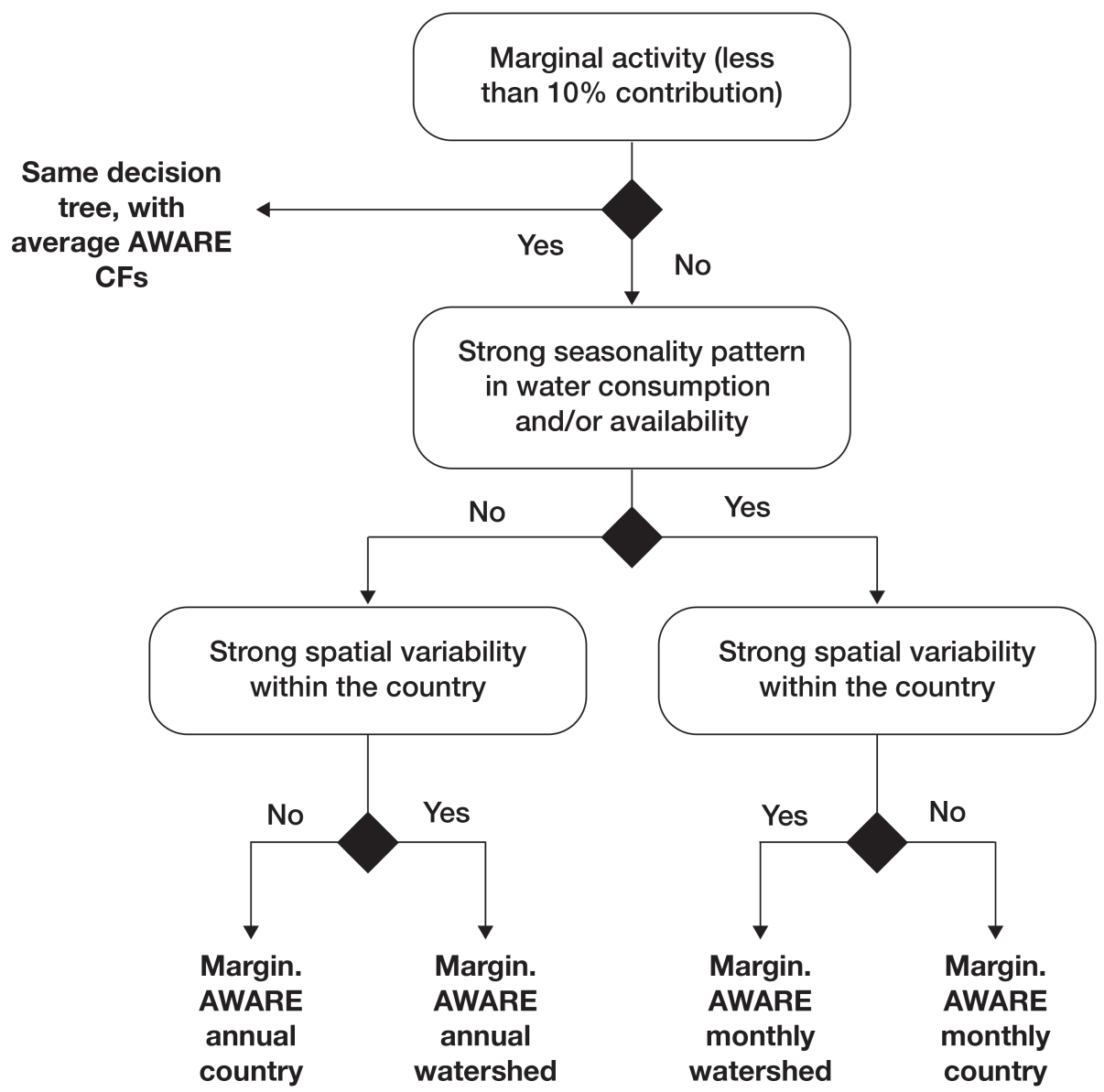

Figure H10. Decision tree to select AWaRe CFs dimension.

8. Wheat, maize, rice, soybean, cotton, canola and rapeseed, barley, rye, managed meadows and pastures, sunflower, legumes, cassava, citrus, cocoa, coffee, date palm, grape and vine, peanuts, millet, coconut palm oil, potato, sorghum, sugar beet, sugar cane, and "other annuals", as well as "other perennials". 
In Simapro, only a water scarcity footprint at country and annual resolution can be performed. It is possible to increase resolution for a few foreground processes by adding specific CFs and corresponding elementary flows manually. This should be done with caution and keeping in mind differences in databases structures for water flows: Agrifootprint provides directly the water consumption whereas ecoinvent provides the water withdrawn and released (Figure H9).

High-resolution (monthly / watershed level) and non-marginal CFs are only available in Excel format or Google Earth. Table H8 summarizes where to find the various AWaRe CFs.

Table H8. Availability of AWaRe CFs in different sources and formats.

\begin{tabular}{ll}
\hline Simapro & Country and Annual \\
\hline Google Earth & Basin and Monthly \\
\hline Excel & Basin and Annual and Agri/ Non-agri/ Unspecified \\
\hline & Same as Google Earth (Basin ID = Watergap ID) \\
\hline & Country or region and Agri/ Non-agri/ Unspecified \\
\hline & Non-marginal, all resolutions \\
\hline & Subnational (3428 admin. regions), all resolutions \\
\hline & Country and crop-specific \\
\hline
\end{tabular}

Check for update and more resource on AWaRe at https://wulca-waterlca.org/

\section{Updated research propositions}

Helias (2020) showed that AWaRe CF only covers $62 \%$ of the world water consumption because of the upper and lower boundaries of the CFs. In particular, regions with fair or poor water conditions are treated the same regardless of the extent of the ecosystem degradation. Helias (2020) offers an improvement in line with the AWaRe model features, but without its validity limits and induced thresholds: the Demand-To-Remaining model (ratio of the ecosystem demands and the remaining after human activities). 


\section{Appendix I \\ LCIA methods recommended by the Life Cycle Initiative and EF 3.0}

Source: Zampori and Pant 2019.

EF impact categories with respective impact category indicators and characterization models. The CFs that shall be used are available at: http://eplca.jrc.ec.europa. eu/LCDN/developerEF.xhtml.

\begin{tabular}{|c|c|c|c|c|}
\hline EF Impact category & $\begin{array}{l}\text { Impact category } \\
\text { Indicator }\end{array}$ & Unit & $\begin{array}{l}\text { Characterization } \\
\text { model }\end{array}$ & Robust-ness \\
\hline $\begin{array}{l}\text { Climate change, } \\
\text { total }\end{array}$ & $\begin{array}{l}\text { RF as global warming } \\
\text { potential (GWP100) }\end{array}$ & $\mathrm{kg} \mathrm{CO}_{2}$ eq & $\begin{array}{l}\text { Baseline model of } 100 \\
\text { years of the IPCC } \\
\text { (based on IPCC } \\
\text { 2013) }\end{array}$ & I \\
\hline Ozone depletion & $\begin{array}{l}\text { Ozone Depletion } \\
\text { Potential (ODP) }\end{array}$ & kg CFC-11 eq & $\begin{array}{l}\text { Steady-state ODPs } \\
\text { as in WMO (2014) + } \\
\text { integrations }\end{array}$ & I \\
\hline $\begin{array}{l}\text { Human toxicity, } \\
\text { cancer }\end{array}$ & $\begin{array}{l}\text { Comparative Toxic } \\
\text { Unit for humans } \\
\text { (CTUh) }\end{array}$ & CTUh & $\begin{array}{l}\text { USEtox model } 2.1 \\
\text { (Fantke (Ed.) et al. } \\
\text { 2017) }\end{array}$ & III \\
\hline $\begin{array}{l}\text { Human toxicity, } \\
\text { non- cancer }\end{array}$ & $\begin{array}{l}\text { Comparative Toxic } \\
\text { Unit for humans } \\
\text { (CTUh) }\end{array}$ & CTUh & USEtox model 2.1 & III \\
\hline $\begin{array}{l}\text { Particulate matter } \\
\text { (PM) }\end{array}$ & $\begin{array}{l}\text { Impact on human } \\
\text { health }\end{array}$ & disease incidence & $\begin{array}{l}\text { PM method } \\
\text { recommended by } \\
\text { UNEP (UNEP 2016) }\end{array}$ & I \\
\hline $\begin{array}{l}\text { Ionising radiation, } \\
\text { human health }\end{array}$ & $\begin{array}{l}\text { Human exposure } \\
\text { efficiency relative to } \\
U^{235}\end{array}$ & $\mathrm{kBq} \mathrm{U}^{235} \mathrm{eq}$ & $\begin{array}{l}\text { Human health effect } \\
\text { model as developed } \\
\text { by Dreicer } \text { et al. } 1995 \\
\text { (Frischknecht } \text { et al. } \\
\text { 2000) }\end{array}$ & II \\
\hline $\begin{array}{l}\text { Photochemical } \\
\text { ozone formation, } \\
\text { human health }\end{array}$ & $\begin{array}{l}\text { Tropospheric ozone } \\
\text { concentration increase }\end{array}$ & kg NMVOC eq & $\begin{array}{l}\text { LOTOS- } \\
\text { EUROS model } \\
\text { as implemented } \\
\text { in ReCiPe } 2008 \\
\text { (Goedkoop et al. } \\
\text { 2009) }\end{array}$ & II \\
\hline
\end{tabular}




\begin{tabular}{|c|c|c|c|c|}
\hline EF Impact category & $\begin{array}{l}\text { Impact category } \\
\text { Indicator }\end{array}$ & Unit & $\begin{array}{l}\text { Characterization } \\
\text { model }\end{array}$ & Robust-ness \\
\hline Acidification & $\begin{array}{l}\text { Accumulated } \\
\text { Exceedance (AE) }\end{array}$ & $\mathrm{mol} \mathrm{H}+\mathrm{eq}$ & $\begin{array}{l}\text { AE (Seppälä et al. } \\
\text { 2006; Posch et al. } \\
\text { 2008) }\end{array}$ & II \\
\hline $\begin{array}{l}\text { Eutrophication, } \\
\text { terrestrial }\end{array}$ & $\mathrm{AE}$ & $\mathrm{mol} \mathrm{N}$ eq & $\mathrm{AE}$ & II \\
\hline $\begin{array}{l}\text { Eutrophication, } \\
\text { freshwater }\end{array}$ & $\begin{array}{l}\text { Fraction of nutrients } \\
\text { reaching freshwater } \\
\text { end compartment }(\mathrm{P})\end{array}$ & kg P eq & $\begin{array}{l}\text { EUTREND model } \\
\text { as implemented in } \\
\text { ReCiPe } 2008\end{array}$ & II \\
\hline $\begin{array}{l}\text { Eutrophication, } \\
\text { marine }\end{array}$ & $\begin{array}{l}\text { Fraction of nutrients } \\
\text { reaching marine end } \\
\text { compartment }(\mathrm{N})\end{array}$ & $\mathrm{kg} \mathrm{N} \mathrm{eq}$ & $\begin{array}{l}\text { EUTREND model } \\
\text { as implemented in } \\
\text { ReCiPe } 2008\end{array}$ & II \\
\hline $\begin{array}{l}\text { Ecotoxicity, } \\
\text { freshwater }\end{array}$ & $\begin{array}{l}\text { Comparative Toxic } \\
\text { Unit for ecosystems } \\
\text { (CTUe) }\end{array}$ & CTUe & USEtox model 2.1 & III \\
\hline Land use & $\begin{array}{l}\text { 1. Soil quality index } \\
\text { (aggregation of } \\
\text { LANCA }^{\circledR} \text { indicators)2. } \\
\text { Biotic production3. } \\
\text { Erosion resistance4. } \\
\text { Mechanical filtration5. } \\
\text { Groundwater } \\
\text { replenishment }\end{array}$ & $\begin{array}{l}\text { 1. Dimensionless } \\
(\mathrm{Pt}) 2 . \mathrm{kg} \text { biotic } \\
\text { production } 3 . \mathrm{kg} \\
\text { soil } 4 . \mathrm{m}^{3} \text { water } 5 \text {. } \\
\mathrm{m}^{3} \text { groundwater }\end{array}$ & $\begin{array}{l}\text { Soil quality index } \\
\text { based on LANCA } \\
\text { (Beck et al. 2010; Bos } \\
\text { et al. 2016) }\end{array}$ & III \\
\hline Water use & $\begin{array}{l}\text { User deprivation } \\
\text { potential (deprivation- } \\
\text { weighted water } \\
\text { consumption) }\end{array}$ & $\mathrm{m}^{3}$ world eq & $\begin{array}{l}\text { AWaRe as } \\
\text { recommended by } \\
\text { (UNEP 2016) }\end{array}$ & III \\
\hline $\begin{array}{l}\text { Resource use, } \\
\text { minerals and metals }\end{array}$ & $\begin{array}{l}\text { Abiotic resource } \\
\text { depletion (ADP } \\
\text { ultimate reserves) }\end{array}$ & $\mathrm{kg} \mathrm{Sb} \mathrm{eq}$ & $\begin{array}{l}\text { CML } 2002 \text { (Guinée } \\
\text { et al. 2002; van Oers } \\
\text { et al. 2002) }\end{array}$ & III \\
\hline Resource use, fossils & $\begin{array}{l}\text { Abiotic resource } \\
\text { depletion - fossil fuels } \\
\text { (ADP-fossil) }\end{array}$ & MJ & CML 2002 & III \\
\hline
\end{tabular}




\title{
Appendix J \\ Detailed guidance on the use of the qualitative assessment of data in LCA according to the European PEFCR Guidance (EC 2018)
}

\author{
C. Bessou, CIRAD
}

\section{Qualitative diagnosis}

The most detailed guidance on the use of the qualitative assessment of data in LCA is provided in the latest version of the European PEFCR Guidance (EC 2018).

The DQR system consists in:

- Four criteria:

o Precision $(P)$

o Time representativeness $(T i \mathrm{R})$

o Geographical representativeness $(G \mathrm{R})$

o Technological representativeness (TeR)

- A two-tier approach to score those criteria depending on the data:

o Primary data: score for precision cannot be higher than 3 and the other scores cannot be higher than $2^{9}$

o Secondary data: scores from 1 to 5

- A formula to aggregate the scores (Eq. 1).

The scoring approach somehow mixes qualitative and quantitative information. For primary data, the qualitative assessment should be focused on the "most relevant processes and direct elementary flows that account for at least $80 \%$ of the total environmental impact". This threshold should be calculated based on process contributions to the total single score (excluding the 3 toxicity-related ones). It requires an iterative approach were LCIA results are calculated first in order to target the processes and input data to be assessed for the DQR. For all important processes and flows, as selected based on their contributions, the scores should be estimated separately, and the total DQR should be calculated

9. In PEFCR guidance, which applies to company as a regulatory framework, it is considered that primary data shall be company specific and as precise as possible. 
based on the weighted average of the scores (i.e. multiplied by the contribution to the total of $80 \%$ of total impact) as shown in Eq. 1.

$$
D Q R=\frac{\overline{T e R}+\overline{G R}+\overline{T i R}+\bar{P}}{4}
$$

Precise guidelines are provided in order to estimate the scores for primary and secondary data (cf. Table J1). They also explain how to combine scores from primary and secondary data for elementary flows (abbreviated EF in Table J1), activity data $(\mathrm{AD})$ and secondary data $(\mathrm{SD})$.

Table J1. Abstract (two first scores) from PEFCR guidance on "how to assign the values to DQR criteria when using company-specific information?".

\begin{tabular}{|c|c|c|c|c|c|}
\hline Score & $\begin{array}{l}\text { PEF and } \\
\text { PAD }\end{array}$ & TiR-EF and TiR-AD & TiR-SD & $\begin{array}{l}\text { TeR-EF and } \\
\text { TeR-SD }\end{array}$ & GR-EF and GR-SD \\
\hline 1 & $\begin{array}{l}\text { Measured/ } \\
\text { calculated } \\
\text { and externally } \\
\text { verified }\end{array}$ & $\begin{array}{l}\text { The data refers to the } \\
\text { most recent annual } \\
\text { administration period } \\
\text { with respect to the } \\
\text { EF report publication } \\
\text { date }\end{array}$ & $\begin{array}{l}\text { The EF report } \\
\text { publication date } \\
\text { happens within } \\
\text { the time validity } \\
\text { of the dataset }\end{array}$ & $\begin{array}{l}\text { The elementary } \\
\text { flows and the } \\
\text { secondary dataset } \\
\text { reflect exactly the } \\
\text { technology of the } \\
\text { newly developed } \\
\text { dataset }\end{array}$ & $\begin{array}{l}\text { The data(set) reflects } \\
\text { the exact geography } \\
\text { where the process } \\
\text { modelled in } \\
\text { the newly created } \\
\text { dataset takes place }\end{array}$ \\
\hline 2 & $\begin{array}{l}\text { Measured/ } \\
\text { calculated } \\
\text { and internally } \\
\text { verified, } \\
\text { plausibility } \\
\text { checked by } \\
\text { reviewer }\end{array}$ & $\begin{array}{l}\text { The data refers to } \\
\text { maximum } 2 \text { annual } \\
\text { administration } \\
\text { periods with respect } \\
\text { to the EF report } \\
\text { publication date }\end{array}$ & $\begin{array}{l}\text { The EF report } \\
\text { publication } \\
\text { date happens } \\
\text { not later than } \\
2 \text { years beyond } \\
\text { the time validity } \\
\text { of the dataset }\end{array}$ & $\begin{array}{l}\text { The elementary } \\
\text { flows and the } \\
\text { secondary dataset } \\
\text { is a proxy of the } \\
\text { technology of the } \\
\text { newly developed } \\
\text { dataset }\end{array}$ & $\begin{array}{l}\text { The data(set) } \\
\text { partly reflects } \\
\text { the geography } \\
\text { where the process } \\
\text { modelled in the } \\
\text { newly created } \\
\text { dataset takes place }\end{array}$ \\
\hline
\end{tabular}

PEF: Precision for elementary flows; PAD: Precision for activity data; TiR-EF: Time Representativeness for elementary flows; TiR-AD: Time representativeness for activity data; TiR-SD: Time representativeness for secondary datasets; TeR-EF: Technology representativeness for elementary flows; TeR-SD: Technology representativeness for secondary datasets; GR-EF: Geographical representativeness for elementary flows; GR-SD: Geographical representativeness for secondary datasets.

In order to comply with the regulatory PEFCR, all details on the DQR assessment should be provided, including the quantitative contributions. This approach is very comprehensive and constitutes a robust information on qualitative assessment of an LCA study. Alternatively, a PEFCR-DQR based qualitative assessment could be more rapidly done by LCA authors, based on their expert-judgement on process and flows contribution and providing non-weighted DQR scores. Such a simplified approach may be a first step in data quality assessment but would not consist in full PEFCR compliance.

The data quality assessment done at each inventory flow level, without weighting and aggregation is the first step in applying the pedigree matrix. 


\section{Uncertainty approximation}

In ecoinvent databases, an uncertainty factor (expressed as a contribution to the square of the geometric standard deviation) is attributed to each of the score of the data quality criteria (Frischknecht et al. 2007; Weidema et al. 2013). In the version v.3.0, five criteria are considered with five levels of score (see ecoinvent 3.0 pedigree matrix in Ciroth et al., 2016). The total uncertainty accounts for a basic uncertainty based on expert knowledge (and varying depending on the type of input/output) and the cumulated uncertainty factors related to the five scores, which were recently updated based on several datasets compiled by Ciroth et al. (2016) (see Empirically based uncertainty factors for the pedigree matrix in ecoinvent v.3.0). 


\section{Appendix K \\ How to display LCA results \\ while avoiding bias due \\ to visualization choices?}

LCA results are typically very large in terms of the number of series and the number of variables represented, and it can be difficult to know how to present the data in the most effective and unbiased way. The tips and recommendations listed below are an application of the main concepts of effective scientific communication applied to classical LCIA results (histograms, scenario comparisons, contribution analysis...)

\section{Refer to "useful ink" concept}

The concept of "useful ink" emphasizes that the ink used for graphics should be as informational as possible. The question to ask is: Is each ink pixel deposited on the paper provides useful information? If not, delete it! This simple concept allows to make the graphics often more simple, clear and accurate. In practice, this concept is often translated into the following modifications:

1. Remove unnecessary borders, lines, and backgrounds.

2.Remove unnecessary labels and markers.

3. Use flat styles and solid colors.

4.Highlight important values.

\section{Which type of graph is the most effective for most LCIA results? (histograms)}

Graphs of LCIA results are meant to reveal something about the results, and in particular to highlight the elements that will be detailed in the analysis of the results. Based on the classical formats of LCIA result tables, and considering that LCA results are always expressed as continuous variables, it is relevant to consider that:

- For scenario comparisons, histograms are the most efficient visualization mode in the first instance to present LCIA results (obviously applying the useful ink 
concept). Histograms are even more effective when they are aligned at one end (see Figure $\mathrm{K} 1$ as one example). Minor improvements can further enhance the graphical representation, by avoiding the use of too many colors (color blind, if possible), by using horizontal bars, by adding tabular information and especially by rearranging the series in ascending or descending order of value, if there is no logical order in the series.

- For time trends (or other continuous input variables), it is imperative that the axes keep the right spacing and are not considered as categories. The most efficient type of graph in this case is not necessarily the histogram, because it does not make multiple comparisons easy; in this case, one can use connected points by emphasizing certain evolutions.

$$
\text { USD2013 } \approx \text { species.yr } \approx \text { DALY }
$$

\section{$1 \mathrm{~kg}$ of fresh mangoes sold to consumers $\quad 8 \%$ on the local market of Bobo Dioulasso $\quad 10 \%$

$1 \mathrm{~kg}$ of fresh mangoes exported to Europe (Antwerp) by boat via Abidjan (Côte d'Ivoire)

$1 \mathrm{~kg}$ of fresh mangoes exported to Morocco (Casablanca) with refrigerated trucks

$1 \mathrm{~kg}$ of premium fresh mangoes exported to Europe (Paris) by air via Ouagadougou airport

Figure K1. Example of a graph for LCIA results. 


\section{References}

Abdou K (2017) Évaluation des impacts environnementaux du chalutage de fond et de l'aquaculture en Tunisie : approche comparative par les Analyses de Cycle de Vie ( ACV ). PhD thesis. Institut National Agronomique de Tunisie, Université de Bretagne Occidentale. https://tel. archives-ouvertes.fr/tel-01769977

Abdou K, Ben Rais Lasram F, Romdhane MS, et al. (2017) Rearing performances and environmental assessment of sea cage farming in Tunisia using life cycle assessment (LCA) combined with PCA and HCPC. Int J Life Cycle Assess 1-14. https://doi.org/10.1007/s11367-017-1339-2

Acosta-Alba I, Avadí A (2021) Mapping fisheries value chains to facilitate their sustainability assessment: case studies in The Gambia and Mali. Marine Policy. https://doi.org/10.1016/j. marpol.2021.104854

Acosta-Alba I, Boissy J, Chia E, Andrieu N (2020) Integrating diversity of smallholder coffee cropping systems in environmental analysis. Int J Life Cycle Assess 25:252-266. https://doi. org/10.1007/s11367-019-01689-5

Acosta-alba I, Chia E, Andrieu N (2019) The LCA4CSA framework: Using life cycle assessment to strengthen environmental sustainability analysis of climate smart agriculture options at farm and crop system levels. Agric Syst 171:155-170. https://doi.org/10.1016/j.agsy.2019.02.001

Adeyeye SAO, Oyewole OB (2016) An overview of traditional fish smoking in Africa. J Culin Sci Technol 14:198-215. https://doi.org/10.1080/15428052.2015.1102785

Adhikari K, Hartemink AE (2016) Linking soils to ecosystem services - A global review. Geoderma 262:101-111. https://doi.org/10.1016/j.geoderma.2015.08.009

AFNOR (2012) BP X30-323-15 Octobre 2012. Principes généraux pour l'affichage environnemental des produits de grande consommation - Partie 15 : méthodologie d'évaluation des impacts environnementaux des produits alimentaires

Albanito F, Lebender U, Cornulier T, et al. (2017) Direct nitrous oxide emissions from tropical and sub-tropical agricultural systems - A review and modelling of emission factors. Sci Rep 7:112. https://doi.org/10.1038/srep44235

Albers A (2019) Prise en compte de la dimension temporelle dans l'évaluat ion environnementale des produits de la biomasse : Modélisat ion dynamique du carbone. $\mathrm{PhD}$ thesis. École doctorale GAIA - Biodiversité, Agriculture, Alimentation, Environnement, Terre, Eau Portée par l'Université de Montpellier.

Alejandre EM, van Bodegom PM, Guinée JB (2019) Towards an optimal coverage of ecosystem services in LCA. J Clean Prod 231:714-722. https://doi.org/10.1016/j.jclepro.2019.05.284

Alkemade R, Van Oorschot M, Miles L, et al. (2009) GLOBIO3: A framework to investigate options for reducing global terrestrial biodiversity loss. Ecosystems 12:374-390. https://doi. org/10.1007/s10021-009-9229-5

Andrianandraina A (2015) Approche d'éco-conception basée sur la combinaison de l'Analyse de Cycle de Vie et de l'Analyse de Sensibilité. PhD thesis. Ecole Centrale de Nantes. https://hal. archives-ouvertes.fr/tel-01202139

Andrieu N, Howland F, Acosta-Alba I, et al. (2019) Co-designing climate-smart farming systems with local stakeholders: A methodological framework for achieving large-scale change. Front Sustain Food Syst 3:37. https://doi.org/10.3389/fsufs.2019.00037 
Arvelo Sánchez MÁ, Gonzáles León D, Delgado López T, et al. (2017) Estado actual sobre la producción, el comercio y cultivo del cacao en América. Instituto Interamericano de Cooperación para la Agricultura, Fundación Colegio de Postgraduados en Ciencias Agrícolas. - San José, C.R. Avadí A (2020) Screening LCA of French organic amendments and fertilisers. Int J Life Cycle Assess 25:698-718. https://doi.org/10.1007/s11367-020-01732-w

Avadí A, Cole SM, Kruijssen F, et al. (2021) How to enhance the sustainability and inclusiveness of smallholder aquaculture production systems in Zambia? Aquaculture. https://doi.org/10.1016/j. aquaculture.2021.737494

Avadí A, Corson MS, van der Werf HMG (2017) Modelling environmental effects of selected agricultural management strategies with regional statistically based screening LCA. Int J Life Cycle Assess. https://doi.org/10.1007/s11367-017-1300-4

Avadí A, Deme M, Mbaye A, Ndenn J (2020a) Fisheries and aquaculture value chain analysis in the Gambia. Brussels: European Commission, Directorate-General for International Cooperation and Development.

Avadí A, Fréon P (2014) A set of sustainability performance indicators for seafood: Direct human consumption products from Peruvian anchoveta fisheries and freshwater aquaculture. Ecol Indic 48:518-532. https://doi.org/10.1016/j.ecolind.2014.09.006

Avadí A, Fréon P (2013) Life cycle assessment of fisheries: A review for fisheries scientists and managers. Fish Res 143:21-38. https://doi.org/10.1016/j.fishres.2013.01.006

Avadí A, Fréon P, Quispe I (2014) Environmental assessment of Peruvian anchoveta food products: is less refined better? Int J Life Cycle Assess 19:1276-1293. https://doi.org/10.1007/s11367-014-0737-y

Avadí A, Galland V, Versini A, Bockstaller C (2022) Suitability of operational N direct field emissions models to represent contrasting agricultural situations in agricultural LCA: Review and prospectus. Sci Total Environ 802:149960. https://doi.org/10.1016/j.scitotenv.2021.149960

Avadí A, Henriksson PJG, Vázquez-Rowe I, Ziegler F (2018) Towards improved practices in Life Cycle Assessment of seafood and other aquatic products. Int J Life Cycle Assess 23:979-981. https://doi.org/10.1007/s11367-018-1454-8

Avadí A, Hodomihou NR, Amadji GL, Feder F (2021a) LCA and nutritional assessment of southern Benin market vegetable gardening across the production continuum. Int J Life Cycle Assess. https://doi.org/10.1007/s11367-021-01977-z

Avadí A, Marcin M, Biard Y, et al. (2020b) Life cycle assessment of organic and conventional non-Bt cotton products from Mali. Int J Life Cycle Assess. https://doi.org/10.1007/s11367-020-01731-x

Avadí A, Nitschelm L, Corson M, Vertès F (2016) Data strategy for environmental assessment of agricultural regions via LCA: case study of a French catchment. Int J Life Cycle Assess 21:476491. https://doi.org/10.1007/s11367-016-1036-6

Avadí A, Pelletier N, Aubin J, et al. (2015) Comparative environmental performance of artisanal and commercial feed use in Peruvian freshwater aquaculture. Aquaculture 435:52-66. https:// doi.org/10.1016/j.aquaculture.2014.08.001

Avadí A, Vázquez-Rowe I (2019a) Life cycle inventories of wild capture and aquaculture. ecoinvent association, Zürich, Switzerland.

Avadí A, Vázquez-Rowe I (2019b) First series of seafood datasets in ecoinvent: setting the pace for future development. Int J Life Cycle Assess 19:1276-1293. https://doi.org/10.1007/s11367-019-01659-x

Ayón P, Swartzman G, Espinoza P, Bertrand A (2011) Long-term changes in zooplankton size distribution in the Peruvian Humboldt Current System: Conditions favouring sardine or anchovy. Mar Ecol Prog Ser 422:211-222. https://doi.org/10.3354/meps08918 
Azevedo LB, Henderson AD, Zelm R Van, et al. (2013a) Assessing the importance of spatial variability versus model choices in life cycle impact assessment: The case of freshwater eutrophication in Europe. Environ Sci Technol 47:13565-13570. http://doi.org/10.1021/es403422a

Azevedo LB, van Zelm R, Elshout PMF, et al. (2013b) Species richness - phosphorus relationships for lakes and streams worldwide. Glob Ecol Biogeogr 22:1304-1314. https://doi.org/10.1111/geb.12080

Bamber N, Turner I, Arulnathan V, et al. (2020) Comparing sources and analysis of uncertainty in consequential and attributional life cycle assessment: review of current practice and recommendations. Int J Life Cycle Assess 25:168-180. https://doi.org/10.1007/s11367-019-01663-1

Basset-Mens C, Edewa A, Gentil C (2019) An LCA of French beans from Kenya for decision-makers. Indones Journa LCA Sustain 1:1-11.

Basset-Mens C, Payen S, Vannière H, et al. (2018) Life cycle assessment of mango systems. In: Galán Saúco V, Lu P (eds) Achieving sustainable cultivation of mangoes. Burleigh Dodds Science Publishing, Cambridge, UK, pp 429-456.

Beck T, Bos U, Wittstock B, et al. (2010) LANCA - Land use indicator value calculation in life cycle assessment - Method report. Fraunhofer Institute for Building Physics and University of Stuttgart. Echterding.

Bélières J-F, Rasolofo P, Rivolala B, et al. (2017) Elaboration de typologies d'exploitations agricoles au niveau infra-national à Madagascar : Lac Alaotra et region du Menabe.

Benjamin N, Beegle K, Recanatini F, Sanntini M (2014) Informal economy and the world bank. Policy Res Work Pap Ser 6888:1-36. https://doi.org/10.1097/ICO.0b013e3181eadd0f

Benoist A, Bessou C (2018) Prise en compte en analyse de cycle de vie (ACV) du lien usage des sols - changement climatique : revue critique des méthodologies existantes. Projet SOCLE, soil organic carbon changes in LCA, which evaluations to improve environmental assessments? ADEME.

Bernard JT, Gavin M, Khalaf L, Voia M (2015) Environmental kuznets curve: Tipping points, uncertainty and weak identification. Environ Resour Econ 60:285-315. https://doi.org/10.1007/ s10640-014-9767-y

Bertrand A, Lengaigne M, Takahashi K, et al. (2020) El Niño Southern Oscillation (ENSO) effects on fisheries and aquaculture. Rome: Food and Agriculture Organization of the United Nations.

Bessou, C., C. Basset-Mens, T. Tran, and A. Benoist. (2013). LCA applied to perennial cropping systems: a review focused on the farm stage. Int J Life Cycle Assess 18(2): 340-361. https://doi. org/ 10.1007/s11367-012-0502-z

Bessou C, Basset-Mens C, Latunussa C, et al. (2016) Partial modelling of the perennial crop cycle misleads LCA results in two contrasted case studies. Int J Life Cycle Assess 21:297-310. https:// doi.org/10.1007/s11367-016-1030-z

Bessou C, Benoist A, Tailleur A, et al. (2018) Soil organic carbon changes in LCA, which evaluations to improve environmental assessments? Projet SOCLE, ADEME.

Biard Y, Basset-Mens C, Bessou C, et al. (2016) Introducing ethical rules in the Life Cycle Inventory phase with local partners in developing countries. In: LCA FOOD 2016.

Biermann G, Geist J (2019) Life cycle assessment of common carp (Cyprinus carpio L.) - A comparison of the environmental impacts of conventional and organic carp aquaculture in Germany. Aquaculture 501:404-415. https://doi.org/10.1016/j.aquaculture.2018.10.019

Birkved M, Hauschild MZ (2006) PestLCI-A model for estimating field emissions of pesticides in agricultural LCA. Ecol Modell 198:433-451. https://doi.org/10.1016/j.ecolmodel.2006.05.035 
Bjørn A, Owsianiak M, Laurent A, et al. (2013) Mapping and characterization of LCA networks. Int J Life Cycle Assess 18:812-827. https://doi.org/10.1007/s11367-012-0524-6

Blonk Consultants (2014) Agri-footprint methodology and basic principles.

Blonk Consultants (2019) Agri-footprint 5.0 Part 1: Methodology and basic principles.

Bockstaller C, Galland V, Avadí A (2021) Indigo-N v.3: a semi-mechanistic operational model for direct field nitrogen emissions in life cycle assessment of cropping systems under contrasting agricultural situations. Eur J Agron.

Bockstaller C, Girardin P (2010) Mode de calcul des indicateurs agri-environnementaux de la methode Indigo ${ }^{\circ}$. Colmar: INRA.

Bohnes FA, Hauschild MZ, Schlundt J, Laurent A (2018) Life cycle assessments of aquaculture systems: a critical review of reported findings with recommendations for policy and system development. Rev Aquac 1-19. https://doi.org/10.1111/raq.12280

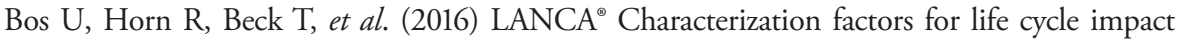
assessment. Version 2.0. Fraunhofer Institute for Building Physics. Frauenhofer Verlag. Stuttgart. Germany.

Bos U, Maier SD, Horn R, et al. (2020) A GIS based method to calculate regionalized land use characterization factors for life cycle impact assessment using LANCA ${ }^{\odot}$. Int J Life Cycle Assess 1259-1277. https://doi.org/10.1007/s11367-020-01730-y

Boulay A, Bouchard C, Bulle C, et al. (2011) Categorizing water for LCA inventory. Int J Life Cycle Assess 16:639-651. https://doi.org/10.1007/s11367-011-0300-z

Boulay AM, Bare J, Benini L, et al. (2018) The WULCA consensus characterization model for water scarcity footprints: assessing impacts of water consumption based on available water remaining (AWARE). Int J Life Cycle Assess 23:368-378. https://doi.org/10.1007/s11367-017-1333-8

Boulay AM, Lenoir L, Manzardo A (2019) Bridging the data gap in the water scarcity footprint by using crop-specific AWARE factors. Water 11, 2634. https://doi.org/10.3390/w11122634

Boulay AM, Benini L, Sala S (2020) Marginal and non-marginal approaches in characterization: how context and scale affect the selection of an adequate characterization model. The AWARE model example. Int J Life Cycle Assess 25:2380-2392. https://doi.org/10.1007/s11367-019-01680-0

Bouwman A, van der Hoek K (1997) Scenarios of animal waste production and fertilizer use and associated ammonia emission for the developing countries. Atmos Environ 31:4095-4102. https://doi.org/10.1016/S1352-2310(97)00288-4

Bouwman AF, Boumans LJM, Batjes NH (2002a) Modeling global annual $\mathrm{N}_{2} \mathrm{O}$ and $\mathrm{NO}$ emissions from fertilized fields. Global Biogeochem Cycles 16:28-1-28-9. https://doi.org/10.1029/2001GB001812

Bouwman AF, Boumans LJM, Batjes NH (2002b) Estimation of global $\mathrm{NH}_{3}$ volatilization loss from synthetic fertilizers and animal manure applied to arable lands and grasslands. Global Biogeochem Cycles 16:8-1-8-14. https://doi.org/10.1029/2000GB001389

Bouwman AF, Boumans LJM, Batjes NH (2002c) Emissions of $\mathrm{N}_{2} \mathrm{O}$ and $\mathrm{NO}$ from fertilized fields: Summary of available measurement data. Global Biogeochem Cycles 16:6-1-6-13. https:// doi.org/10.1029/2001GB001811

Bove A, Hartmann O, Stokenberga A, et al. (2018) Le transport routier en Afrique de l'Ouest et en Afrique centrale. SSATP.

Brandão M, Kirschbaum MUF, Cowie AL, Hjuler SV (2019) Quantifying the climate change effects of bioenergy systems: Comparison of 15 impact assessment methods. GCB Bioenergy 1-17. https://doi.org/10.1111/gcbb.12593 
Brandão M, Milà i Canals L (2013) Global characterisation factors to assess land use impacts on biotic production. Int J Life Cycle Assess 18:1243-1252. https://doi.org/10.1007/s11367-012-0381-3

Brankatschk G, Finkbeiner M (2015) Modeling crop rotation in agricultural LCAs - Challenges and potential solutions. Agric Syst 138:66-76. https://doi.org/10.1016/j.agsy.2015.05.008

Brent AC, Rohwer MB, Friedrich E, Blottnitz H Von (2002) Status of life cycle assessment and engineering research in South Africa. Int J Life Cycle Assess 7:167-172. https://doi.org/10.1007/ BF02994051

Breton C, Blanchet P, Amor B (2018) Assessing the climate change impacts of biogenic carbon in buildings : A critical review of two main dynamic approaches. Sustainability 10:1-30. https:// doi.org/10.3390/su10062020

Bright RM, Cherubini F, Strømman AH (2012) Climate impacts of bioenergy: Inclusion of carbon cycle and albedo dynamics in life cycle impact assessment. Environ Impact Assess Rev 37:2-11. https://doi.org/10.1016/j.eiar.2012.01.002

Brisson N, Garya C, Justes E, et al. (2003) An overview of the crop model STICS. Eur J Agron 18:309-332. https://doi.org/10.1016/S1161-0301(02)00110-7

Bruun S, Hansen TL, Christensen TH, et al. (2006) Application of processed organic municipal solid waste on agricultural land - A scenario analysis. Environ Model Assess 11:251-265. https:// doi.org/10.1007/s10666-005-9028-0

BSi (2012) PAS 2050-1:2012. Assessment of life cycle greenhouse gas emissions from horticultural products. Supplementary requirements for the cradle to gate stages of GHG assessments of horticultural products undertaken in accordance with PAS 2050. British Standards Institution (BSI).

Bulle C, Margni M, Patouillard L, et al. (2019) IMPACT World+: a globally regionalized life cycle impact assessment method. Int J Life Cycle Assess 24:1653-1674. https://doi.org/10.1007/ s11367-019-01583-0

Cardinael R, Umulisa V, Toudert A, et al. (2018) Revisiting IPCC Tier 1 coefficients for soil organic and biomass carbon storage in agroforestry systems. Environ Res Lett 13. https://doi. org/10.1088/1748-9326/aaeb5f

Cariolle M (2002) Deac-azote : un outil pour diagnostiquer le lessivage d'azote à l'échelle de l'exploitation agricole de polyculture. in: Proceedings of the 65th IRB Congress, $13-14$ février 2002, Bruxelles. pp. 67-74

Chaudhary A, Brooks TM (2018) Land use intensity-specific global characterization factors to assess product biodiversity footprints. Environ Sci Technol 52:5094-5104. https://doi.org/10.1021/ acs.est.7b05570

Chaudhary A, Verones F, De Baan L, Hellweg S (2015) Quantifying land use impacts on biodiversity: Combining species-area models and vulnerability indicators. Environ Sci Technol 49:99879995. https://doi.org/10.1021/acs.est.5b02507

Cherubini F, Peters GP, Berntsen T, et al. (2011) $\mathrm{CO}_{2}$ emissions from biomass combustion for bioenergy: atmospheric decay and contribution to global warming. GCB Bioenergy 3:413-426. https://doi.org/10.1111/j.1757-1707.2011.01102.x

Cherubini E, Franco D, Zanghelini GM, Soares SR (2018) Uncertainty in LCA case study due to allocation approaches and life cycle impact assessment methods. Int J Life Cycle Assess 20552070, https://doi.org/10.1007/s11367-017-1432-6.

Cho CY, Kaushik SJ (1990) Nutritional energetics in fish: energy and protein utilization in rainbow trout (Salmo gairdneri). World Rev Nutr Diet 61:132-172. https://doi.org/10.1159/000417529 
Ciroth A, Muller S, Weidema B, Lesage P (2016) Empirically based uncertainty factors for the pedigree matrix in ecoinvent. Int J Life Cycle Assess 21:1338-1348. https://doi.org/10.1007/ s11367-013-0670-5

Coleman K, Jenkinson DS (2014) RothC - A model for the turnover of carbon in soil. Model description and users guide (updated June 2014). Rothamsted Research. Herts, UK.

Collado-Ruiz D, Ostad-Ahmad-Ghorabi H (2010) Comparing LCA results out of competing products: developing reference ranges from a product family approach. J Clean Prod 18:355-364. https://doi.org/10.1016/j.jclepro.2009.11.003

COMIFER (2013) Calcul de la fertilisation azotée - Cultures annuelles et prairies. COMIFER - Comité Français d’Étude et de Développement de la Fertilisation Raisonée, Groupe Azote.

Constantin J, Willaume M, Murgue C, et al. (2015) The soil-crop models STICS and AqYield predict yield and soil water content for irrigated crops equally well with limited data. Agric For Meteorol 206:55-68. https://doi.org/10.1016/j.agrformet.2015.02.011

Cosme N, Mayorga E, Hauschild MZ (2017) Spatially explicit fate factors of waterborne nitrogen emissions at the global scale. Int J Life Cycle Assess 1-11. https://doi.org/10.1007/s11367-017-1349-0

Cowie AL, Orr BJ, Castillo Sanchez VM, et al. (2018) Land in balance: The scientific conceptual framework for land degradation neutrality. Environ Sci Policy 79:25-35. https://doi.org/10.1016/j. envsci.2017.10.011

Curran M, De Baan L, De Schryver AM, et al. (2011) Toward meaningful end points of biodiversity in life cycle assessment. Environ Sci Technol 45:70-79. https://doi.org/10.1021/es101444k

Curran M, De Souza DM, Antón A, et al. (2016) How well does LCA model land use impacts on Biodiversity? - A comparison with approaches from ecology and conservation. Environ Sci Technol 50:2782-2795. https://doi.org/10.1021/acs.est.5b04681

de Baan L, Alkemade R, Koellner T (2013) Land use impacts on biodiversity in LCA: a global approach. Int J Life Cycle Assess 18:1216-1230. https://doi.org/10.1007/s11367-012-0412-0

De Klein C, Novoa RSA, Ogle S, et al. (2006) Chapter 11: $\mathrm{N}_{2} \mathrm{O}$ emissions from managed soils, and $\mathrm{CO}_{2}$ emissions from lime and urea application. Intergovernmental Panel on Climate Change (IPCC).

De Laurentiis V, Secchi M, Bos U, et al. (2019) Soil quality index: Exploring options for a comprehensive assessment of land use impacts in LCA. J Clean Prod 215:63-74. https://doi. org/10.1016/j.jclepro.2018.12.238

De Schryver AM, Brakkee KW, Goedkoop MJ, Huijbregts MAJ (2009) Characterization factors for global warming in life cycle assessment based on damages to humans and ecosystems. Environ Sci Technol 43:1689-1695. https://doi.org/10.1021/es800456m

Dijkman TJ, Birkved M, Hauschild MZ (2012) PestLCI 2.0: A second generation model for estimating emissions of pesticides from arable land in LCA. Int J Life Cycle Assess 17:973-986. https://doi.org/10.1007/s11367-012-0439-2

Dominati E, Patterson M, Mackay A (2010) A framework for classifying and quantifying the natural capital and ecosystem services of soils. Ecol Econ 69:1858-1868. https://doi.org/10.1016/j. ecolecon.2010.05.002

Dong Y, Gandhi N, Hauschild MZ (2014) Development of comparative toxicity potentials of 14 cationic metals in freshwater. Chemosphere 112:26-33. https://doi.org/10.1016/j. chemosphere.2014.03.046 
Du X, Xie Z (2020) Occurrence of turning point on environmental Kuznets curve in the process of (de)industrialization. Struct Chang Econ Dyn 53:359-369. https://doi.org/10.1016/j. strueco.2019.06.003

EC-JRC (2010) General guide for Life Cycle Assessment - Detailed guidance. European Commission - Joint Research Centre - Institute for Environment and Sustainability.

EC-JRC (2013) Official Journal. Off J Eur Union 56:216. https://doi. org/10.3000/19770677.L_2013.124.eng

EC-JRC (2011) Recommendations for Life Cycle Impact Assessment in the European context.

EC (2018) Product Environmental Footprint Category Rules Guidance v6.3.

Elshout PMF, Van Zelm R, Karuppiah R, et al. (2014) A spatially explicit data-driven approach to assess the effect of agricultural land occupation on species groups. Int J Life Cycle Assess 19:758769. https://doi.org/10.1007/s11367-014-0701-x

EMEP/CORINAIR (2006) Air polluant emission inventory guidebook. European Environment Agency (EEA), Copenhagen, Danemark.

EMEP/EEA (2009) Air polluant emission inventory guidebook. European Environment Agency (EEA), Copenhagen, Danemark

EMEP/EEA (2013) EMEP/EEA air pollutant emission inventory guidebook 2013: Technical guidance to prepare national emission inventories. European Environment Agency (EEA), Copenhagen, Danemark.

EMEP/EEA (2016) EMEP/EEA air pollutant emission inventory guidebook 2016: Technical guidance to prepare national emission inventories. EEA Rep No 21/2016 1-76. https://doi. org/10.1158/1078-0432.CCR-08-2545

EMEP/EEA (2019) EMEP/EEA air pollutant emission inventory guidebook 2019: Technical guidance to prepare national emission inventories (3.B Manure Management). EEA Tech Rep 74. https://doi.org/10.2800/293657

Estrada RD, Holmann F (2008) Competitividad de la producción de leche frente a los tratados de libre comercio en Nicaragua, Costa Rica y Colombia. Cali, Co: Centro Internacional d Agricultura Tropical (CIAT), International Livestock Research Institute (ILRI).

Faist Emmenegger M, Reinhard J, Zah R (2009) Sustainability Quick Check for Biofuels intermediate background report. With contributions from T. Ziep, R. Weichbrodt, Prof. Dr. V. Wohlgemuth, FHTW Berlin and A. Roches, R. Freiermuth Knuchel, Dr. G. Gaillard. Agroscope Reckenholz-Tänikon. Dübendorf.

Fantke P, Charles R, de Alencastro LF, et al. (2011) Plant uptake of pesticides and human health: Dynamic modeling of residues in wheat and ingestion intake. Chemosphere 85:1639-1647. https:// doi.org/10.1016/j.chemosphere.2011.08.030

Fantke P (Ed.), Bijster M, Guignard C, et al. (2017) USEtox 2.0 Documentation (Version 1).

Fantke P (2019) Modelling the environmental impacts of pesticides in agriculture. In: Weidema BP (ed) Assessing the environmental impact of agriculture. Burleigh Dodds Science Publishing. Cambridge, United Kingdom. pp 177-228. https://doi.org/10.19103/AS.2018.0044.08

Fantke P, Anton A, Grant T, Hayashi K (2017) Pesticide emission quantification for life cycle assessment: A global consensus building process. Int J Life Cycle Assess 13:245-251. https://doi. org/10.3370/lca.13.245

Fantke P, Jolliet O (2016) Life cycle human health impacts of 875 pesticides. Int J Life Cycle Assess 722-733. https://doi.org/10.1007/s11367-015-0910-y 
Fantke P, Juraske R, Friedrich R, Jolliet O (2011) Dynamic multicrop model to characterize impacts of pesticides in food. Environ Sci Technol 45:8842-8849. https://doi.org/10.1021/es201989d FAO (2017a) The future of food and agriculture - Trends and challenges. Rome: Food and Agriculture Organization of the United Nations.

FAO (2016) The state of world fisheries and aquaculture 2016. Contributing to food security and nutrition for all. Rome: Food and Agriculture Organization of the United Nations.

FAO (2018a) The state of food and agriculture 2018. Migration, agriculture and rural development.

FAO (2020a) The state of world fisheries and aquaculture 2020. Sustainability in action. Rome: Food and Agriculture Organization of the United Nations.

FAO (2020b) FAOSTAT Crops.

FAO (2017b) Fishery and aquaculture statistics. Global aquaculture production 1950-2015 (FishstatJ). In: FAO Fisheries and Aquaculture Department [online].

FAO (2020c) Biodiversity Integrated Assessment and Computation Tool | B-INTACT guidelines. Rome: Food and Agriculture Organization of the United Nations.

FAO (2018b) Global livestock environmental assessment model. Version 2. Rome: Food and Agriculture Organization of the United Nations.

Flisch R, Sinaj S, Charles R, Richner W (2009) GRUDAF 2009 - Grundlagen für die Düngung im Acker und Futterbau. Agrarforschung 16:97.

FOLA (2018) Focus on land in Africa. In: Landesa World Resour. Inst.

Food SCP RT (2013), ENVIFOOD Protocol, Environmental Assessment of Food and Drink Protocol, European Food Sustainable Consumption and Production Round Table (SCP RT), Working Group 1, Brussels, Belgium.

Foster RG (2005) Revised universal soil loss equation - Version 2 (RUSLE2). USDA - Agricultural Research Service, Washington D.C., USA.

Freiermuth R (2006) Modell zur Berechnung der Schwermetall- flüsse in der Landwirtschaftlichen Ökobilanz Inhaltsverzeichnis. Agroscope FAL Zürich-Reckenholz 28.

Fréon P, Avadí A, Marin Soto W, Negrón R (2014a) Environmentally extended comparison table of large- versus small- and medium-scale fisheries: the case of the Peruvian anchoveta fleet. Can J Fish Aquat Sci 71:1459-1474. https://doi.org/10.1139/cjfas-2013-0542

Fréon P, Avadí A, Vinatea RA, Iriarte F (2014b) Life cycle assessment of the Peruvian industrial anchoveta fleet: boundary setting in life cycle inventory analyses of complex and plural means of production. Int J Life Cycle Assess 19:1068-1086. https://doi.org/10.1007/s11367-014-0716-3

Fréon P, Durand H, Avadí A, et al. (2017) Life cycle assessment of three Peruvian fishmeal plants: Toward a cleaner production. J Clean Prod 145:50-63. https://doi.org/10.1016/j.jclepro.2017.01.036

Frischknecht R, Braunschweig A, Hofstetter P, Suter P (2000) Human health damages due to ionising radiation in life cycle impact assessment. Environ Impact Assess Rev 20:159-189. https:// doi.org/10.1016/S0195-9255(99)00042-6

Frischknecht R, Jungbluth N, Althaus H, et al. (2007) Overview and methodology. Data v2.0 (2007), ecoinvent Report No. 1. Swiss Center For Life Cycle Inventories.

Gentil-Sergent C, Basset-Mens C, Gaab J, et al. (2021) Quantifying pesticide emission fractions for tropical conditions. Chemosphere 275. https://doi.org/10.1016/j.chemosphere.2021.130014 
Gentil-Sergent C (2020) Advancing emission and impact modeling for agricultural pesticides under tropical conditions, to improve scientific foundation of the environmental evaluation of tropical agri-food systems. Phd thesis, Montpellier Supagro, 177p + annexes.

Gentil C, Basset-Mens C, Manteaux S, et al. (2020) Coupling pesticide emission and toxicity characterization models for LCA: Application to open-field tomato production in Martinique. J Clean Prod 277: https://doi.org/10.1016/j.jclepro.2020.124099

Gentil C, Fantke P, Mottes C, Basset-Mens C (2019) Challenges and ways forward in pesticide emission and toxicity characterization modeling for tropical conditions. Int J Life Cycle Assess. https://doi.org/10.1007/s11367-019-01685-9

Gephart JA, Henriksson PJG, Parker RWR, et al (2021) Environmental performance of blue foods. Nature 597: 360-365. https://doi.org/10.1038/s41586-021-03889-2

Gheewala SH, Bonnet S, Silalertruksa T (2016) Environmental sustainability assessment of sugarcane bioenergy. Sugarcane-based Biofuels Bioprod 363-378. https://doi.org/10.1002/9781118719862. ch14

Ghemawat P, Altman S (2016) Emerging economies: Differences and distances. AIB Insights 16:7-10.

Gibbs HK, Salmon JM (2015) Mapping the world's degraded lands. Appl Geogr 57:12-21. https:// doi.org/10.1016/j.apgeog.2014.11.024

Goedkoop M, Heijungs R, Huijbregts M, et al. (2009) ReCiPe 2008 A life cycle impact assessment method which comprises harmonised category indicators at the midpoint and the endpoint level. First edition Report I: Characterisation.

Goedkoop M, Oele M, Vieira M, et al. (2016) SimaPro tutorial. SimaPro.

Goglio P, Brankatschk G, Knudsen MT, et al. (2017) Addressing crop interactions within cropping systems in LCA. Int J Life Cycle Assess 23:1-9. https://doi.org/10.1007/s11367-017-1393-9

Grewer U, Bockel L, Schiettecatte L-S, Bernoux M (2017) Ex-Ante Carbon-balance Tool (EX-ACT). Quick guidance. Rome: Food and Agriculture Organization of the United Nations.

Groen EA, Heijungs R (2017) Ignoring correlation in uncertainty and sensitivity analysis in life cycle assessment: what is the risk? Environ Impact Assess Rev 62:98-109. https://doi.org/10.1016/j. eiar.2016.10.006

Groen EA, Heijungs R, Bokkers EAM, de Boer IJM (2014) Methods for uncertainty propagation in life cycle assessment. Environ Model Softw 62:316-325. https://doi.org/10.1016/j. envsoft.2014.10.006

Groenendijk P, Renaud LV, Roelsma J (2005) Prediction of Nitrogen and Phosphorus leaching to groundwater and surface waters. Process descriptions of the ANIMO4.0 model. Alterra Report 983, Wageningen.

Guérin-Schneider L, Tsanga-Tabi M, Roux P, et al. (2018) How to better include environmental assessment in public decision-making: Lessons from the use of an LCA-calculator for wastewater systems. J Clean Prod 187. https://doi.org/10.1016/j.jclepro.2018.03.168

Guinée J, Kleijn R, Henriksson P (2010) Environmental life cycle assessment of South-East Asian aquaculture systems for tilapia, pangasius catfish, peneid shrimp and macrobrachium prawns Goal \& Scope Definition Report. SEAT: Sustaining Ethical Aquaculture Trade.

Guinée JB, Gorrée M, Heijungs R, et al. (2002) Handbook on life cycle assessment. Operational guide to the ISO standards. I: LCA in perspective. IIa: Guide. IIb: Operational annex. III: Scientific background. Kluwer Academic Publishers, Dordrecht. 
Hanafiah MM, Xenopoulos MA, Pfister S, et al. (2011) Characterization factors for water consumption and greenhouse gas emissions based on freshwater fish species extinction. Environ Sci Technol 45:5272-5278. https://doi.org/10.1021/es1039634

Hartemink AE (2002) Soil science in tropical and temperate regions - Some differences and similarities. Adv Agron 77:269-292. https://doi.org/10.1016/S0065-2113(02)77016-8

Hauschild MZ, Macleod M, Rosenbaum RK (2008) Building a model based on scientific consensus for life cycle impact assessment of chemicals : The search for harmony and parsimony. Environ Sci Technol 42:7032-7037. https://doi.org/10.1021/es703145t.

Heijungs R (2021) Selecting the best product alternative in a sea of uncertainty. Int J Life Cycle Assess. https://doi.org/10.1007/s11367-020-01851-4

Heijungs R (2019) On the number of Monte Carlo runs in comparative probabilistic LCA. Int J Life Cycle Assess 394-402. https://doi.org/10.1007/s11367-019-01698-4

Helias A, Langlois J, Fréon P (2018) Fisheries in Life Cycle Assessment: operational factors for biotic resources depletion. Fish Fish Submitted 1-42. https://doi.org/10.1111/faf.12299

Helias A (2020) Comments on the international consensus model for the water scarcity footprint (AWARE) and proposal for an improvement. Sci. Total Environ. 709:136189. https://doi. org/10.1016/j.scitotenv.2019.136189

Helmes RJK, Huijbregts MAJ, Henderson AD, Jolliet O (2012) Spatially explicit fate factors of phosphorous emissions to freshwater at the global scale. Int J Life Cycle Assess 17:646-654. https:// doi.org/10.1007/s11367-012-0382-2

Henriksson PJG, Belton B, Jahan KM-, Rico A (2018) Measuring the potential for sustainable intensification of aquaculture in Bangladesh using life cycle assessment. Proc Natl Acad Sci 201716530. https://doi.org/10.1073/pnas.1716530115

Henriksson PJG, Guinée JB, Heijungs R, et al. (2013) A protocol for horizontal averaging of unit process data - including estimates for uncertainty. Int J Life Cycle Assess 19:429-436. https:// doi.org/10.1007/s11367-013-0647-4

Henriksson PJG, Guinée JB, Kleijn R, De Snoo GR (2012) Life cycle assessment of aquaculture systems - A review of methodologies. Int J Life Cycle Assess 17:304-313. https://doi.org/10.1007/ s11367-011-0369-4

Henriksson PJG, Heijungs R, Dao HM, et al. (2015a) Product carbon footprints and their uncertainties in comparative decision contexts. PLoS One 10:e0121221. https://doi.org/10.1371/ journal.pone. 0121221

Henriksson PJG, Rico A, Zhang W, et al. (2015b) Comparison of Asian aquaculture products by use of statistically supported life cycle assessment. Environ Sci Technol 49:14176-14183. https:// doi.org/10.1021/acs.est.5b04634

Hergoualc'h K, Akiyama H, Bernoux M, et al. (2019) Chapter 11: $\mathrm{N}_{2} \mathrm{O}$ Emissions from managed soils, and $\mathrm{CO}_{2}$ emissions from lime and urea application. Intergovernmental Panel on Climate Change (IPCC).

Hillier J, Walter C, Malin D, et al. (2011) A farm-focused calculator for emissions from crop and livestock production. Environ Model Softw 26, 1070-1078. https://doi.org/10.1016/j.envsoft.2011.03.014

Holzworth D, Huth NI, Fainges J, et al. (2018) APSIM Next Generation: Overcoming challenges in modernising a farming systems model. Environ Model Softw 103:43-51. https://doi. org/10.1016/j.envsoft.2018.02.002

Hooijer A, Page S, Canadell JG, et al. (2010) Current and future $\mathrm{CO}_{2}$ emissions from drained peatlands in Southeast Asia. Biogeosciences 7:1505-1514. https://doi.org/10.5194/bg-7-1505-2010 
Hou Q, Mao G, Zhao L, et al. (2015) Mapping the scientific research on life cycle assessment: a bibliometric analysis. Int J Life Cycle Assess 20:541-555. https://doi.org/10.1007/s11367-015-0846-2

Huijbregts M (1998a) Application of uncertainty and variability in LCA. Part I: A General Framework for the Analysis of Uncertainty and Variability in Life Cycle Assessment. Int J Life Cycle Assess 3:273-280. https://doi.org/10.1007/BF02979835

Huijbregts M a. J (1998b) Application of uncertainty and variability in LCA. Part II: Dealing with parameter uncertainty and uncertainty due to choices in life cycle assessment. Int J Life Cycle Assess 3:343-351. https://doi.org/10.1007/BF02979345

Huijbregts MAJ, Steinmann ZJN, Elshout PMF, et al. (2016) ReCiPe2016 : a harmonized life cycle impact assessment method at midpoint and endpoint level. Report I: Characterisation. Int J Life Cycle Assess 1-152. https://doi.org/10.1007/s11367-016-1246-y

IFA/FAO (2001) Global estimates of gaseous emissions of $\mathrm{NH}_{3}, \mathrm{NO}$ and $\mathrm{N}_{2} \mathrm{O}$ from agricultural land. Rome, International Fertilizer Industry Association and Food and Agriculture Organization of the United Nations.

Igos E (2018) How to treat uncertainties in life cycle assessment studies? Int J Life Cycle Assess. https://doi.org/10.1007/s11367-018-1477-1

Igos E, Benetto E (2015) Les différentes sources d'incertitudes en ACV, leurs modes de calculs et impacts sur l'interpretation. Scorelca - Etude N ${ }^{\circ} 2014-03$ 33:1-74

IPCC (2006) Volume 4. Agriculture, forestry and other land use. Intergovernmental Panel on Climate Change, Prepared by the National Greenhouse Gas Inventories Programme, Eggleston S, Buendia L, Miwa K, Ngara T, Tanabe K (eds).

IPCC (2013) Climate Change 2013 The physical science basis. Contribution of working group I to the fifth assessment report of the Intergovernmental Panel on Climate Change. Cambridge University Press, Cambridge and New York https://doi.org/10.1017/CBO9781107415324.Summary

IPCC (2014) 2013 Revised supplementary methods and good practice guidance arising from the Kyoto protocol. The Intergovernmental Panel on Climate Change (IPCC).

IPCC (2019) Refinement to the 2006 IPCC Guidelines for National Greenhouse Gas Inventories, Calvo Buendia E, Tanabe K, Kranjc A, Baasansuren J, Fukuda M, Ngarize S, Osako A, Pyrozhenko Y, Shermanau P, Federici S (eds). Published: IPCC, Switzerland.

ISO (2006a) ISO 14040 Environmental management - Life cycle assessment - Principles and framework. The International Standards Organisation.

ISO (2006b) ISO 14044 Environmental management - Life cycle assessment - Requirements and guidelines. The International Standards Organisation.

ISO (2014) ISO 14046: Environmental management - Water footprint: Principles, requirements and guidelines. ISO, Geneva, Switzerland.

ISO/TS 14071 (2016) Environmental management - Life cycle assessment - Critical review processes and reviewer competencies: Additional requirements and guidelines to ISO 14044:2006.

ISO (2017) ISO 14046 - Environmental management - Water Footprint: A practical guide for SMEs. ISO, Geneva, Switzerland.

Jarroud M (2016) Global guidelines on land tenure making headway in Latin America. IPS News Agency.

Jeanneret P, Baumgartner DU, Freiermuth Knuchel R, et al. (2014) An expert system for integrating biodiversity into agricultural life-cycle assessment. Ecol Indic 46:224-231. https://doi. org/10.1016/j.ecolind.2014.06.030 
Jonell M, Phillips M, Rönnbäck P, Troell M (2013) Eco-certification of farmed seafood: Will it make a difference? Ambio 42:659-674. https://doi.org/10.1007/s13280-013-0409-3

Joos F, Roth R, Fuglestvedt JS, et al. (2013) Carbon dioxide and climate impulse response functions for the computation of greenhouse gas metrics: A multi-model analysis. Atmos Chem Phys 13:2793-2825. https://doi.org/10.5194/acp-13-2793-2013

Karkour S, Rachid S, Maaoui M, Lin C (2021) Status of Life Cycle Assessment (LCA) in Africa. Environments 8(2):10. https://doi.org/10.3390/environments8020010

Karlen DL, Mausbach MJ, Doran JW, et al. (1997) Soil quality: A concept, definition, and framework for evaluation. Soil Sci Soc Am J61:4-10. https://doi.org/10.2136/sssaj1997.03615995006100010001x

Kasper M, Foldal C, Kitzler B, et al. (2019) $\mathrm{N}_{2} \mathrm{O}$ emissions and $\mathrm{NO}_{3}$ - leaching from two contrasting regions in Austria and influence of soil, crops and climate: a modelling approach. Nutr Cycl Agroecosystems 113:95-111. https://doi.org/10.1007/s10705-018-9965-z

Kibblewhite MG, Ritz K, Swift MJ (2008) Soil health in agricultural systems. Philos Trans R Soc B Biol Sci 363:685-701. https://doi.org/10.1098/rstb.2007.2178

Kinda SR (2015) Essays on environmental degradation and economic development. Université d'Auvergne Clermont-Ferrand I Ecole. https://tel.archives-ouvertes.fr/tel-01167047

Knudsen MT, Dorca-Preda T, Djomo SN, et al. (2019) The importance of including soil carbon changes, ecotoxicity and biodiversity impacts in environmental life cycle assessments of organic and conventional milk in Western Europe. J Clean Prod 215:433-443. https://doi.org/10.1016/j. jclepro.2018.12.273

Koch P, Salou T (2014) AGRIBALYSE ${ }^{\bullet}$ Rapport méthodologique - Version 1.1. ADEME

Koch P, Salou T (2016) AGRIBALYSE ${ }^{\bullet}$ Rapport méthodologique - Version 1.3. ART, INRA, ADEME

Koch P, Salou T (2015) AGRIBALYSE ${ }^{\oplus}$ : Methodology Version 1.2. Ed. ADEME, Angers, France

Koellner T, Baan L, Beck T, et al. (2013a) UNEP-SETAC guideline on global land use impact assessment on biodiversity and ecosystem services in LCA. Int J Life Cycle Assess 18:1188-1202. https://doi.org/10.1007/s11367-013-0579-z

Koellner T, de Baan L, Beck T, et al. (2013b) Principles for life cycle inventories of land use on a global scale. Int J Life Cycle Assess 18:1203-1215. https://doi.org/10.1007/s11367-012-0392-0

Laë R, Williams S, Massou a M, et al. (2003) Review of the present state of the environment, fish stocks and fisheries of the river Niger (West Africa). Proc Second Int Symp Manag Large Rivers Fish Sustain Livelihoods Biodivers New Millenn 11-14 Febr 2003, Phnom Penh, Kingdom Cambodia 199-228.

Lammoglia SK, Moeys J, Barriuso E, et al. (2017) Sequential use of the STICS crop model and of the MACRO pesticide fate model to simulate pesticides leaching in cropping systems. Environ Sci Pollut Res 24:6895-6909. https://doi.org/10.1007/s11356-016-6842-7

Larson WE, Pierce FJ (1991) Conservation and enhancement of soil quality. In: Evaluation for sustainable land management in the developing world. Proceedings of the International Workshop on Evaluation for Sustainable Land Management in the Developing World. International Board of Soil Research and Management: Bangkok, pp 175-203.

Lele U, Pretty J, Terry E, Trigo E (2010) Transforming agricultural research for development. Global Forum on Agricultural Research (GFAR).

Levasseur A, Brandão M, Lesage P, et al. (2012) Valuing temporary carbon storage. Nat Clim Chang 2:1-3. doi:10.1038/nclimate1335 
Lindner JP, Fehrenbach H, Winter L, et al. (2019) Valuing biodiversity in life cycle impact assessment. Sustain 11. https://doi.org/10.3390/su11205628

Lopes Silva DA, Nunes AO, Piekarski CM, et al. (2019) Why using different Life Cycle Assessment software tools can generate different results for the same product system? A cause-effect analysis of the problem. Sustain Prod Consum 20:304-315. https://doi.org/10.1016/j.spc.2019.07.005

Meier MS, Stoessel F, Jungbluth N, et al. (2015) Environmental impacts of organic and conventional agricultural products - Are the differences captured by life cycle assessment? J Environ Manage 149:193-208. https://doi.org/10.1016/j.jenvman.2014.10.006

Mekonnen MM, Hoekstra, AY (2010) The green, blue and grey water footprint of crops and derived crop products - Volume 1: Main Report (Vol. 1).

Mendoza Beltran A, Heijungs R, Guinée J, Tukker A (2016) A pseudo-statistical approach to treat choice uncertainty: the example of partitioning allocation methods. Int J Life Cycle Assess 252-264. https://doi.org/10.1007/s11367-015-0994-4

Menzi H, Katz P, Fahrni M, Keller M (1997) Ammonia emissions following the application of solid manure to grassland. In: Gaseous Nitrogen Emissions from Grasslands (Eds. Jarvis S. and Pain B.). CAB International, Oxon, UK, pp 265-274.

Milà i Canals L, Bauer C, Depestele J, et al. (2007) Key elements in a framework for land use impact assessment within LCA. Int J Life Cycle Assess 12:5-15. https://doi.org/10.1065/lca2006.05.250

Motoshita M, Ono Y, Pfister S, Boulay A (2014) Consistent characterisation factors at midpoint and endpoint relevant to agricultural water scarcity arising from freshwater consumption. Int J Life Cycle Assess 23:2276-2287. https://doi.org/10.1007/s11367-014-0811-5

Müller-Wenk R, Brandão M (2010) Climatic impact of land use in LCA - carbon transfers between vegetation / soil and air. Int J Life Cycle Assess 15:172-182. https://doi.org/10.1007/ s11367-009-0144-y

Nemecek T, Bengoa X, Lansche J, et al. (2015) World Food LCA Database: Methodological guidelines for the life cycle inventory of agricultural products. Version 3.0.

Nemecek T, Bengoa X, Rossi V, et al. (2020) World Food LCA Database: Methodological guidelines for the life cycle inventory of agricultural products. Version 3.5. Agroscope and Quantis.

Nemecek T, Bengoa X, Rossi V, Humbert S (2014) World Food LCA Database: Methodological guidelines for the life cycle inventory of agricultural products. Version 2.0. 79.

Nemecek T, Dubois D, Huguenin-Elie O, Gaillard G (2011a) Life cycle assessment of Swiss farming systems: I. Integrated and organic farming. Agric Syst 104:217-232. https://doi.org/10.1016/j. agsy.2010.10.002

Nemecek T, Dubois D, Huguenin-Elie O, Gaillard G (2011b) Life cycle assessment of Swiss farming systems: II. Extensive and intensive production. Agric Syst 104:233-245. https://doi. org/10.1016/j.agsy.2010.07.007

Nemecek T, Schnetzer J (2012) Methods of assessment of direct field emissions for LCIs of agricultural production systems. Data v3.0, Agroscope Reckenholz-Tanikon Research station.

Nguyen TTH, Doreau M, Corson MS, et al. (2013) Effect of dairy production system, breed and co-product handling methods on environmental impacts at farm level. J Environ Manage 120:127-37. https://doi.org/10.1016/j.jenvman.2013.01.028

Nilsson P, Ziegler F (2007) Spatial distribution of fishing effort in relation to seafloor habitats in the Kattegat, a GIS analysis. Aquat Conserv Mar Freshw Ecosyst 17:421-440. https://doi. org/10.1002/aqc.792 
Nortcliff S (2002) Standardisation of soil quality attributes. Agric Ecosyst Environ 88:161-168. https://doi.org/10.1016/S0167-8809(01)00253-5

Notarnicola B, Sala S, Anton A, et al. (2017) The role of life cycle assessment in supporting sustainable agri-food systems: A review of the challenges. J Clean Prod 140:399-409. https://doi. org/10.1016/j.jclepro.2016.06.071

Ogle SM, Wakelin SJ, Buendia L, et al. (2019) Chapter 5: Cropland. Intergovernmental Panel on Climate Change (IPCC).

Othoniel B, Rugani B, Heijungs R, et al. (2019) An improved life cycle impact assessment principle for assessing the impact of land use on ecosystem services. Sci Total Environ 693:133374. https://doi.org/10.1016/j.scitotenv.2019.07.180

Owsianiak M, Holm PE, Fantke P, et al. (2015) Assessing comparative terrestrial ecotoxicity of $\mathrm{Cd}, \mathrm{Co}, \mathrm{Cu}, \mathrm{Ni}, \mathrm{Pb}$, and $\mathrm{Zn}$ : The influence of aging and emission source. Environ Pollut 206:400410. https://doi.org/10.1016/j.envpol.2015.07.025

Owsianiak M, Rosenbaum RK, Huijbregts MAJ, Hauschild MZ (2013) Addressing geographic variability in the comparative toxicity potential of copper and nickel in soils. Environ Sci Technol 47:3241-3250. https://doi.org/10.1021/es3037324

OXFAM (2016) Unearthed: Land, power and inequality in Latin America. Oxfam International, 71p + appendix. Available at: https://oi-files-d8-prod.s3.eu-west-2.amazonaws.com/s3fs-public/ file_attachments/bp-land-power-inequality-latin-america-301116-en.pdf

Papatryphon E, Petit J, Van Der Werf HMG, et al. (2005) Nutrient-balance modeling as a tool for environmental management in aquaculture: The case of trout farming in France. Environ Manage 35:161-174. https://doi.org/10.1007/s00267-004-4020-z

Pardo G, Zufía J (2012) Life cycle assessment of food-preservation technologies. J Clean Prod 28:198-207. https://doi.org/10.1016/j.jclepro.2011.10.016

Patzel N, Sticher H, Karlen DL (2000) Soil fertility - Phenomenon and concept. J Plant Nutr Soil Sci 163:129-142. https://doi.org/10.1002/(SICI)1522-2624 (200004)163:2<129::AID-JPLN129>3.0.CO;2-D

Pauly D, Zeller D (2017) Comments on FAOs state of world fisheries and aquaculture (SOFIA 2016). Mar Policy 77:176-181. https://doi.org/10.1016/j.marpol.2017.01.006

Payen S, Basset-Mens C, Colin F, Roignant P (2018) Inventory of field water flows for agri-food LCA: critical review and recommendations of modelling options. Int J Life Cycle Assess 23:13311350. https://doi.org/10.1007/s11367-017-1353-4

Perrin A, Basset-Mens C, Gabrielle B (2014) Life cycle assessment of vegetable products: A review focusing on cropping systems diversity and the estimation of field emissions. Int J Life Cycle Assess 19:1247-1263. https://doi.org/10.1007/s11367-014-0724-3

Pfister S, Bayer P, Koehler A, Hellweg S (2011) Environmental impacts of water use in global crop production: Hotspots and trade-offs with land use. Environ Sci Technol 45:5761-5768. https:// doi.org/10.1021/es1041755

Pfister S, Bayer P (2014) Monthly water stress: Spatially and temporally explicit consumptive water footprint of global crop production. J Clean Prod 73:52-62. https://doi.org/10.1016/j. jclepro.2013.11.031

Pfister S, Koehler A, Hellweg S (2009) Assessing the environmental impacts of freshwater consumption in LCA. Environ Sci Technol 43:4098-4104 https://doi.org/10.1021/es802423e

Poore J, Nemecek T (2018) Reducing food's environmental impacts through producers and consumers. Science 360:987-992. https://doi.org/10.1126/science.aaq0216 
Posch M, Seppälä J, Hettelingh J, Johansson M (2008) The role of atmospheric dispersion models and ecosystem sensitivity in the determination of characterisation factors for acidifying and eutrophying emissions in LCIA. Int J Life Cycle Assess 13:477-486. https://doi.org/10.1007/ s11367-008-0025-9

Prasuhn V (2006) Erfassung der PO4-Austräge für die Ökobilanzierung - SALCA-Phosphor. Agroescope Reckenholz 20

Quispe I, Vázquez-Rowe I, Kahhat R, et al. (2016) Preface (Special issue: Life Cycle Assessment: A tool for innovation in Latin America). Int J Life Cycle Assess. https://doi.org/10.1007/s11367-016-1178-6

Ramjeawon T, Von Blottnitz H, Kituyi E, Mebratu D (2005) LCA knowledge network in Africa (ALCANET). Int J Life Cycle Assess 10:449. https://doi.org/10.1065/lca2005.11.007

Reap J, Roman F, Duncan S, Bras B (2008) A survey of unresolved problems in life cycle assessment. Part 1: Goal and scope and inventory analysis. Int J Life Cycle Assess 13:290-300. https:// doi.org/10.1007/s11367-008-0008-x

Reap J, Roman F, Duncan S, Bras B (2008) A survey of unresolved problems in life cycle assessment. Part 2: Impact assessment and interpretation. Int J Life Cycle Assess 13:374-388. https:// doi.org/10.1007/s11367-008-0009-9

Richner W, Oberholzer H-R, Freiermuth R, et al. (2014) Modell zur Beurteilung der Nitratauswaschung in Ökobilanzen - SALCA-NO $\mathrm{N}_{3}$, Agroscope.

Rizzati V, Briand O, Guillou H, Gamet-Payrastre L (2016) Effects of pesticide mixtures in human and animal models: An update of the recent literature. Chem Biol Interact 254:231-246. https:// doi.org/10.1016/j.cbi.2016.06.003

Rosenbaum RK, Anton A, Bengoa X, et al. (2015a) The Glasgow consensus on the delineation between pesticide emission inventory and impact assessment for LCA. Int J Life Cycle Assess 20:765-776. https://doi.org/10.1007/s11367-015-0871-1

Rosenbaum RK, Bachmann TM, Gold LS, et al. (2008) USEtox - the UNEP-SETAC toxicity model: recommended characterisation factors for human toxicity and freshwater ecotoxicity in life cycle impact assessment. Int J Life Cycle Assess 13:532-546. https://doi.org/10.1007/ s11367-008-0038-4

Rosenbaum RK, Georgiadis S, Fantke P (2018) Uncertainty Management and Sensitivity Analysis. In: Hauschild MZ, Rosenbaum RK, Olsen SI (eds) Life Cycle Assessment: Theory and Practice. Springer International Publishing, Cham, 271-321. https://doi.org/10.1007/978-3-319-56475-3_11

Rosenbaum RK, Meijer A, Demou E, et al. (2015b) Indoor air pollutant exposure for Life Cycle Assessment: Regional health impact factors for households. Environ Sci Technol 49:12823-12831. https://doi.org/10.1021/acs.est.5b00890

Rouault A, Perrin A, Renaud-Gentié C, et al. (2020) Using LCA in a participatory eco-design approach in agriculture: the example of vineyard management. Int J Life Cycle Assess 25:13681383. https://doi.org/10.1007/s11367-019-01684-w

Roy P, Huijbregts M, Deschênes L, Margni M (2012) Spatially-differentiated atmospheric source e receptor relationships for nitrogen oxides, sulfur oxides and ammonia emissions at the global scale for life cycle impact assessment. Atmos Environ 62:74-81. https://doi.org/10.1016/j. atmosenv.2012.07.069

Roy RN, Misra RV, Lesschen JP, Smaling EM (2003) Assessment of soil nutrient balance. Approaches and methodologies, FAO Fertiliser and Plant Nutrition Bulletin 14. Rome, Food and Agriculture Organization of the United Nations. 
Rugani B, Maia de Souza D, Weidema BP, et al. (2019) Towards integrating the ecosystem services cascade framework within the Life Cycle Assessment (LCA) cause-effect methodology. Sci Total Environ 690:1284-1298. https://doi.org/10.1016/j.scitotenv.2019.07.023

Salou T, Le Mouël C, van der WerfHMG (2016) Environmental impacts of dairy system intensification: the functional unit matters! J Clean Prod 1-10. https://doi.org/10.1016/j.jclepro.2016.05.019

Sarkodie SA, Strezov V (2018) Empirical study of the Environmental Kuznets curve and Environmental Sustainability curve hypothesis for Australia, China, Ghana and USA. J Clean Prod 201:98-110. https://doi.org/10.1016/j.jclepro.2018.08.039

Scherer L, Pfister S (2015) Modelling spatially explicit impacts from phosphorus emissions in agriculture. Int J Life Cycle Assess 20:785-795. https://doi.org/10.1007/s11367-015-0880-0

Seppälä J, Posch M, Johansson M, Hettelingh J (2006) LCA methodology country-dependent characterisation factors for acidification and terrestrial eutrophication based on accumulated exceedance as an impact category indicator. Int J Life Cycle Assess 11:403-416. https://doi. org/10.1065/lca2005.06.215

Shin Y, Shannon LJ, Bundy A, et al. (2010) Using indicators for evaluating, comparing, and communicating the ecological status of exploited marine ecosystems. 2. Setting the scene. ICES J Mar Sci J du Cons 67:692-716. https://doi.org/10.1093/icesjms/fsp294

Sieber P, Ericsson N, Hammar T, Hansson PA (2020) Including albedo in time-dependent LCA of bioenergy. GCB Bioenergy 12:410-425. https://doi.org/10.1111/gcbb.12682

Silalertruksa T, Pongpat P, Gheewala SH (2017) Life cycle assessment for enhancing environmental sustainability of sugarcane biorefinery in Thailand. J Clean Prod 140:906-913. https:// doi.org/10.1016/j.jclepro.2016.06.010

Six J, Feller C, Denef K, et al. (2002) Soil organic matter, biota and aggregation in temperate and tropical soils - Effects of no-tillage. Agron EDP Sci 22:755-775. https://doi.org/10.1051/ agro:2002043

Stehfest E, Bouwman L (2006) $\mathrm{N}_{2} \mathrm{O}$ and NO emission from agricultural fields and soils under natural vegetation: Summarizing available measurement data and modeling of global annual emissions. Nutr Cycl Agroecosystems 74:207-228. https://doi.org/10.1007/s10705-006-9000-7

Stern DI (2004) The rise and fall of the environmental Kuznets curve. World Dev 32:1419-1439. https://doi.org/10.1016/j.worlddev.2004.03.004

Suh S, Lenzen M, Treloar GJ, et al. (2004) System boundary selection in Life-Cycle Inventories using hybrid approaches. Environ Sci Technol 38:657-664. https://doi.org/10.1021/es0263745

Taelman SE, Schaubroeck T, De Meester S, et al. (2016) Accounting for land use in life cycle assessment: The value of NPP as a proxy indicator to assess land use impacts on ecosystems. Sci Total Environ 550:143-156. https://doi.org/10.1016/j.scitotenv.2016.01.055

Tailleur A, Cohan J, Laurent F, Lellahi A (2012) A simple model to assess nitrate leaching from annual crops for life cycle assessment at different spatial scales. In: Corson M.S., van der Werf H.M.G. (Eds), Proceedings of the 8th International Conference on Life Cycle Assessement in the Agri-Food Sector (LCA Food 2012), 1-4 October 2012, Saint-Malo, France. INRA, Rennes France. pp 903-904.

Tejada de Walter A, Peralta Bidó S (2000) Mercados de tierras rurales en la República Dominicana. Santiago de Chile: Economic Commission for Latin America and the Caribbean.

Thatje S, Heilmayer O, Laudien J (2008) Climate variability and El Niño Southern Oscillation: Implications for natural coastal resources and management. Helgol Mar Res 62:5-14. https://doi. org/10.1007/s10152-008-0104-0 
Thoumazeau A, Bessou C, Renevier MS, et al. (2019) Biofunctool: a new framework to assess the impact of land management on soil quality. Part B: investigating the impact of land management of rubber plantations on soil quality with the Biofunctool ${ }^{\circledR}$ index. Ecol Indic 97:429-437. https://doi.org/10.1016/j.ecolind.2018.10.028

Tirado-Seco P (2005) Development of damage functions for aquatic eutrophication in life cycle assessment. Université de Genève, Geneva.

UN-Habitat (2019) Land tenure and climate vulnerability. Report 03/2019. HS Number: HS/026/19E.

UN-Habitat (2015) Land tenure in Asia and the Pacific: Challenges, opportunities and way forward. United Nations Human Settlements Programme.

UNEP (2016) Global guidance for life cycle impact assessment indicators. Volume 1. UNEP/ SETAC Life Cycle Initiative. Frischknecht R. and Jolliet O, Eds. 166 p.

UNEP (2019) Global guidance for life cycle impact assessment indicators. Volume 2. UNEP/ SETAC Life Cycle Initiative. Frischknecht R. and Jolliet O, Eds. 202 p.

Urban MC (2015) Accelerating extinction risk from climate change. Science 348(6234):571-573. http://doi.org/10.1126/science.aaa4984

Van Der Sluijs JP, Craye M, Funtowicz S, et al. (2005) Combining quantitative and qualitative measures of uncertainty in model-based environmental assessment: The NUSAP system. Risk Anal 25:481-492. https://doi.org/10.1111/j.1539-6924.2005.00604.x

van der Werf HMG, Kanyarushoki C, Corson MS (2009) An operational method for the evaluation of resource use and environmental impacts of dairy farms by life cycle assessment. J Environ Manage 90:3643-52. https://doi.org/10.1016/j.jenvman.2009.07.003

van der Werf HMG, Knudsen MT, Cederberg C (2020) Towards better representation of organic agriculture in life cycle assessment. Nat Sustain 3:419-425. https://doi.org/10.1038/ s41893-020-0489-6

van Oers L, Koning A De, Guinée JB, Huppes G (2002) Abiotic resource depletion in LCA: Improving characterisation factors for abiotic resource depletion as recommended in the new Dutch LCA Handbook. Road and Hydraulic Engineering Institute.

van Tonder C, Hillier J. (2014) Technical Documentation for the online Cool Farm Tool.

van Zeijts H, Leneman H, Wegener Sleeswijk A (1999) Fitting fertilisation in LCA: allocation to crops in a cropping plan.J Clean Prod 7:69-74. https://doi.org/10.1016/S0959-6526(98)00040-7

Van Zelm R, Huijbregts MAJ, Van De Meent D (2009) USES-LCA 2.0-a global nested multi-media fate, exposure, and effects model. Int J Life Cycle Assess 14:282-284. https://doi.org/10.1007/ s11367-009-0066-8

Van Zelm R, Larrey-Lassalle P, Roux P (2014) Bridging the gap between life cycle inventory and impact assessment for toxicological assessments of pesticides used in crop production. Chemosphere 100:175-181. https://doi.org/10.1016/j.chemosphere.2013.11.037

van Zelm R, Schipper AM, Snepvangers J, Huijbregts MAJ (2011) Implementing Groundwater Extraction in Life Cycle Impact Assessment: Characterization Factors Based on Plant Species Richness for the Netherlands. Environ Sci Technol 45:629-635 https://doi.org/10.1021/es102383v

Vayssières J, Vigne M, Alary V, Lecomte P (2011) Integrated participatory modelling of actual farms to support policy making on sustainable intensification. Agric Syst 104:146-161. https:// doi.org/10.1016/j.agsy.2010.05.008

Vázquez-Rowe I, Hospido A, Moreira MT, Feijoo G (2012) Best practices in life cycle assessment implementation in fisheries. Improving and broadening environmental assessment for seafood 
production systems. Trends in Food Science and Technology 28(2):116-131 https://doi.org/10.1016/j. tifs.2012.07.003

Vázquez N, Pardo A, Suso ML, Quemada M (2005) A methodology for measuring drainage and nitrate leaching in unevenly irrigated vegetable crops. Plant Soil 269:297-308. https://doi. org/10.1007/s11104-004-0630-8

Vega JP (2018). La informalidad pesa $42 \%$ del sector lacteo en el pais y afecta a la cadena. La Republica, Retrieved from https://www.agronegocios.co/agricultura/ la-informalidad-pesa-42-del-sector-lacteo-en-el-pais-y-afecta-a-la-cadena-2737442

Veit P (2013) Shedding light on land tenure in Africa. In: World Resour. Inst.

Verones F, Hanafiah MM, Pfister S, et al. (2010) Characterization factors for thermal pollution in freshwater aquatic environments. Environ Sci Technol 44:9364-9369 https://doi.org/10.1021/ es102260c

Verones F, Hellweg S, Antón A, et al. (2020) LC-IMPACT: A regionalized life cycle damage assessment method. J Ind Ecol 1-19. https://doi.org/10.1111/jiec.13018

Verones F, Huijbregts MAJ, Azevedo LB, et al. (2019) LC-IMPACT Version 1.0. A spatially differentiated life cycle impact assessment approach.

Verones F, Pfister S, Zelm R Van, Hellweg S (2017) Biodiversity impacts from water consumption on a global scale for use in life cycle assessment. Int J Life Cycle Assess 22:1247-1256. https:// doi.org/10.1007/s11367-016-1236-0

Vidal Legaz B, Maia De Souza D, Teixeira RFM, et al. (2016) Soil quality, properties, and functions in Life Cycle Assessment: an evaluation of models. J Clean Prod 140:1-14. https://doi. org/10.1016/j.jclepro.2016.05.077

Wang X, Olsen LM, Reitan KI, Olsen Y (2012) Discharge of nutrient wastes from salmon farms: Environmental effects, and potential for integrated multi-trophic aquaculture. Aquac Environ Interact 2:267-283. https://doi.org/10.3354/aei00044

Weidema BP (1997) Guidelines for critical review of life cycle assessments. Orig Publ 1997 by SPOLD (www.spold.org), Brussels, 14p.

Weidema BP, Bauer C, Hischier R, et al. (2013) Overview and methodology: Data quality guideline for the ecoinvent database version 3. Ecoinvent Report 1(v3). St. Gallen: The ecoinvent Centre.

Weidema BP, Wesnæs MS (1996) Data quality management for life cycle inventories-an example of using data quality indicators. J Clean Prod 4:167-174. https://doi.org/10.1016/ S0959-6526(96)00043-1

WHO (2013) Research priorities for the environment, agriculture and infectious diseases of poverty. World Health Organization, Technical report series, no. 976.

Winter L, Lehmann A, Finogenova N, Finkbeiner M (2017) Including biodiversity in life cycle assessment - State of the art, gaps and research needs. Environ Impact Assess Rev 67:88-100. https://doi.org/10.1016/j.eiar.2017.08.006

WMO (2014) Scientific assessment of Ozone depletion: 2014. World Meteorological Organization, Global Ozone Research and Monitoring Project-Report No. 55, Geneva, Switzerland, 88 p.

Zampori L, Pant R (2019) Suggestions for updating the Product Environmental Footprint (PEF) method, EUR 29682 EN, JRC Technical Report, Publications Office of the European Union, Luxembourg, 2019, ISBN 978-92-76-00653-4, doi:10.2760/265244, JRC115959. https://doi. org/10.2760/424613 


\section{Glossary}

\section{Allocation}

The division of the input or output flows of a process or a product system among the product system under study and one or more other product systems (ISO 14040:2006).

\section{Background process}

A process describing the production of the inputs used on the production site considered.

\section{Biogenic carbon}

Carbon stored or emitted by natural (short-cycle) sources, i.e. not from fossil energy sources.

\section{Characterization factor (CF)}

A factor derived from a characterization model which is applied to convert an assigned life cycle inventory analysis result to the common unit of the category indicator (ISO 14040:2006).

\section{Critical review (CR)}

A process intended to ensure consistency between a life cycle assessment and the principles and requirements of the International Standards on Life Cycle Assessment (ISO 14040:2006).

The principles are described in ISO 14040 (clause 4.1) (ISO, 2006a).

The requirements are described in ISO 14044 (ISO, 2006b).

\section{Cut-off criteria}

The specification of the amount of material or energy flow or the level of environmental significance associated with unit processes or product systems to be excluded from a study (ISO 14040:2006).

\section{Data quality}

Characteristics of data that relate to their ability to satisfy stated requirements (ISO 14040:2006).

\section{Direct emissions}

Flows of potentially polluting substances into the environment directly associated with animal and plant production and which cross the boundaries between technosphere and ecosphere in the studied system for the first time.

\section{Elementary flow}

An exchange with the natural, social or economic environment. Examples: unprocessed inputs from nature; emissions into air, water and soil; physical impacts; working hours under specified conditions. 


\section{Developing and emerging economies}

Countries, regions and economies not fully industrialised, in socio-economic terms.

\section{Foreground process}

A process describing the system of interest to the LCA study, on the production site considered.

\section{Functional unit (FU)}

The quantified performance of a product system for use as a reference unit (ISO 14040:2006).

\section{Impact category}

A class representing environmental issues of concern to which life cycle inventory analysis results may be assigned (ISO 14040:2006).

\section{Indirect emissions}

Flows of potentially polluting substances to the environment and which are derived from the secondary transformation/degradation of a substance emitted into the environment (from a direct emission).

\section{Life cycle assessment (LCA)}

The compilation and evaluation of the inputs, outputs and the potential environmental impacts of a product system throughout its life cycle (ISO 14040:2006).

\section{Life cycle impact assessment (LCIA)}

The phase of life cycle assessment aimed at understanding and evaluating the magnitude and significance of the potential environmental impacts for a product system throughout the life cycle of the product (ISO 14040:2006).

\section{Life cycle inventory (LCl)}

The phase of life cycle assessment involving the compilation and quantification of inputs and outputs for a product throughout its life cycle (ISO 14040:2006).

\section{Low- and middle-income countries (LMIC)}

Countries which are defined as low-income economies according to FAO. The World Bank differentiates between low-income countries (LIC) and middle-income countries (MIC); there are also least developed countries (LDC), according to the UN.

\section{Process}

A term used in the LCA community and LCI databases; 'process' represents a set of interrelated or interacting activities that transforms inputs into outputs (ISO 14040).

\section{Product}

A good or service output of a human activity with a positive market or non-market value.

\section{Soil organic carbon (SOC)}

The major component of soil organic matter. It is essentially derived from residual plant and animal material, synthesized by microbes and decomposed under the influence of temperature, moisture and ambient soil conditions. 


\section{System boundaries}

A set of criteria that specify which elementary processes are part of the product system.

\section{Technosphere}

Represents all human activities. There can be an exchange of a certain activity and the environment (elementary exchange, e.g. $\mathrm{N}_{2} \mathrm{O}$ emissions into air) or between two activities.

\section{Uncertainty analysis}

A systematic procedure to quantify the uncertainty introduced into the results of a life cycle inventory analysis due to the cumulative effects of model imprecision, input uncertainty and data variability (ISO 14040:2006).

\section{Water footprint}

A life cycle impact indicator that assesses the contribution of products and services to water-related impacts on the environment. 


\section{Abbreviations}

ACV. Analyse de cycle de vie (Life cycle assessment in French)

ADEME. Agence de l'environnement et de la maîtrise de l'énergie

AFNOR. Association française de normalisation

AFOLU. agriculture, forestry, land use and land use change

AGWP. Absolute global warming potential

APSIM. Agricultural production systems simulator

CF. Characterization factor

CGIAR. Consultative group on international agricultural research

CR. Critical review

DG-DEVCO. Directorate general for international cooperation and development

DMP. Data management plan

DQR. Data quality rating

EC. European commission

EC-JRC. European commission joint research centre

EEA. European environment agency

EF. Environmental footprint

EMEP. European monitoring and evaluation program

EPD. Environmental product declaration

EU. European union

FAO. Food and agriculture organization

FOLA. Focus on land in Africa

FU. Functional unit

GDP. Gross domestic product

GTP. Global temperature change potential

GDPR. General data protection regulation

GFLI. Global Feed LCA Institute

GHG. Greenhouse gases

GLAD. Global LCA data access 
GLAM. Global guidance for life cycle impact assessment indicators and methods GWP. Global warming potential

HCPC. Hierarchical clustering of principal components

HESTIA. Harmonized environmental storage and tracking of the impacts of agriculture

IES. Institute for environment and sustainability

IFA. Impact focus area

ILCD. International reference life cycle data system

IPCC. Intergovernmental panel on climate change

ISO. International organization for standardization

LCA. Life cycle assessment

LCDN. Life cycle data network

LCI. Life cycle inventory

LCIA. Life cycle impact assessment

LDC. Least developed countries

LEAP. Livestock environmental assessment and performance

LIC. Low-income countries

LMIC. Low- and middle-income countries

LULUC. Land use and land use change

MC. Monte Carlo

MIC. Middle-income countries

MEANS. MulticritEria AssessmeNt of Sustainability

MSA. Mean species abundance

NGO. Non-governmental organization

NMVOC. Non-methane volatile organic compounds

NSTDA. National science and technology development agency

OECD. Organisation for economic co-operation and development

OEF. Organisation environmental footprint

OXFAM. Oxford committee for famine relief

PAF. Potentially affected araction

PAS. Publicly available specification

PCA. Principal component analysis

PCR. Product category rules

PDF. Potentially disappeared fraction

PEF. Product environmental footprint

PEFCR. Product environmental footprint category rules 
RF. Radiative forcing

SALCA. Swiss agricultural LCA

SD. Standard deviation

SETAC. Society of environmental toxicology and chemistry

SOC. Soil organic carbon

SCP. Sustainable consumption and production

SQCB. Sustainability quick check for biofuels

STICS. Simulateur multidiscplinaire pour les cultures standard UN. United nations

UNEP. United nations environment program

VCA4D. Value chain analysis for development

WFLDB. World food LCA database 


\section{List of authors}

\section{Editors and main authors of the guide:}

Claudine Basset-Mens, CIRAD, France

Agronomist and LCA scientist since early 2000s. She has been involved in applying and adapting the LCA framework to agrifood chains (animal and crop production) in a wide range of situations and countries (France, New Zealand, Caribbean islands, Africa, Asia). Her main research interests relate to the inclusion of agricultural systems diversity, the modelling of field emissions and flows, the modelling of perennial crops within LCA, the inclusion of uncertainty and more recently the modelling of biodiversity due to LULUC in LCA.

Angel Avadí, CIRAD, France

Environmental assessment expert at CIRAD since 2015, has been involved in many studies applying LCA to agri-food production systems, especially in Latin America and Africa. His main research interests include the development of adapted models for direct field emissions, soil carbon sequestration and terrestrial ecotoxicity. One of his main drivers is to advance the agroecological transition of vegetable production in periurban areas of developing countries.

Cécile Bessou, CIRAD, France

Agronomist and LCA scientist, she has been working at Cirad since 2010. She has been involved in applying and adapting the LCA framework to various agrifood chains with a specific focus on perennial cropping systems in tropical countries. Her main research interests relate to the modelling of field emissions related to carbon and nitrogen cycling within agroeocological systems and the accounting for impacts on soil quality within LCA.

Ivonne Acosta-Alba, EvaLivo, France

Agronomist and Environmental assessment expert since 2010. She has contributed to the methodological development and application of LCA for the operationalization of sustainable development, climate-smart agriculture and co-design of agricultural and livestock systems. Her main research interest is the improvement of environmental efficiency of agri-food systems associating socio-economic indicators. She works as independent researcher in Europe, Latin American \& the Caribbean region and Africa. Associate researcher at Innovation research unit - CIRAD.

Yannick Biard, CIRAD, France

Agronomist and expert in calculation tools for environmental assessment at CIRAD since 2011. He started his career as project manager of the AGRIBALYSE program for the production of the Life Cycle Inventory database on environmental 
impacts of French agricultural products. He has been involved in applying LCA to agri-food value chains (animal and plant production) in a wide range of situations and countries. His main interests include LCI/LCA databases and calculation tools, Data Quality Management Systems (DQMS) and coupling environmental data with economic and social data for integrated multi-criteria assessments.

Sandra Payen, CIRAD, France

Agronomist and LCA scientist, she has been working at CIRAD since 2019. She has been involved in applying and adapting the LCA framework to agrifood chains (animal and crop production) in a wide range of situations and countries (New Zealand, Africa, Asia). Her main research interests relate to the modelling of field fluxes (water, salts, nutrients), water deprivation, salinization and eutrophication impacts. She is also in charge of the design and implementation of LCA courses for CIRAD scientists and partners.

\section{Contributors of Part 3 (in addition to all editors, by decreasing order of contribution):}

Patrik Henriksson, Beijer Institute of Ecological Economics Stockholm Resilience Centre, Stockholm University WorldFish, Sweden (participation in all workshops, contribution to accounting for variability and uncertainty aspects)

Shabbir Gheewala, King Mongkut's University of Technology Thonburi, Thailand (participation in all workshops, review of Chapters 8 and 9)

Joël Aubin, INRAE, France (participation in all workshops, review of Chapters 8 and 9)

Edi Iswanto Wiloso, Research Center for Science, Technology and Innovation Policy and Management; Indonesian Institute of Sciences, Indonesia (participation in all workshops, review of Chapters 8 and 9)

Jessica Hanafi, Sustainability and Life Cycle Assessment Consultant, PT Life Cycle Indonesia, Indonesia (participation in all workshops)

Anthony Benoist, CIRAD, France (participation in all workshops)

Thierry Tran, CIRAD, France (expertise on food technology aspects)

All experts who completed the online questionnaire 

Photo credits :

Cover : Claudine Basset-Mens (c) Cirad, Caroline Dangleant (C) Cirad, Cécile Bessou (C) Cirad;

p.40 Claudine Basset-Mens (C) Cirad; p.53 Lionel Dabbadie (C) Cirad; p.54 Guy Trébuil (C) Cirad; p.61 Pierre Charmetant (C) Cirad; p.63 Isabelle Vagneron (C) Cirad, Yannick Briard () Cirad; p.144 Alain Rival (c) Cirad ; p.152 Cécile Bessou (C) Cirad ; p.158 Alain Rival (C) Cirad ; p.166 Dominique Louppe (C) Cirad ; p.170 Emmanuel Daou (C) Cirad.

Layout: E EliLoCom 
Life Cycle Assessment (LCA) is the internationally recognized method to assess the environmental impacts of products and services. Its application to agri-food systems in developing or emerging contexts is recent and represents many challenges of, scientific, partnerial and operational nature. With more than 10 years of scientific and field experience, the CIRAD LCA team has synthesized, with other internationally recognized experts, the best knowledge and approaches available to apply LCA under these conditions. This operational guide is a useful tool for LCA practitioners; it provides best practice recommendations to carry out LCA studies on agri-food products in developing and emerging contexts.

Claudine Basset-Mens, agronomist and LCA scientist since early 2000s, she has been working at Cirad since 2009.

Angel Avadí, environmental assessment expert at Cirad since 2015.

Cécile Bessou, agronomist and LCA scientist, she has been working at Cirad since 2010.

Ivonne Acosta-Alba, agronomist and environmental assessment expert since 2010, EVALIVO, France and associated scientist at Innovation unit of Cirad since 2018.

Yannick Biard, agronomist and expert in LCl database and LCA of agri-food products at Cirad since 2011.

Sandra Payen, agronomist and LCA scientist, she has been working at Cirad since 2019. 